\title{
The Chemistry, Crystallization, Physicochemical Properties and Behavior of Sodium Aluminosilicate Solid Phases: Final Report ${ }^{\#}$
}

\author{
Jonas Addai-Mensah* \\ Jun $\mathrm{Li}^{*}$ \\ Marek Zbik ${ }^{*}$ \\ Scott Rosencrance
}

Publication Date: November 20, 2002

\footnotetext{
${ }^{\#}$ Report contents a joint effort between WSRC and the University of South Australia under ERDA contract GA0083

"University of South Australia, Mawson Lakes, Adelaide. 5095 Australia.
} 
This document was prepared in conjunction with work accomplished under Contract No. DE-AC09-96SR18500 with the U. S. Department of Energy.

\section{DISCLAIMER}

This report was prepared as an account of work sponsored by an agency of the United States Government. Neither the United States Government nor any agency thereof, nor any of their employees, makes any warranty, express or implied, or assumes any legal liability or responsibility for the accuracy, completeness, or usefulness of any information, apparatus, product or process disclosed, or represents that its use would not infringe privately owned rights. Reference herein to any specific commercial product, process or service by trade name, trademark, manufacturer, or otherwise does not necessarily constitute or imply its endorsement, recommendation, or favoring by the United States Government or any agency thereof. The views and opinions of authors expressed herein do not necessarily state or reflect those of the United States Government or any agency thereof.

This report has been reproduced directly from the best available copy.

Available for sale to the public, in paper, from: U.S. Department of Commerce, National Technical Information Service, 5285 Port Royal Road, Springfield, VA 22161, phone: (800) 553-6847, fax: (703) 605-6900

email: orders@ntis.fedworld.gov

online ordering: http://www.ntis.gov/help/index.asp

Available electronically at http://www.osti.gov/bridge

Available for a processing fee to U.S. Department of Energy and its contractors, in paper, from: U.S. Department of Energy, Office of Scientific and Technical Information, P.O. Box 62, Oak Ridge, TN 37831-0062,

phone: (865)576-8401,

fax: (865)576-5728

email: $\underline{\text { reports@ adonis.osti.gov }}$ 


\subsection{Executive summary}

The synthesis of sodium aluminosilicate solids phases precipitated from $\mathrm{NO}_{2} / \mathrm{NO}_{3}$-free and $\mathrm{NO}_{2} / \mathrm{NO}_{3}$-rich liquors has been performed. Four sodium aluminosilicate precipitation products were formed. These are i.) X-ray/electron diffraction-indifferent amorphous phase ii.) crystalline zeolite $\mathrm{A}$ iii.) $\mathrm{NO}_{2} / \mathrm{NO}_{3}$-rich crystalline sodalite and iv.) $\mathrm{NO}_{2} / \mathrm{NO}_{3}$-rich crystalline cancrinite phase. Characterization of the physicochemical properties for these phases has been performed under conditions simulating Westinghouse Savannah River Company (WSRC) liquid waste processing.

New information on structural and crystallographic characteristics, which directly impact upon thermodynamic and kinetic behavior of the solid phases in caustic and caustic aluminate solutions, has emerged. Reliable equilibrium solubility as a function of solution conditions and temperature has been measured to facilitate the formulation and/or testing and validation of extant, empirical thermodynamics-based models. Furthermore, the information gleaned from the solubility data will enable accurate definition of the metastable limits of the concentration driving force (supersaturation) upon which the various precipitation mechanisms and fouling strongly depend. The transformation behavior of pure solid phases has been determined as a function of solution conditions and temperature. Nucleation and growth of the sodium aluminosilicate solid phases have been studied, allowing the kinetics of the various mechanisms underpinning the crystallization process to be rigorously modeled for. Links between thermodynamic, structural and crystallographic properties of the solid phases and solution conditions and the crystallization rate processes have been established.

The emerging information from this work provides new knowledge and a better understanding for to assist in regulating and control of plant liquid waste processing in evaporators. The overall findings point to the fact that over a relatively short time frame, the rapidly occurring kinetic processes dominate the crystallization behavior more strongly than the thermodynamics. Over a long time period however, the entire process behavior is governed by thermodynamics. These two facets of the system must be integrated in our understanding to achieve the desired evaporator operations.

\subsection{Sodium Aluminosilicate Solid Phase Synthesis}


Well-defined physicochemical conditions for the synthesis of various sodium aluminosilicate solid phases through homogeneous nucleation have been established and demonstrated. Fresh, synthetic, highly $\mathrm{SiO}_{2}$-supersaturated, nitrated/nitrited sodium aluminate solutions may be used in the synthesis of colloidal size particles of the following solids (except Zeolite A) at specific temperatures and crystallization times.

- The synthesis of gel/amorphous solid phase requires very high relative supersaturation $(>10)$ for spontaneous nucleation at low temperature $\left(<65{ }^{\circ} \mathrm{C}\right)$ and over short crystallization times (30 $\mathrm{min})$.

- Zeolite A synthesis from supersaturated nitrate/nitrite-rich caustic aluminosilicate solution is very difficult due to the fact its transformation to sodalite occurs too rapidly, preventing a significant quantity of a $100 \%$ pure phase to be recovered from the crystallization suspension. Pure Zeolite A may be synthesized from nitrate and nitritefree $\mathrm{SiO}_{2}$-supersaturated caustic aluminate solutions or from solutions containing zeolite templating ions such as $\mathrm{CO}_{3}{ }^{2-}$ at temperatures in the range $60-80{ }^{\circ} \mathrm{C}$. Nitrate and nitrite are good templating agents for sodalite and cancrinite formation.

- Nitrated and nitrited sodalite and cancrinite crystals may be synthesized from supersaturated nitrate/nitrite-rich caustic aluminosilicate solution. Sodalite is preferably crystallized at lower temperature $\left(80^{\circ} \mathrm{C}\right)$ over a short time $(<1.5 \mathrm{~h})$. Crystallization of cancrinite may be achieved at higher temperatures $\left(130200{ }^{\circ} \mathrm{C}\right.$ and under high pressure (180 - 250 psig). At lower temperatures (e.g. 80 - $100{ }^{\circ} \mathrm{C}$ ), a significant component of sodalite phase may persist over long crystallization times up to $20 \mathrm{~h}$.

- The amorphous solid phase is more space filling, displaying lower mass density, than the crystalline zeolite A, sodalite and cancrinite phases.

\subsection{Sodium Aluminosilicate Solid Phase Characterization}

- X-ray powder diffraction methodology and characteristic peaks for establishing the crystallographic characteristics of the various sodium aluminosilicate polymorphic phases have been established. These are a useful diagnostic tool in phase transformationcharacterization studies where 2 or more phases are present.

- X-ray Photoelectron Spectroscopy (XPS) core level spectra reveal that amorphous and zeolite A solid phases precipitated from $\mathrm{NO}_{2}{ }^{-}$and $\mathrm{NO}_{3}{ }^{-}$-rich liquors do not contain noticeable amounts of $\mathrm{NO}_{2}{ }^{-}$and $\mathrm{NO}_{3}{ }^{-}$ions while the crystalline sodalite and cancrinite phases do contain the expected anions.

- XPS valence band spectra of crystalline phases revealed distinct and well resolved peaks reflecting different levels of $\mathrm{AlO}_{4} / \mathrm{SiO}_{4}$ tetrahedra clusters and $\mathrm{O}$ bonding in well-ordered structures. The amorphous material, on the other hand, exhibits features of low degree ordering and bonding between species.

- The lack of detection of nitrogen-based species in the amorphous and zeolite A solid phases suggests that $\mathrm{NO}_{2}{ }^{-}$and $\mathrm{NO}_{3}{ }^{-}$species do not play a key role in the sodium 
aluminosilicate poly-condensation reactions and 3-dimensional embryo structure development that underpins nuclei formation and growth of these types of solid phases.

- $\mathrm{NO}_{2}^{-}$and $\mathrm{NO}_{3}^{-}$species play specific structure stabilization and phase directing or templating roles in the formation sodalite and cancrinite phases. Previous theory postulating that the partially covalent-ionic aluminosilicate crystal phase nucleation and growth from solution aluminosilicate species occurring by poly-condensation and crosslinking of alumino-silicate species, and accompanied by cation (e.g. $\mathrm{Na}^{+}$) and anion (e.g. $\mathrm{NO}_{2}^{-}$and $\mathrm{NO}_{3}^{-}$) incorporation for charge balance, to form a diffuse amorphous/gel phase precursor structure which directly undergoes, sub-crystalline interfacial structuring and densification into a crystalline structure, may be discounted.

- Spectroscopic (FTIR) data show that the amorphous phase does not display Al-O-Si symmetric stretch and bend vibrations as well as double ring structures characteristically found in crystalline solids (zeolite A, sodalite and cancrinite). This provides further evidence that the initial amorphous/gel structure is not a direct "building block" or precursor to nucleation and growth of the crystalline phase solids. In other words, the possibility of direct gel transformation to crystalline structures may be eliminated. A more developed intermediate structure is warranted.

- Thermal analysis data suggest that amorphous solid particles are less thermally stable than the crystalline sodium aluminosilicate phases and, hence, are composed of non-rigid molecular structures with lower order bonding of $\mathrm{AlO}_{4} / \mathrm{SiO}_{4}$ clusters.

- Zeolite A particle thermal decomposition data indicated that the particles consist of rigid supra molecular structures (thermally stable) with strong chemisorption of water molecules, high degree of $\mathrm{AlO}_{4} / \mathrm{SiO}_{4}$ cluster ordering and chemical bonding.

- Decomposition of sodalite crystals occurred by gradual structural dehydration $\left(<400{ }^{\circ} \mathrm{C}\right)$, accompanied by minor denitrification, denitration and decarbonation. Furthermore, solid-state structural transformation to another more stable solid phase occurred.

- Cancrinite endothermic transitions revealed by thermal analysis showed the presence of structurally chemisorbed water together with nitrification, nitration and carbonation products. The data showed that both sodalite and cancrinite particles have high thermal stability.

Based on our work the structural formula of the 4 sodium aluminosilicate solid phases may be stated as:

Amorphous/gel sodium aluminosilicate (Ideally $\sim \mathbf{N a}_{12} \mathbf{A l}_{12} \mathbf{S i}_{12} \mathbf{O}_{48} . \mathbf{2 7} \mathbf{H}_{2} \mathbf{O}$ )

$\mathrm{Na}_{11.76} \mathrm{Al}_{12} \mathrm{Si}_{11.76} \mathrm{O}_{47.4} .27 \mathrm{H}_{2} \mathrm{O}$, which is $0.98 \mathrm{Na}_{2} \mathrm{O}: \mathrm{Al}_{2} \mathrm{O}_{3}: 1.96 \mathrm{SiO}_{2} .4 .5 \mathrm{H}_{2} \mathrm{O}$.

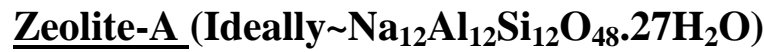

$\mathrm{Na}_{11.88} \mathrm{Al}_{12} \mathrm{Si}_{11.22} \mathrm{O}_{46.38} .27 \mathrm{H}_{2} \mathrm{O}$ or $0.99 \mathrm{Na}_{2} \mathrm{O}: \mathrm{Al}_{2} \mathrm{O}_{3}: 1.87 \mathrm{SiO}_{2} .4 .5 \mathrm{H}_{2} \mathrm{O}$

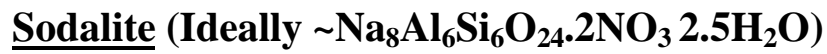

$\mathrm{Na}_{12} \mathrm{Al}_{12} \mathrm{Si}_{11.95} \mathrm{O}_{47.29} \cdot 1.56 \mathrm{NaNO}_{3} \cdot 3.5 \mathrm{H}_{2} \mathrm{O}$ or $1.13 \mathrm{Na}_{2} \mathrm{O}: \mathrm{Al}_{2} \mathrm{O}_{3}: 1.95 \mathrm{SiO}_{2} \cdot 0.58 \mathrm{H}_{2} \mathrm{O}$

Cancrinite (Ideally $\sim \mathrm{Na}_{8} \mathrm{Al}_{6} \mathrm{Si}_{6} \mathrm{O}_{24} .2 \mathrm{NO}_{3} 3.5 \mathrm{H}_{2} \mathrm{O}$ )

$\mathrm{Na}_{12} \mathrm{Al}_{12} \mathrm{Si}_{11.94} \mathrm{O}_{47.88} .2 .04 \mathrm{NaNO}_{3} .2 .5 \mathrm{H}_{2} \mathrm{O}$ or $1.17 \mathrm{Na}_{2} \mathrm{O}: \mathrm{Al}_{2} \mathrm{O}_{3}: 1.99 \mathrm{SiO}_{2} .0 .42 \mathrm{H}_{2} \mathrm{O}$ 


\subsection{Sodium Aluminosilicate Solid Phase Transformation}

- Phase transformations involving amorphous, zeolite A, sodalite and cancrinite particles occurred by solution-mediated dissolution of the less stable phase and subsequent recrystallization of the more stable phase at different rates, all of which increase rapidly with increasing temperature. Thus solid-state martensitic type of transformation may be completely discounted.

- The phase transformation rates are strongly dependent upon solution composition and ionic strength. The rates increased with increased ionic strength and Al (III), nitrate and nitrite concentrations.

- Dimorphic phase transformation reaction orders of 0.5 and 1 were obtained for amorphous/zeolite to sodalite, and sodalite to cancrinite phase transformation, respectively.

- These reaction orders are highly consistent with the chemical structures of the 4 aluminosilicate solid phases (amorphous / zeolite $\mathrm{A}=\mathrm{Na}_{12} \mathrm{Al}_{12} \mathrm{Si}_{12} \mathrm{O}_{48} \cdot 27 \mathrm{H}_{2} \mathrm{O}$ ) and ( sodalite/cancrinite $\left.=\mathrm{Na}_{8} \mathrm{Al}_{6} \mathrm{Si}_{6} \mathrm{O}_{24} \cdot 2 \mathrm{NO}_{3}{ }^{*} 2.5 / 3.5 \mathrm{H}_{2} \mathrm{O}\right)$.

- Activation energies of $49 \pm 4 \mathrm{~kJ} \mathrm{~mol}^{-1}, 71 \pm 4 \mathrm{~kJ} \mathrm{~mol}^{-1}$ and $102 \pm 4 \mathrm{~kJ} \mathrm{~mol}^{-1}$ were calculated from the 0.5 th and 1 st order rate laws for amorphous, zeolite and sodalite phase transformations.

- The amorphous $\rightarrow$ zeolite $\mathrm{A} \rightarrow$ sodalite phase transformation in nitrate/nitrite rich liquors at $65{ }^{\circ} \mathrm{C}$ or higher temperatures appears to be so rapid that the zeolite A solid phase in the product was practically undetectable by XRD (i.e. <4 wt\%).

\subsection{Equilibrium Solubility}

- A very high seed charge (high particle surface area to solution volume ratio) is required in solubility measurements due to the ephemeral nature of amorphous and zeolite A phases.

- The equilibrium silica solubility of all sodium aluminosilicate solid phases showed strong solid phase type and temperature dependency, the magnitude increasing significantly with increasing temperature.

- Solubilities of sodium aluminosilicate particles increased non-linearly with increasing temperature and caustic concentration but decreased significantly with increasing $\mathrm{Al}$ (III), nitrate and nitrite concentrations.

- The reduction in the solubility with Al (III) concentration is more pronounced at high than low concentration of caustic and nitrate/nitrite. 
- Solubility increased in the following sequence: cancrinite < sodalite < zeolite A < amorphous phase at 30,65 and $130{ }^{\circ} \mathrm{C}$.

\subsection{Seeded Nucleation and Crystal Growth}

- Upon seeding supersaturated liquors the $\mathrm{SiO}_{2}$ and $\mathrm{Al}$ (III) concentrations quickly reduced for all sodium aluminosilicate seeded systems.

- The desupersaturation behavior of $\mathrm{SiO}_{2}$ and $\mathrm{Al}$ (III) mirrored each other.

- The variation in suspension solid content and available solid surface area (BET) with time correlated strongly with the liquor desilication rate.

- A constancy of the total particle number was established through particle size- number count (population balance) analysis.

- This balance reveals that at low relative supersaturation $(\square<0.5)$ secondary nucleation and agglomeration were not significant.

- For all phases growth occurs by a size-independent mechanism with no noticeable growth rate dispersion or size dependent growth effects.

- Under identical initial conditions, the growth rate of the solid phases followed the following order: amorphous $>$ zeolite $>$ sodalite $>$ cancrinite.

- The secondary nucleation reaction order (n) was reproducibly found to 2 with respect to individual $\mathrm{SiO}_{2}$ and $\mathrm{Al}$ (III) relative supersaturations.

- For pure growth a dependence of $\mathrm{SiO}_{2}$ and $\mathrm{Al}$ (III) relative supersaturations to the power of unity was observed.

- These results indicate an overall $4^{\text {th }}$ and $2^{\text {nd }}$ order dependence of secondary nucleation and growth rates on relative supersaturation, respectively.

- Secondary nucleation of zeolite, sodalite and cancrinite involves activation energies of 47,48 and $82 \mathrm{kJmol}^{-1}$, respectively.

- The high reaction order $(>2)$ and high activation energy involved in the nucleation processes indicate a strongly chemical reaction controlled phenomena.

- Activation energies of $2.5 \pm 0.5,22.9 \pm 1.0$ and $31.1 \pm 2.0$ and $66.6 \pm 3.0 \mathrm{kJmol}^{-1}$ were estimated for the amorphous solid phase, zeolite, sodalite and cancrinite growth, respectively.

- The very low activation energy barrier estimated for the growth of the amorphous solid phase indicate that the integration of growth units is fast and involves relatively low interaction energy potential and weak forces (e.g. van der Waals and polar interactions). 
- The growth process of the amorphous solid appears to be volume diffusion controlled, particularly at low temperatures $\left(<65^{\circ} \mathrm{C}\right)$.

- The high activation energy and high reaction order $(>1)$ observed for the growth of the crystalline solid phases indicate that the bimolecular, aluminosilicate poly-condensation reactions underpinning the crystal growth process are chemical-reaction controlled.

- A critical relative supersaturation was observed above which substantial secondary nucleation occurred in tandem with crystal/particle growth, the former proceeding as the dominant crystallization mechanism, and below which pure crystal growth predominated.

- At 65 and $130{ }^{\circ} \mathrm{C}$, the critical metastable supersaturation limit for growth/secondary nucleation were $0.8-1.0$ and 0.56 , respectively.

- At the lower temperature $\left(30{ }^{\circ} \mathrm{C}\right)$, the critical relative supersaturation increased significantly with the thermodynamic stability of the sodium aluminosilicate solid phase present.

- The critical values of supersaturation were considerably higher for the other phases. Specifically, 1.91 for zeolite A, 6.46 for sodalite and 12.41 for cancrinite crystals. For the amorphous seeded system however, the transition occurred at about 0.45 .

- The critical metastable supersaturation limit for transition from growth/secondary nucleation to heterogeneous/heterogeneous nucleation was 0.67 at $130{ }^{\circ} \mathrm{C}$.

- The metastable supersaturation limit for all the observed crystallization mechanisms are homogeneous/heterogeneous nucleation>Secondary nucleation>crystal growth.

- At low relative supersaturation heterogeneous steel substrate-mediated precipitation was significantly suppressed upon seeding.

- The impact of the nature of sodium aluminosilicate solid phase on the heterogeneous precipitation-fouling behavior was very subtle.

- The crystal growth kinetics $\left(\mathrm{n}=2\right.$ and $\left.\mathrm{Ea}>20 \mathrm{~kJ} \mathrm{~mol}^{-1}\right)$ suggest that the theoretical treatment of the mechanisms may be achieved using surface integration-controlled crystal growth theories/models.

- The present data are currently being analyzed further to identify which model best describes the growth mechanism(s).

\subsection{Self-nucleation Behavior of Unseeded Liquors}

- Self-nucleation of supersaturated, unseeded and optically-clear liquor was investigated at $130{ }^{\circ} \mathrm{C}$ for liquors with $[\mathrm{Si}][\mathrm{Al}]=4 \times 10^{-3} \mathrm{M}^{2}$ and $[\mathrm{Si}][\mathrm{Al}]=2 \times 10^{-3} \mathrm{M}^{2}$. 
- In both cases fouling of stainless steel substrates exposed to the liquors occurred. The extent increased with increasing supersaturation and the solids were identified as sodalite.

- The desupersaturation kinetics showed a dependence on $\mathrm{SiO}_{2}$ relative supersaturation to the power of $4.4-5.4$, consistent with the existence of substrate-mediated heterogeneous and homogeneous nucleation mechanisms.

- In aqueous environment of low ionic strength $\left(10^{-2} \mathrm{M} \mathrm{NaNO}_{3}\right)$, all four sodium aluminosilicate solid phases were positively charged $(\sim+40-+60 \mathrm{mV})$ in the acidic $\mathrm{pH}$ range $(0-6)$ and negatively charged in alkaline $\mathrm{pH}(-40 \mathrm{mV}$ at $\mathrm{pH} \approx 13$ for the amorphous phase and $-50--70 \mathrm{mV}$ for the zeolite A, sodalite and cancrinite phases).

- $\quad$ The isoelectric points were found to be inn $\mathrm{pH}$ range 7.2 - 8.5.

- Under high ionic strength, however, specific adsorption of sodium ions at particle surface in conjunction with electrical double layer compression will occur, impacting dramatically upon colloidal stability.

New knowledge and understanding of the mechanisms and physicochemical-structural properties that underpin sodium aluminosilicate formation, growth and transformation has been obtained. This information relates to and governs various fouling processes. The information provides new and accurate sodium aluminosilicate data for quantifying nucleation and growth mechanisms and predicting the kinetics by which these mechanisms advance within the WSRC waste liquid evaporator system. 


\subsection{Introduction}

Westinghouse Savannah River Company (WSRC) plant circuits contain liquors comprised of high ionic strength, high caustic, sodium, nitrate, nitrate, silica and aluminate species. Sodium aluminosilicate scale is formed during the evaporation process. Formation of uranium containing solids also takes place and has been observed to accumulate in evaporator. Currently, the management and mitigation of this fouling is of high importance. Thus considerable research with an international multi-disciplinary approach has been pursued to assist in formulating an effective solution.

SRS 2H evaporator fouling appears to involve several parallel processes: initiation of sodium aluminosilicate nucleation, particle/crystal growth, transport of solution species and particles (bulk solution nuclei), particle attachment and removal and scale layer growth. The fouling mechanisms underlying scale layer growth is accompanied by dimorphic phase transformation and is substantially influenced by solute composition, ionic strength, multiphase interfacial chemistry, particle interactions and hydrodynamics. It has been demonstrated that the formation of sub-crystalline and crystalline polymorphic sodium aluminosilicate phases underpins both crystallization and fouling processes.

Although basic understanding of the $2 \mathrm{H}$ evaporator fouling process has emerged from inhouse studies in conjunction with previous investigations (Univ. of S. Australia - WSRC Consultancy Report 2001), there was a considerable paucity of knowledge of physicochemical properties (e.g. equilibrium solubility of solid phases), interfacial chemistry, particle growth, particle-steel substrate interactions, and kinetic behavior of sodium aluminosilicate solid phase-supersaturated liquor system. A number of crucial issues underpinning the sodium aluminosilicate fouling behavior and related crystallization processes, that has remained a subject of conjecture for long time, are the foci of the present work as described in this report.

\subsection{Aims and Objectives}

The main thrust of the present investigations is to obtain important physiochemical property data and understanding of the mechanisms and kinetics of sodium aluminosilicate particle formation and growth under conditions pertinent to SRS caustic aluminate liquor processing. 
The information derived from these studies will certainly provide a strong foundation to assist in formulating process control and fouling mitigation strategies. The specific objectives of the proposed studies are to:

(i) Synthesize and characterize the amorphous, zeolite A, nitrated/nitrited sodalite and cancrinite phases.

(ii) Supply well characterized amorphous and crystalline sodium aluminosilicate solid phases and recipe for synthesis.

(iii) Determine the equilibrium solubilities of the amorphous, zeolite, sodalite and cancrinite phases in caustic and nitrate/nitrite rich, caustic aluminate solutions at selected temperatures $\left(30,65\right.$ and $\left.130{ }^{\circ} \mathrm{C}\right)$.

(iv) Establish the mechanisms of formation, growth and polymorphic transformation of sodium aluminosilicate solid phases: gel/amorphous, zeolite, sodalite and cancrinite.

(v) Identify the metastable limits for heterogeneous nucleation, secondary nucleation and particle growth.

(vi) Quantify kinetics of gel/amorphous, zeolite, sodalite and cancrinite secondary nucleation.

(vii) Quantify kinetics of sodium aluminosilicate solid particles' (gel/amorphous, zeolite A, sodalite and cancrinite) growth.

(viii) Quantify kinetics of sodium aluminosilicate transformation involving gel/amorphous, zeolite A, and sodalite and cancrinite solid phases.

(ix) Establish the mechanisms involved in crystal/particle growth.

(x) Probe the fouling behavior of the four sodium aluminosilicate solid phases. 


\subsection{Experimental}

\subsection{Synthetic Caustic and Aluminosilicate Liquors}

Fresh, synthetic, optically clear solutions of composition similar to those of SRS $2 \mathrm{H}$ evaporator process liquors were used. All solutions were prepared from Milli- $\mathrm{Q}^{\circledR}$ water and analytical grade reagents $\mathrm{NaOH}, \mathrm{Al}(\mathrm{OH})_{3}, \mathrm{Al}\left(\mathrm{NO}_{3}\right)_{3}, \mathrm{NaNO}_{3}, \mathrm{NaNO}_{2}$ and sodium metasilicate.

\subsection{Approach and Methodology}

Isothermal batch, precipitation experiments to produce amorphous sodium aluminosilicate and crystalline (Zeolite, Sodalite and Cancrinite) solid phases were conducted under welldefined conditions of solution composition and temperature. Detailed description of the synthesis methodology follows.

\subsection{Synthesis of Solid Phases}

\subsubsection{Need for Synthesis}

Solids phase particles of the various aluminosilicates and gibbsite were needed as inputs for scope such as equilibrium solubility determinations and crystal growth studies as well as the uranium-aluminosilicate interaction program at SRTC. Crystallization of fine particles requires very high supersaturations to initiate massive, spontaneous nucleation of large number of particles. Due to time-dependent, polymorphic sodium aluminosilicate phase formation and transformations, driven by supersaturation, temperature and liquor composition, specific solid product crystallization and product isolation from the crystallization media was performed extremely carefully and verified using multiple analytical techniques and external laboratories for confirmatory analysis.

\subsubsection{Overview of Strategy}

Fresh, synthetic, highly $\mathrm{SiO}_{2}$-supersaturated, nitrated/nitrited sodium aluminate solutions may be used in the synthesis of colloidal size particles of the phases of interest except Zeolite A. For pure zeolite A synthesis from highly supersaturated nitrate/nitrite-rich solution is made difficult by the fact its transformation to sodalite occurs too rapidly. This prevents a $100 \%$ pure phase to be recovered from the crystallization suspension. Thus, the termination 
of the reaction at temperatures in the range 40 to $80{ }^{\circ} \mathrm{C}$ to isolate large quantities Zeolite $\mathrm{A}$ in using nitrate/nitrite containing liquors has proven to be difficult.

As a result another approach was taken to synthesis pure zeolite A. A pure Zeolite A may be synthesized from $\mathrm{SiO}_{2}$-supersaturated caustic aluminate solution of composition: $0.2 \mathrm{M} \mathrm{SiO}_{2}$, 1.7 $\mathrm{M} \mathrm{Al}$ (III), 4.0 M NaOH, and $0.38 \mathrm{M} \mathrm{Na}_{2} \mathrm{CO}_{3}$. In this liquor containing no nitrate/nitrite, zeolite $\mathrm{A}$ is quite metastable, requiring $\sim 48 \mathrm{~h}$ to completely transform into sodalite.

\subsubsection{Preparation of Supersaturated Silica-rich Caustic Aluminate Solution}

Solution $\mathrm{C}$ in the following table may be prepared from sodium hydroxide $(\mathrm{NaOH})(97.0 \%$ pure, $\left.2.0 \% \mathrm{Na}_{2} \mathrm{CO}_{3}, 0.01 \% \mathrm{Si}\right)$, sodium nitrate $\left(\mathrm{NaNO}_{3}\right)(99 \%$ pure $)$, sodium nitrate $\left(\mathrm{NaNO}_{2}\right)\left(98.0 \%\right.$ pure), aluminium nitrate $\left(\mathrm{Al}\left(\mathrm{NO}_{3}\right)_{3} .9 \mathrm{H}_{2} \mathrm{O}\right)(98.9 \%$ pure $)$ and sodium metasilicate $\left(\mathrm{Na}_{2} \mathrm{SiO}_{3} .5 \mathrm{H}_{2} \mathrm{O}\right)(99.8 \%$ pure) and Milli-Q or de-ionized water (surface tension $72.8 \mathrm{mN} \mathrm{m}^{-1}$ at $20{ }^{\circ} \mathrm{C}$, specific conductivity $<0.5 \mu \mathrm{S} \mathrm{cm}^{-1}$ and $\mathrm{pH}$ 5.6).

\begin{tabular}{|c|c|c|c|}
\hline Chemical & Solution A (M) & Solution B (M) & $\begin{array}{c}\mathbf{5 0 \%} \text { A : 50\% B Mix } \\
\text { Solution C(M) }\end{array}$ \\
\hline $\mathbf{N a O H}$ & 4.0 & 4.0 & 4.0 \\
\hline $\mathbf{N a N O}_{3}$ & 2.0 & 0.0 & 1.0 \\
\hline $\mathbf{N a N O}_{\mathbf{2}}$ & 2.0 & 0.0 & 1.0 \\
\hline $\mathrm{Al}_{\mathbf{N O}} \mathbf{N O}_{\mathbf{3}} \cdot \mathbf{9 H}_{\mathbf{2}} \mathbf{O}$ & 0.94 & - & 0.47 \\
\hline $\mathbf{N a}_{\mathbf{2}} \mathbf{O S i O}_{\mathbf{2}} . \mathbf{5} \mathbf{H}_{2} \mathbf{0}$ & 0.0 & 0.75 & 0.35 \\
\hline
\end{tabular}

Table 1 Sodium Aluminosilicate Solution Composition

\subsubsection{Recipes for Specific Phases}

\subsubsection{Amorphous Sodium Aluminosilicate}

Isothermal batch crystallization over 1 hour may be performed at $40{ }^{\circ} \mathrm{C}$ with Solution $\mathrm{C}$ (Table 1 above) and at a moderate agitation rate $(\sim 400 \mathrm{rpm})$. At this temperature, a crystallization time of $1.5 \mathrm{~h}$ begins to lead to observable zeolite A.

\subsubsection{Zeolite A}

Isothermal batch crystallization lasting $2-4$ hours is may be performed at $90{ }^{\circ} \mathrm{C}$ with a liquor of composition 0.2 M SiO $, 1.7 \mathrm{M} \mathrm{Al}(\mathrm{III}), 4.0 \mathrm{M} \mathrm{NaOH}$, and $0.38 \mathrm{M} \mathrm{Na}_{2} \mathrm{CO}_{3}$ and a 
moderate agitation rate $(\sim 400 \mathrm{rpm})$. Under these solution conditions and temperature, longer times (> $6 \mathrm{~h}$ ) will lead to zeolite - sodalite phase transformation with $100 \%$ conversion to the latter in $48 \mathrm{~h}$.

\subsubsection{Sodalite}

To produce sodalite crystals, isothermal batch crystallization lasting 1.5 hours is performed at $80{ }^{\circ} \mathrm{C}$ with Solution $\mathrm{C}$ (Table 1) and under moderate agitation rate ( 400 rpm). At longer crystallization times ( $>2 \mathrm{~h}$ ) transformation from sodalite to cancrinite begins to occur.

\subsubsection{Cancrinite}

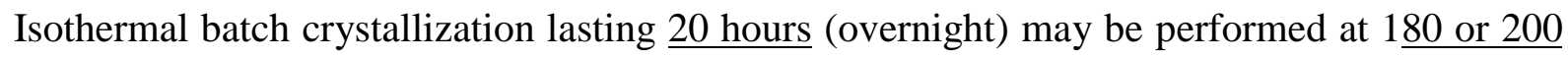
${ }^{\circ} \mathrm{C}$ with Solution $\mathrm{C}$ (Table 1$)$ at a moderate agitation rate $(\sim 400 \mathrm{rpm})$ and under high pressure (180 - 250 psig). At lower temperatures (e.g. $130{ }^{\circ} \mathrm{C}$ ), a significant component of sodalite phase may persist over long crystallization times up to $20 \mathrm{~h}$. Consequently, higher temperatures are necessary to ensure complete transformation of sodalite into cancrinite. Cancrinite may be synthesized at lower temperatures (Barrer, Cole, Sticher, 1968) using kaolinite as alumina and silica source for reaction with nitrated caustic soda solution at $80{ }^{\circ} \mathrm{C}$.

\subsubsection{Aluminum Hydroxide Phases}

Pure, synthetic, supersaturated sodium aluminate solutions (3.3 $\mathrm{M} \mathrm{Al}$ (III) in $4 \mathrm{M} \mathrm{NaOH}$ ) are used in the synthesis of gibbsite $\left(\gamma-\mathrm{Al}(\mathrm{OH})_{3}\right)$. They may be prepared from: aluminum metal (99.99\% pure, $0.01 \% \mathrm{Si}$ ), sodium hydroxide (97.0\% pure, $2.0 \% \mathrm{Na}_{2} \mathrm{CO}_{3}$ ) and Milli-Q or de-ionized water (surface tension $72.8 \mathrm{mN} \mathrm{m}^{-1}$ at $20{ }^{\circ} \mathrm{C}$, specific conductivity $<0.5 \mu \mathrm{S} \mathrm{cm}^{-1}$ and $\mathrm{pH}$ 5.6).

\subsection{Homogeneous Crystallization of $\mathrm{Al}(\mathrm{OH})_{3}$}

Pure gibbsite synthesis from unseeded, self-nucleating liquors is achieved by performing isothermal $\left(65{ }^{\circ} \mathrm{C}\right.$ or $\left.75{ }^{\circ} \mathrm{C}\right)$, batch crystallization over 48 hours to allow all the bayerite ( $\alpha$ $\mathrm{Al}(\mathrm{OH})_{3}$ ) dimorphic phase formed to transform into gibbsite crystals. If homogeneous crystallization is conducted over shorter times $(<24 \mathrm{~h})$ bayerite, which is less stable and 
more soluble than gibbsite, will be present and detected by XRD in the solid product as a minor component.

\subsection{Secondary Crystallization of $\mathrm{Al}(\mathrm{OH})_{3}$}

When previously made gibbsite crystals are available they may be employed as seeds to facilitate the crystallization process and produce more gibbsite particles (a larger number) by

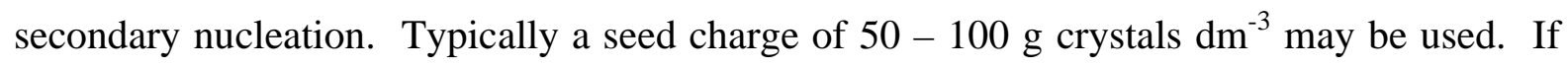
too high seed charge is used (> $300 \mathrm{~g}$ crystals $\mathrm{dm}^{-3}$ ), the growth of existing seeds (parent) crystals will dominate the crystallization process such that coarser particles with no secondary nuclei formation will result.

The seed can be added at the beginning of the crystallization as a dry powder or wet solids and mixed with the supersaturated liquor by agitation throughout the run. Gibbsite seeded experiments may be carried out for a few $(\sim 6 \mathrm{~h})$ to several hours $(<24)$, the longer the time the greater the product yield.

At the end of the crystallization, the slurry is filtered and the crystals washed several times with de-ionized water until they are as free as possible from alkali. The may be dried at low temperatures $\left(30-60{ }^{\circ} \mathrm{C}\right)$.

\subsubsection{3 $\quad \underline{\text { Boehmite (AlOOH) }}$}

Boehmite may be prepared hydrothermally from gibbsite by heating the 10 - $20 \mathrm{wt} \%$ gibbsite slurry at $\sim \mathrm{pH} 10-12$ and at elevated temperatures $\left(150-160{ }^{\circ} \mathrm{C}\right)$, high pressure $(\sim 7$ Bars $100 \mathrm{psig}$ ) and agitation (400 rpm) for at least 5 days. Preformed gibbsite (produced as in above recipe) may be used.

\subsubsection{Crystallization Equipment/Seperations}

Batch crystallizer operating below $100^{\circ} \mathrm{C}$. 
For processing a $2 \mathrm{dm}^{3}$ of solution, a baffled, well sealed, agitated (e.g. $\left.400 \mathrm{rpm}\right) 316$ stainless steel vessel of volume $2.5 \mathrm{dm}^{3}$ may be used for isothermal batch crystallization. Smaller (1 ) or larger crystallizers (2 gallons) can be used.

\section{Batch crystallizer operating above $100^{\circ} \mathrm{C}$.}

A well stirred ( $400 \mathrm{rpm})$ autoclave capable of operating at high pressures and temperatures is required to synthesize solids hydrothermally above $100{ }^{\circ} \mathrm{C}$ and prevent or minimize solution water flashing or vaporization. The required internal pressure may be maintained by metering $\mathrm{N}_{2}$ gas for a source to the autoclave vessel. A standard 1 gallon autoclave supplied by Autoclave Engineers (USA) with inconel or Teflon liner (be careful) is sufficient.

\section{Solid Product - Liquid Separation}

Separation of large quantities of the crystallized solid products from the mother liquor can be time-consuming challenge if the particles are of colloidal dimensions $(<5 \mu \mathrm{m})$ where both filtration and sedimentation are slow. Centrifugation at 10,000 - 15,000 rpm for 15 mins may be used for fast solid recovery. The solids must be washed and centrifugation repeated until they free from alkali as possible before drying.

\section{Crystallographic Characteristics of Solid phases}

X-ray diffraction patterns were collected on powdered samples in $\theta / 2 \theta$ scanning mode using $\mathrm{Cu} \mathrm{K} \alpha$ radiation $(\lambda=1.5406 \AA)$. The scan speed was $1^{\circ}$ per minute between $0^{\circ}$ and $70^{\circ} 2 \theta$.

\section{Particle size}

Solid particle size and its distribution may be measured by a laser diffraction method using the Malvern 2600C particle sizer (Malvern Instruments Ltd., Malvern, UK). The measurement is carried out in deionized water. Prior to analysis, the samples are agitated to homogenize for one hour followed by 5 -min sonication in order to break up aggregates that result from sampling, handling, and filtration or drying.

$\underline{\text { Si(IV), Al (III) and Caustic Concentration Analysis }}$ 
Solution $\mathrm{Si}$ (IV), $\mathrm{Al}$ (III) and $\mathrm{NaOH}$ concentrations were confirmed by inductively coupled plasma atomic emission spectroscopy (ICP-AE, Spectro Analytical Instruments, SIM-SEQ) and calibrated electrodeless conductivity analyzer 873EC fitted with an 871EC-SP sensor. 


\subsection{Characterization}

In this section various characterization studies of the structure and physicochemical properties of amorphous/gel, zeolite A, sodalite and cancrinite solid phases are presented.

\subsection{Crystallographic characteristics of Solid Phases}

X-ray powder diffraction and transmission electron diffraction analyses showed that different sodium aluminosilicate solids phases formed from supersaturated nitrate/nitrite-rich sodium aluminate solutions with time during the course of crystallization and followed the sequence:

$\mathrm{NO}_{2} / \mathrm{NO}_{3}$-rich sodium aluminosilicate species $\rightarrow$ amorphous $\rightarrow$ Zeolite $\mathrm{A} \rightarrow \mathrm{NO}_{2}{ }^{-} / \mathrm{NO}_{3}{ }^{-}{ }^{-}$Sodalite $\rightarrow \mathrm{NO}_{2} / \mathrm{NO}_{3}-\mathrm{Cancrinite}$

The lifetime of each metastable phase was strongly temperature and solution composition dependent, as exemplified by the data presented in phase transformation Section that follows. It appears that in $\mathrm{NO}_{2}{ }^{-} / \mathrm{NO}_{3}{ }^{-}$-rich sodium aluminosilicate solutions the amorphous and zeolite $\mathrm{A}$ phases are highly ephemeral at temperatures $>30^{\circ} \mathrm{C}$, transforming rapidly to sodalite and cancrinite. Consequently, the synthesis and isolation of pure phases has been carried very carefully.

Crystalline phase identification, subsequent to complete transformation of the X-ray indifferent amorphous phase, was performed using established, standard diffraction lines for zeolite, sodalite and cancrinite [1-8] shown in Figures 1-4. It is pertinent to note that while each sodium aluminosilicate crystalline phase has exclusive "diagnostic" diffraction lines, it may share common diffraction lines with other phases. For example, both sodalite and cancrinite crystals display similar 110 diffraction lines and also possess 211 diffraction lines but the latter occur at different d-spacings or 2 theta degrees. Hence, only the intensities of major diagnostic lines relative to the common lines can be used to assess the possible presence or absence of other phases. The diagnostic diffraction lines for identifying pure zeolite, sodalite and cancrinite phases and their mixtures are given in Table 2. 

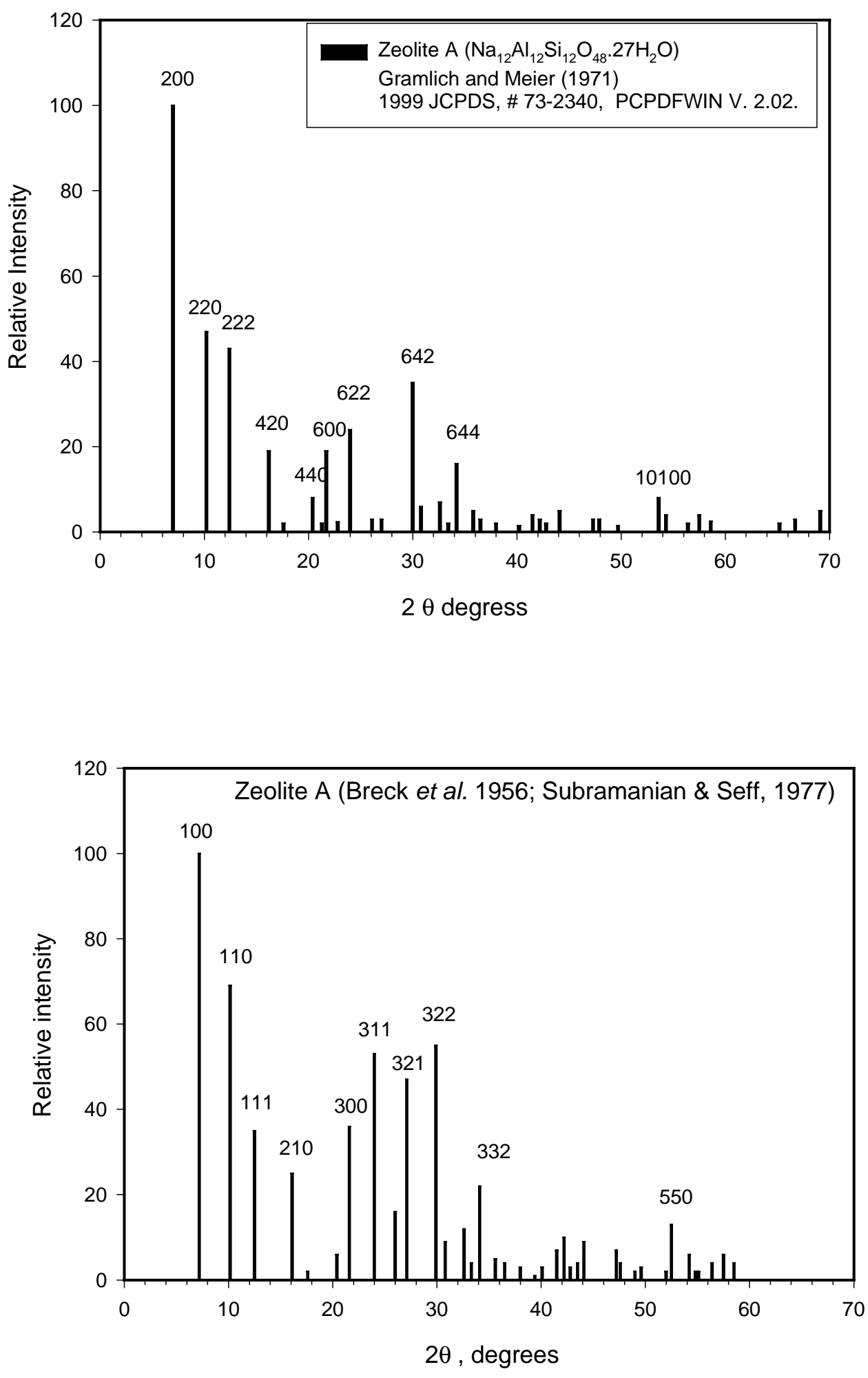

Figures 1 and 2 Standard XRD Patterns for Zeolite A 

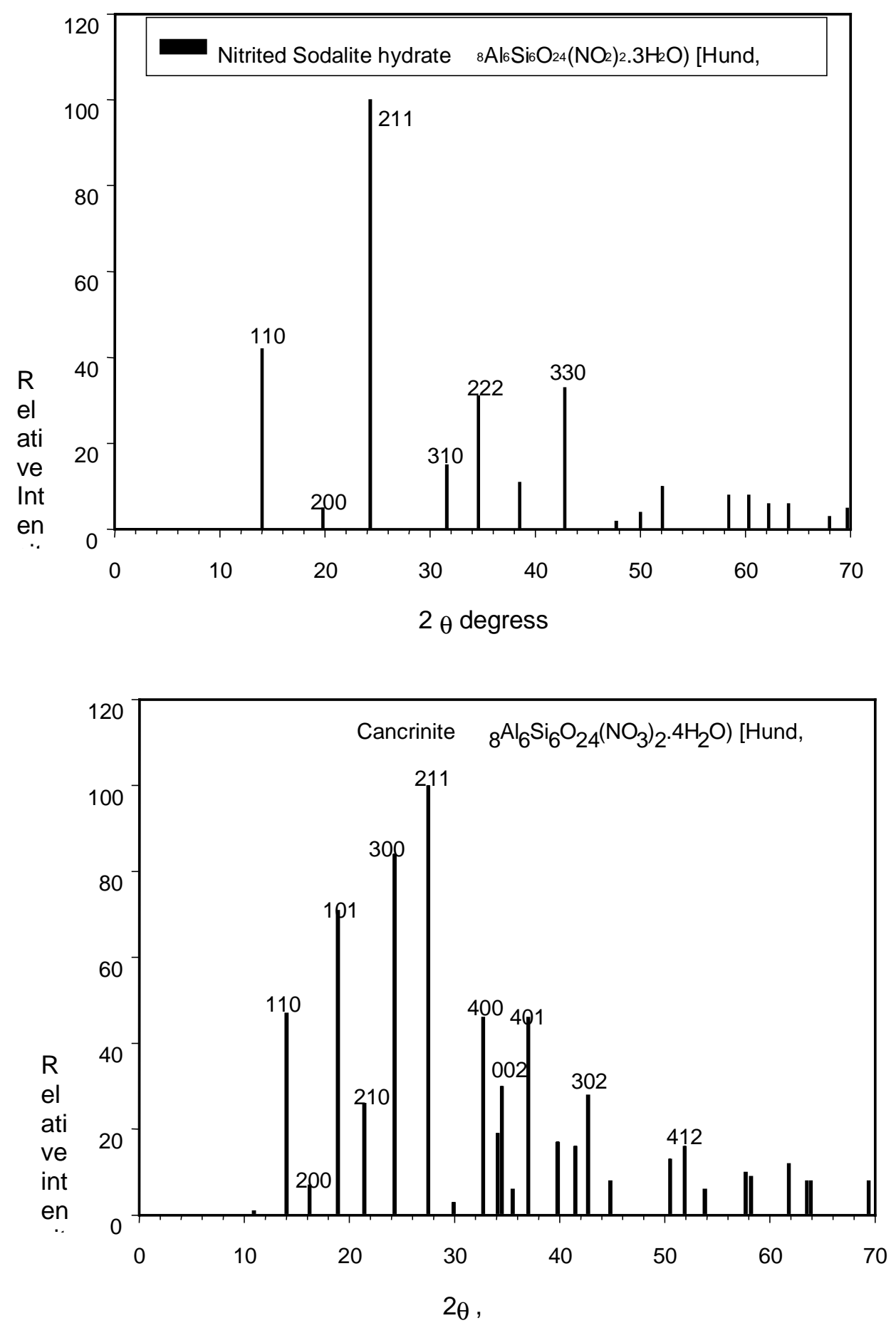

Figures 3 and 4 Standard XRD Patterns for Sodalite and Cancrinite

Major \& diagnostic powder diffraction lines $(h k l)$ 


\begin{tabular}{|c|c|c|}
\hline Zeolite A & Sodalite & Cancrinite \\
\hline $\mathbf{1 0 0 / 2 0 0}$ & 110 & \\
$110 / 220$ & $\mathbf{S 2 1 1}$ & 110 \\
$\mathbf{2 1 0}$ & 222 & $\mathbf{1 0 1}$ \\
222 & $\mathbf{3 3 0}$ & $\mathbf{3 0 0}$ \\
$\mathbf{3 2 2}$ & $\mathbf{4 1 1}$ & $\mathbf{C 2 1 1}$ \\
$\mathbf{6 4 2}$ & $\mathbf{3 1 0}$ & $\mathbf{4 0 1}$ \\
& & $\mathbf{4 0 0}$ \\
\hline
\end{tabular}

\section{Table 2 Powder diffraction lines $(h k l)$ for identifying Solids}

Typical powder diffraction patterns of the solid phases synthesized and identified as Zeolite A, Sodalite and Cancrinite phases are given in Figures 5-7. The zeolite phase formed was Linde A type $\left(\mathrm{Na}_{12} \mathrm{Al}_{12} \mathrm{Si}_{12} \mathrm{O}_{48} .27 \mathrm{H}_{2} \mathrm{O}\right)$ with unit cell parameter $\mathrm{a}=24.60 \pm 0.03 \AA$, while both sodalite (unit cell parameter $\mathrm{a}=8.95 \pm 0.005 \AA$ ) and cancrinite (unit cell parameter $\mathrm{a}=12.68 \pm 0.005 \AA$; c $=5.19 \pm 0.005 \AA$ ) may be generically described as a mixture of $\mathrm{Na}_{8} \mathrm{Al}_{6} \mathrm{Si}_{6} \mathrm{O}_{24}\left(\mathrm{NO}_{2}\right)_{2} \cdot \mathrm{mH}_{2} \mathrm{O}$ and $\mathrm{Na}_{8} \mathrm{Al}_{6} \mathrm{Si}_{6} \mathrm{O}_{24}\left(\mathrm{NO}_{3}\right)_{2} \cdot \mathrm{mH}_{2} \mathrm{O}, 2<\mathrm{m}<4$.

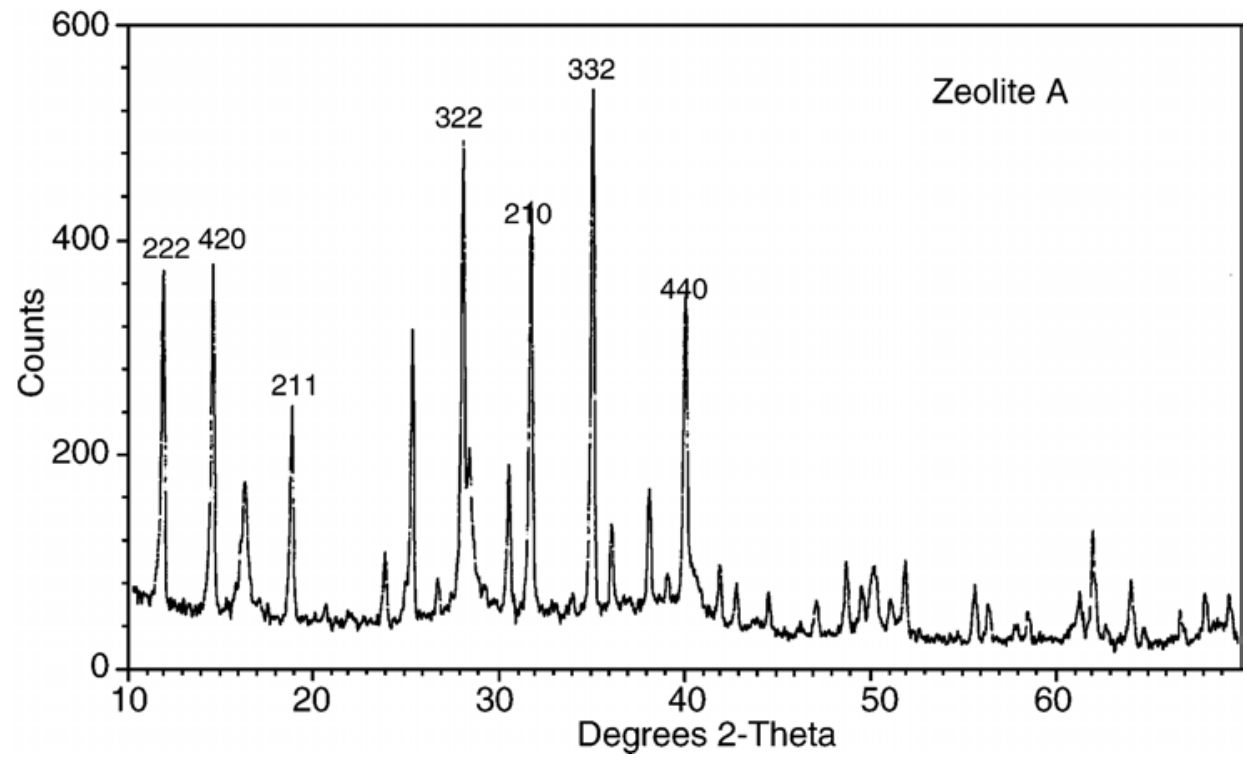

Figure 5 XRD pattern of synthetic zeolite A 


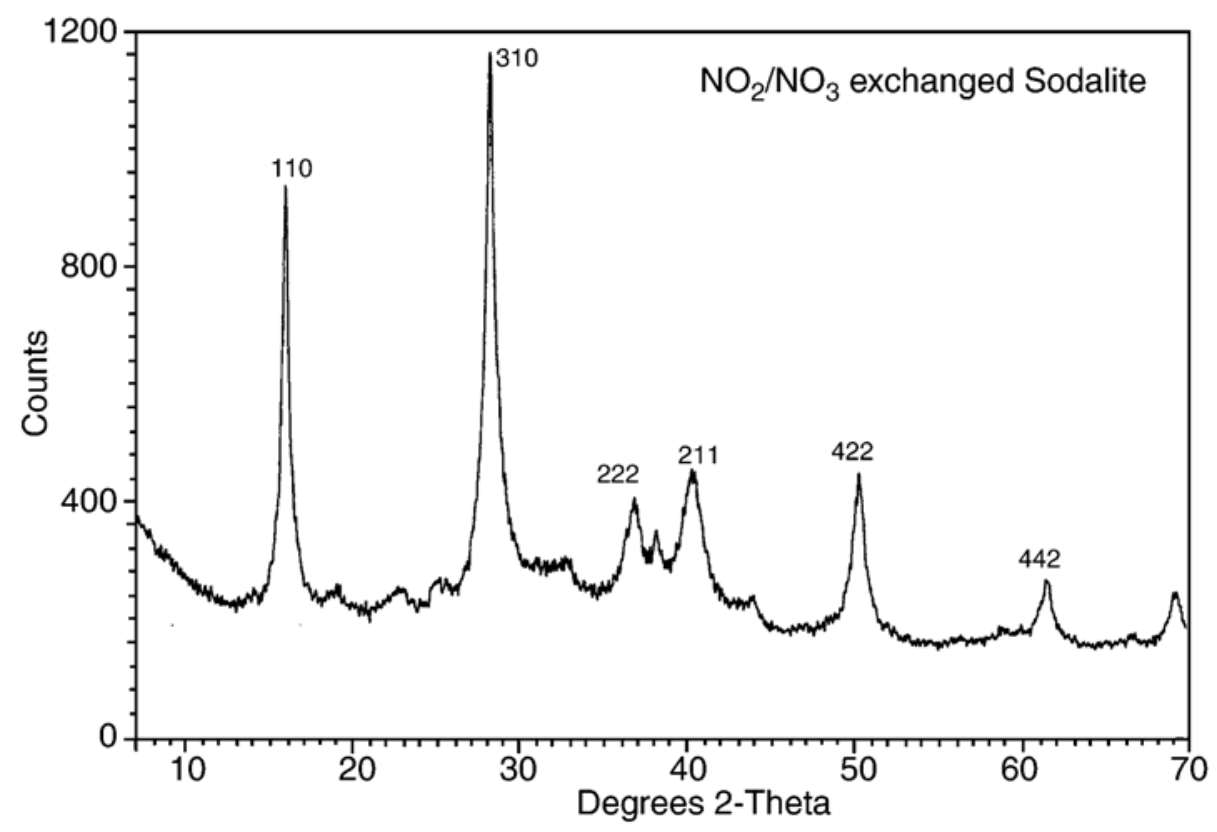

Figure 6 XRD pattern of synthetic sodalite

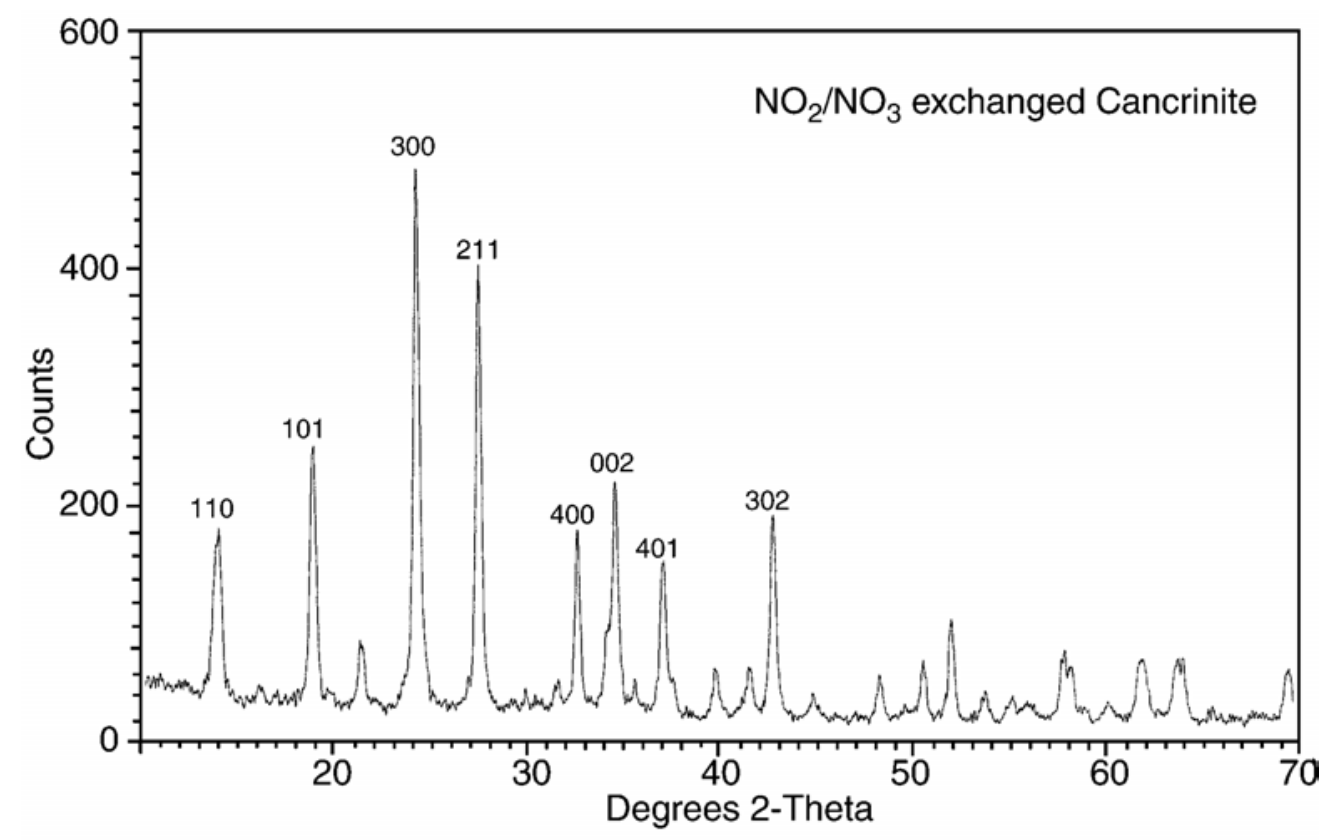

Figure 7 XRD pattern of synthetic cancrinite

\subsection{Morphological characteristics and size of Solid particles}

SEM photomicrographs of the colloidal sized sodium aluminosilicate particles produced in the present work and used for the above x-ray powder diffraction analysis are shown below in 
Figures 8-11. In general, the particles are observed to be primary and secondary agglomerates, formed from colloidally unstable dispersions of high ionic strength (> $4 \mathrm{M})$.

The amorphous product was gelatinous in texture as well as space filling, exhibiting a lower mass density in comparison with the solid crystalline phases. High magnification secondary electron image indicated that the amorphous phase was poorly formed, unfacetted, globular primary particles, $\sim 100 \mathrm{~nm}$ in size. It displayed a high degree of random agglomeration, typical of high surface energy particles interacting strongly with little or no repulsive energy barrier.

The zeolite A particles (unit cell parameter $\mathrm{a}=24.60 \pm 0.03 \AA$ ) of size $\sim 0.5-1 \mu \mathrm{m}$ formed as a result of amorphous phase transformation appeared more compact or denser when compared with the amorphous phase. The finer particles showed needle-like morphology and 'cotton ball' agglomeration behavior whilst the coarse particles displayed chamfered, cubic crystal morphology commonly observed for sodium-exchanged zeolites.

Sodalite and cancrinite crystals were also noted be denser than the amorphous particles. SEM showed the sodalite crystals (unit cell parameter $\mathrm{a}=8.95 \pm 0.005 \AA$ ) as having "cotton ball" type morphology. The individual, primary sodalite particles were highly colloidal, 25$50 \mathrm{~nm}$ in diameter, which agglomerated into 200 - $500 \mathrm{~nm}$ sized globular particles. The cancrinite crystals were rounded particles of 50 - $100 \mathrm{~nm}$ diameter. Notably, the primary particles of the sodalite phase were nearly 2 - 8 times smaller than the amorphous, zeolite A and cancrinite particles. 
WSRC-MS-2002-00907

Page 24 of 141
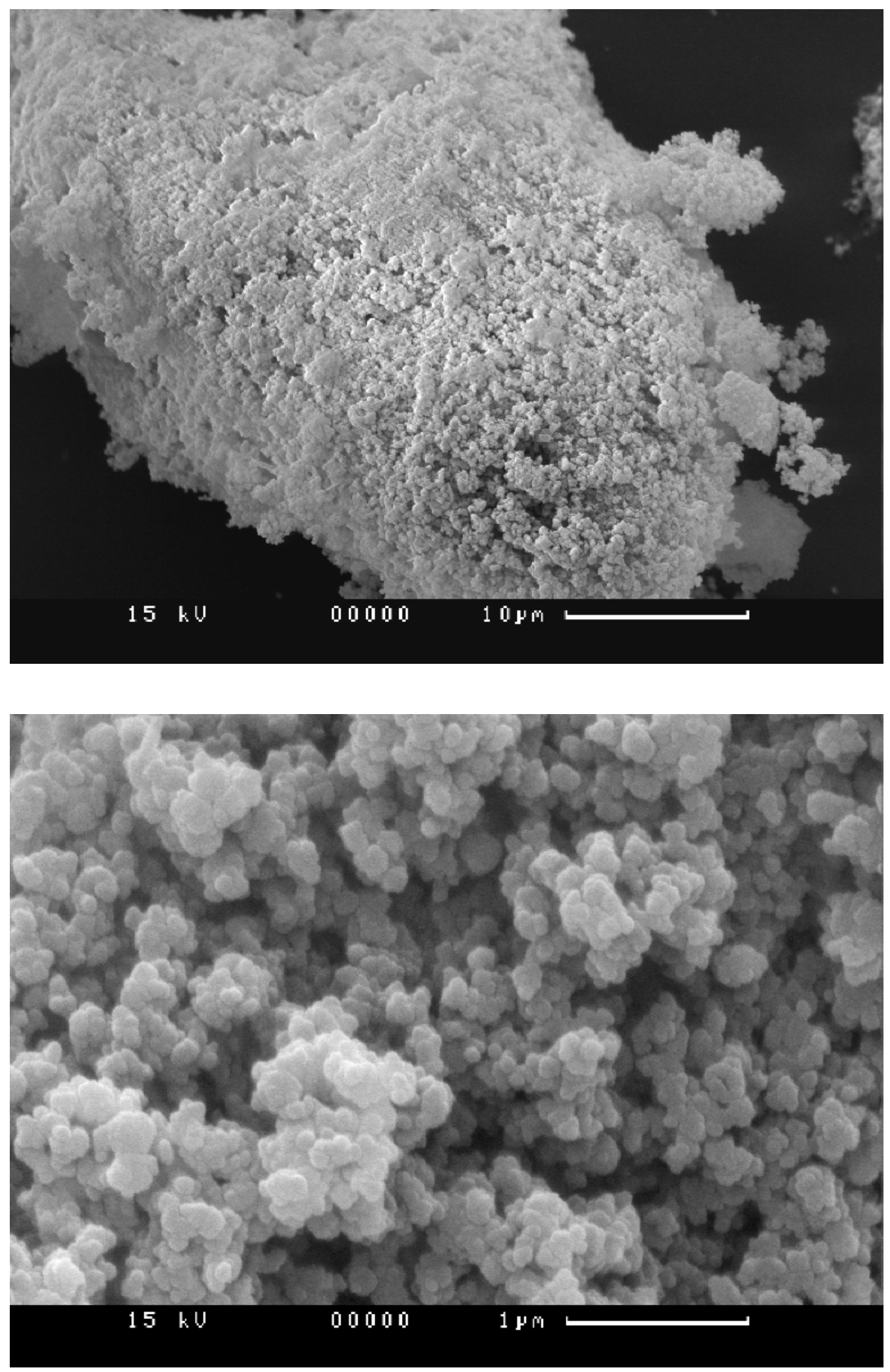

Figure 8

SEM of synthetic Amorphous Sodium Aluminosilicate 
WSRC-MS-2002-00907

Page 25 of 141
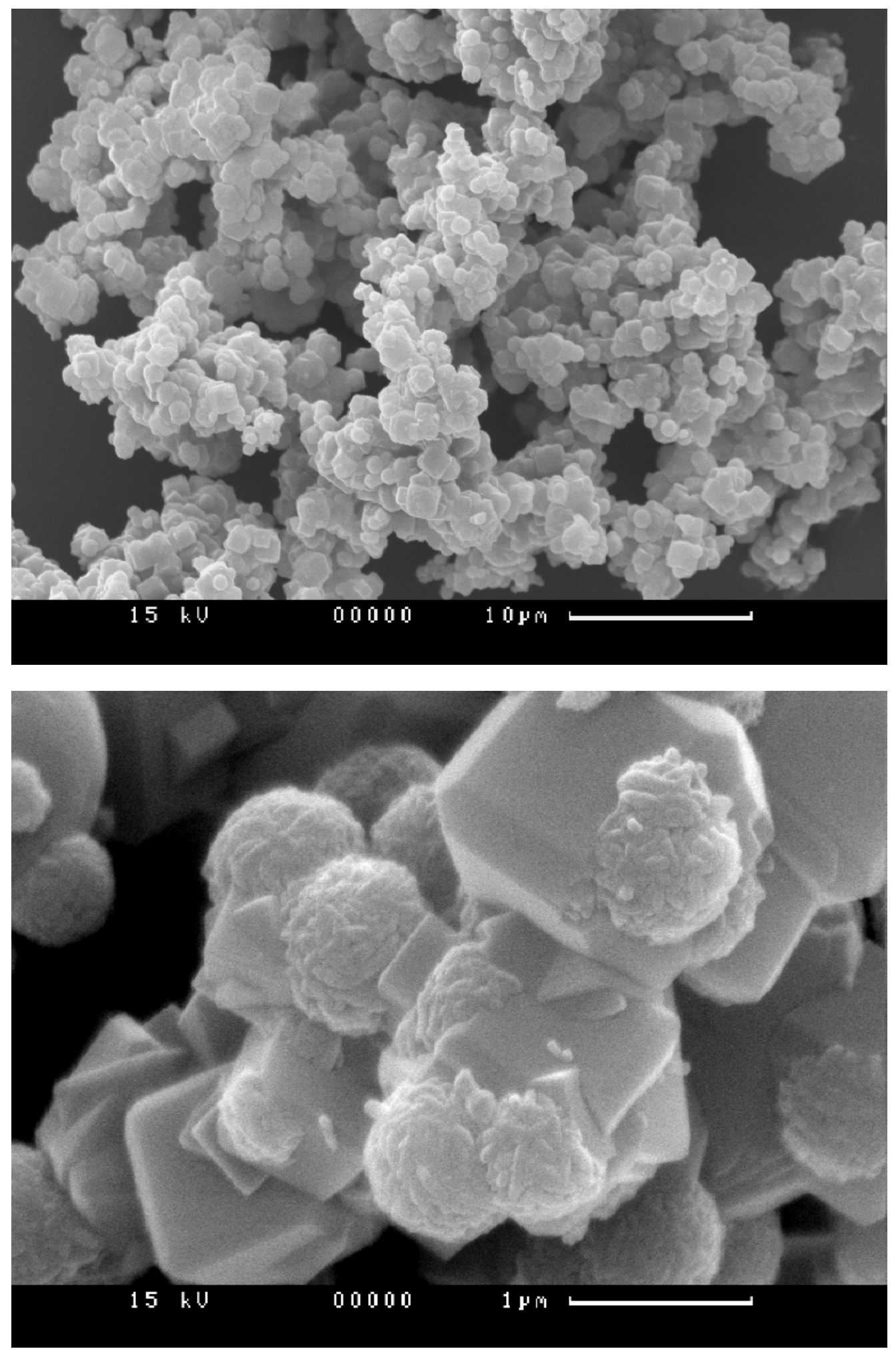

Figure 9 SEM photomicrographs of synthetic zeolite A 
WSRC-MS-2002-00907

Page 26 of 141
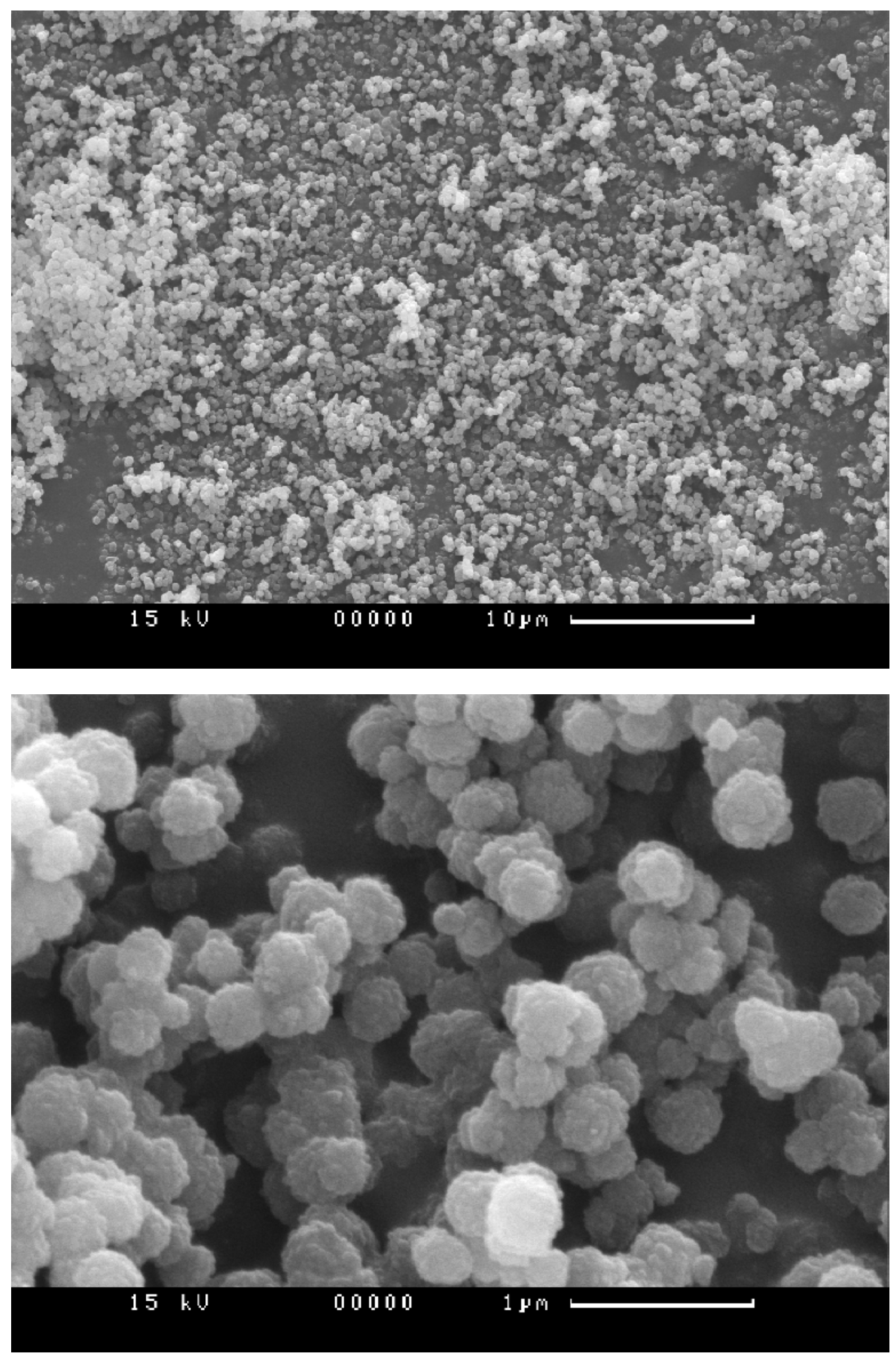

Figure 10 SEM photomicrographs of synthetic sodalite 
WSRC-MS-2002-00907

Page 27 of 141
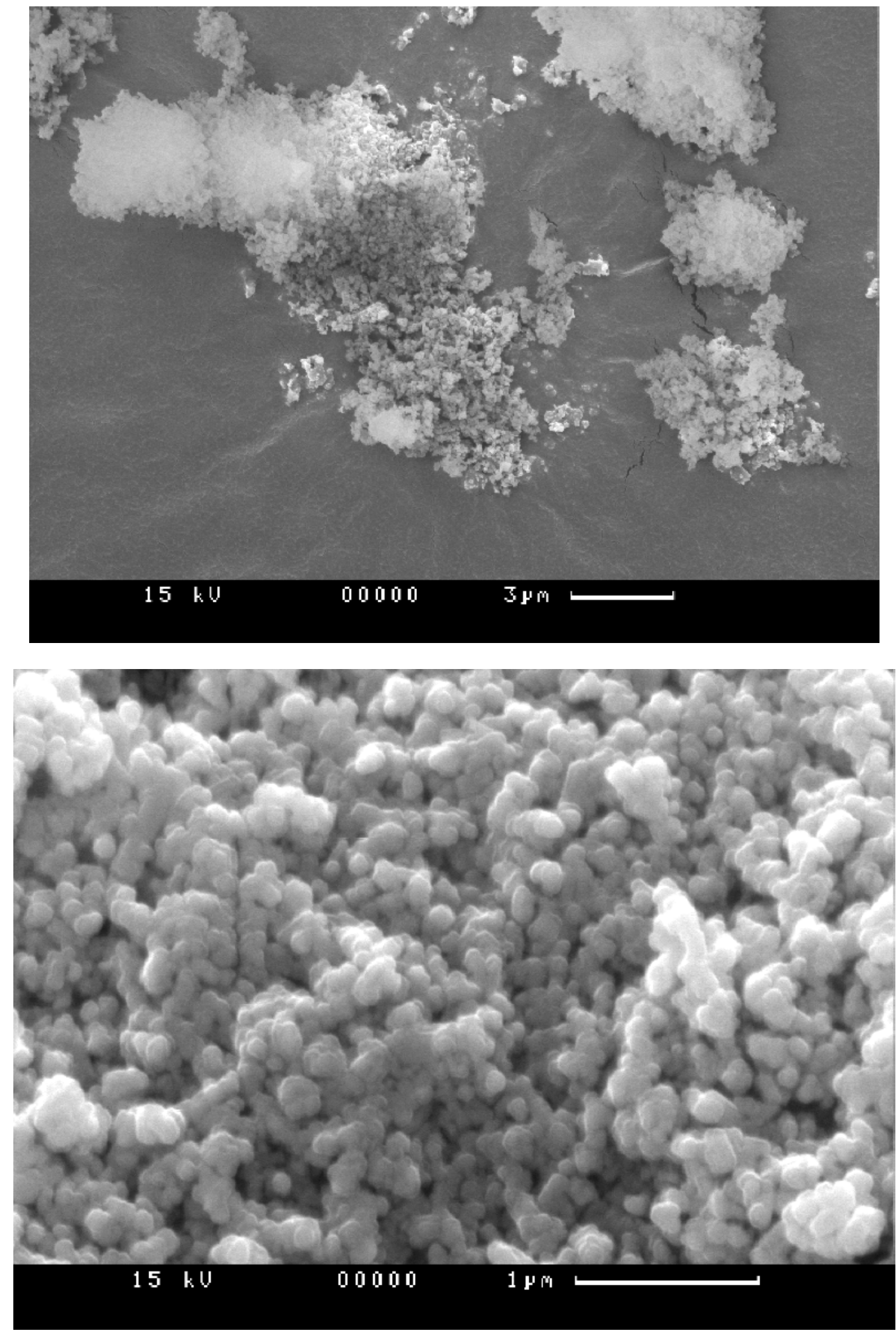

Figure 11 SEM photomicrographs of synthetic Cancrinite

4.3 Solid particles shape, aggregate structure and size characteristics

\subsubsection{Amorphous Phase}


Transmission electron micrographs of the amorphous material, shown in figure 12, revealed high-order aggregation behavior of the submicron $(<25 \mathrm{~nm})$ particles. The primary particles within the agglomerates of 100 to $200 \mathrm{~nm}$ sizes and the agglomerates connected together to form porous superstructure. Selected Area Electron Diffraction (SAED) performed on these aggregates showed no diffraction spots indicative of a high degree ordering of atoms as characteristically observed in crystalline structures. High-resolution TEM images confirmed the absence of lattice fringes.

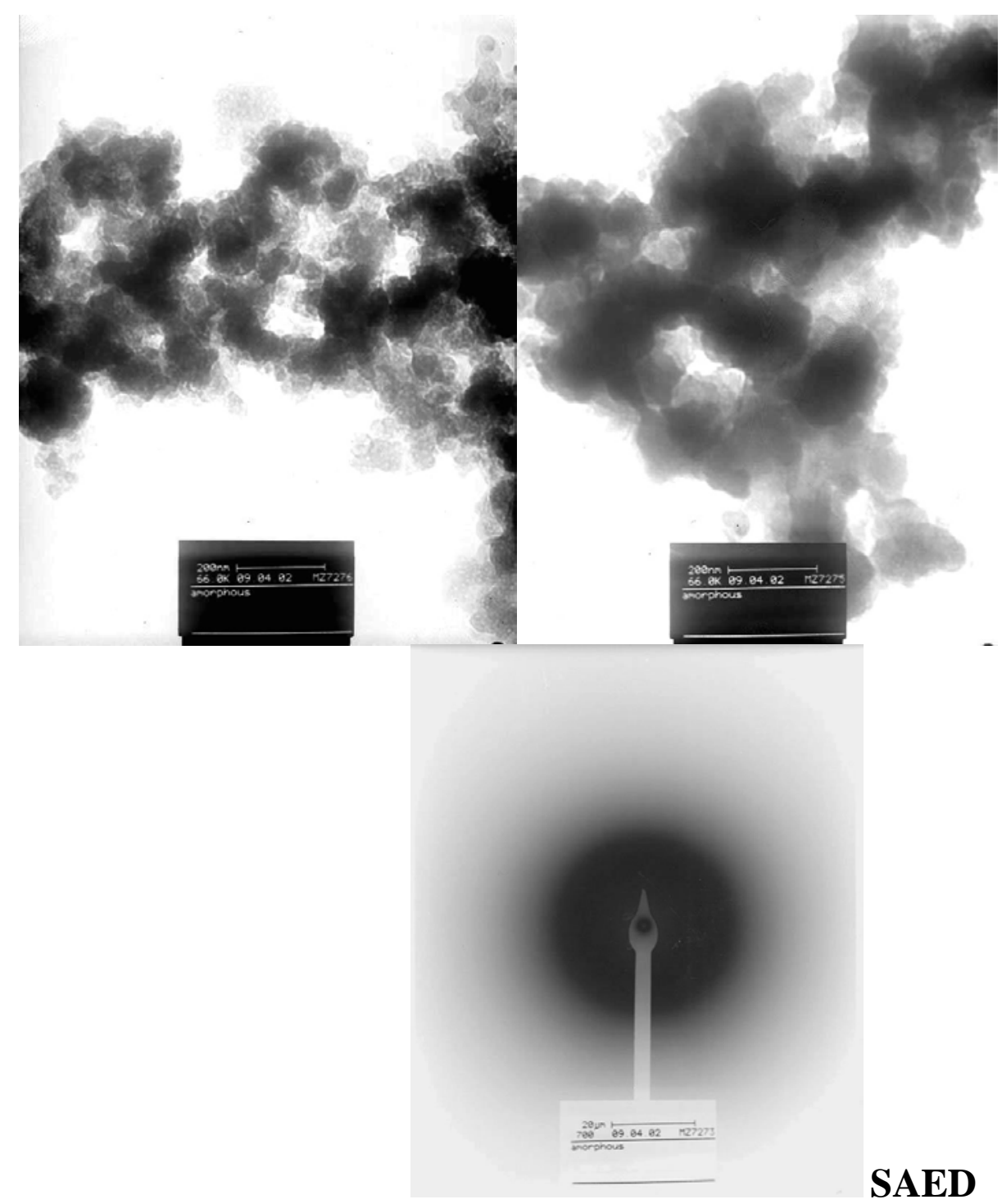

Figure 12 TEM micrographs and SAED of synthetic amorphous sodium aluminosilicate particles

\subsubsection{Zeolite A}

TEM micrographs of the zeolite particles, shown in figure 13, demonstrate spherical aggregates of the smaller crystals. The aggregates of 100 and $500 \mathrm{~nm}$ in diameter consisted of ultra-fine crystals of about $20 \mathrm{~nm}$ in dimension. These spherical aggregates inter-linked to 
WSRC-MS-2002-00907

Page 29 of 141

form porous superstructures. High-resolution images confirmed the presence of lattice fringes, even to the very edge of the crystals. SAED patterns observed showed a highly crystalline structure similar to that of cancrinite.
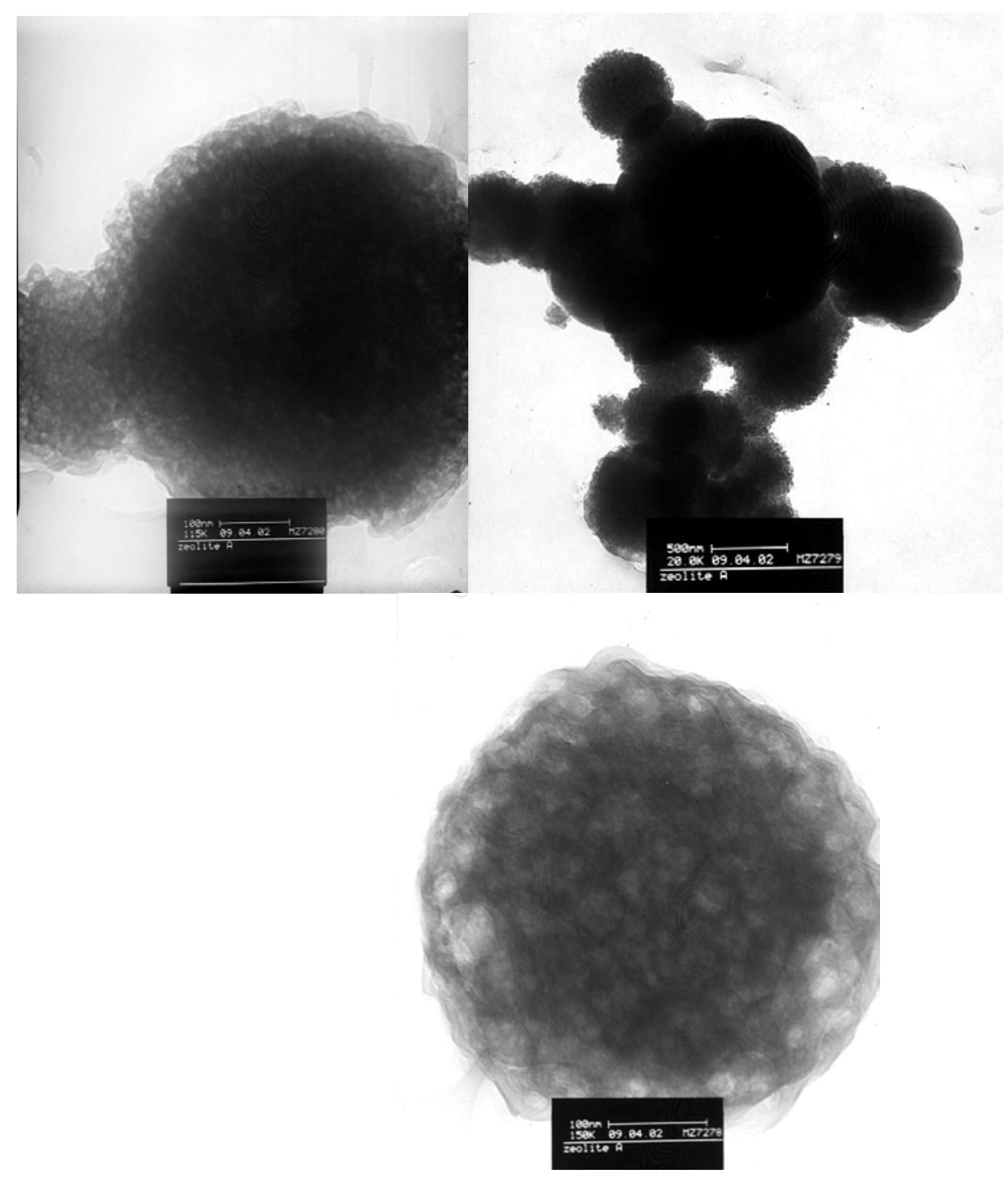

Figure 13 TEM micrographs of synthetic Zeolite A crystals 


\subsubsection{Sodalite}

TEM micrographs of sodalite, shown in figure 14, revealed that this mineral phase consists of ultra-fine needle shaped individual particles, 20 - $30 \mathrm{~nm}$ in dimension, which aggregated into porous globules of 200 to $300 \mathrm{~nm}$ diameter. High resolution images confirmed the existence of lattice fringes throughout the crystals. SAED patterns recorded showed strong diffraction spots, and this together with the presence of lattice fringes indicated the solid material to be highly crystalline.

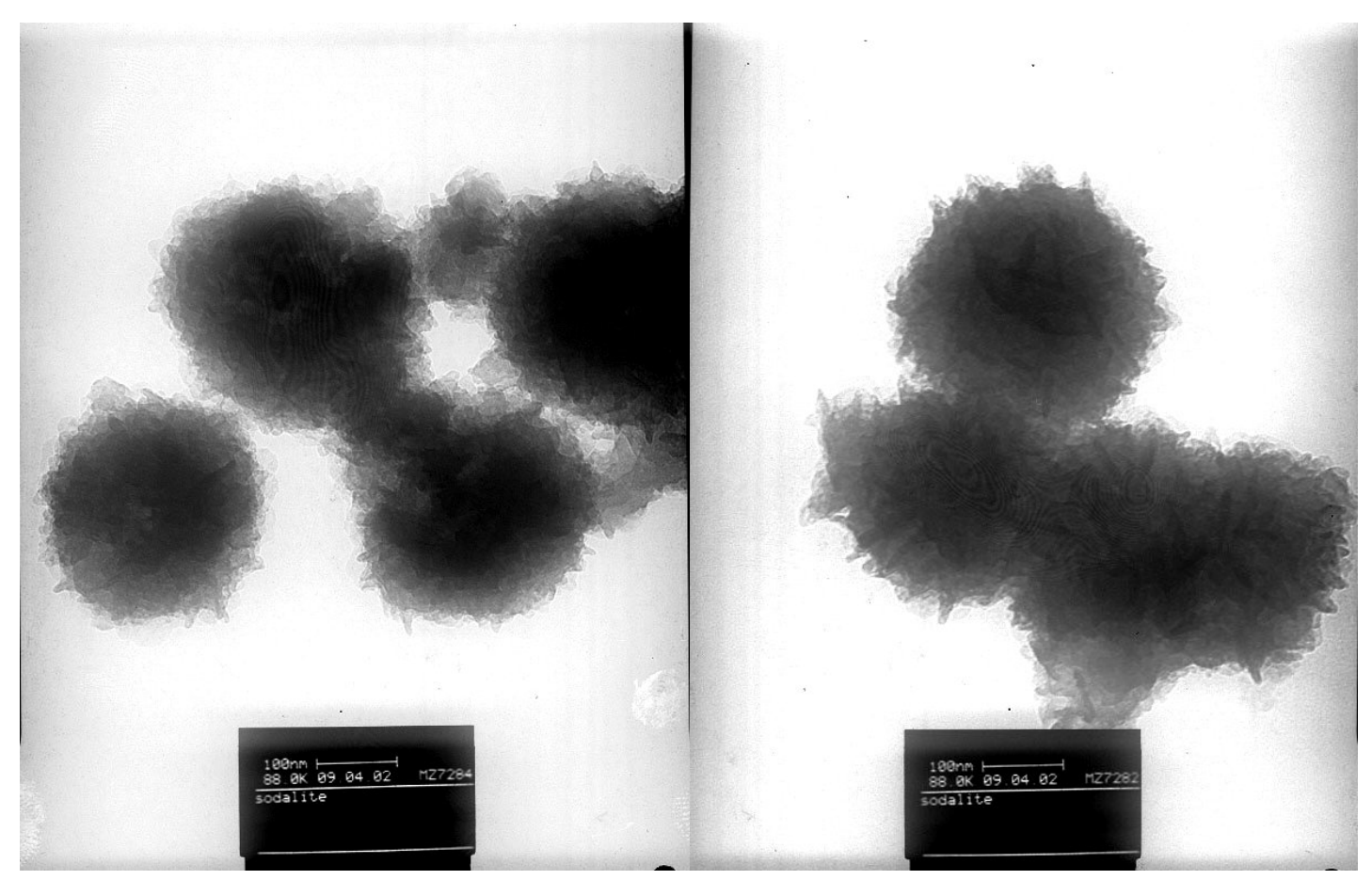

Figure 14 TEM micrographs of synthetic Sodalite crystals

\subsubsection{Cancrinite}

TEM micrographs indicated the cancrinite particles to be porous aggregates consisting of regular shaped granular crystals of $50 \mathrm{~nm}$ in dimension and rectangular in shape (Figure 15). Occasionally, particles of about $50 \mathrm{~mm}$ wide and $500 \mathrm{~nm}$ long were present. High resolution TEM images indicated the existence of lattice fringes throughout the crystals and to the very edges. Selected area electron diffraction of both small and large particles also showed strong diffraction spots typical of highly crystalline material. 
WSRC-MS-2002-00907

Page 31 of 141

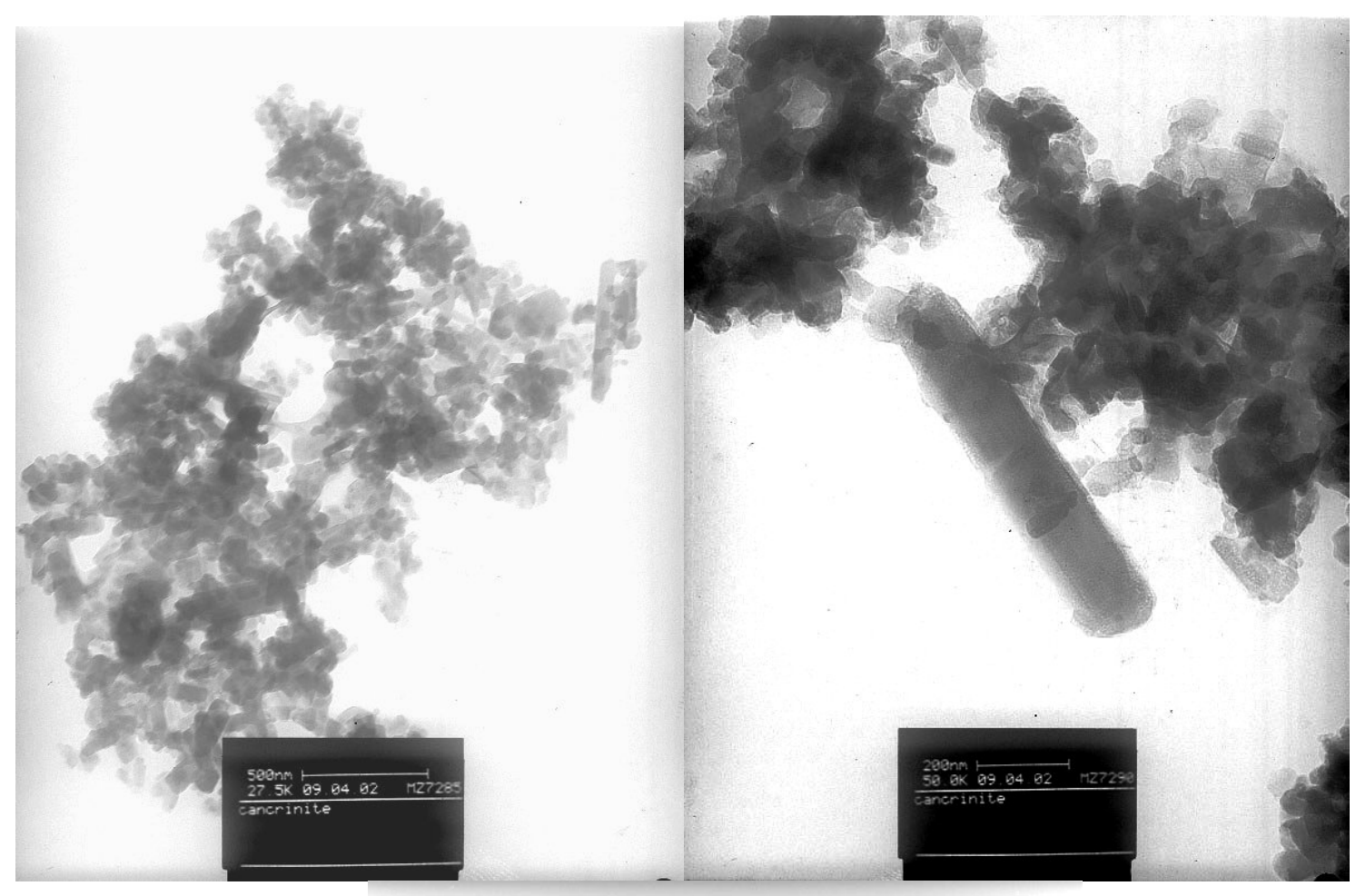

Figure 15 TEM micrographs and SAED of synthetic Cancrinite crystals

\subsection{Particle Size}


The analysis of size of all solids particles was performed prior to drying using the laser diffraction technique described earlier. The complete size distribution data are available from the University of South Australia while the average particle sizes measured as the $10^{\text {th }}, 50^{\text {th }}$ and $90^{\text {th }}$ percentile and sauter mean diameter $\left(D_{32}\right)$ are summarized in Table 3.

\begin{tabular}{|l|c|c|c|c|}
\hline Solid phase & $\mathbf{D}_{\mathbf{1 0}}[\mu \mathbf{m}]$ & $\mathbf{D}_{\mathbf{5 0}}[\mu \mathbf{m}]$ & $\mathbf{D}_{\mathbf{9 0}}[\mu \mathbf{m}]$ & $\mathbf{D}_{\mathbf{3 2}}[\mu \mathbf{m}]$ \\
\hline Amorphous & 0.5 & 10.0 & 18.0 & 7.9 \\
\hline Zeolite A & 1.2 & 3.5 & 6.0 & 2.2 \\
\hline Sodalite & 1.9 & 4.0 & 8.0 & 2.9 \\
\hline Cancrinite & 0.3 & 1.0 & 8.0 & 0.7 \\
\hline
\end{tabular}

\section{Table $310^{\text {th }}, 50^{\text {th }}$ and $90^{\text {th }}$ percentile particle size and sauter mean diameter}

The size distribution data naturally contain some particle interactions and agglomeration behavior. They indicate that agglomeration was more dominant for the amorphous phase and less pronounced for cancrinite crystals, consistent with the SEM image analysis. This observation may be, in part, rationalized in terms of the higher ionic strength which typically prevailed during the amorphous phase formation in comparison with the reduced ionic strength when cancrinite formed in situ from a sodalite phase. Higher ionic strengths should lead to greater compression of the electrical double layers around the particles, thereby facilitating primary minimum particle agglomeration.

\subsection{Specific surface area of solid phases}

BET specific surface areas of the amorphous and crystalline solid phases are given in Table 4. Each measurement has been replicated 3 times from 2 independent batches of samples synthesized at different times. The specific surface areas are consistent with the particle size and network structure information provided by SEM and TEM. The sodalite specific surface area is noted to be higher than what we usually observe for $\mathrm{CO}_{3}{ }^{2-}$-rich sodalite crystals. SEM and TEM imaging (secondary electron) showed that the individual sodalite primary particles are highly colloidal structures which agglomerated into globular particles. These appear to be highly porous and strongly $\mathrm{N}_{2}$ adsorbing, judging by the reproducible BET adsorption isotherms recorded. 


\section{Amorphous \\ Zeolite A \\ $\mathrm{NO}_{2} / \mathrm{NO}_{3}$-Sodalite \\ $\mathrm{NO}_{2}{ }^{-} \mathrm{NO}_{3}{ }^{-}$Cancrinite}

$79.8 \pm 1.9$

$9.2 \pm 1.0$

$187.4 \pm 3.0$

$45.3 \pm 1.6$

Table 4 BET specific surface area of the sodium aluminosilicate solid phases

\subsection{Surface and bulk chemical composition and structure of Solid particles}

The chemical composition and structure of the solid phases were examined using both surface and bulk sensitive techniques. X-ray Photoelectron Spectroscopy (XPS) which analyses surface chemical structures over a depth of about $10-40 \mathrm{~nm}$ provides useful quantitative information about the surface of the solid material. Depth profiling by surface etching yields further information relating to the bulk. Energy Dispersive Spectroscopy (EDAX) is a bulk technique which provides semi-quantitative composition information over a depth of $1 \mu \mathrm{m}$. The summary of the results obtained using both analytical techniques are given in Figure 16 and Tables 5 and 6.

The core and valence band spectra are shown in Figure 15. They display all the principal elements in sodium aluminosilicate solid phases: $\mathrm{Na}, \mathrm{Al}, \mathrm{Si}, \mathrm{O}$, and in addition the presence of carbon (C). These observations were made for all phases. Nitrogen was observed for sodalite and cancrinite but not the amorphous and zeolite A phases. The presence of carbon can be traced to 2 sources of contamination: atmospheric graphitic or adventitious carbon/hydrocarbon and carbonate present as an impurity in caustic soda used in synthesis and also formed by atmospheric $\mathrm{CO}_{2}$ dissolution during synthesis. This is quite common given the high sensitivity of XPS.

The results in Table 5 show that the atomic $\mathrm{Al} / \mathrm{Si}$ concentration ratio was close 1 for all phases. The $\mathrm{O} / \mathrm{Al}$ or $\mathrm{O} / \mathrm{Si}$ ranged between 4 and 6 . These are consistent with hydrated amorphous and zeolite, and $\mathrm{NO}_{2}{ }^{-}$and $\mathrm{NO}_{3}{ }^{-}$-rich, hydrated sodalite and cancrinite phases. The $\mathrm{Na} / \mathrm{Al}$ or Si ratio is slightly less than 1 for zeolite or 1.33 expected for sodalite and cancrinite. This may be attributed to surface migration or diffusion effects of the relatively mobile $\mathrm{Na}^{+}$ ions during analysis. Similar relative elemental concentration trends were observed when depth profiling was carried out on deeper (etched) layers. The bulk solid EDAX analysis shown in Table 6 indicate that $\mathrm{Na}$ to $\mathrm{Al}$ or $\mathrm{Si}$ mass ratios were substantially similar for all 
solid phases and within $\pm 5 \%$ of expectation. ICP analysis showed that $\mathrm{Al} / \mathrm{Si}$ molar ratio $=1.0$ \pm 0.05 for all 4 phases.

Five minutes of surface etching led to $40-50 \%$ reduction in atomic carbon concentration. This indicating the extent of adventitious $\mathrm{C}$. A marked reduction in $\mathrm{N}$ concentration in sodalite and cancrinite phases occurred due to the etching process. This is believed to reflect the high mobility of $\mathrm{NO}_{2}{ }^{-}$and $\mathrm{NO}_{3}{ }^{-}$in the cages and channels of sodalite and cancrinite. Like $\mathrm{Na}^{+}$, these anions appear to respond to the higher energy beam used in etching by acquiring sufficient kinetic energy to diffuse away, hence reduced concentration at greater depths.

The lack of detection of nitrogen-based species in the amorphous and zeolite A solid phases suggests that $\mathrm{NO}_{2}{ }^{-}$and $\mathrm{NO}_{3}{ }^{-}$species do not play a key role in polycondensation reactions and 3-dimensional embryo structure development which underpins nuclei formation and growth of these solid phases. $\mathrm{NO}_{2}{ }^{-}$and $\mathrm{NO}_{3}{ }^{-}$species do play a pivotal role in structure stabilization and templating in the formation sodalite and cancrinite. Thus, $\mathrm{NO}_{2}{ }^{-}$and $\mathrm{NO}_{3}{ }^{-}$acted to promote metastable amorphous and zeolite phase transformation to sodalite and cancrinite phases. Furthermore, these observations suggests that the previous theory which suggests a diffuse gel/amorphous phase undergoes direct sub-crystalline interfacial structure densification into a crystalline structure may be discounted. It appears that another intermediate structure exists during this transformation process. Such a condition is not, however, a strong requirement for zeolite A formation. 
WSRC-MS-2002-00907

Page 35 of 141

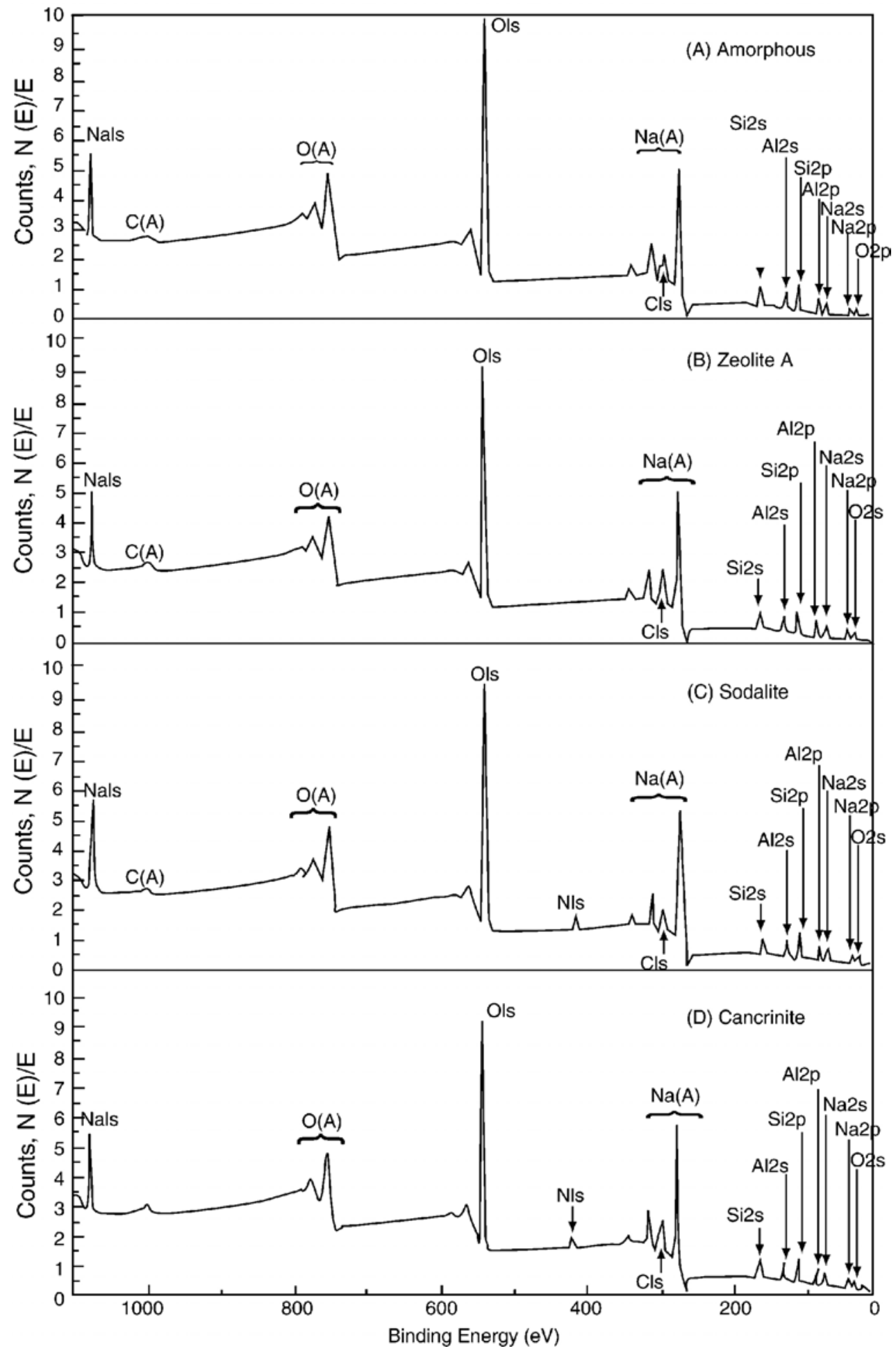

Figure 15 XPS analysis of solids

\begin{tabular}{|c|c|c|c|c|c|c|c|c|}
\hline \multirow[t]{2}{*}{ Element } & \multicolumn{2}{|c|}{$\begin{array}{c}\text { Amorphous } \\
\text { Concentration }(\%)\end{array}$} & \multicolumn{2}{|c|}{$\begin{array}{c}\text { Zeolite A } \\
\text { Concentration }(\%) \\
\end{array}$} & \multicolumn{2}{|c|}{$\begin{array}{c}\text { Sodalite } \\
\text { Concentration }(\%) \\
\end{array}$} & \multicolumn{2}{|c|}{$\begin{array}{c}\text { Cancrinite } \\
\text { Concentration }(\%)\end{array}$} \\
\hline & Normal & Etched & Normal & Etched & Normal & tched & Normal & ched \\
\hline C1s & 23.07 & 13.20 & 26.37 & 14.25 & 22.41 & 13.14 & 26.31 & 14.06 \\
\hline O1s & 50.82 & 54.30 & 47.50 & 53.35 & 50.11 & 54.15 & 47.52 & 53.32 \\
\hline Na1s & 6.23 & 7.04 & 5.93 & 7.15 & 6.66 & 7.00 & 5.72 & 6.46 \\
\hline
\end{tabular}




\begin{tabular}{|l|c|c|c|c|c|c|c|c|}
\hline Si2p & 10.44 & 12.62 & 10.28 & 12.58 & 9.66 & 12.79 & 9.59 & 12.48 \\
\hline Al2p & 9.43 & 12.84 & 9.92 & 12.66 & 9.72 & 12.18 & 9.21 & 12.54 \\
\hline N1s & - & - & - & - & 1.44 & 0.74 & 1.65 & 0.64 \\
\hline
\end{tabular}

Table 5 XPS of solid phases showing elemental composition at the surface

\begin{tabular}{|l|c|c|c|c|}
\hline \multirow{2}{*}{ Solid phase } & \multicolumn{4}{|c|}{ Elements (wt \%) } \\
\cline { 2 - 5 } & Al & Si & Na & O \\
\hline Amorphous & 22.5 & 23.0 & 18.7 & 35.8 \\
\hline Zeolite A & 22.6 & 22.0 & 19.0 & 36.4 \\
\hline Sodalite & 22.1 & 22.9 & 21.3 & 33.8 \\
\hline Cancrinite & 21.8 & 22.6 & 21.8 & 33.8 \\
\hline
\end{tabular}

Table 6 EDAX analysis of solid phases showing bulk composition of elements

Analysis of the valence band spectra (at binding energy $<22 \mathrm{eV}$ ) revealed a marked distinction between the amorphous and crystalline solids phases and is shown in figure 16. The crystalline phases showed 4 distinct and well-resolved peaks reflecting different levels of $\mathrm{Al}-\mathrm{O}-\mathrm{Si}$ and $\mathrm{O}$ bonding in well-ordered $\mathrm{AlO}_{4} / \mathrm{SiO}_{4}$ structures with internal regularity. The amorphous material, on the other hand, barely exhibits such features of high degree ordering and bonding between species. The peaks indicated at higher binding energies ( 16 and $18 \mathrm{eV})$ relate to $\mathrm{AlO}_{4} / \mathrm{SiO}_{4}$ clusters in the solid while the one at the lowest binding energy $(\sim 9 \mathrm{eV})$ is believed to be associated with chemisorbed water. It is evident from the valence band data that all three crystalline phases display quite similar $\mathrm{AlO}_{4} / \mathrm{SiO}_{4}$ bonding behavior characteristics but these differ from those shown by the amorphous phase. 


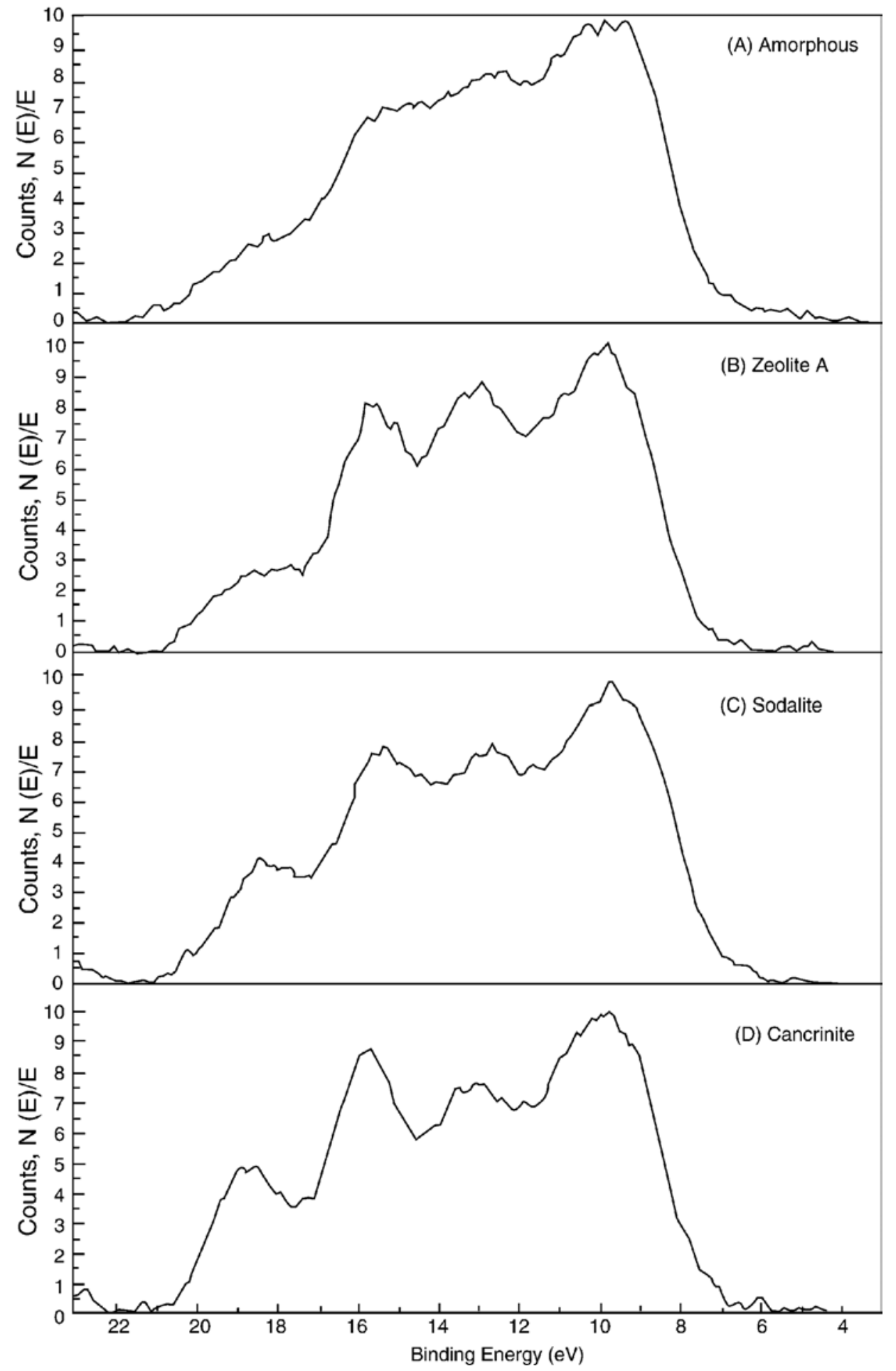

Figure 16 XPS valence band analysis (Oxygen) of solid phases

The presence and relative abundance of $\mathrm{NO}_{3}{ }^{-}$and $\mathrm{NO}_{2}{ }^{-}$ions in sodalite and cancrinite framework structures are shown in Figure 17. Three nitrogen based-products are present. The third product is indicated as $\mathrm{X}$ and the exact chemical identify of this species is not clear 
at this stage. On the basis of its relatively lower binding energy (402- $404 \mathrm{eV})$, it may be suggested to be an ion of which nitrogen has a lower oxidation state of 1 , such as $\mathrm{N}_{2} \mathrm{O}_{2}{ }^{2-}$. Such a product may possibly form as a result of certain nitrogen disproportionation reactions.

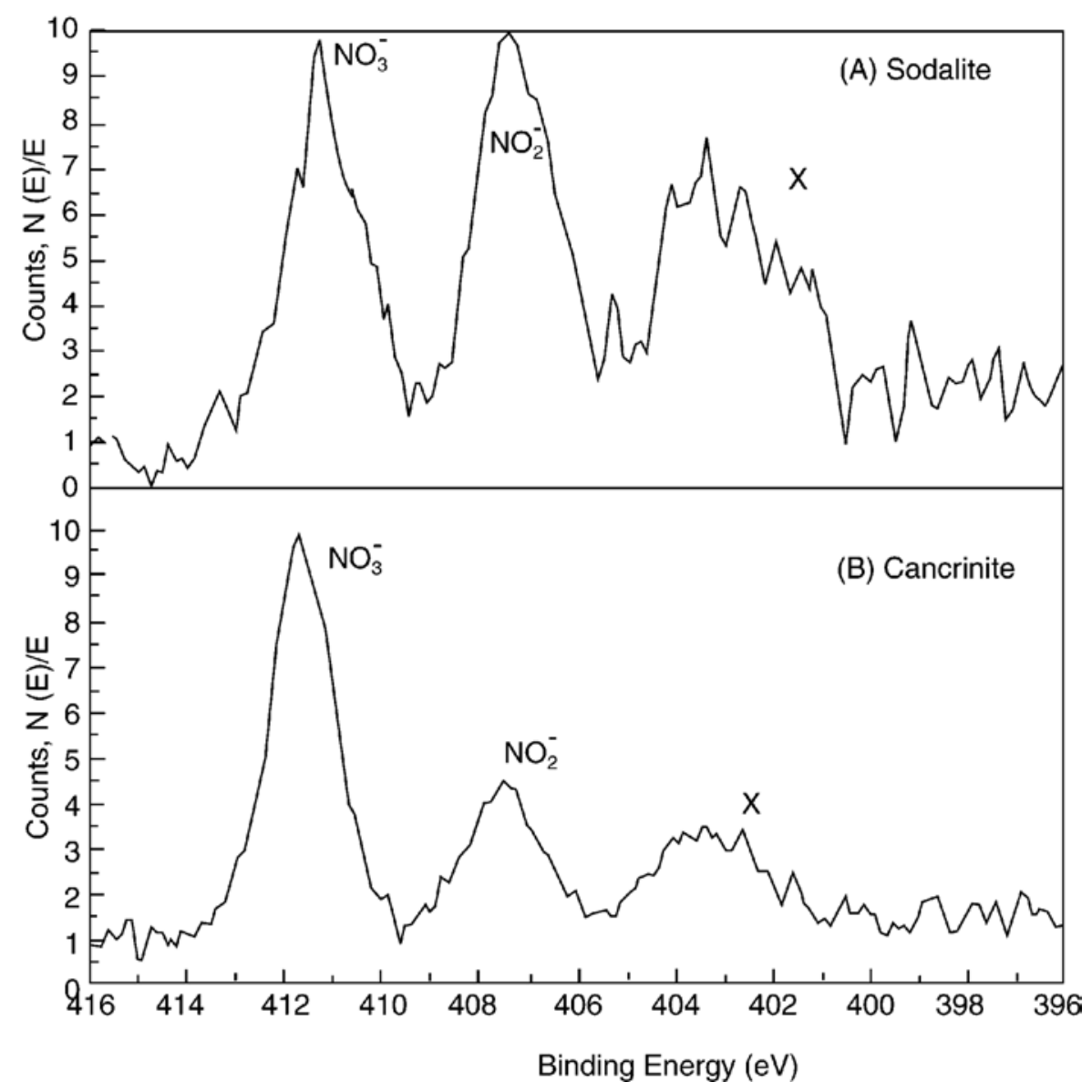

Figure 17 XPS analysis of nitrogen species of solid phases

The peak areas under $\mathrm{NO}_{3}{ }^{-}\left(1570\right.$ units $\left.^{2}\right)$ and $\mathrm{NO}_{2}{ }^{-}\left(1581\right.$ units $\left.^{2}\right)$ were noted to be similar for sodalite with $\mathrm{X}\left(=\mathrm{N}_{2} \mathrm{O}_{2}{ }^{2-}\right)=1300$ units $^{2}$. For cancrinite, $\mathrm{NO}_{3}{ }^{-}=1870$ units $^{2}$ and $\mathrm{NO}_{2}{ }^{-}=779$ units ${ }^{2}$ and $X=750$ units ${ }^{2}$. It appears that the oxidation of $\mathrm{NO}_{2}{ }^{-}$to $\mathrm{NO}_{3}{ }^{-}$increased in the course of precipitation as more sodalite transforms to cancrinite, and this involved disproportionate, lower oxidation state species.

The presence of carbon-based species was indicated by XPS C1s core level spectra, shown in figure 18, which showed a charging effect. Two types of species are apparent a graphitic carbon/adventitious hydrocarbon at the lower binding energy (289.6 eV) and a carbonate species at the higher binding energy. 
WSRC-MS-2002-00907

Page 39 of 141

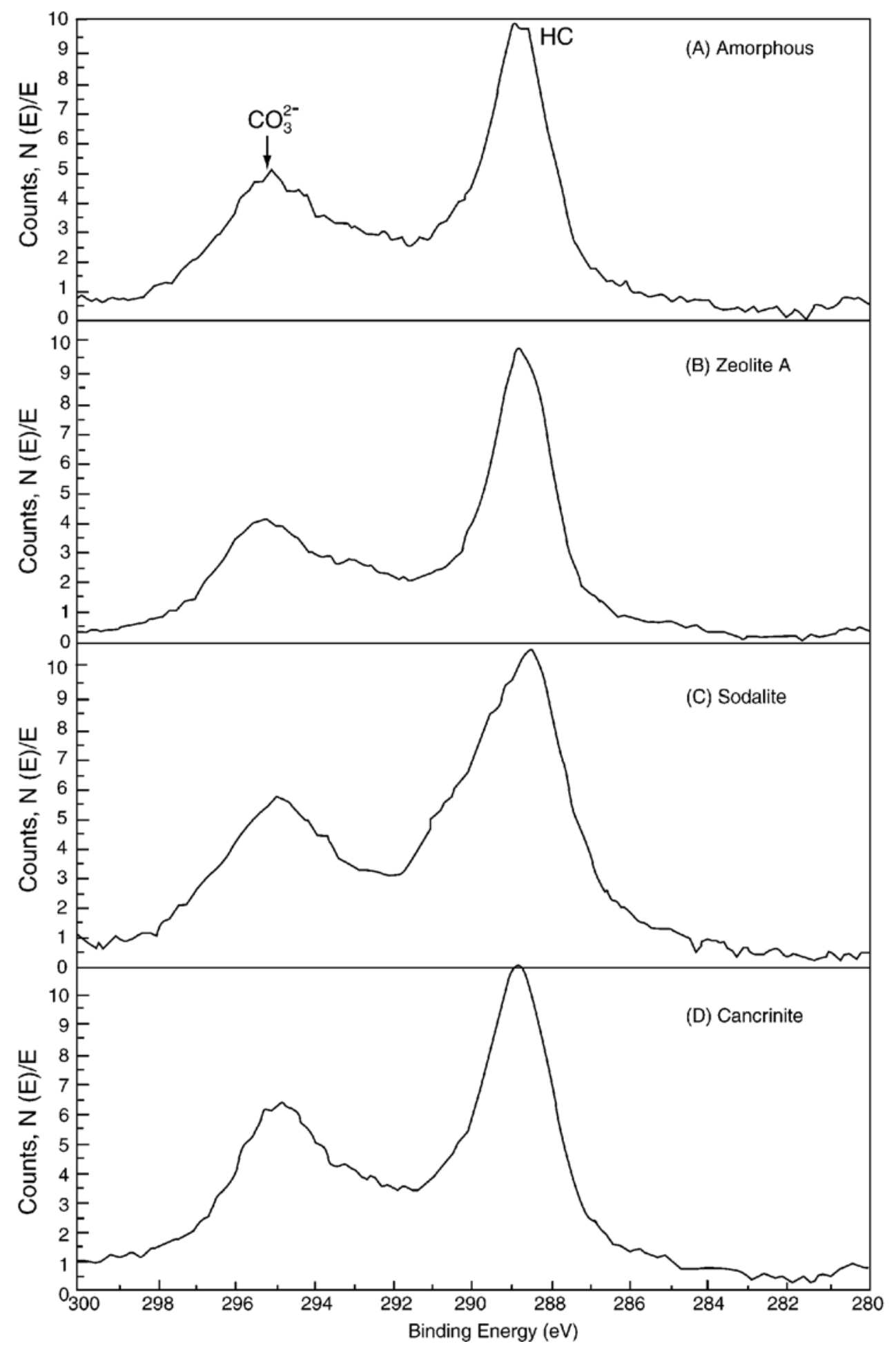

Figure 18 XPS of solid phases showing carbon species 


\subsection{Infrared Spectroscopy}

The surface/bulk chemical speciation of the solid phases (mixed with KBR) was investigated by Fourier transform infrared (FTIR) spectroscopy using the DRIFT method. Spectra of at least 3 reproducible preparations were accepted to indicate the characteristic features of the samples. Spectral resolution was better than $5 \mathrm{~cm}^{-1}$. The measurements were limited to the spectra in the range $4000-400 \mathrm{~cm}^{-1}$ where vibrations within and external to the $\mathrm{AlO}_{4}$ and $\mathrm{SiO}_{4}$ tetrahedra framework are revealed [9-15]. This enables the fundamental differences between the solid phases and anion adsorption to be established. Although the spectra in the far-IR region (350-30 $\left.\mathrm{cm}^{-1}\right)$ is where the presence or absence of adsorbed extra-framework cations can be determined $[16,17]$ they were not recorded in the present work and were outside of this scope. Such measurements would however be essential in the determination of adsorption sites and ion exchange of non-framework species.

Assignments of infrared spectra of phases having zeolite A, sodalite, and cancrinite structures have been published and are shown in Tables 7-9. Vibrations may be assigned either to Al$\mathrm{O}-\mathrm{Si}$ (Koselova, 1959) or $(\mathrm{Si} / \mathrm{Al}) \mathrm{O}_{4}$ tetrahedra clusters in the manner of Flanigen et al. The literature reported vibration-spectra peak assignments are given in Tables 7-9 while the recorded spectra for all 4 solid phases are depicted in Figures 19-21.

\subsubsection{Zeolite}

Vibrations within framework $\mathrm{AlO}_{4}$ and $\mathrm{SiO}_{4}$ tetrahedra and those due to external linkages between species occur at $1250-400 \mathrm{~cm}^{-1}$. Internal options are an asymmetric ( $\left.\mathrm{Al}, \mathrm{Si}\right)-\mathrm{O}-$ stretch at $1250-950 \mathrm{~cm}^{-1}$, a symmetric $\mathrm{O}-(\mathrm{Al} / \mathrm{Si})-\mathrm{O}$ stretch at $720-650 \mathrm{~cm}^{-1}$ and an ( $\left.\mathrm{Al}, \mathrm{Si}\right)-\mathrm{O}-$ bend at $480-420 \mathrm{~cm}^{-1}$. Vibrations due to an asymmetric (Al/Si)-O- stretch occur at 1150-1050 $\mathrm{cm}^{-1}$. External linkages include double rings are indicated at $550-500 \mathrm{~cm}^{-1}$ with a symmetric O-(Al, Si)-O stretch at 850-800 and 650-550 $\mathrm{cm}^{-1}$. The latter appear as broad peak bands $(\downarrow)$ in Figure 19.

\subsubsection{Sodalite}

The infrared peaks arising from the framework vibrations of the sodalite structure are characterised by (Al, Si)-O- asymmetric stretch bands at approximately 1095, 1000 and 855 $\mathrm{cm}^{-1}$, O-(Al, Si)-O symmetric stretch bands at approximately 730 and $665 \mathrm{~cm}^{-1}$, bands arising 
from vibrations in parallel 4 or 6 membered rings at approximately 630 and $600 \mathrm{~cm}^{-1}$ and bend vibrations within the $\mathrm{AlO}_{4}$ and $\mathrm{SiO}_{4}$ tetrahedra at approximately 500 and $435 \mathrm{~cm}^{-1}$.

\subsubsection{Cancrinite}

The vibrations arising from the aluminosilicate framework of the cancrinite structure are also many. These include (Al, Si)-O- asymmetric stretch bands at approximately 1113, 1032, 1000, and $980 \mathrm{~cm}^{-1}, \mathrm{Al}-\mathrm{O}-\mathrm{Si}$ symmetric stretch bands at approximately 764, and $685 \mathrm{~cm}^{-1}$, bands arising from vibrations in parallel 4 or 6 membered rings at approximately 624 and $575 \mathrm{~cm}^{-1}$ and bend vibrations within the $\mathrm{AlO}_{4}$ and $\mathrm{SiO}_{4}$ tetrahedra at $\sim 505,452$ and $430 \mathrm{~cm}^{-}$ 1.

\subsubsection{Amorphous sodium aluminosilicate}

This material exhibits asymmetric vibrations similar to the crystalline phases. Namely all of the Al-O-Si symmetric stretch and bend vibrations as well as double rings found in the crystalline solid phases are characteristically absent for the amorphous phase in the "fingerprint" infrared region of $800-400 \mathrm{~cm}^{-1}$ (Figure 19).

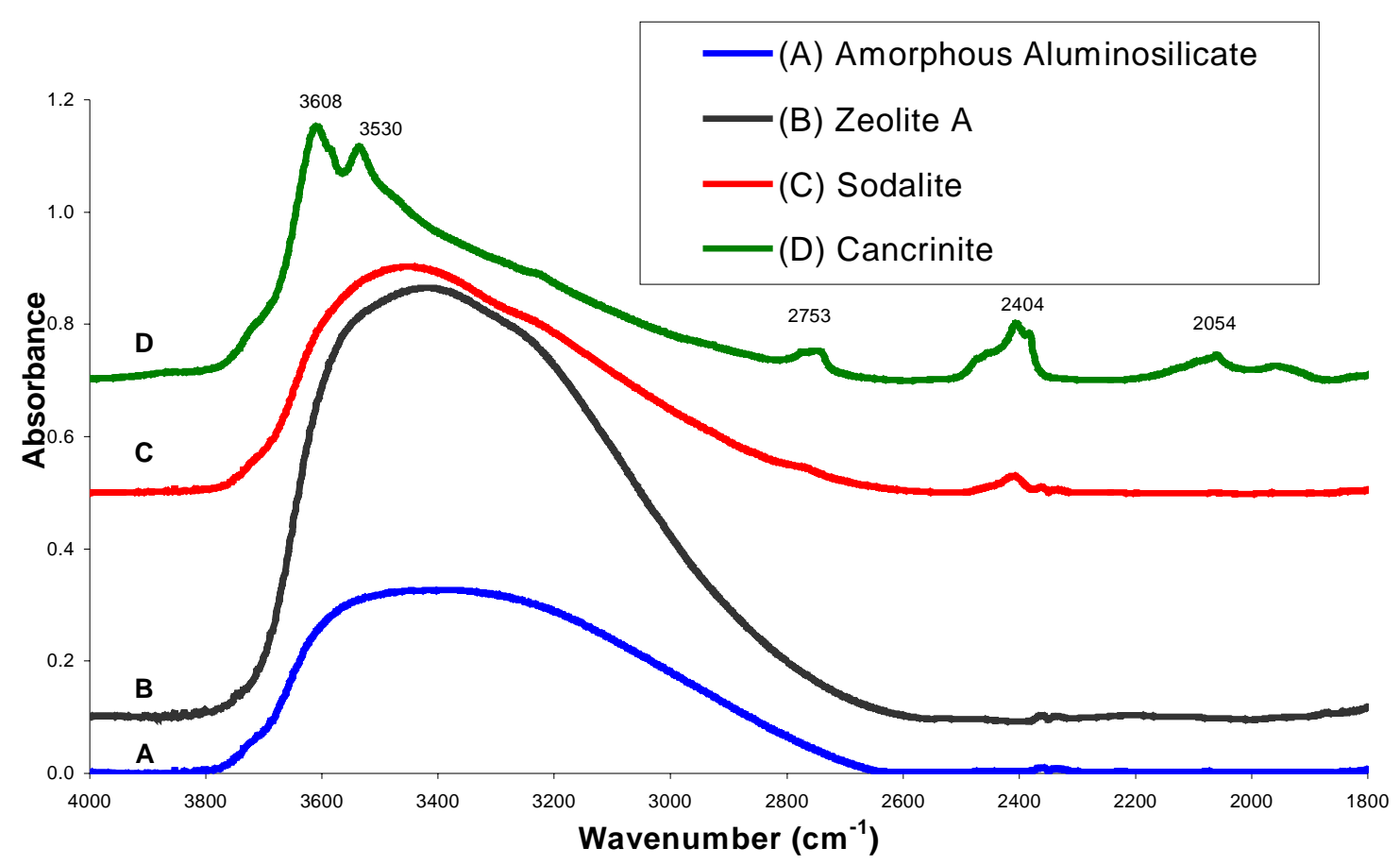

Figure 19 FTIR spectra of sodium aluminosilicate solid phases 


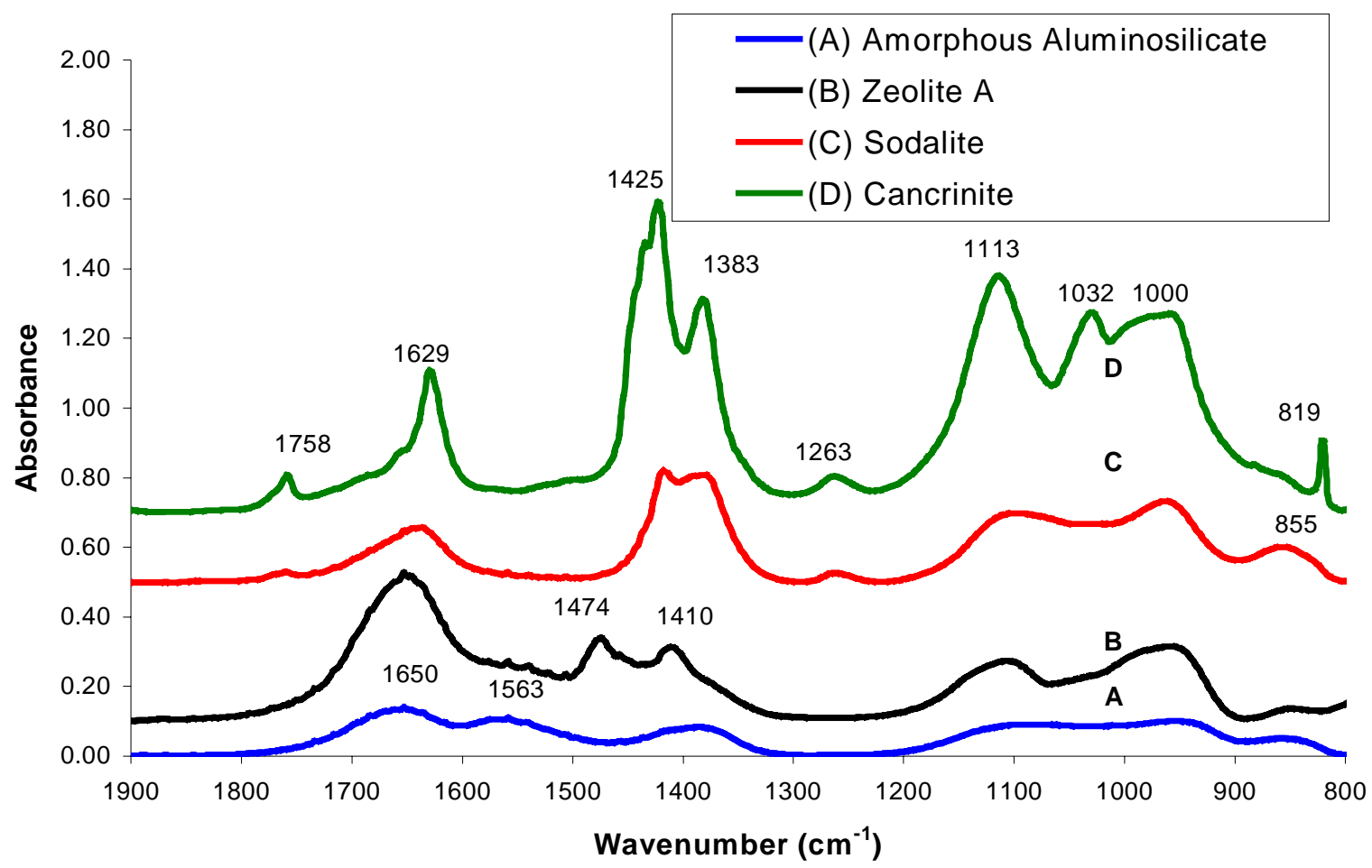

Figure 20 FTIR spectra of sodium aluminosilicate solid phases

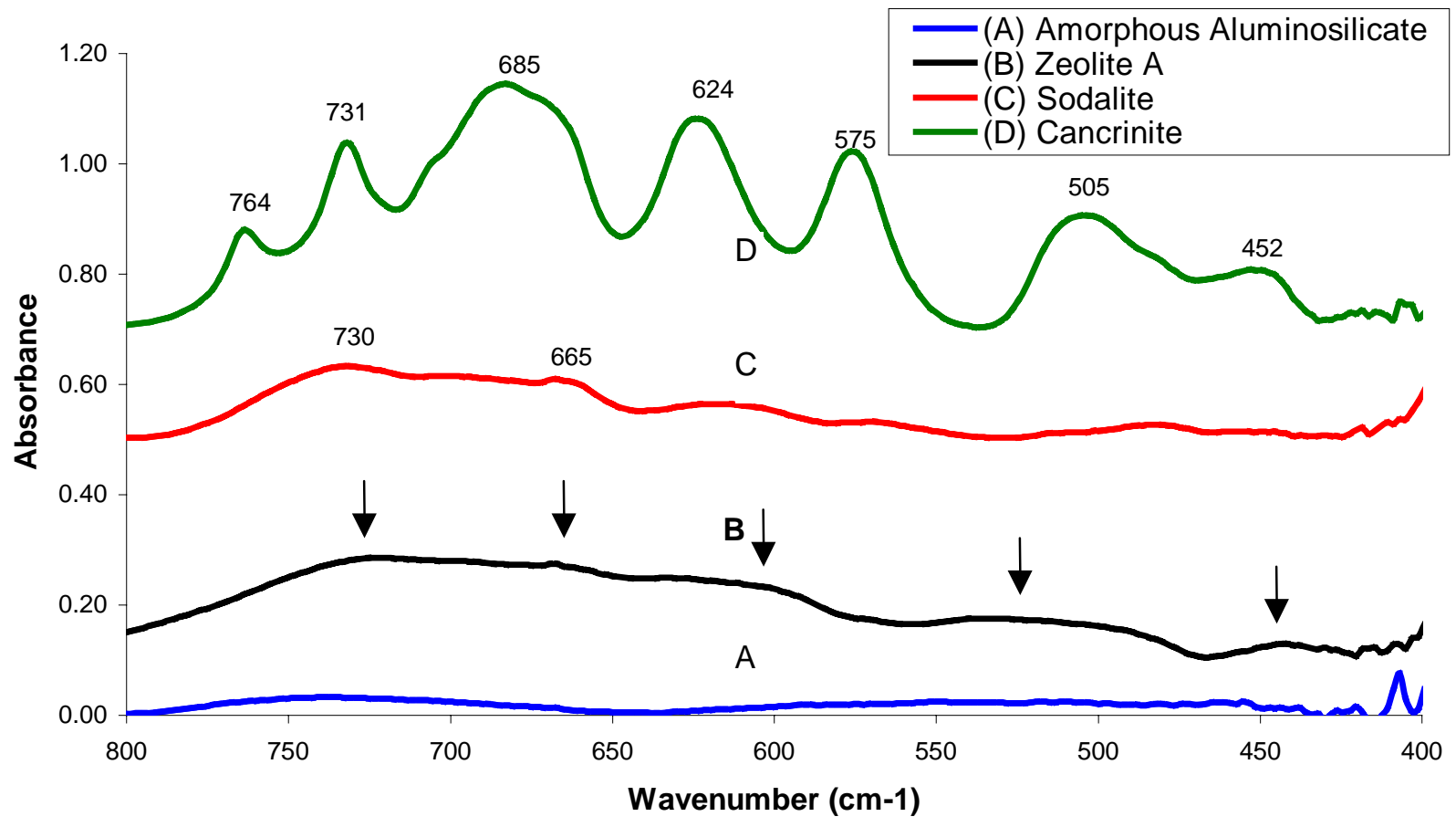

Figure 21 FTIR spectra of sodium aluminosilicate solid phases

Non-framework species (Anions) 
$\mathrm{NO}_{2}{ }^{-}, \mathrm{NO}_{3}{ }^{-}$and $\mathrm{CO}_{3}{ }^{2-}$, and $\mathrm{H}_{2} \mathrm{O}, \mathrm{Na}-\mathrm{OH}$ vibrations are observed at $\sim 1270,1380,1430,1650$ and $3600 \mathrm{~cm}^{-1}$ respectively. The presence of $\mathrm{NO}_{2}{ }^{-}$and $\mathrm{NO}_{3}{ }^{-}$is indicated at $\sim 1265,1380 \mathrm{~cm}^{-1}$ respectively [5] for sodalite and cancrinite but not the amorphous and zeolite A solid phases, a finding which supports the XPS data.

\begin{tabular}{|l|l|l|l|l|}
\hline \multicolumn{1}{|c|}{ Author } & \multicolumn{1}{|c|}{ Asym. Stretch } & Symmetric Stretch* & Double Ring & T-O Bend \\
\hline Flanigen et al. & $1250-950^{1}$ & $720-650^{1}$ & $480-420^{1}$ \\
\hline Flanigen et al. & $1150-1050^{2}$ & $850-800,650-550^{2}$ & $550-500^{2}$ & \\
\hline
\end{tabular}

Table 7 Assignments of peaks observed by infrared for Zeolite

${ }^{1}$ internal tetrahedra , ${ }^{2}$ external linkages. *These appear as broad peak bands $(\downarrow)$ in Figure 19

\begin{tabular}{lllll}
\hline Author & Asym. Stretch $^{1}$ & Symmetric Stretch $^{1}$ & Double Ring $^{2}$ & T-O Bend \\
\hline Hermeler et al. [49] & 1096986 & 729701660 & & \\
Farmer [66] & 1020980 & 737712670 & & \\
Porotnikova et al. [67] & 1005 & 863748720666 & & 470440 \\
Avdeeva et al. [68] & 1000 & 710680660 & 630565 & 440 \\
Flanigen et al. [69] & 1096986 & 729701660 & & \\
This Work & $995(\mathrm{~s})$ & $734(\mathrm{~m}) 712(\mathrm{w})$ & $630-635(\mathrm{vw})$ & $460(\mathrm{~m})$ \\
& & $660-665(\mathrm{~m})$ & & \\
\hline
\end{tabular}

\section{Table 8 Assignments of peaks observed by infrared for sodalite.}

${ }^{1} \mathrm{vAl}-\mathrm{O}$ for the Si-O-Al framework $\quad{ }^{2}$ parallel 4 or 6 member rings

${ }^{3}$ tetrahedron $\mathrm{SiO}_{4}$ or $\mathrm{AlO}_{4} \quad \mathrm{~s}=$ strong $\mathrm{m}=$ medium $\quad \mathrm{w}=$ weak.

\begin{tabular}{lllll}
\hline Author & Asym. Stretch & Symmetric Stretch & Double Ring & \\
\hline Ni et al. [48] & 11201000 & 695 & 575 & \\
Hermeler et al. [49] & 109510351000965755680 & & \\
Farmer [66] & 11301015 & 860690748 & 625570 & 500 \\
Porotnikova et al. [67] & 1000 & 770684 & 626575 & 505466431 \\
Avdeeva et al. [68] & 1000 & 875750670 & & 510455 \\
Flanigen et al. [69] & 109510351000 & 755680 & 624567 & \\
& 965 & & & \\
This Work & $1110(\mathrm{~s}) 1050(\mathrm{~s})$ & $770(\mathrm{~m}) 688(\mathrm{~m})$ & $624(\mathrm{~m})$ & $510(\mathrm{~m})$ \\
\hline
\end{tabular}


Table 9 Assignments of peaks observed by infra-red for cancrinite.

${ }^{1} v \mathrm{Al}-\mathrm{O}$ for the Si-O-Al framework

${ }^{3}$ tetrahedron $\mathrm{SiO}_{4}$ or $\mathrm{AlO}_{4}$
${ }^{2}$ parallel 4 or 6 member rings

$\mathrm{s}=$ strong $\mathrm{m}=$ medium $\mathrm{w}=$ weak

\subsection{Thermal Analysis}

Thermal gravimetric (TG) and differential thermal (DT) analyses under $\mathrm{N}_{2}$ atmosphere were carried out to determine the solid phase thermal decomposition and structural properties. Data obtained from two replicate analyses are shown in Figures 22-25 as sample weight loss, temperature difference (between sample and $\mathrm{Al}_{2} \mathrm{O}_{3}$ reference), and derivative weight loss are all shown as a function of temperature. The loss in weight below $120{ }^{\circ} \mathrm{C}$ is due to removal of physically sorbed water while weight loss up to $400{ }^{\circ} \mathrm{C}$ involved the removal of chemisorbed water. Removal of $\mathrm{OH}$ species may occur around $400-500{ }^{\circ} \mathrm{C}$. Denitrification, denitration, and decarbonation occurred in the temperature range $780-900{ }^{\circ} \mathrm{C}$.

The data show that the amorphous particle thermal decomposition occurs by rapid but systematic loss of water (below $400{ }^{\circ} \mathrm{C}$ ) and a small amount of carbonate species (refer to XPS C1s spectrum), the latter indicated by a small endotherm at $900{ }^{\circ} \mathrm{C}$ (Figure 22). No solid phase transformation occurred. Heat absorption at lower temperatures $\left(<400{ }^{\circ} \mathrm{C}\right)$ was sufficient to desorb most of the volatile mass. The entire data tend to suggest that the particles involve non-rigid molecular structures with low degree of ordering and bonding.

Zeolite A particle decomposition occurred by structural dehydration and decarbonation, with 2 endotherms at 300 and $900{ }^{\circ} \mathrm{C}$ and 2 exotherms at 800 and $950{ }^{\circ} \mathrm{C}$ (Figure 23). The endotherm at $300{ }^{\circ} \mathrm{C}$ is associated with chemisorbed water removal while the one at $900{ }^{\circ} \mathrm{C}$ is due to high heat energy absorption for desorption of carbonate impurity ions. Solid structure modification to more stable solid phases was only possible through strong heat absorption (exotherms at 800 and $950{ }^{\circ} \mathrm{C}$ ). The data suggest that the particles consist of rigid supra molecular structures with a high degree of ordering and chemical bonding.

Decomposition of sodalite crystals occurred by gradual structural dehydration $\left(<400{ }^{\circ} \mathrm{C}\right)$ which was accompanied by minor denitrification, denitration and decarbonation at $825{ }^{\circ} \mathrm{C}$ (Figure 24). In addition a strong solid-state structural transformation to another more stable solid phase occurred (exotherm at $850{ }^{\circ} \mathrm{C}$ ). Cancrinite showed similar gradual water 
removal, minor and major endotherms and no exotherm. Cancrinite did not re-crystallize to a more stable phase (Figure 25). The minor endotherm (at $\sim 250{ }^{\circ} \mathrm{C}$ ) is due to absorption of heat to remove structurally chemisorbed water. Strong denitrification, denitration and decarbonation occurred at close to $800{ }^{\circ} \mathrm{C}$. The data showed that both sodalite and cancrinite particles are comprised of rigid supra molecular structures with a high degree of ordering and chemical bonding.

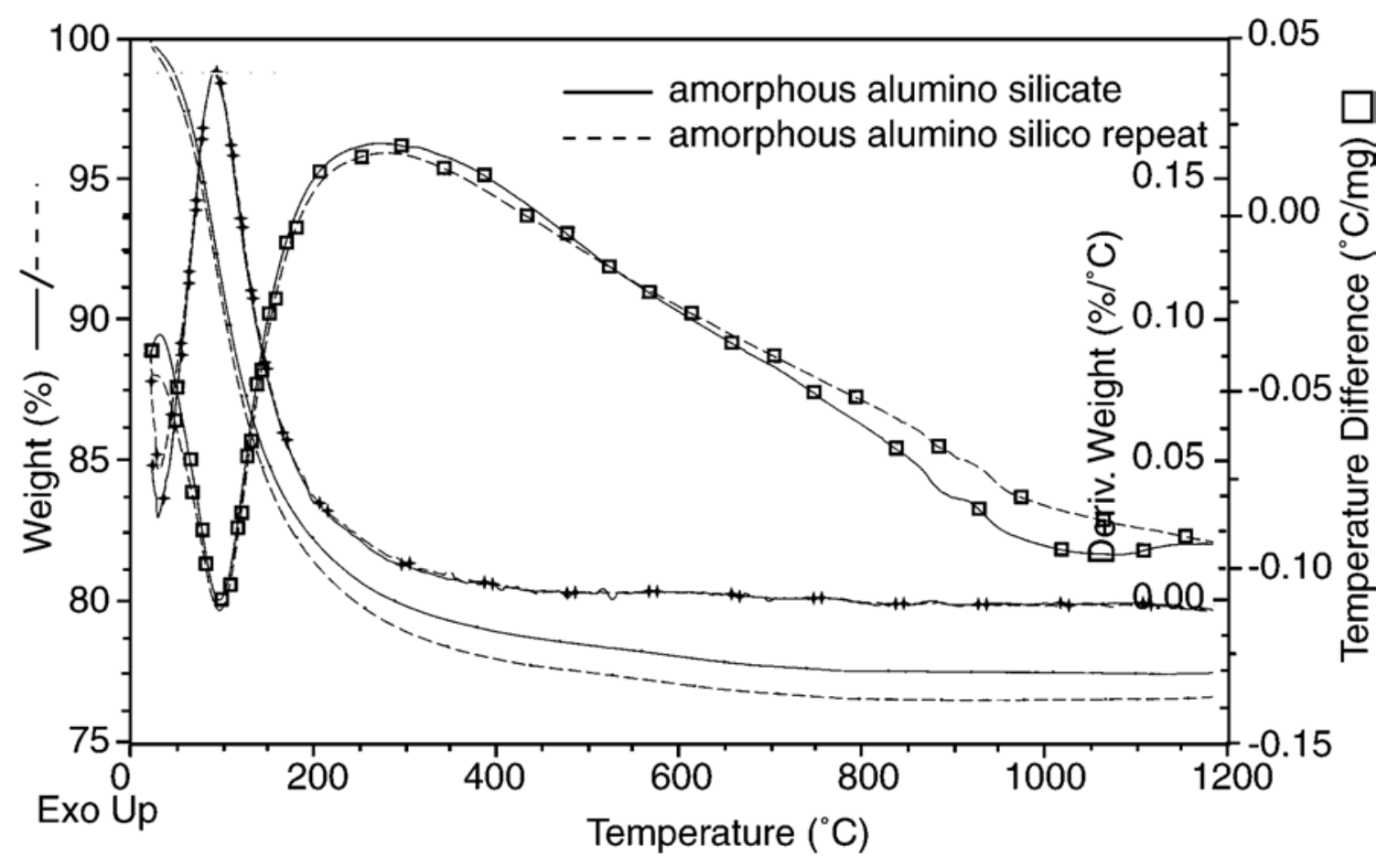

Figure 22 TG/DTA analysis of amorphous sodium aluminosilicate 


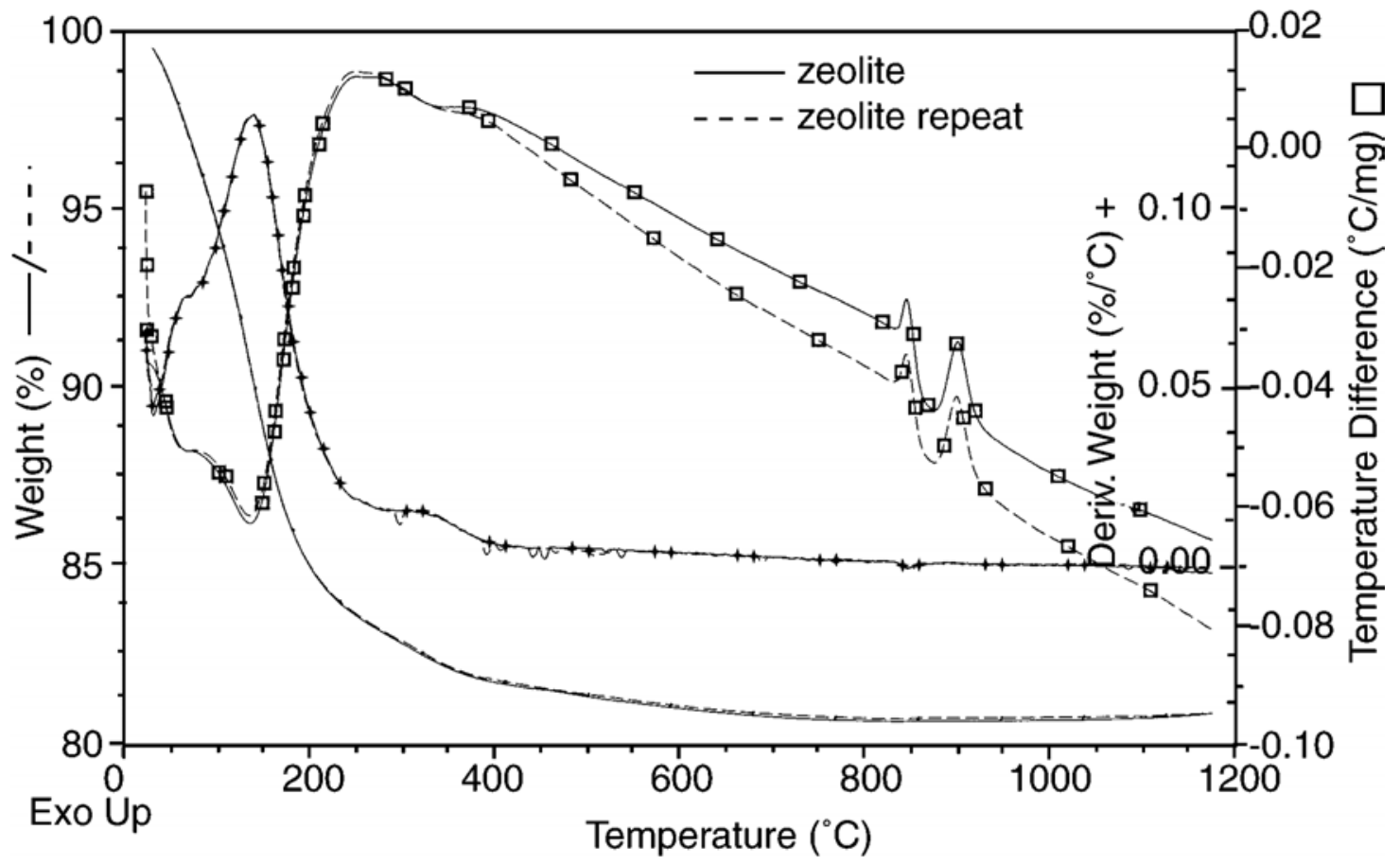

Figure 23 TG/DTA analysis of zeolite A crystals.

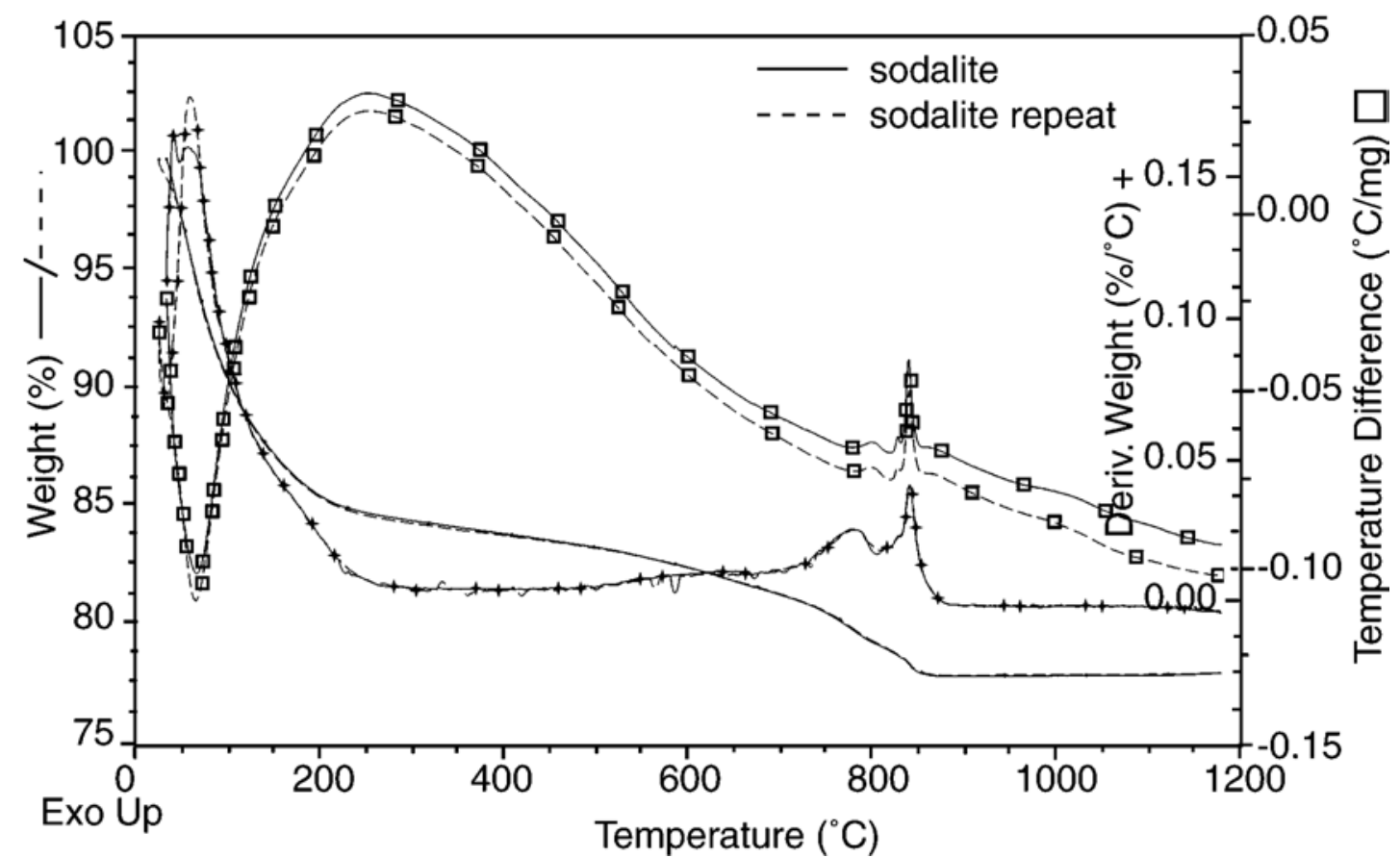

Figure 24 TG/DTA analysis of sodalite crystals 


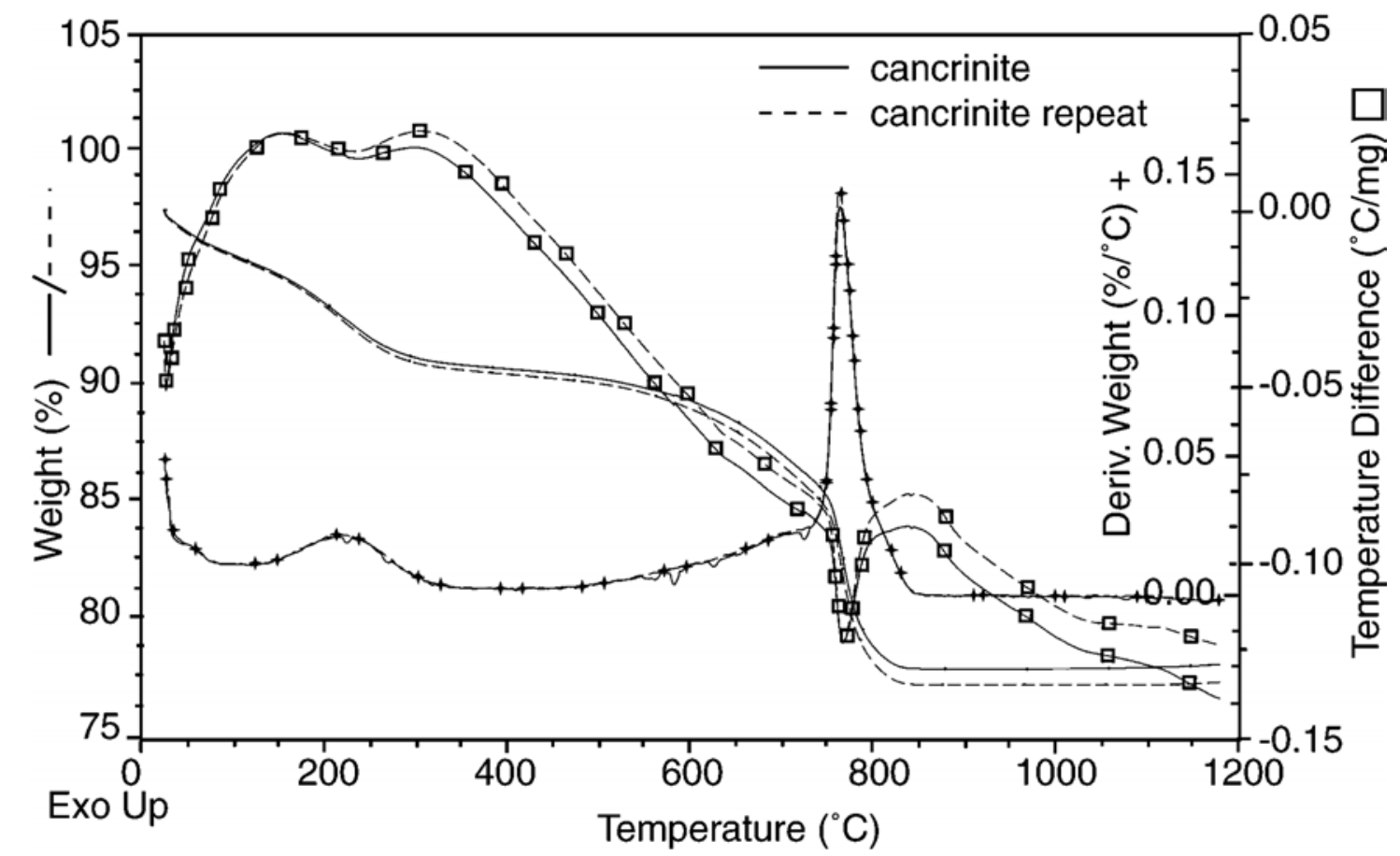

Figure 25 TG/DTA analysis of cancrinite crystals

\subsection{Wet Chemistry and Structural Formulas}

Subsequent to EDAX, XPS and TGA/DTA analyses for solid phase composition a wet chemical analysis of solutions produced by controlled acid leach of solid samples was performed to provide direct chemical composition of all four solid phases. The data are expressed in moles using a basis of 6 or 12 moles $\mathrm{Al}(\mathrm{III})$ released in solution and are given in the Table 10.

\begin{tabular}{|l|c|c|c|c|c|}
\hline \multicolumn{5}{|c|}{ Solid phase } & \multicolumn{5}{c|}{ Species (Moles) } \\
\hline & $\mathrm{Na}$ & $\mathrm{Al}$ & $\mathrm{Si}$ & $\mathrm{NO}_{3}{ }^{-}+\mathrm{NO}_{2}{ }^{-}$ & $\mathrm{H}_{2} \mathrm{O}$ \\
\hline Amorphous & $11.95 \pm 0.32$ & $12.00 \pm .0 .25$ & $\mathbf{1 1 . 9 6} \pm \mathbf{0 . 3 8}$ & - & $26.0 \pm 1.5$ \\
\hline Zeolite A & $11.97 \pm 0.28$ & $12.00 \pm 0.20$ & $11.98 \pm 0.33$ & - & $26.9 \pm 0.5$ \\
\hline Sodalite & $7.95 \pm 0.12$ & $6.00 \pm 0.11$ & $\mathbf{6 . 0 4} \pm 0.14$ & $1.97 \pm 0.08$ & $3.5 \pm 0.2$ \\
\hline Cancrinite & $\mathbf{8 . 0 5} \pm \mathbf{0 . 1 4}$ & $\mathbf{6 . 0 0} \pm \mathbf{0 . 1 1}$ & $\mathbf{5 . 9 5} \pm 0.13$ & $1.95 \pm 0.06$ & $\mathbf{2 . 5} \pm 0.1$ \\
\hline
\end{tabular}

Table 10 Composition of solids by wet chemical assay

The structural formulae derived from the EDAX may be given as: 


\section{Amorphous/gel sodium aluminosilicate}

$\mathrm{Na}_{11.76} \mathrm{Al}_{12} \mathrm{Si}_{11.76} \mathrm{O}_{47.4} \cdot 27 \mathrm{H}_{2} \mathrm{O}$ which is $0.98 \mathrm{Na}_{2} \mathrm{O}: \mathrm{Al}_{2} \mathrm{O}_{3}: 1.96 \mathrm{SiO}_{2} \cdot 4.5 \mathrm{H}_{2} \mathrm{O}$.

\section{Zeolite-A}

$\mathrm{Na}_{11.88} \mathrm{Al}_{12} \mathrm{Si}_{11.22} \mathrm{O}_{46.38} .27 \mathrm{H}_{2} \mathrm{O}$ or $0.99 \mathrm{Na}_{2} \mathrm{O}: \mathrm{Al}_{2} \mathrm{O}_{3}: 1.87 \mathrm{SiO}_{2} \cdot 4.5 \mathrm{H}_{2} \mathrm{O}$

\section{Sodalite}

$\mathrm{Na}_{12} \mathrm{Al}_{12} \mathrm{Si}_{11.95} \mathrm{O}_{47.29} \cdot 1.56 \mathrm{NaNO}_{3} \cdot 3.5 \mathrm{H}_{2} \mathrm{O}$ or $1.13 \mathrm{Na}_{2} \mathrm{O}: \mathrm{Al}_{2} \mathrm{O}_{3}: 1.95 \mathrm{SiO}_{2} .0 .58 \mathrm{H}_{2} \mathrm{O}$

\section{Cancrinite}

$\mathrm{Na}_{12} \mathrm{Al}_{12} \mathrm{Si}_{11.94} \mathrm{O}_{47.88} .2 .04 \mathrm{NaNO}_{3} .2 .5 \mathrm{H}_{2} \mathrm{O}$ or $1.17 \mathrm{Na}_{2} \mathrm{O}: \mathrm{Al}_{2} \mathrm{O}_{3}: 1.99 \mathrm{SiO}_{2} .0 .42 \mathrm{H}_{2} \mathrm{O}$

The values are consistent between wet chemistry, EDAX and XPS except for sodium in sodalite and cancrinite (e.g. the atomic $\mathrm{Al} / \mathrm{Si}$ concentration ratios by wet chemical analysis are in good agreement with those observed by EDAX and after XPS depth profiling). As discussed earlier, this sodium difference is likely due to $\mathrm{Na}$ ion migration caused by sputtering. The sodium concentration determined by wet chemical analysis of sodalite and cancrinite is higher than by EDAX. The values obtained by wet chemical analysis are more accurate and hence must be used in preference to those by EDAX. In the amorphous phase (taking a weighted standard errors into account) the amount of water present is estimated as $26.0 \pm 1.5$ Mole water per 12 mole Al. It is pertinent to note that the water content in the amorphous phase "reproducibly" showed a higher variation than the crystalline phases. The range 24 - 27 given previously reflects typical values obtained in replications. Statistically, the structural formulae of both amorphous aluminosilicate and zeolite A may be considered the same. 


\subsection{Equilibrium solubility}

\subsection{Experiments to Determine Solubility}

Equilibrium solubilities of all four aluminosilicate phases have been measured in terms of $\mathrm{SiO}_{2}$ and $\mathrm{Al}(\mathrm{III})$ concentrations in a variety of pertinent caustic solutions at 30, 65 and 130 ${ }^{\circ} \mathrm{C}$. These solubilities were evaluated using two modes. An approach to equilibrium from "below" in dissolution experiments and an approach from "above" in precipitation experiments. At least 3 replicate measurements were made for each data point. The errors limits stated represent the $95 \%$ confidence interval.

When approaching equilibrium from below caustic liquors that were $\mathrm{SiO}_{2} / \mathrm{Al}$ (III)-free were seeded with known solid phase material. Solution and particles were periodically removed and analyzed throughout the experimental run to establish their concentrations and particle crystallographic identity or integrity. This ensured that no noticeable phase transformation of the original seed occurred when the solubility was reached.

The data shown below (Tables 11-14 and Figures 26-33) clearly depict well-defined equilibrium solubility behavior. These results demonstrate effects of solution composition, ionic strength, temperature and seed phase type. The equilibrium $\mathrm{SiO}_{2}$ concentration was rapidly reached within minutes to an hour for all solid phases and solution types at high temperatures $\left(>65{ }^{\circ} \mathrm{C}\right)$. The equilibration time at $30{ }^{\circ} \mathrm{C}$, however, increased significantly to several hours. Good agreement was achieved when the data from "above" and "below" methodology were compared. The differences were found to be within $5 \%$. Where possible, comparison with literature values [19-24] was made (Table 15).

It was observed that metastable phase changes to more stable phases (less soluble) may occur over longer equilibration times. Consequently in these cases one will observe that the $\mathrm{SiO}_{2}$ concentration reaches the solubility of the initial seed phase and then decreases with time. This decrease then approaches the solubility of the new solid phase product. 


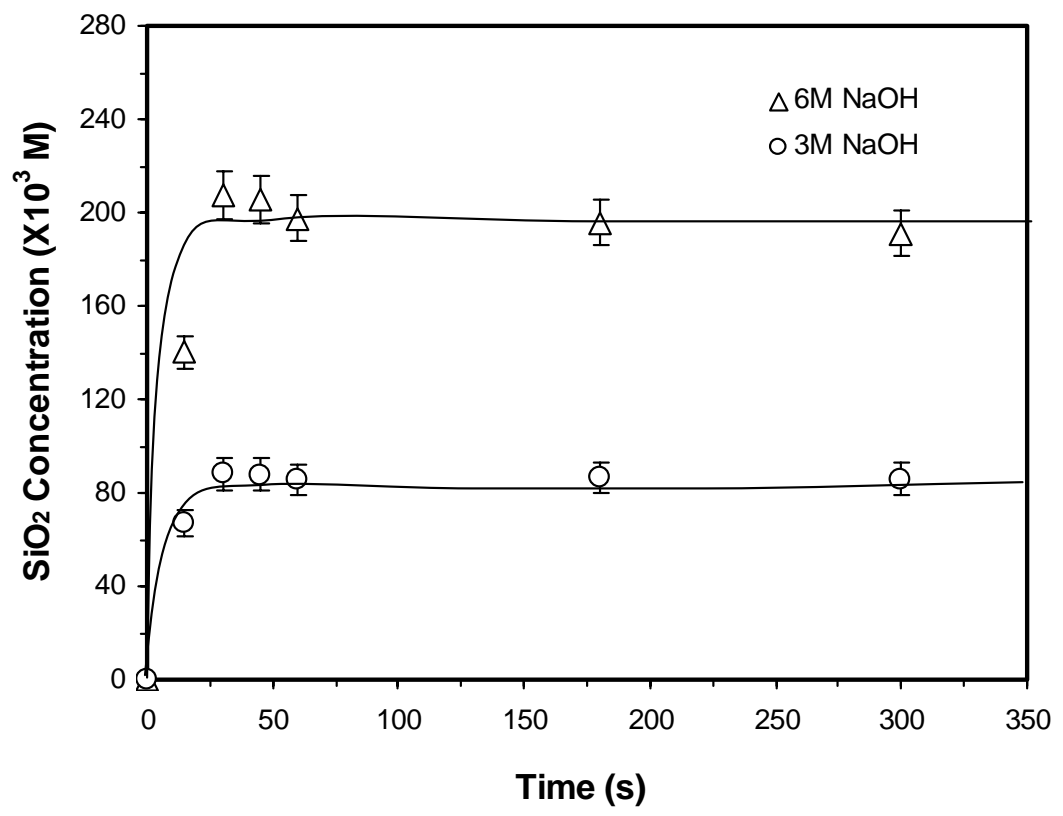

Figure 26 Dissolution of amorphous phase at $65^{\circ} \mathrm{C}$ (seed charge: $120 \mathrm{~g} \mathrm{dm}^{-3}$ )

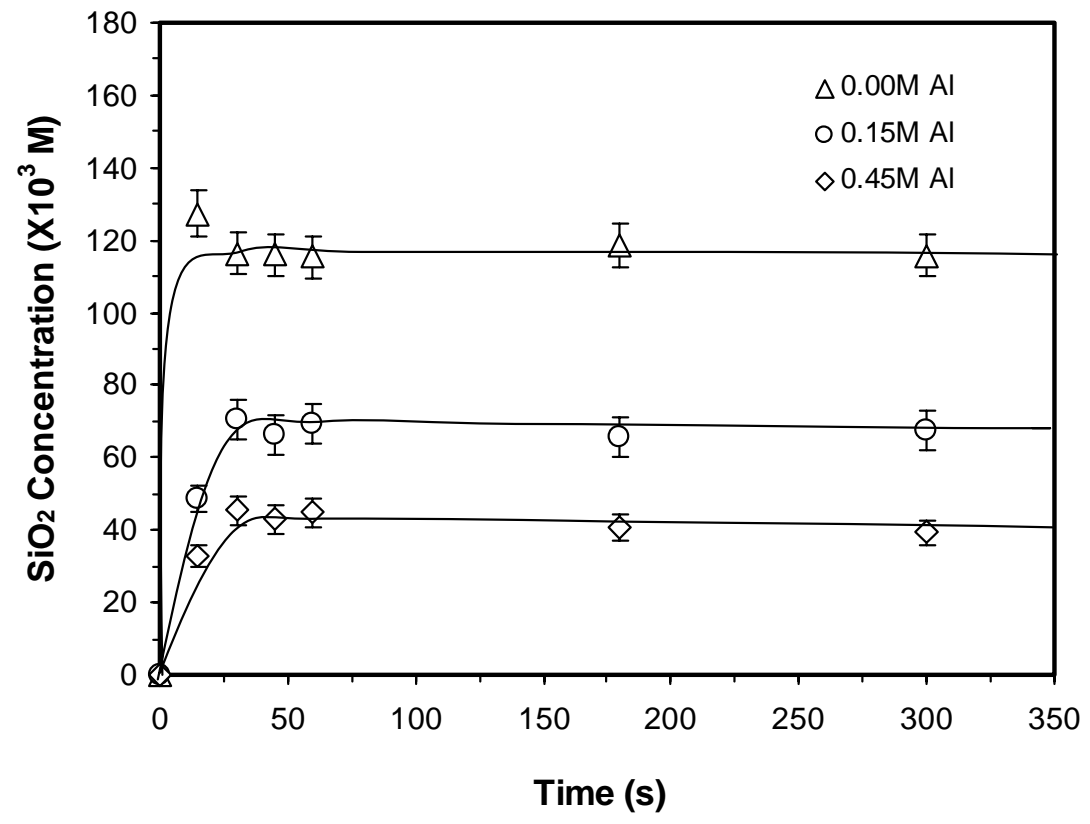

Figure 27 Dissolution of amorphous phase in $4 \mathrm{M} \mathrm{NaOH}, 1 \mathrm{M} \mathrm{NaNO}_{3}$ and $1 \mathrm{M}$ $\mathrm{NaNO}_{2}$ solutions versus $\mathrm{Al}(\mathrm{III})$ concentrations at $65^{\circ} \mathrm{C}$ (seed charge: $120 \mathrm{~g} \mathrm{dm}^{-3}$ ) 


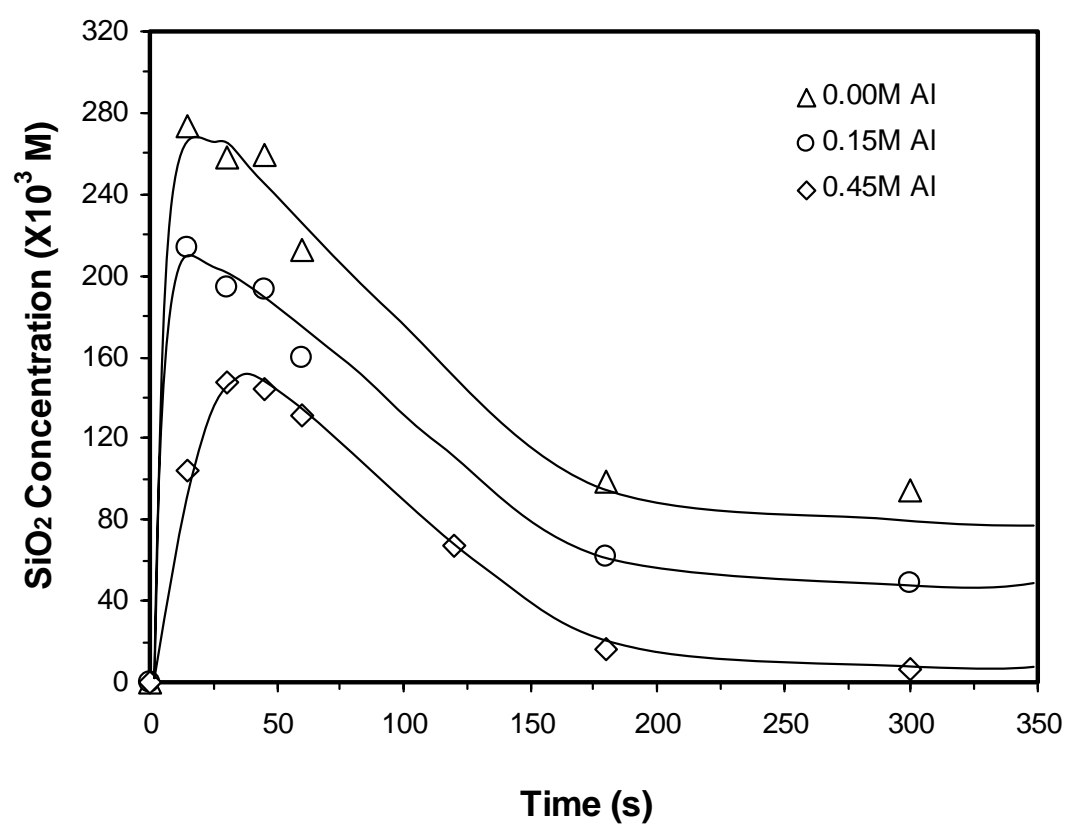

Figure 28 Dissolution of amorphous phase in $8 \mathrm{M} \mathrm{NaOH}, 2 \mathrm{M} \mathrm{NaNO}_{3}$ and $2 \mathrm{M}$ $\mathrm{NaNO}_{2}$ solutions versus $\mathrm{Al}(\mathrm{III})$ concentrations at $65^{\circ} \mathrm{C}$ (seed charge: $120 \mathrm{~g} \mathrm{dm}^{-3}$ )

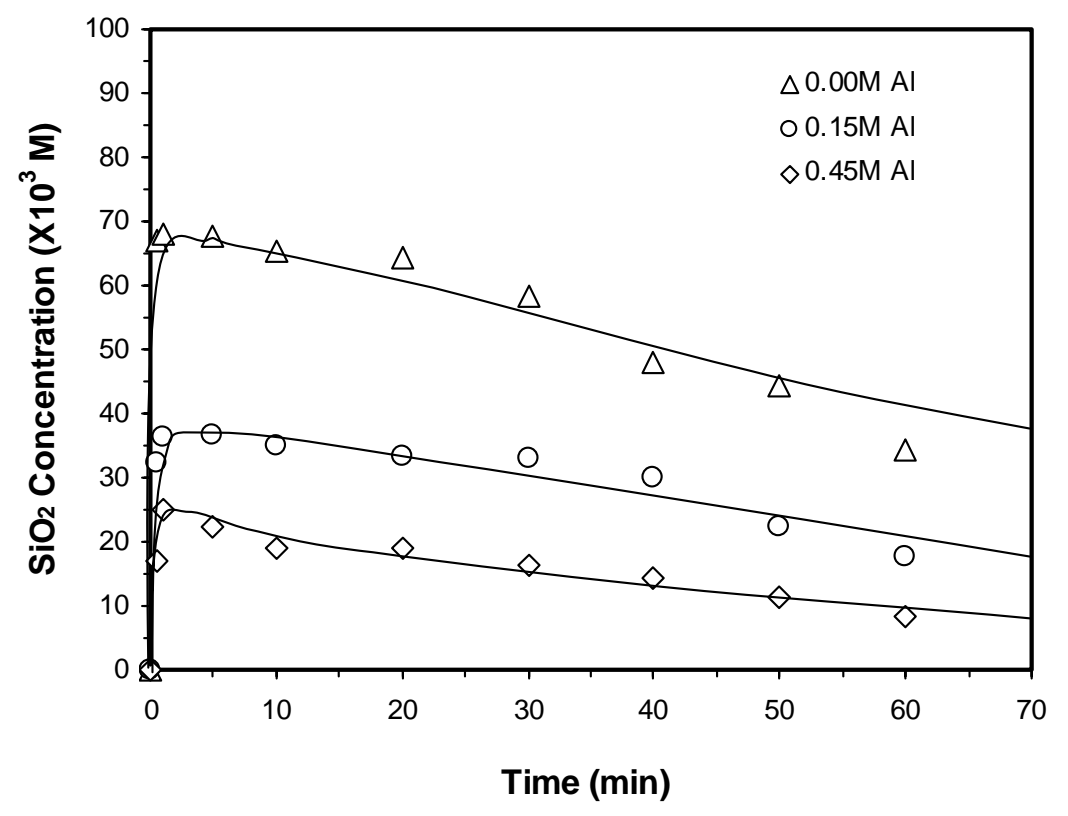

Figure 29 Dissolution of zeolite $\mathrm{A}$ in $8 \mathrm{M} \mathrm{NaOH}, 2 \mathrm{M} \mathrm{NaNO}$ and $2 \mathrm{M} \mathrm{NaNO}_{2}$ solutions at different $\mathrm{Al}(\mathrm{III})$ concentrations at $65^{\circ} \mathrm{C}$ (seed charge: $120 \mathrm{~g} \mathrm{dm}^{-3}$ ) 


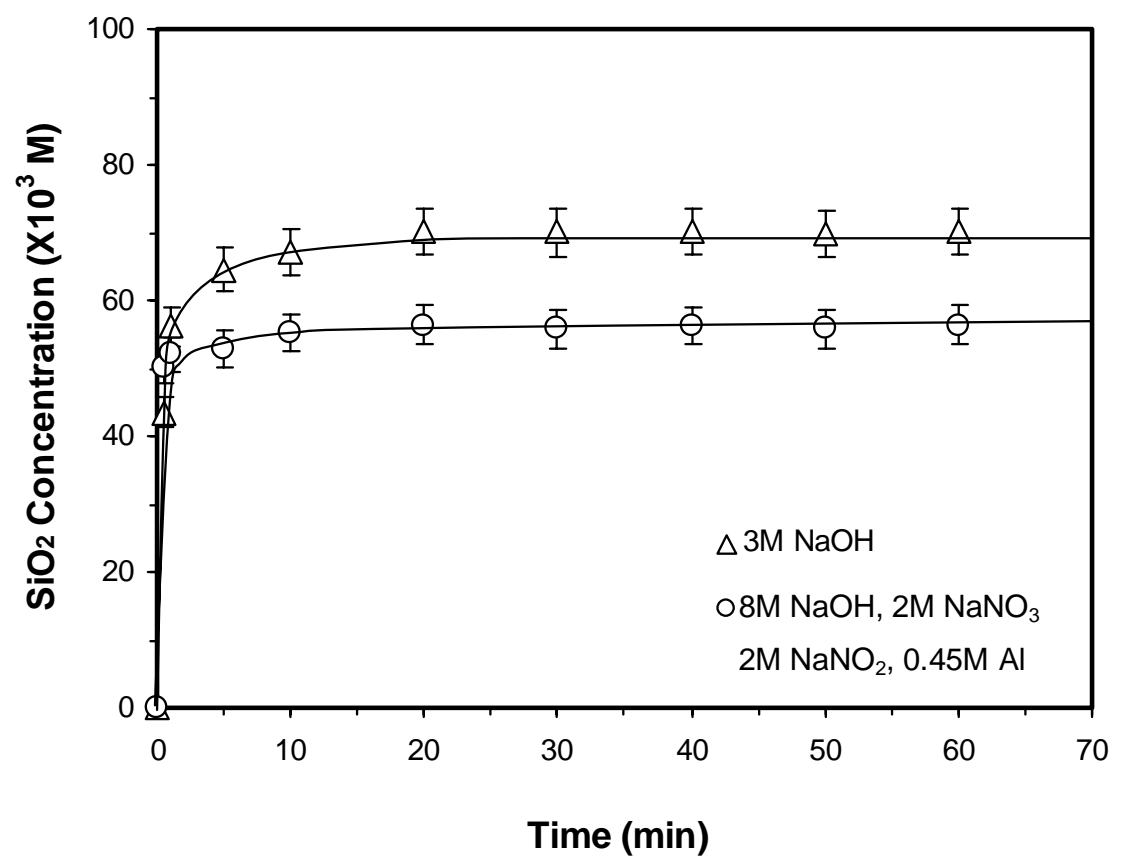

Figure 30 Dissolution of the amorphous phase in different solutions at $30{ }^{\circ} \mathrm{C}$ (seed charge: $120 \mathrm{~g} \mathrm{dm}^{-3}$ )

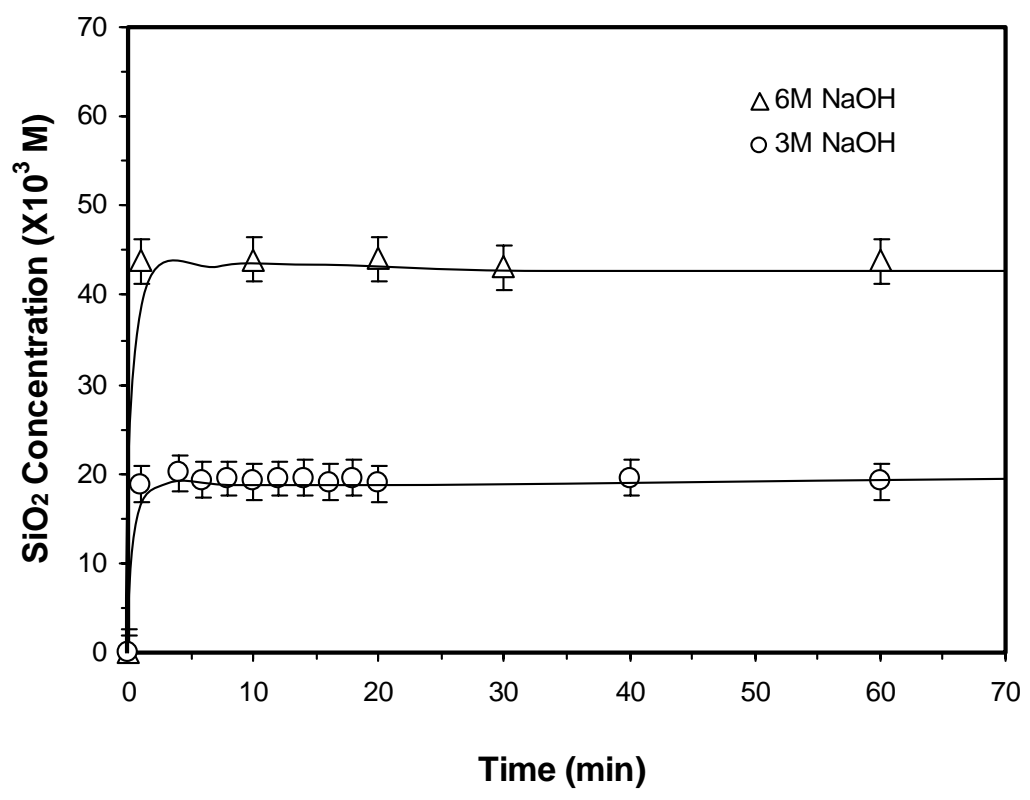

Figure 31 Dissolution of zeolite $\mathrm{A}$ in $\mathrm{NaOH}$ solutions at $65^{\circ} \mathrm{C}$ (seed charge: $120 \mathrm{~g}$ $\mathbf{d m}^{-3}$ ) 


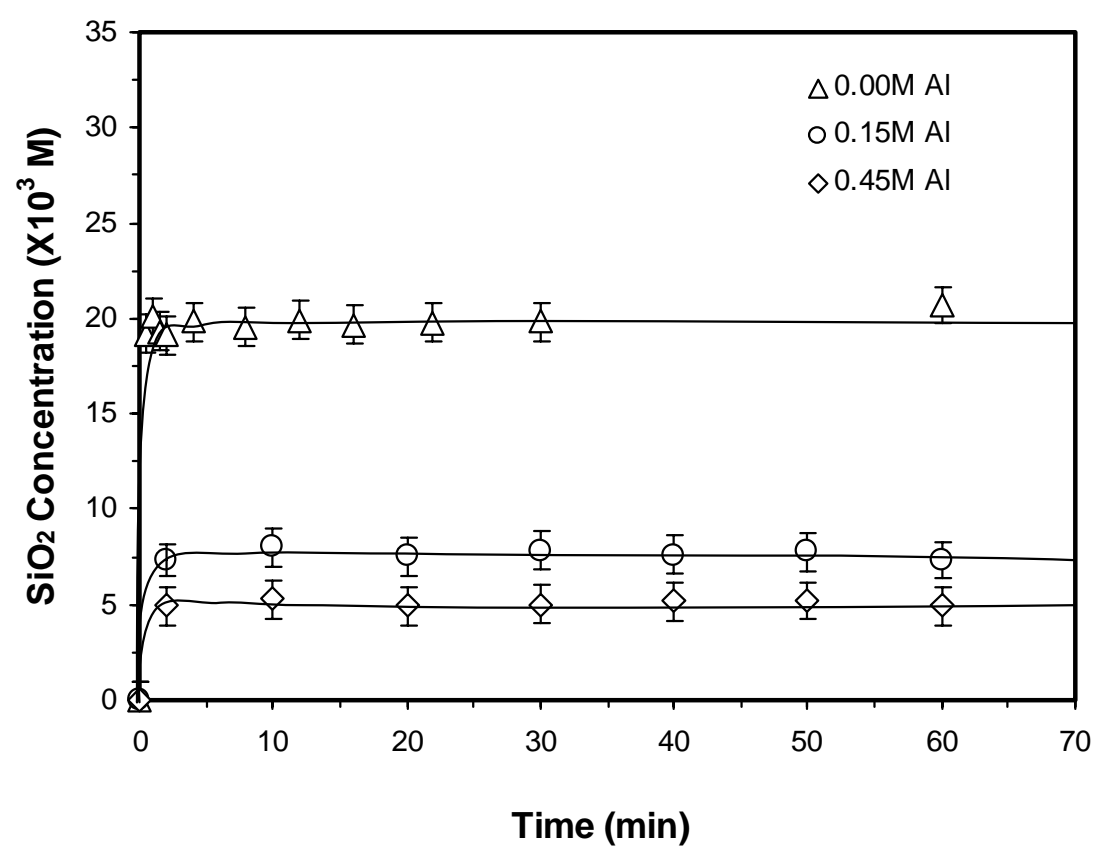

Figure 32 Dissolution of zeolite $\mathrm{A}$ in $4 \mathrm{M} \mathrm{NaOH}, 1 \mathrm{M} \mathrm{NaNO} \mathrm{N}_{3}$ and $1 \mathrm{M} \mathrm{NaNO}_{2}$ solutions at different $\mathrm{Al}(\mathrm{III})$ concentrations and $65^{\circ} \mathrm{C}$ (seed charge: $120 \mathrm{~g} \mathrm{dm}^{-3}$ )

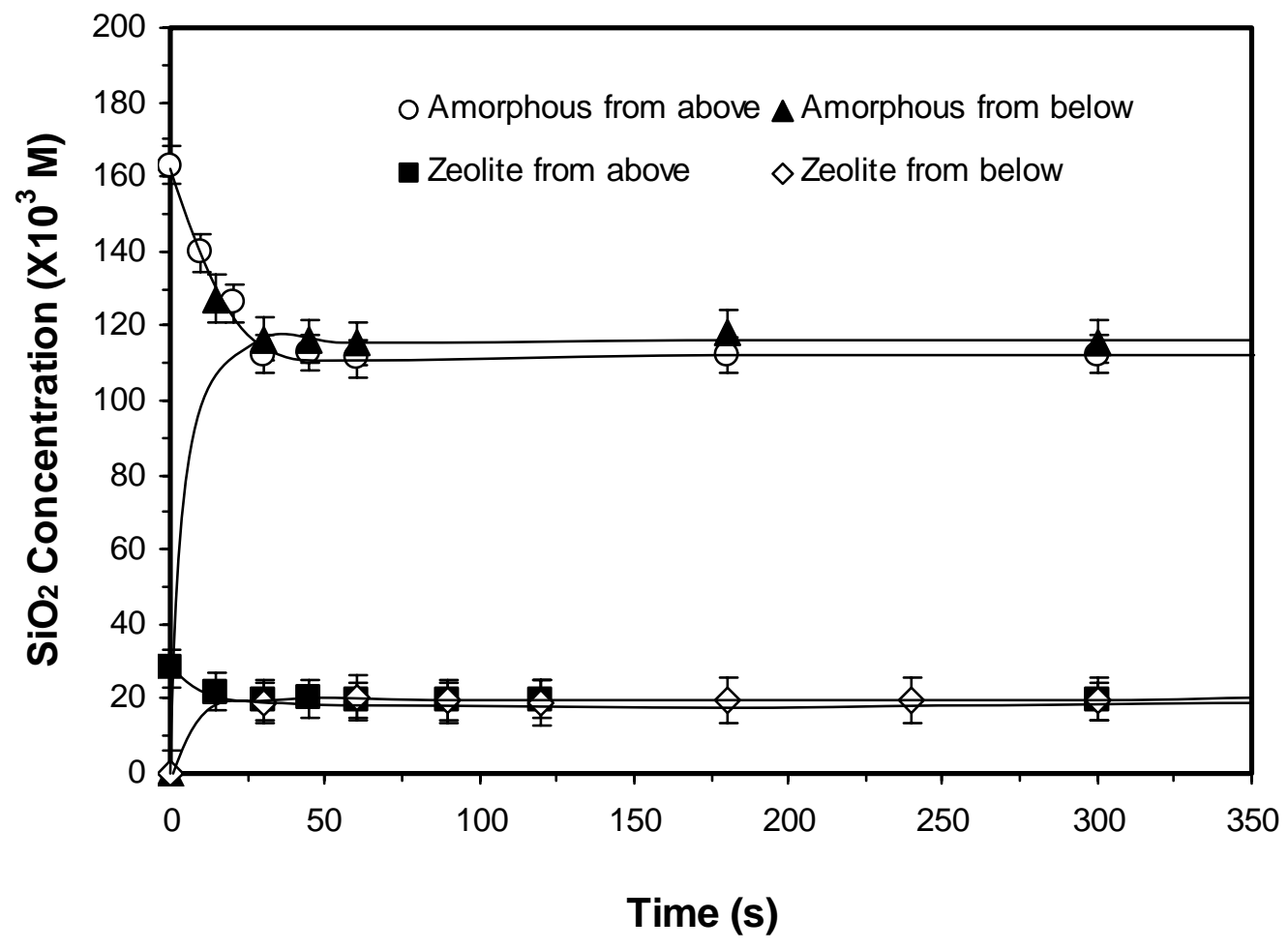

Figure 33 Dissolution and precipitation of sodium aluminosilicate particles in $4 \mathrm{M}$ $\mathrm{NaOH}, 1 \mathrm{M} \mathrm{NaNO}_{3}$ and $1 \mathrm{M} \mathrm{NaNO}_{2}$ solutions at $65^{\circ} \mathrm{C}$

\subsection{Equilibrium Solubility Summary}


- The equilibrium solubility of sodium aluminosilicate phases is highly dependant on the solid phase type, temperature, solution caustic, $\mathrm{Al}(\mathrm{III})$, nitrate and nitrite concentrations.

- The equilibrium solubility of all sodium aluminosilicate solid phases increased nonlinearly with increasing temperature and caustic concentration but decreased significantly with increasing $\mathrm{Al}(\mathrm{III})$.

- The reduction in solubility upon increasing $\mathrm{Al}(\mathrm{III})$ concentration was more pronounced at high than low concentration of caustic and nitrate/nitrite.

- The presence of hydroxide ions lead to higher solubilities than do nitrate and nitrite ions.

- Solubility increased in following sequence: cancrinite < sodalite < zeolite A < amorphous phase at 30,65 and $130{ }^{\circ} \mathrm{C}$.

- The influence of hydroxide, nitrate and nitrite species on solubility may be rationalized in terms of the specific interactions between $\mathrm{SiO}_{2}, \mathrm{Al}(\mathrm{III})$ and sodium containing species in solution resulting in different changes in speciation as well the activity and activity coefficients these species and that of $\mathrm{H}_{2} \mathrm{O}$.

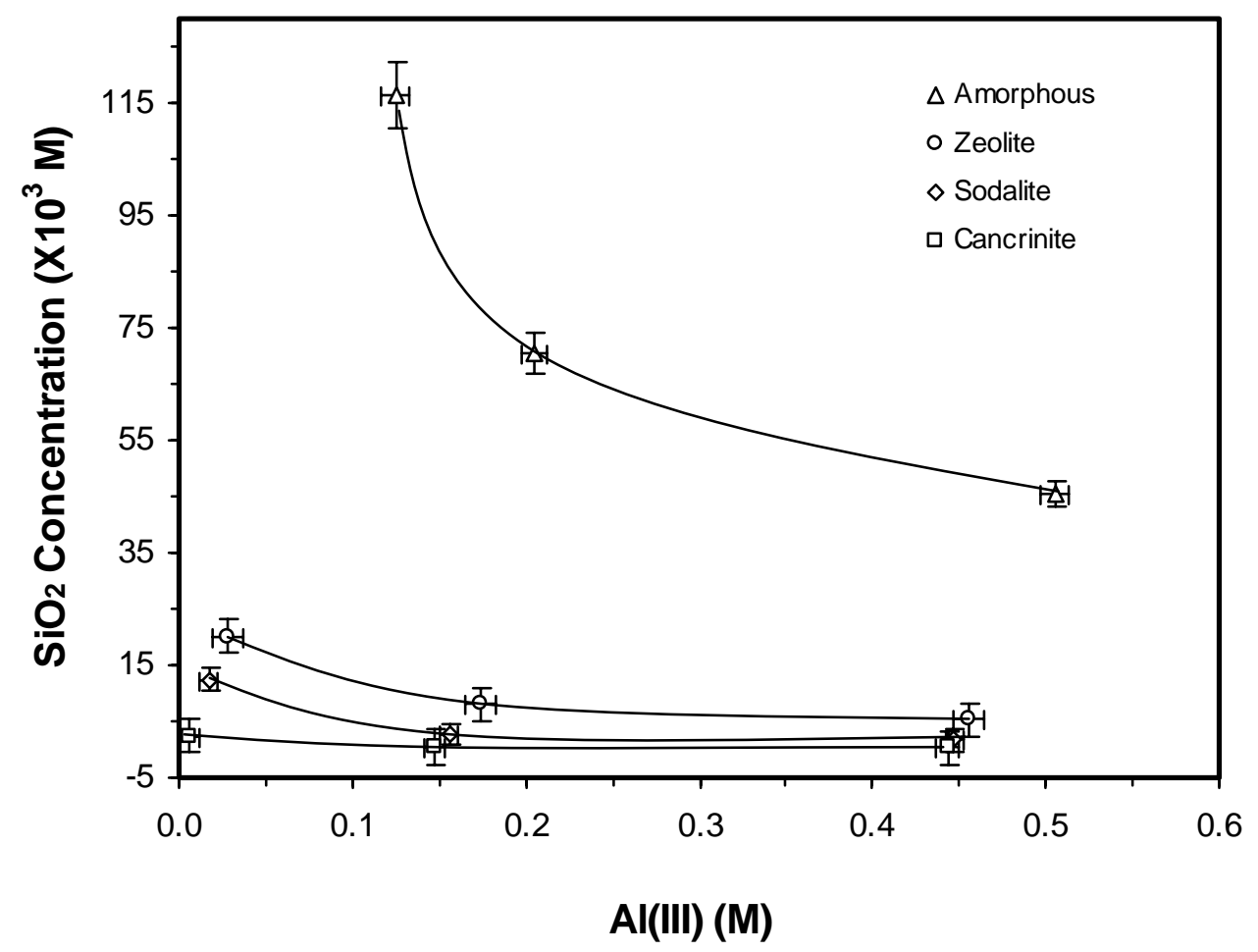

Figure 34 Equilibrium solubility as a function of $\mathrm{Al}(\mathrm{III})$ concentration in $4 \mathrm{M}$ $\mathrm{NaOH}, 1 \mathrm{M} \mathrm{NaNO}$ and $1 \mathrm{M} \mathrm{NaNO}_{2}$ solution at $65^{\circ} \mathrm{C}$ 


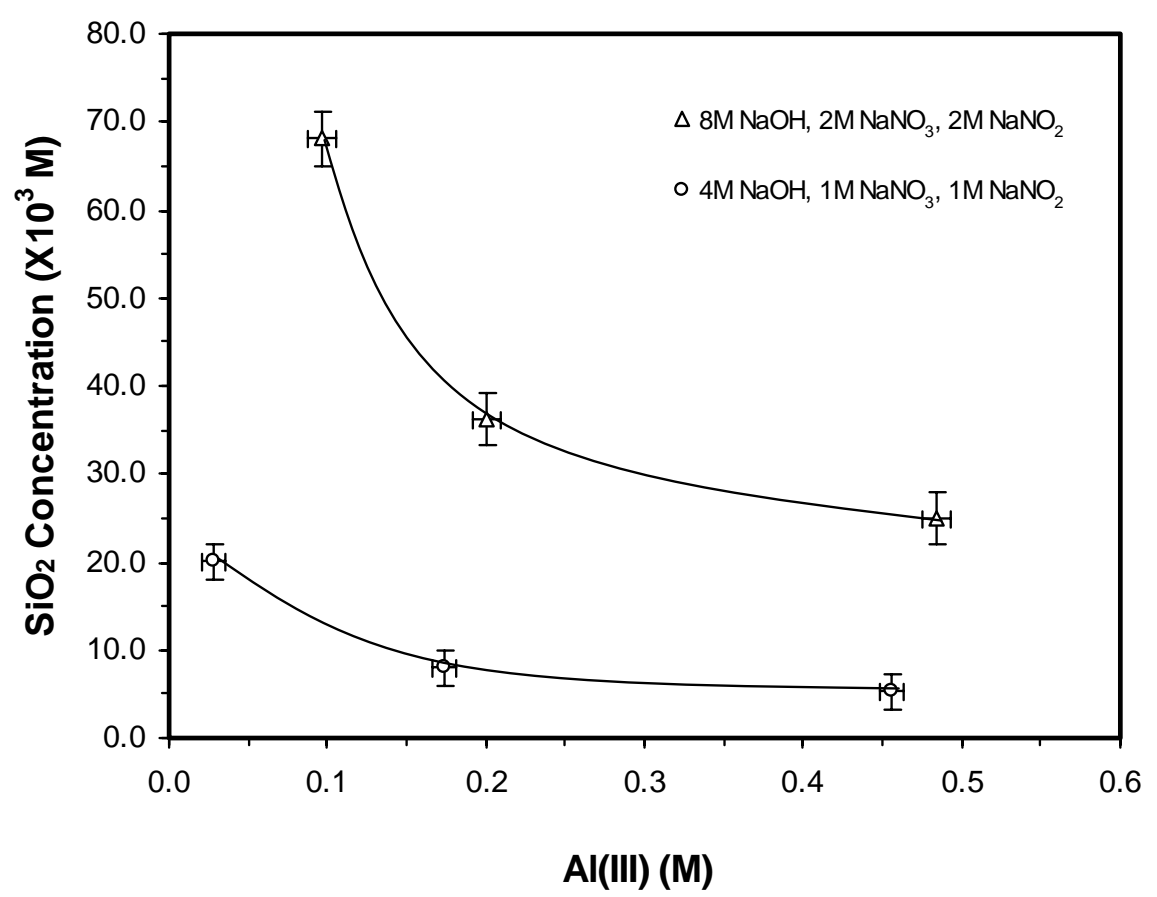

Figure 35 Equilibrium solubility of solutions seeded with zeolite at $65^{\circ} \mathrm{C}$

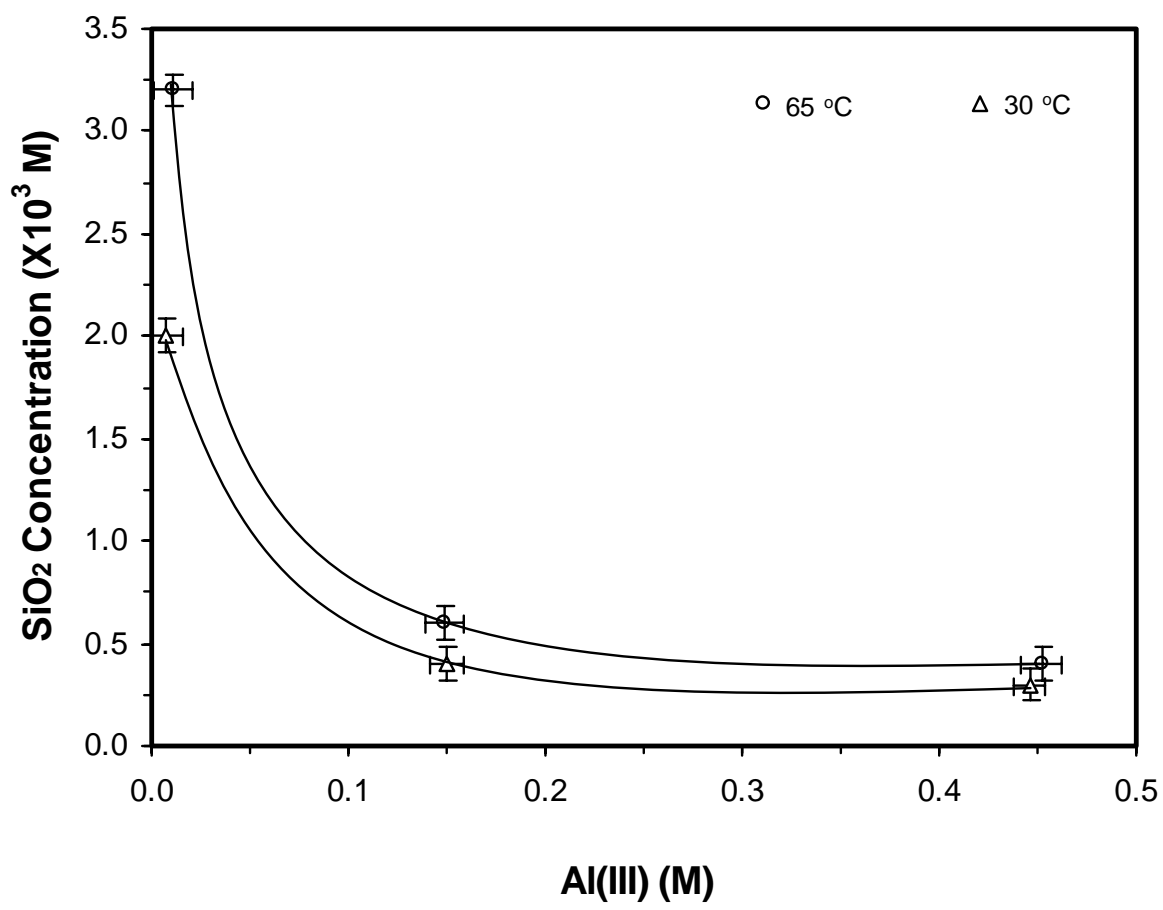

Figure 36 Equilibrium solubility as a function of $\mathrm{AI}$ (III) concentration and temperature for cancrinite in $8 \mathrm{NaOH}, 2 \mathrm{M} \mathrm{NaNO}_{3}$ and $2 \mathrm{M} \mathrm{NaNO}_{2}$ solutions 


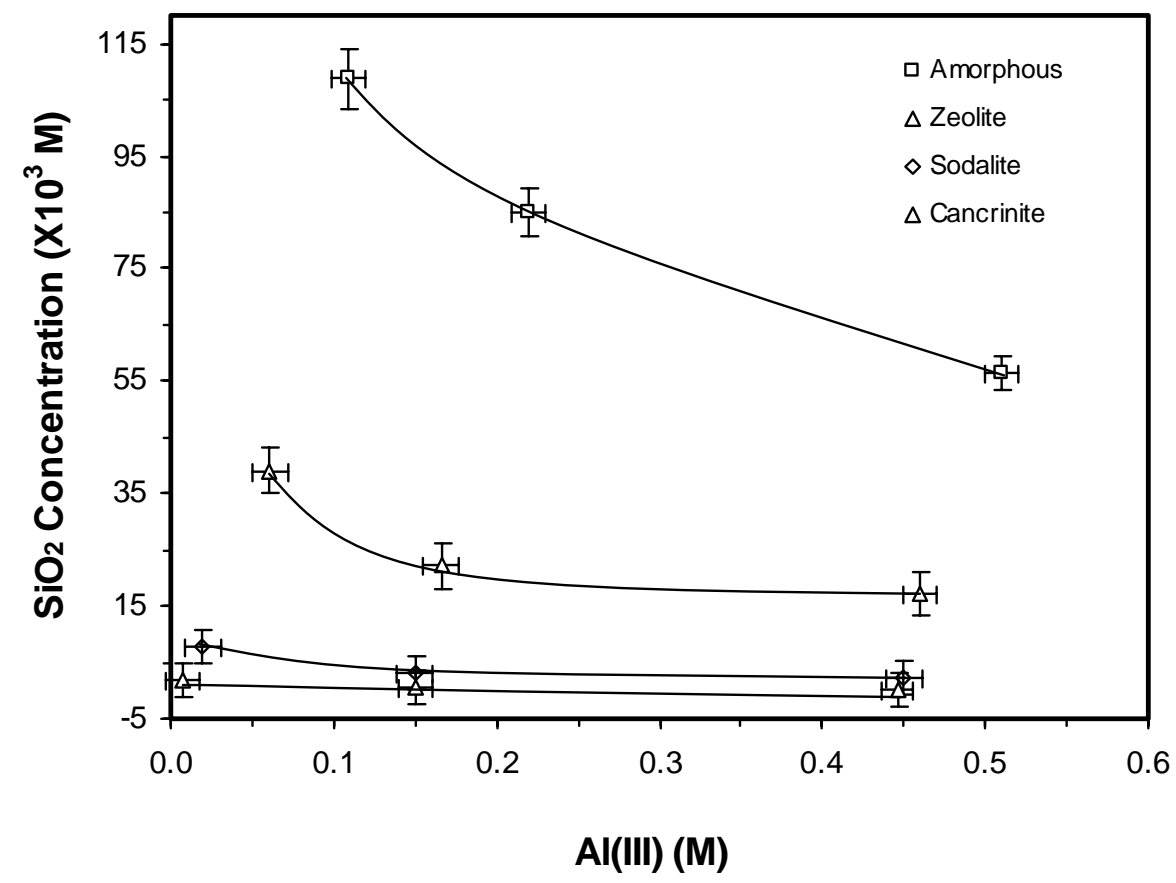

Figure 37 Equilibrium solubility versus Al(III) concentration as a function of phase in $8 \mathrm{M} \mathrm{NaOH}, 2 \mathrm{M} \mathrm{NaNO}_{3}$ and $2 \mathrm{M} \mathrm{NaNO}_{2}$ solution at $30{ }^{\circ} \mathrm{C}$

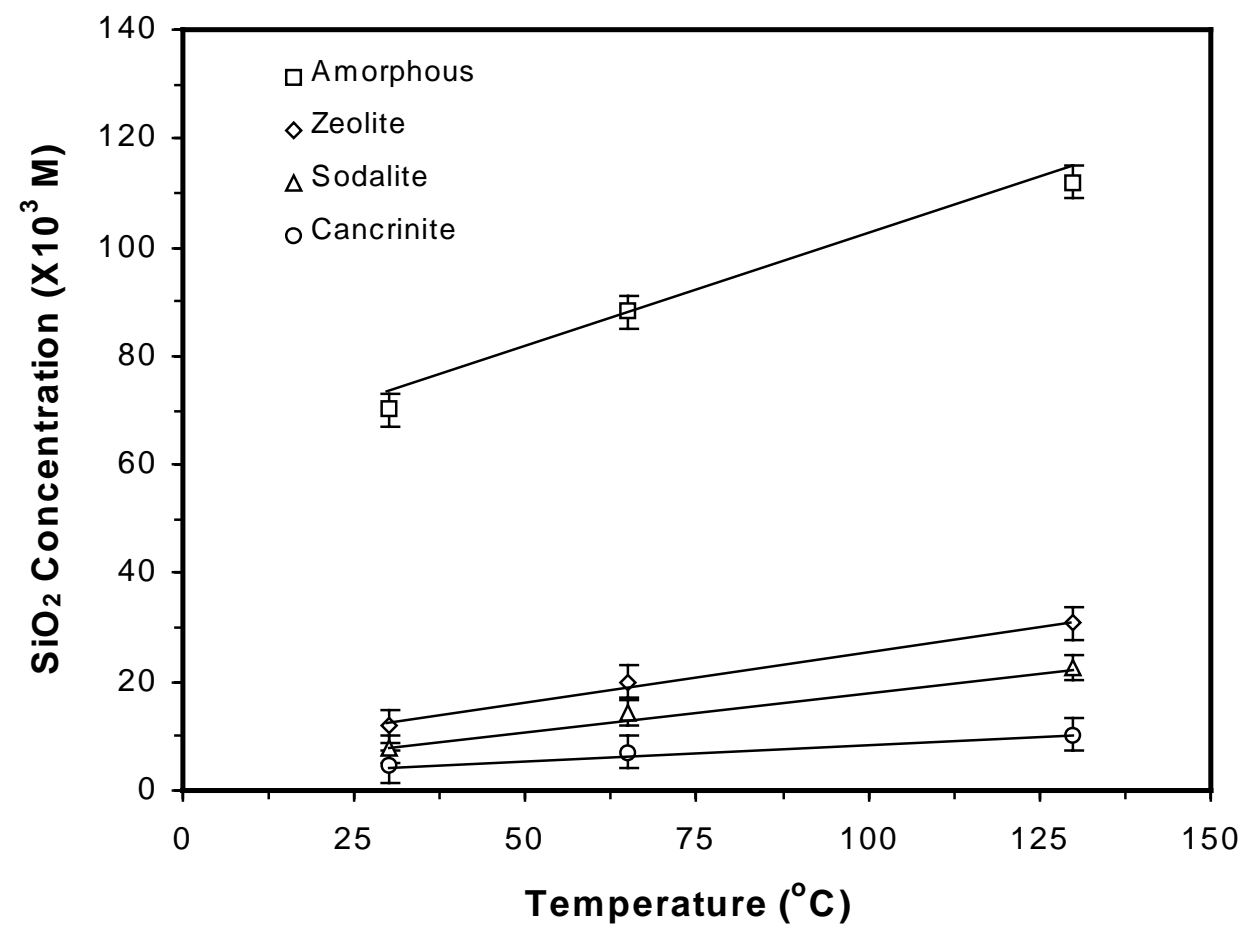

Figure 38 Equilibrium solubility of different aluminosilicate phases as a function of temperature in $3 \mathrm{M} \mathrm{NaOH}$ solution 


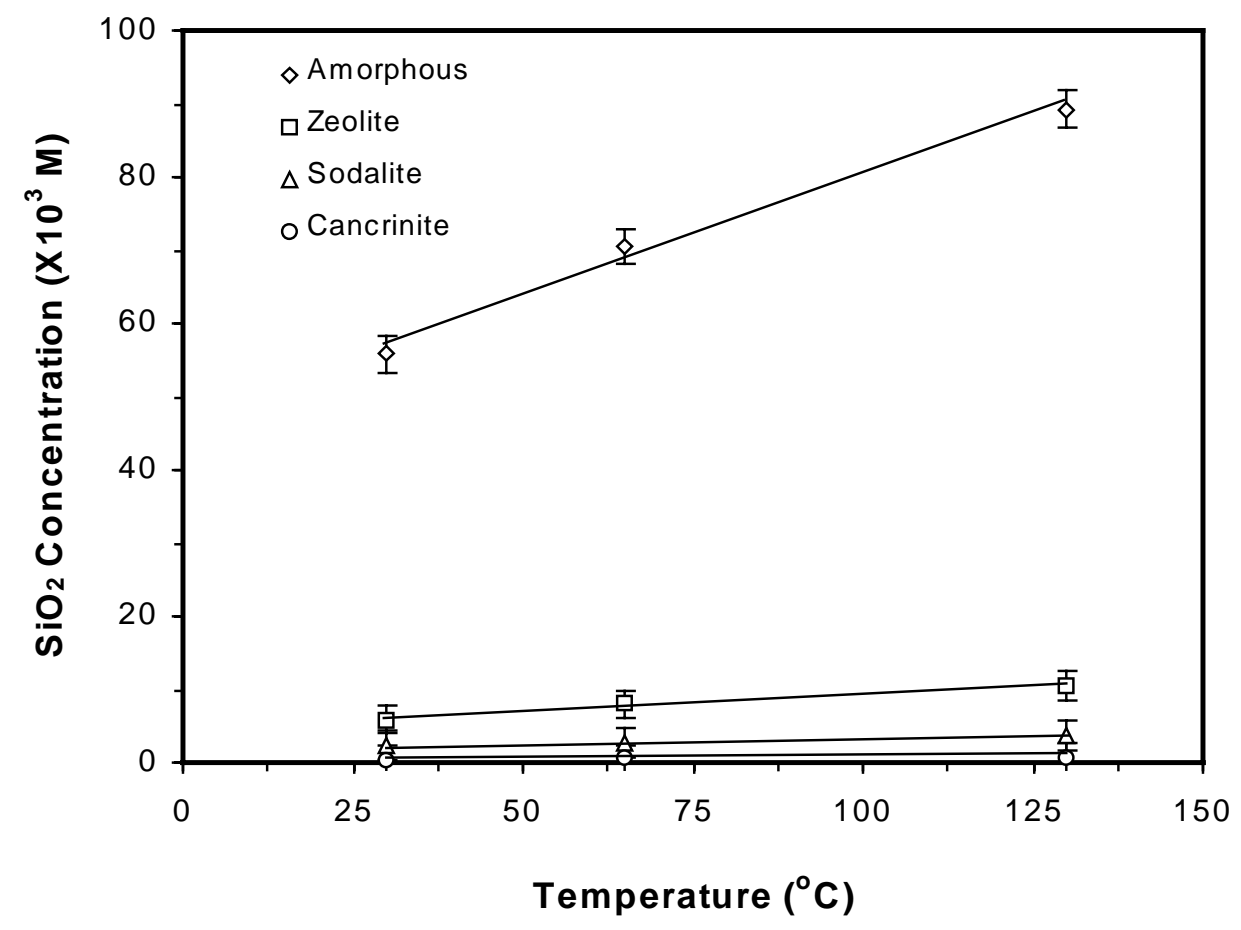

Figure 39 Equilibrium solubility of different phases as a function of temperature in $4 \mathrm{M}$ NaOH, $1 \mathrm{M} \mathrm{NaNO}_{3}, 1 \mathrm{M} \mathrm{NaNO}_{2}$ and $0.15 \mathrm{M} \mathrm{Al}$ (III) solution

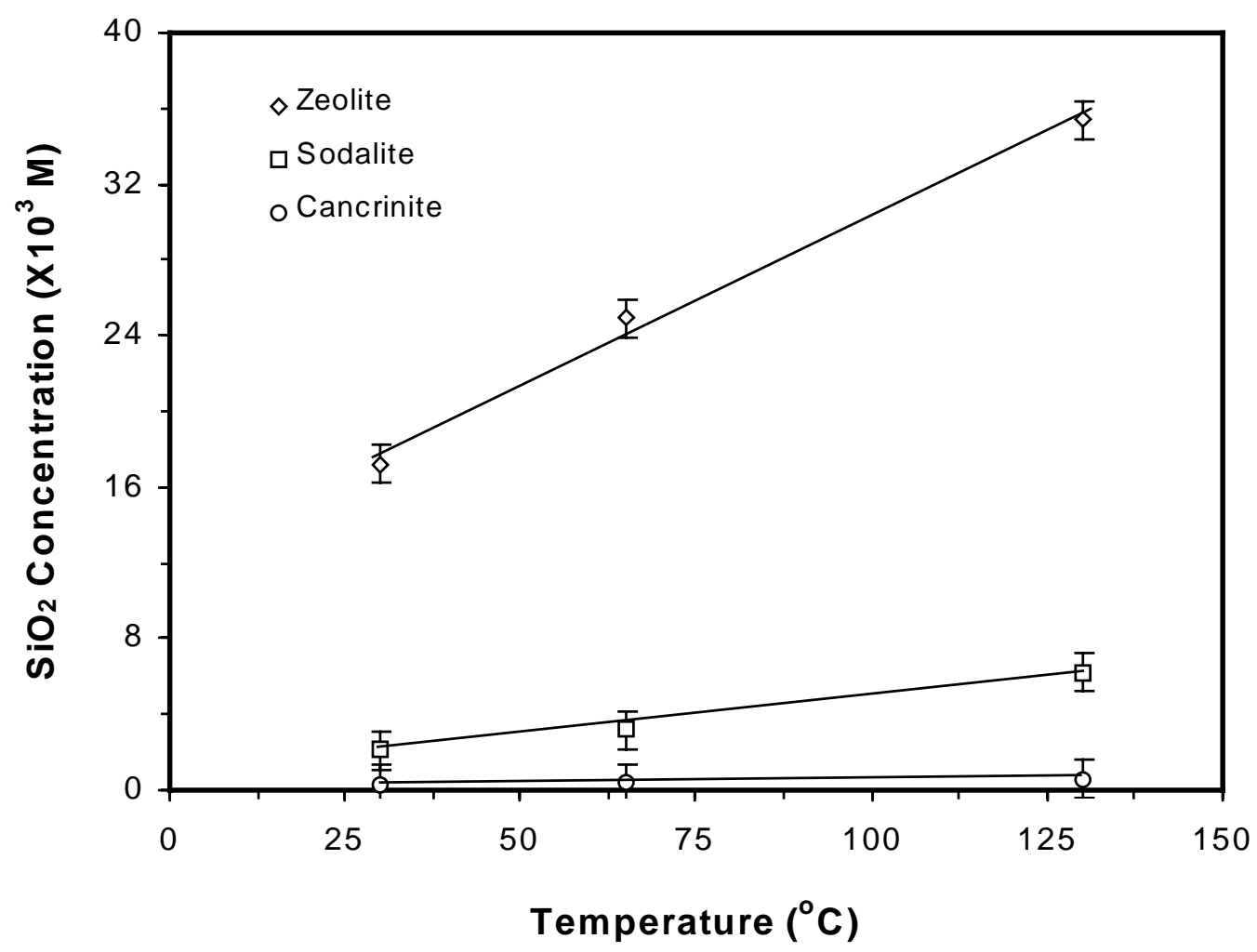

Figure 40 Equilibrium solubility of different phases as a function of temperature in $8 \mathrm{M} \mathrm{NaOH}, 2 \mathrm{M} \mathrm{NaNO}_{3}, 2 \mathrm{M} \mathrm{NaNO}_{2}$ and $0.45 \mathrm{M} \mathrm{Al}$ (III) solution 


\subsection{Solubility - Comparison with Literature Data}

Some of the reported solubility values measured under comparable solution conditions are summarised in Table 14. It is clearly evident that key process variables such as sodium aluminosilicate solid phase, temperature, solution composition and ionic strength of caustic, $\mathrm{Al}(\mathrm{III})$ and salts (sodium chloride, sodium carbonate) determine the equilibrium solubility. The data reported by Grujic et al. (1989) for solubility of zeolite A in $8 \mathrm{M} \mathrm{NaOH}$ solutions exemplify the good agreement displayed with present data when ionic stength and temperature are taken into account. 


\begin{tabular}{|c|c|c|c|c|c|c|c|}
\hline \multirow{2}{*}{$\begin{array}{c}\text { Solid Phase of } \\
\text { Seed }\end{array}$} & \multicolumn{5}{|c|}{ Initial Solution Composition } & \multicolumn{2}{|l|}{ Solubility } \\
\hline & $\begin{array}{l}\mathrm{Na}^{+} \\
(\mathrm{M})\end{array}$ & $\begin{array}{l}\mathrm{OH}^{-} \\
(\mathrm{M})\end{array}$ & $\begin{array}{r}\mathrm{NO}_{3}^{-} \\
(\mathrm{M})\end{array}$ & $\begin{array}{l}\mathrm{NO}_{2}^{-} \\
(\mathrm{M})\end{array}$ & $\begin{array}{c}\mathbf{A l}(\mathbf{I I I}) \\
(\mathbf{M})\end{array}$ & $\begin{array}{c}\mathrm{SiO}_{2} \\
\left(\times 10^{3} \mathrm{M}\right)\end{array}$ & $\begin{array}{c}\mathrm{Al}(\mathrm{III}) \\
\left(\times 10^{3} \mathrm{M}\right)\end{array}$ \\
\hline Amorphous & 3 & 3 & 0 & 0 & 0 & $70.2 \pm 1.5$ & $79.1 \pm 1.2$ \\
\hline Zeolite & 3 & 3 & 0 & 0 & 0 & $11.8 \pm 0.5$ & $20.1 \pm 3.0$ \\
\hline Sodalite & 3 & 3 & 0 & 0 & 0 & $7.8 \pm 0.3$ & $10.5 \pm 0.4$ \\
\hline Cancrinite & 3 & 3 & 0 & 0 & 0 & $4.6 \pm 0.2$ & $7.9 \pm 0.3$ \\
\hline Amorphous & 6 & 6 & 0 & 0 & 0 & $101.3 \pm 1.1$ & $98.9 \pm 1.2$ \\
\hline Zeolite & 6 & 6 & 0 & 0 & 0 & $31.4 \pm 0.3$ & $49.9 \pm 1.0$ \\
\hline Sodalite & 6 & 6 & 0 & 0 & 0 & $17.7 \pm 0.8$ & $19.9 \pm 0.4$ \\
\hline Cancrinite & 6 & 6 & 0 & 0 & 0 & $9.1 \pm 0.4$ & $11.7 \pm 0.5$ \\
\hline Amorphous & 6 & 4 & 1 & 1 & 0 & $86.1 \pm 2.5$ & $79.1 \pm 2.2$ \\
\hline Zeolite & 6 & 4 & 1 & 1 & 0 & $15.1 \pm 0.3$ & $31.4 \pm 0.3$ \\
\hline Sodalite & 6 & 4 & 1 & 1 & 0 & $5.8 \pm 0.2$ & $6.2 \pm 0.9$ \\
\hline Cancrinite & 6 & 4 & 1 & 1 & 0 & $1.9 \pm 0.1$ & $3.3 \pm 1.2$ \\
\hline Amorphous & 6 & 4 & 1 & 1 & 0.15 & $55.8 \pm 2.0$ & $194.1 \pm 5.3$ \\
\hline Zeolite & 6 & 4 & 1 & 1 & 0.15 & $5.9 \pm 0.2$ & $148.5 \pm 7.2$ \\
\hline Sodalite & 6 & 4 & 1 & 1 & 0.15 & $2.4 \pm 0.1$ & $152.8 \pm 7.0$ \\
\hline Cancrinite & 6 & 4 & 1 & 1 & 0.15 & $0.33 \pm 0.01$ & $146.5 \pm 4.5$ \\
\hline Amorphous & 6 & 4 & 1 & 1 & 0.45 & $39.8 \pm 1.6$ & $470.3 \pm 5.6$ \\
\hline Zeolite & 6 & 4 & 1 & 1 & 0.45 & $4.2 \pm 0.1$ & $440 \pm 10.0$ \\
\hline Sodalite & 6 & 4 & 1 & 1 & 0.45 & $0.81 \pm 0.03$ & $439.6 \pm 8.0$ \\
\hline Cancrinite & 6 & 4 & 1 & 1 & 0.45 & $0.22 \pm 0.01$ & $440.2 \pm 9.2$ \\
\hline Amorphous & 12 & 8 & 2 & 2 & 0 & $108.8 \pm 0.7$ & $109.1 \pm 2.0$ \\
\hline Zeolite & 12 & 8 & 2 & 2 & 0 & $39.0 \pm 0.7$ & $60.8 \pm 5.0$ \\
\hline Sodalite & 12 & 8 & 2 & 2 & 0 & $7.9 \pm 0.5$ & $19.6 \pm 0.9$ \\
\hline Cancrinite & 12 & 8 & 2 & 2 & 0 & $2.0 \pm 0.1$ & $7.7 \pm 0.3$ \\
\hline Amorphous & 12 & 8 & 2 & 2 & 0.15 & $85.2 \pm 0.8$ & $220.1 \pm 2.2$ \\
\hline Zeolite & 12 & 8 & 2 & 2 & 0.15 & $22.1 \pm 1.1$ & $165.7 \pm 7.1$ \\
\hline Sodalite & 12 & 8 & 2 & 2 & 0.15 & $3.2 \pm 0.1$ & $150.5 \pm 4.0$ \\
\hline Cancrinite & 12 & 8 & 2 & 2 & 0.15 & $0.41 \pm 0.02$ & $149.9 \pm 1.2$ \\
\hline Amorphous & 12 & 8 & 2 & 2 & 0.45 & $56.4 \pm 0.6$ & $510.4 \pm 5.1$ \\
\hline Zeolite & 12 & 8 & 2 & 2 & 0.45 & $17.2 \pm 0.2$ & $460.3 \pm 6.5$ \\
\hline Sodalite & 12 & 8 & 2 & 2 & 0.45 & $2.1 \pm 0.1$ & $450.2 \pm 2.4$ \\
\hline Cancrinite & 12 & 8 & 2 & 2 & 0.45 & $0.30 \pm 0.01$ & $445.9 \pm 5.1$ \\
\hline
\end{tabular}

Table 11 Equilibrium solubility of sodium aluminosilicate phases at $30{ }^{\circ} \mathrm{C}$ from below 
WSRC-MS-2002-00907

Page 60 of 141

\begin{tabular}{|c|c|c|c|c|c|c|c|}
\hline \multirow{2}{*}{$\begin{array}{c}\text { Solid Phase of } \\
\text { Seed }\end{array}$} & \multicolumn{5}{|c|}{ Initial Solution Composition } & \multicolumn{2}{|l|}{ Solubility } \\
\hline & $\begin{array}{l}\mathrm{Na}^{+} \\
(\mathrm{M})\end{array}$ & $\begin{array}{l}\mathrm{OH}^{-} \\
(\mathrm{M})\end{array}$ & $\begin{array}{l}\mathrm{NO}_{3}^{-} \\
(\mathrm{M})\end{array}$ & $\begin{array}{l}\mathrm{NO}_{2}^{-} \\
(\mathrm{M})\end{array}$ & $\begin{array}{c}\mathbf{A l}(\mathbf{I I I}) \\
(\mathbf{M})\end{array}$ & $\begin{array}{c}\mathrm{SiO}_{2} \\
\left(\times 10^{3} \mathrm{M}\right)\end{array}$ & $\begin{array}{c}\mathrm{Al}(\mathrm{III}) \\
\left(\times 10^{3} \mathrm{M}\right)\end{array}$ \\
\hline Amorphous & 3 & 3 & 0 & 0 & 0 & $88.1 \pm 0.4$ & $104.9 \pm 0.8$ \\
\hline Zeolite & 3 & 3 & 0 & 0 & 0 & $19.9 \pm 0.5$ & $26.9 \pm 1.3$ \\
\hline Sodalite & 3 & 3 & 0 & 0 & 0 & $14.3 \pm 0.4$ & $15.2 \pm 0.7$ \\
\hline Cancrinite & 3 & 3 & 0 & 0 & 0 & $7.1 \pm 0.3$ & $10.1 \pm 0.5$ \\
\hline Amorphous & 6 & 6 & 0 & 0 & 0 & $207.4 \pm 3.7$ & $206.1 \pm 1.7$ \\
\hline Zeolite & 6 & 6 & 0 & 0 & 0 & $44.0 \pm 1.6$ & $73.6 \pm 2.0$ \\
\hline Sodalite & 6 & 6 & 0 & 0 & 0 & $32.4 \pm 1.2$ & $39.9 \pm 1.4$ \\
\hline Cancrinite & 6 & 6 & 0 & 0 & 0 & $14.0 \pm 0.4$ & $14.8 \pm 0.5$ \\
\hline Amorphous & 6 & 4 & 1 & 1 & 0 & $116.3 \pm 4.0$ & $125.0 \pm 3.9$ \\
\hline Zeolite & 6 & 4 & 1 & 1 & 0 & $20.1 \pm 0.3$ & $28.3 \pm 0.4$ \\
\hline Sodalite & 6 & 4 & 1 & 1 & 0 & $12.5 \pm 0.1$ & $17.2 \pm 0.1$ \\
\hline Cancrinite & 6 & 4 & 1 & 1 & 0 & $2.5 \pm 0.1$ & $5.7 \pm 0.2$ \\
\hline Amorphous & 6 & 4 & 1 & 1 & 0.15 & $70.5 \pm 0.4$ & $205.2 \pm 3.7$ \\
\hline Zeolite & 6 & 4 & 1 & 1 & 0.15 & $8.0 \pm 0.2$ & $176.6 \pm 1.8$ \\
\hline Sodalite & 6 & 4 & 1 & 1 & 0.15 & $2.7 \pm 0.1$ & $158.9 \pm 6.0$ \\
\hline Cancrinite & 6 & 4 & 1 & 1 & 0.15 & $0.51 \pm 0.03$ & $149.9 \pm 4.0$ \\
\hline Amorphous & 6 & 4 & 1 & 1 & 0.45 & $45.4 \pm 0.3$ & $508.3 \pm 5.0$ \\
\hline Zeolite & 6 & 4 & 1 & 1 & 0.45 & $5.3 \pm 0.1$ & $456.1 \pm 10.0$ \\
\hline Sodalite & 6 & 4 & 1 & 1 & 0.45 & $1.6 \pm 0.1$ & $446.7 \pm 7.0$ \\
\hline Cancrinite & 6 & 4 & 1 & 1 & 0.45 & $0.32 \pm 0.01$ & $442.6 \pm 7.2$ \\
\hline Amorphous & 12 & 8 & 2 & 2 & 0 & $257.8 \pm 5.3$ & $284.2 \pm 6.6$ \\
\hline Zeolite & 12 & 8 & 2 & 2 & 0 & $68.1 \pm 2.0$ & $96.1 \pm 3.0$ \\
\hline Sodalite & 12 & 8 & 2 & 2 & 0 & $18.1 \pm 0.7$ & $23.1 \pm 1.0$ \\
\hline Cancrinite & 12 & 8 & 2 & 2 & 0 & $3.20 \pm 0.15$ & $11.3 \pm 0.3$ \\
\hline Amorphous & 12 & 8 & 2 & 2 & 0.15 & $193.7 \pm 4.0$ & $350.8 \pm 7.0$ \\
\hline Zeolite & 12 & 8 & 2 & 2 & 0.15 & $36.3 \pm 1.6$ & $280.9 \pm 5.1$ \\
\hline Sodalite & 12 & 8 & 2 & 2 & 0.15 & $5.3 \pm 0.1$ & $155.7 \pm 4.0$ \\
\hline Cancrinite & 12 & 8 & 2 & 2 & 0.15 & $0.60 \pm 0.03$ & $148.7 \pm 3.2$ \\
\hline Amorphous & 12 & 8 & 2 & 2 & 0.45 & $144.7 \pm 3.0$ & $579.6 \pm 9.0$ \\
\hline Zeolite & 12 & 8 & 2 & 2 & 0.45 & $24.9 \pm 1.1$ & $483.7 \pm 3.5$ \\
\hline Sodalite & 12 & 8 & 2 & 2 & 0.45 & $3.2 \pm 0.1$ & $459.1 \pm 8.4$ \\
\hline Cancrinite & 12 & 8 & 2 & 2 & 0.45 & $0.40 \pm 0.02$ & $452.2 \pm 6.1$ \\
\hline
\end{tabular}

Table 12 Equilibrium solubility of sodium aluminosilicate phases at $65^{\circ} \mathrm{C}$ from below 
WSRC-MS-2002-00907

Page 61 of 141

\begin{tabular}{|c|c|c|c|c|c|c|c|}
\hline \multirow{2}{*}{$\begin{array}{c}\text { Solid Phase of } \\
\text { Seed }\end{array}$} & \multicolumn{5}{|c|}{ Initial Solution Composition } & \multicolumn{2}{|l|}{ Solubility } \\
\hline & $\begin{array}{l}\mathrm{Na}^{+} \\
(\mathrm{M})\end{array}$ & $\begin{array}{l}\mathrm{OH}^{-} \\
\text {(M) }\end{array}$ & $\begin{array}{l}\mathrm{NO}_{3}^{-} \\
(\mathrm{M})\end{array}$ & $\begin{array}{l}\mathrm{NO}_{2}^{-} \\
(\mathrm{M})\end{array}$ & $\begin{array}{c}\mathbf{A l}(\mathbf{I I I}) \\
(\mathbf{M})\end{array}$ & $\begin{array}{c}\mathrm{SiO}_{2} \\
\left(\times 10^{3} \mathrm{M}\right)\end{array}$ & $\begin{array}{c}\mathrm{Al}(\mathrm{III}) \\
\left(\times 10^{3} \mathrm{M}\right)\end{array}$ \\
\hline Amorphous & 3 & 3 & 0 & 0 & 0 & $87.4 \pm 1.1$ & $100.4 \pm 2.5$ \\
\hline Zeolite & 3 & 3 & 0 & 0 & 0 & $20.3 \pm 0.7$ & $27.7 \pm 0.7$ \\
\hline Sodalite & 3 & 3 & 0 & 0 & 0 & $15.6 \pm 0.5$ & $16.9 \pm 0.6$ \\
\hline Cancrinite & 3 & 3 & 0 & 0 & 0 & $6.9 \pm 0.2$ & $8.5 \pm 0.6$ \\
\hline Amorphous & 6 & 6 & 0 & 0 & 0 & $205.1 \pm 4.3$ & $206.4 \pm 2.7$ \\
\hline Zeolite & 6 & 6 & 0 & 0 & 0 & $45.3 \pm 0.9$ & $55.3 . \pm 1.6$ \\
\hline Sodalite & 6 & 6 & 0 & 0 & 0 & $31.1 \pm 0.7$ & $38.1 \pm 1.2$ \\
\hline Cancrinite & 6 & 6 & 0 & 0 & 0 & $13.4 \pm 0.2$ & $14.1 \pm 0.6$ \\
\hline Amorphous & 6 & 4 & 1 & 1 & 0 & $112.3 \pm 3.0$ & $120.0 \pm 2.0$ \\
\hline Zeolite & 6 & 4 & 1 & 1 & 0 & $19.3 \pm 0.2$ & $29.1 \pm 0.5$ \\
\hline Sodalite & 6 & 4 & 1 & 1 & 0 & $12.5 \pm 0.3$ & $17.7 \pm 0.3$ \\
\hline Cancrinite & 6 & 4 & 1 & 1 & 0 & $2.6 \pm 0.1$ & $5.9 \pm 0.1$ \\
\hline Amorphous & 6 & 4 & 1 & 1 & 0.15 & $71.7 \pm 0.4$ & $214.1 \pm 2.4$ \\
\hline Zeolite & 6 & 4 & 1 & 1 & 0.15 & $8.2 \pm 0.1$ & $179.3 \pm 0.8$ \\
\hline Sodalite & 6 & 4 & 1 & 1 & 0.15 & $2.6 \pm 0.2$ & $160.2 \pm 3.0$ \\
\hline Cancrinite & 6 & 4 & 1 & 1 & 0.15 & $0.53 \pm 0.05$ & $155.6 \pm 2.0$ \\
\hline Amorphous & 6 & 4 & 1 & 1 & 0.45 & $46.3 \pm 0.2$ & $511.3 \pm 3.0$ \\
\hline Zeolite & 6 & 4 & 1 & 1 & 0.45 & $5.1 \pm 0.2$ & $461.1 \pm 7.0$ \\
\hline Sodalite & 6 & 4 & 1 & 1 & 0.45 & $1.7 \pm 0.1$ & $452.7 \pm 5.0$ \\
\hline Cancrinite & 6 & 4 & 1 & 1 & 0.45 & $0.32 \pm 0.04$ & $449.7 \pm 8.4$ \\
\hline Amorphous & 12 & 8 & 2 & 2 & 0 & $258.1 \pm 3.3$ & $280.6 \pm 4.6$ \\
\hline Zeolite & 12 & 8 & 2 & 2 & 0 & $68.7 \pm 1.0$ & $95.4 \pm 2.3$ \\
\hline Sodalite & 12 & 8 & 2 & 2 & 0 & $17.8 \pm 0.5$ & $22.0 \pm 0.6$ \\
\hline Cancrinite & 12 & 8 & 2 & 2 & 0 & $3.10 \pm 0.09$ & $11.1 \pm 0.2$ \\
\hline Amorphous & 12 & 8 & 2 & 2 & 0.15 & $192.9 \pm 2.0$ & $360.7 \pm 2.0$ \\
\hline Zeolite & 12 & 8 & 2 & 2 & 0.15 & $36.1 \pm 0.6$ & $299.9 \pm 3.1$ \\
\hline Sodalite & 12 & 8 & 2 & 2 & 0.15 & $5.1 \pm 0.1$ & $158.7 \pm 3.0$ \\
\hline Cancrinite & 12 & 8 & 2 & 2 & 0.15 & $0.62 \pm 0.02$ & $153.9 \pm 1.2$ \\
\hline Amorphous & 12 & 8 & 2 & 2 & 0.45 & $143.8 \pm 2.0$ & $587.6 \pm 4.3$ \\
\hline Zeolite & 12 & 8 & 2 & 2 & 0.45 & $24.7 \pm 0.4$ & $487.7 \pm 2.3$ \\
\hline Sodalite & 12 & 8 & 2 & 2 & 0.45 & $3.10 \pm 0.05$ & $457.2 \pm 3.4$ \\
\hline Cancrinite & 12 & 8 & 2 & 2 & 0.45 & $0.41 \pm 0.02$ & $454.7 \pm 3.0$ \\
\hline
\end{tabular}

Table 13 Equilibrium solubility of sodium aluminosilicate phases at $65^{\circ} \mathrm{C}$ from above 
WSRC-MS-2002-00907

Page 62 of 141

\begin{tabular}{|c|c|c|c|c|c|c|c|}
\hline \multirow{2}{*}{$\begin{array}{c}\text { Solid Phase of } \\
\text { Seed }\end{array}$} & \multicolumn{5}{|c|}{ Initial Solution Composition } & \multicolumn{2}{|l|}{ Solubility } \\
\hline & $\begin{array}{l}\mathrm{Na}^{+} \\
(\mathrm{M})\end{array}$ & $\begin{array}{l}\mathrm{OH}^{-} \\
(\mathrm{M})\end{array}$ & $\begin{array}{r}\mathrm{NO}_{3}^{-} \\
(\mathrm{M})\end{array}$ & $\begin{array}{l}\mathrm{NO}_{2}^{-} \\
(\mathrm{M})\end{array}$ & $\begin{array}{c}\mathbf{A l}(\mathbf{I I I}) \\
(\mathbf{M})\end{array}$ & $\begin{array}{c}\mathrm{SiO}_{2} \\
\left(\times 10^{3} \mathrm{M}\right)\end{array}$ & $\begin{array}{c}\mathrm{Al}(\mathrm{III}) \\
\left(\times 10^{3} \mathrm{M}\right)\end{array}$ \\
\hline Amorphous & 3 & 3 & 0 & 0 & 0 & $111.9 \pm 4.1$ & $113.2 \pm 2.2$ \\
\hline Zeolite & 3 & 3 & 0 & 0 & 0 & $30.9 \pm 0.7$ & $34.2 \pm 1.5$ \\
\hline Sodalite & 3 & 3 & 0 & 0 & 0 & $22.6 \pm 1.0$ & $29.6 \pm 0.9$ \\
\hline Cancrinite & 3 & 3 & 0 & 0 & 0 & $10.3 \pm 0.3$ & $13.5 \pm 0.5$ \\
\hline Amorphous & 6 & 6 & 0 & 0 & 0 & $293.4 \pm 4.1$ & $295.2 \pm 3.2$ \\
\hline Zeolite & 6 & 6 & 0 & 0 & 0 & $61.8 \pm 1.3$ & $71.5 \pm 2.0$ \\
\hline Sodalite & 6 & 6 & 0 & 0 & 0 & $43.4 \pm 1.2$ & $48.5 \pm 1.4$ \\
\hline Cancrinite & 6 & 6 & 0 & 0 & 0 & $18.7 \pm 0.2$ & $22.2 \pm 0.1$ \\
\hline Amorphous & 6 & 4 & 1 & 1 & 0 & $156.5 \pm 3.7$ & $158.9 \pm 5.2$ \\
\hline Zeolite & 6 & 4 & 1 & 1 & 0 & $30.6 \pm 0.6$ & $35.1 \pm 1.0$ \\
\hline Sodalite & 6 & 4 & 1 & 1 & 0 & $17.5 \pm 0.8$ & $20.9 \pm 0.9$ \\
\hline Cancrinite & 6 & 4 & 1 & 1 & 0 & $5.1 \pm 0.1$ & $8.1 \pm 0.1$ \\
\hline Amorphous & 6 & 4 & 1 & 1 & 0.15 & $89.2 \pm 3.0$ & $228.2 \pm 7.3$ \\
\hline Zeolite & 6 & 4 & 1 & 1 & 0.15 & $10.5 \pm 0.4$ & $164.8 \pm 5.7$ \\
\hline Sodalite & 6 & 4 & 1 & 1 & 0.15 & $3.7 \pm 0.1$ & $156.0 \pm 7.0$ \\
\hline Cancrinite & 6 & 4 & 1 & 1 & 0.15 & $0.7 \pm 0.03$ & $159.7 \pm 6.7$ \\
\hline Amorphous & 6 & 4 & 1 & 1 & 0.45 & $57.6 \pm 1.2$ & $510.8 \pm 4.2$ \\
\hline Zeolite & 6 & 4 & 1 & 1 & 0.45 & $7.4 \pm 0.1$ & $464.4 \pm 9.0$ \\
\hline Sodalite & 6 & 4 & 1 & 1 & 0.45 & $2.5 \pm 0.1$ & $451.0 \pm 8.0$ \\
\hline Cancrinite & 6 & 4 & 1 & 1 & 0.45 & $0.5 \pm 0.02$ & $451.5 \pm 9.4$ \\
\hline Amorphous & 12 & 8 & 2 & 2 & 0 & I & I \\
\hline Zeolite & 12 & 8 & 2 & 2 & 0 & $100.7 \pm 2.7$ & $100.2 \pm 4.0$ \\
\hline Sodalite & 12 & 8 & 2 & 2 & 0 & $29.8 \pm 1.1$ & $30.5 \pm 0.7$ \\
\hline Cancrinite & 12 & 8 & 2 & 2 & 0 & $7.9 \pm 0.3$ & $9.4 \pm 0.4$ \\
\hline Amorphous & 12 & 8 & 2 & 2 & 0.15 & / & I \\
\hline Zeolite & 12 & 8 & 2 & 2 & 0.15 & $54.0 \pm 1.7$ & $205.4 \pm 4.1$ \\
\hline Sodalite & 12 & 8 & 2 & 2 & 0.15 & $9.4 \pm 0.3$ & $159.9 \pm 5.0$ \\
\hline Cancrinite & 12 & 8 & 2 & 2 & 0.15 & $0.8 \pm 0.03$ & $149.1 \pm 3.4$ \\
\hline Amorphous & 12 & 8 & 2 & 2 & 0.45 & / & / \\
\hline Zeolite & 12 & 8 & 2 & 2 & 0.45 & $35.4 \pm 0.4$ & $488.0 \pm 8.5$ \\
\hline Sodalite & 12 & 8 & 2 & 2 & 0.45 & $6.2 \pm 0.1$ & $460.4 \pm 10.4$ \\
\hline Cancrinite & 12 & 8 & 2 & 2 & 0.45 & $0.6 \pm 0.01$ & $448.7 \pm 0.8$ \\
\hline
\end{tabular}

Table 14 Equilibrium solubility of sodium aluminosilicate phases at $130{ }^{\circ} \mathrm{C}$ from below 


\begin{tabular}{|c|c|c|c|c|}
\hline \multirow[b]{2}{*}{ Author } & \multirow[b]{2}{*}{ Experimental Conditions } & \multicolumn{3}{|c|}{ Solubility } \\
\hline & & $\begin{array}{l}\text { Solid } \\
\text { Phase }\end{array}$ & $\begin{array}{c}\mathrm{SiO}_{2} \\
\left(\times 10^{3} \mathrm{M}\right)\end{array}$ & $\begin{array}{c}\mathrm{Al}(\mathrm{III}) \\
\left(\times 10^{3} \mathrm{M}\right)\end{array}$ \\
\hline \multirow[t]{2}{*}{ Antonic et al., 1994} & $0.2 \mathrm{M} \mathrm{NaOH}$ at $65^{\circ} \mathrm{C}$ & Amorphous & 13.6 & 11.6 \\
\hline & $0.2 \mathrm{M} \mathrm{NaOH}$ at $80^{\circ} \mathrm{C}$. & Amorphous & 15.5 & 13.0 \\
\hline \multirow[t]{4}{*}{$\begin{array}{l}\text { Pevzner et al., } \\
1974\end{array}$} & $\begin{array}{l}5.0 \mathrm{~N} \text { solutions of } \mathrm{NaCl}+ \\
\mathrm{NaOH}\end{array}$ & Amorphous & 13.0 & 120 \\
\hline & $+\mathrm{NaAlO}_{2}$ at $25{ }^{\circ} \mathrm{C}$ & Amorphous & 8.8 & 240 \\
\hline & & Amorphous & 10.5 & 360 \\
\hline & & Amorphous & 9.6 & 480 \\
\hline \multirow[t]{4}{*}{ Cizmek et al., 1991} & $1 \mathrm{M} \mathrm{NaOH}$ at $65^{\circ} \mathrm{C}$ & Zeolite & 11.5 & 11.04 \\
\hline & $2 \mathrm{M} \mathrm{NaOH}$ at $65^{\circ} \mathrm{C}$. & Zeolite & 16.6 & 16.73 \\
\hline & $1 \mathrm{M} \mathrm{NaOH}$ at $80^{\circ} \mathrm{C}$. & Zeolite & 11.38 & 10.82 \\
\hline & $2 \mathrm{M} \mathrm{NaOH}$ at $80^{\circ} \mathrm{C}$. & Zeolite & 17.79 & 17.74 \\
\hline \multirow[t]{2}{*}{ Grujic et al., 1989} & $8 \mathrm{M} \mathrm{NaOH}$ at $65^{\circ} \mathrm{C}$. & Zeolite & 58 & 78 \\
\hline & $8 \mathrm{M} \mathrm{NaOH}$ at $85^{\circ} \mathrm{C}$. & Zeolite & 78 & 86 \\
\hline \multirow[t]{2}{*}{ Grujic et al.,1989 } & $8 \mathrm{M} \mathrm{NaOH}$ at $70^{\circ} \mathrm{C}$. & Sodalite & 37 & 45 \\
\hline & $8 \mathrm{M} \mathrm{NaOH}$ at $85^{\circ} \mathrm{C}$. & Sodalite & 45 & 55 \\
\hline Gasteiger et al., 1992 & $\begin{array}{l}1 \mathrm{M} \mathrm{NaOH} \text { and } 3 \mathrm{M} \mathrm{NaCl} \text { at } 95 \\
{ }^{\circ} \mathrm{C} \text {. }\end{array}$ & Sodalite & 1.38 & 4.00 \\
\hline \multirow[t]{2}{*}{ Barnes et al., 1999} & 3.87M NaOH, $0.38 \mathrm{M} \mathrm{Na}_{2} \mathrm{CO}_{3}$, & Sodalite & 3.55 & 1670 \\
\hline & $\begin{array}{l}1.67 \mathrm{M} \mathrm{Al}(\mathrm{OH})_{3} \text { and } 0.01 \mathrm{M} \\
\mathrm{SiO}_{2} \text { at } 90^{\circ} \mathrm{C} \text {. }\end{array}$ & Cancrinite & 2.00 & 1670 \\
\hline \multirow[t]{2}{*}{ Barnes et al., 1999} & $\begin{array}{l}3.87 \mathrm{M} \mathrm{NaOH}, 0.38 \mathrm{M} \mathrm{Na}_{2} \mathrm{CO}_{3}, \\
1.67 \mathrm{M} \mathrm{Al}(\mathrm{OH})_{3}\end{array}$ & Sodalite & 3.70 & 1670 \\
\hline & and $0.01 \mathrm{M} \mathrm{SiO}_{2} ; 140^{\circ} \mathrm{C}$ & Cancrinite & 2.70 & 1670 \\
\hline
\end{tabular}

Table 15 Reported solubility values of sodium aluminosilicate phases

\subsection{Solution Density for Solubility Experiments}


WSRC-MS-2002-00907

Page 64 of 141

Typical density of caustic aluminate solutions used in the present investigation measured by the pycnometer method is given table 15 below. The influence of solution temperature, species concentration and composition on density is clearly evident for these liquors which attained equilibrium solubility.

\begin{tabular}{|c|c|c|c|c|c|c|c|}
\hline \multicolumn{6}{|c|}{ Initial Solution Composition } & \multicolumn{2}{|c|}{ Density $\left(\mathrm{kg} \mathrm{m}^{-3}\right)$} \\
\hline $\begin{array}{l}\mathrm{Na}^{+} \\
(\mathrm{M})\end{array}$ & $\begin{array}{l}\mathrm{OH}^{-} \\
(\mathrm{M})\end{array}$ & $\begin{array}{l}\mathrm{NO}_{3}^{-} \\
(\mathrm{M})\end{array}$ & $\begin{array}{l}\mathrm{NO}_{2}^{-} \\
(\mathrm{M})\end{array}$ & $\begin{array}{c}\mathrm{SiO}_{2} \\
\left(\times 10^{3} \mathrm{M}\right)\end{array}$ & $\begin{array}{c}\text { Al(III) } \\
\left(\times \mathbf{1 0}^{3} \mathrm{M}\right)\end{array}$ & $30{ }^{\circ} \mathrm{C}$ & $65^{\circ} \mathrm{C}$ \\
\hline 3 & 3 & 0 & 0 & 70.2 & 79.1 & 1153.8 & 1144.4 \\
\hline 3 & 3 & 0 & 0 & 11.8 & 20.1 & 1133.2 & 1087.3 \\
\hline 3 & 3 & 0 & 0 & 7.8 & 10.5 & 1121.5 & 1085.3 \\
\hline 3 & 3 & 0 & 0 & 4.6 & 7.9 & 1109.8 & 1074.0 \\
\hline 6 & 6 & 0 & 0 & 101.3 & 98.9 & 1243.5 & 1210.3 \\
\hline 6 & 6 & 0 & 0 & 31.4 & 49.9 & 1227.5 & 1025.9 \\
\hline 6 & 6 & 0 & 0 & 17.7 & 19.9 & 1218.0 & 1171.9 \\
\hline 6 & 6 & 0 & 0 & 9.1 & 11.7 & 1202.6 & 1180.5 \\
\hline 6 & 4 & 1 & 1 & 86.1 & 79.1 & 1248.4 & 1220.8 \\
\hline 6 & 4 & 1 & 1 & 15.1 & 31.4 & 1239.5 & 1212.1 \\
\hline 6 & 4 & 1 & 1 & 5.8 & 6.2 & 1235.8 & 1201.4 \\
\hline 6 & 4 & 1 & 1 & 1.9 & 3.3 & 1231.7 & 1197.4 \\
\hline 6 & 4 & 1 & 1 & 55.8 & 194.1 & 1251.6 & 1225.3 \\
\hline 6 & 4 & 1 & 1 & 5.9 & 148.5 & 1247.6 & 1220.8 \\
\hline 6 & 4 & 1 & 1 & 2.4 & 152.8 & 1240.5 & 1215.3 \\
\hline 6 & 4 & 1 & 1 & 0.33 & 146.5 & 1238.1 & 1213.0 \\
\hline 6 & 4 & 1 & 1 & 39.8 & 470.3 & 1253.0 & 1225.2 \\
\hline 6 & 4 & 1 & 1 & 4.2 & 440 & 1246.2 & 1218.6 \\
\hline 6 & 4 & 1 & 1 & 0.81 & 439.6 & 1244.7 & 1216.1 \\
\hline 6 & 4 & 1 & 1 & 0.22 & 440.2 & 1243.8 & 1215.3 \\
\hline 12 & 8 & 2 & 2 & 108.8 & 109.1 & 1540.0 & 1516.0 \\
\hline 12 & 8 & 2 & 2 & 39.0 & 60.8 & 1469.2 & 1446.4 \\
\hline 12 & 8 & 2 & 2 & 7.9 & 19.6 & 1403.9 & 1382.0 \\
\hline 12 & 8 & 2 & 2 & 2.0 & 7.7 & 1399.1 & 1377.3 \\
\hline 12 & 8 & 2 & 2 & 85.2 & 220.1 & 1536.9 & 1511.8 \\
\hline 12 & 8 & 2 & 2 & 22.1 & 165.7 & 1456.9 & 1433.1 \\
\hline 12 & 8 & 2 & 2 & 3.2 & 150.5 & 1419.9 & 1396.7 \\
\hline 12 & 8 & 2 & 2 & 0.41 & 149.9 & 1415.5 & 1389.7 \\
\hline 12 & 8 & 2 & 2 & 56.4 & 510.4 & 1542.0 & 1514.8 \\
\hline 12 & 8 & 2 & 2 & 17.2 & 460.3 & 1466.0 & 1439.0 \\
\hline 12 & 8 & 2 & 2 & 2.1 & 450.2 & 1438.1 & 1412.7 \\
\hline 12 & 8 & 2 & 2 & 0.30 & 445.9 & 1435.7 & 1409.2 \\
\hline
\end{tabular}

Table 16 Densities of liquors containing equilibrium concentrations of $\mathrm{Al}(\mathrm{III})$ and $\mathrm{SiO}$ as measured at 30 and $65^{\circ} \mathrm{C}$ 


\subsection{Phase Transformation Overview}

\subsection{Summary of Phase Transformation}

- Phase transformation occurs at different rates for each phase and all associated transformations increase rapidly with increasing temperature.

- The transformation rate is strongly dependent upon solution composition and ionic strength.

- Amorphous seed particles rapidly transformed into sodalite within 5 min without appearance of zeolite phase at $65{ }^{\circ} \mathrm{C}$ in initially $\mathrm{SiO}_{2}$-free solution at high caustic and high nitrite/nitrate concentrations (Figure 41).

- When the solution has low caustic and nitrate/nitrate the amorphous to sodalite transformation was not observed over the same time period at $65{ }^{\circ} \mathrm{C}$ (Figure 42).

- At $30{ }^{\circ} \mathrm{C}$ the amorphous phase initially transformed into zeolite A phase before rapidly transforming into sodalite in $\mathrm{SiO}_{2}$-rich solution at $6 \mathrm{M}$ caustic and $1 \mathrm{M}$ nitrite/nitrate concentrations (Figure 44).

- At $30{ }^{\circ} \mathrm{C}$ the amorphous phase did not undergo noticeable phase change in similar solutions at low and high $\mathrm{Al}(\mathrm{III})$ concentrations over $1 \mathrm{~h}$ period (Figure 43).

- Zeolite A seed phase was stable in initially $\mathrm{SiO}_{2}$-free solution at high caustic and high nitrite/nitrate concentration within $5 \mathrm{~min}$ at $65^{\circ} \mathrm{C}$. Upon further aging to $30 \mathrm{~min}$, sodalite phase appeared alongside with the zeolite. A mixture of sodalite and cancrinite phases formed with the disappearance of the zeolite phase after 60 min (Figures 47 and 48).

- Zeolite A was stable at $65{ }^{\circ} \mathrm{C}$ in solutions at lower caustic and nitrite/nitrate concentrations over $2 \mathrm{~h}$ after which it started transform to sodalite (Figure 45).

- At $30{ }^{\circ} \mathrm{C}$ zeolite A was stable in at high caustic and high nitrite/nitrate concentrations over 7 hour aging time (Figure 46).

- Sodalite seed crystals were found to be stable in the high level caustic and nitrite/nitrate solutions at $65{ }^{\circ} \mathrm{C}$ over $0.5 \mathrm{~h}$ period. Thereafter, dimorphic phase transformation to cancrinite phase occurred (Figure 49).

- No phase transformation of cancrinite crystals in solutions at high caustic and high nitrite/nitrate concentrations was observed over $68 \mathrm{~h}$ aging time (Figure 50). 


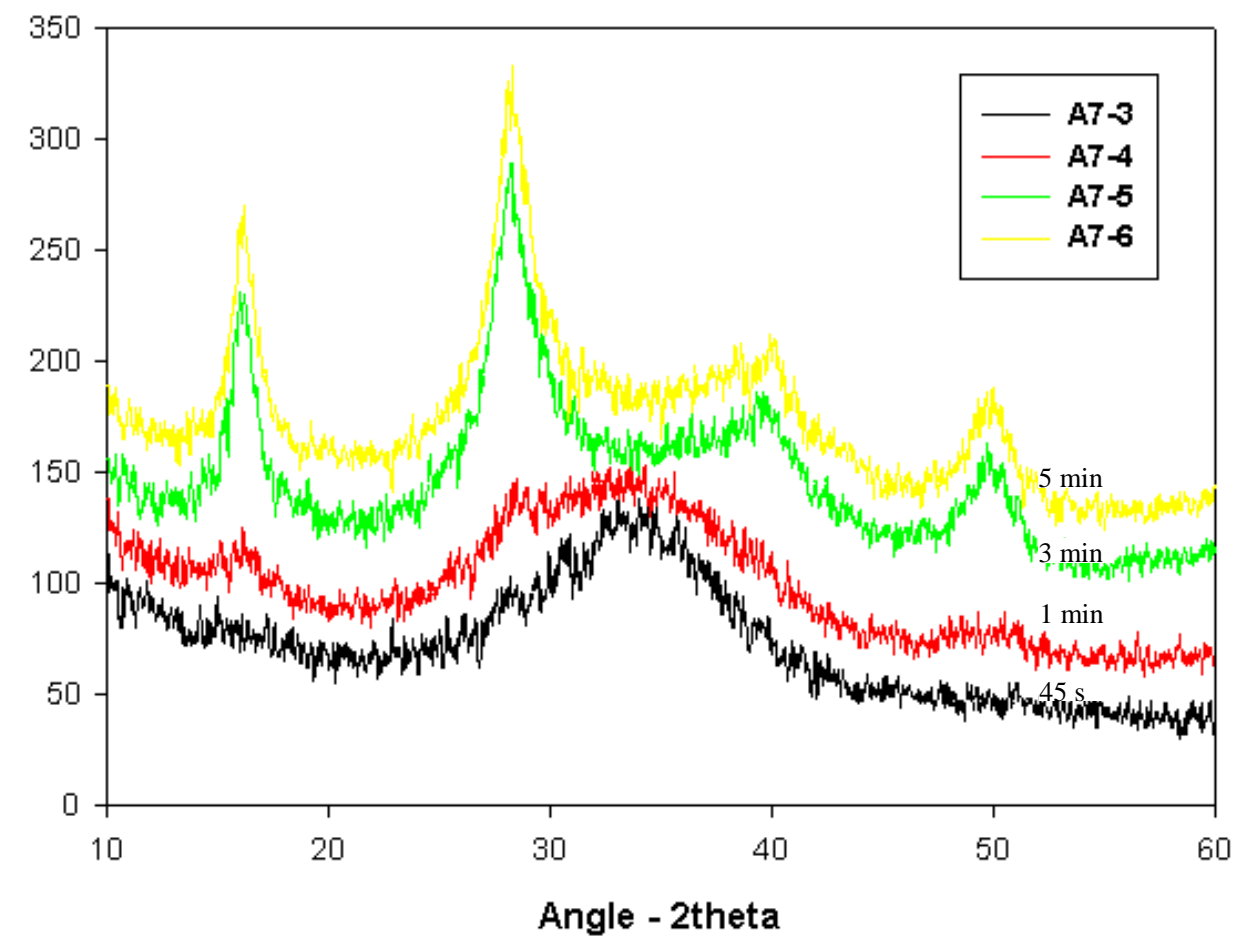

Figure $41 \quad \mathrm{XRD}$ analysis of amorphous seed in $8 \mathrm{M} \mathrm{NaOH}, 2 \mathrm{M} \mathrm{NaNO}, 2 \mathrm{M} \mathrm{NaNO}$ and $0.15 \mathrm{M} \mathrm{Al}$ (III) solutions as a function of dissolution time at $65{ }^{\circ} \mathrm{C}$ showing a rapid phase transformation from the amorphous to sodalite with time.

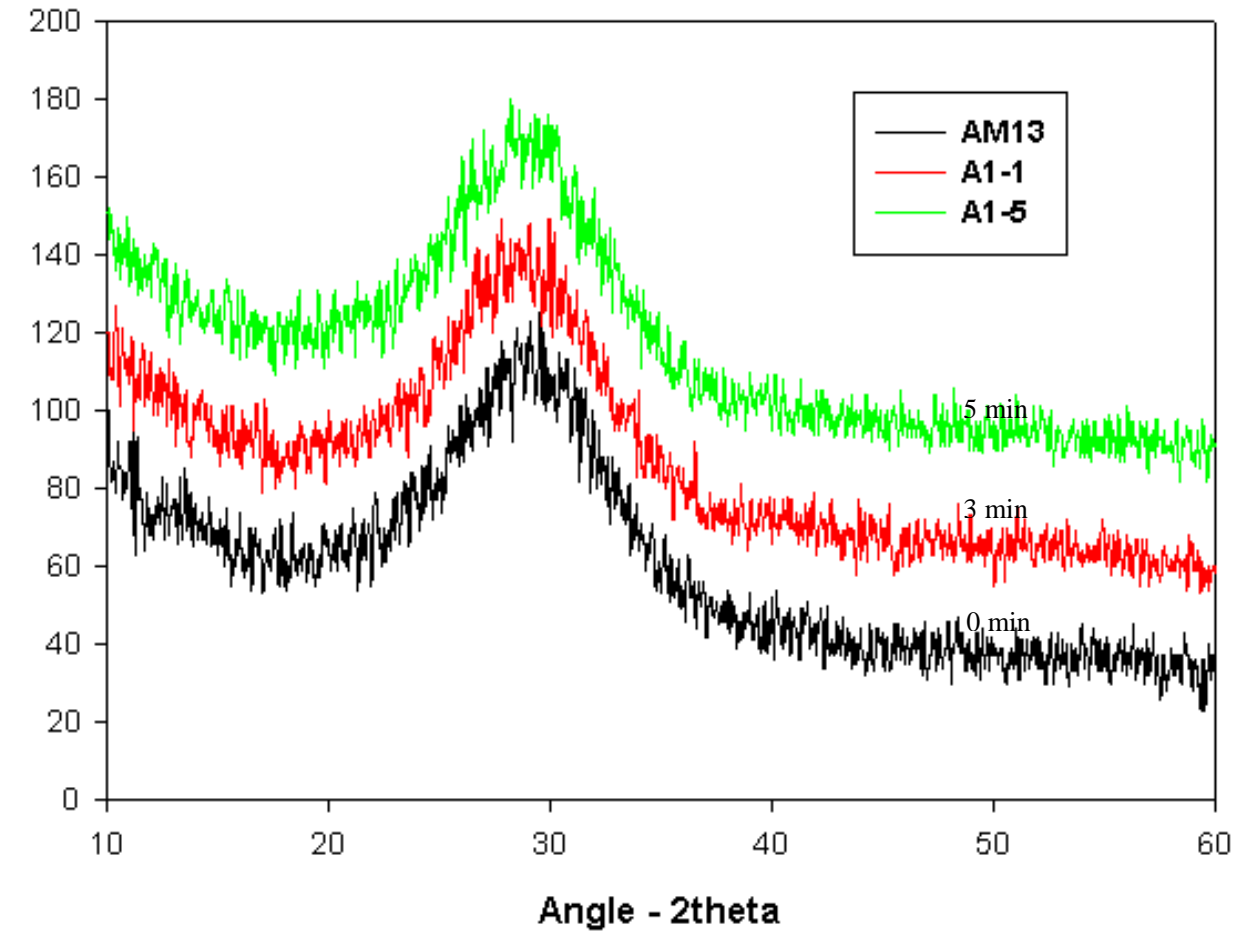

Figure $42 \quad \mathrm{XRD}$ analysis of the amorphous seed in $6 \mathrm{M} \mathrm{NaOH}$, and in $4 \mathrm{M} \mathrm{NaOH}, 1 \mathrm{M}$ $\mathrm{NaNO}_{3}$ and $1 \mathrm{M} \mathrm{NaNO}$ solutions as a function of dissolution time at $65{ }^{\circ} \mathrm{C}$ 


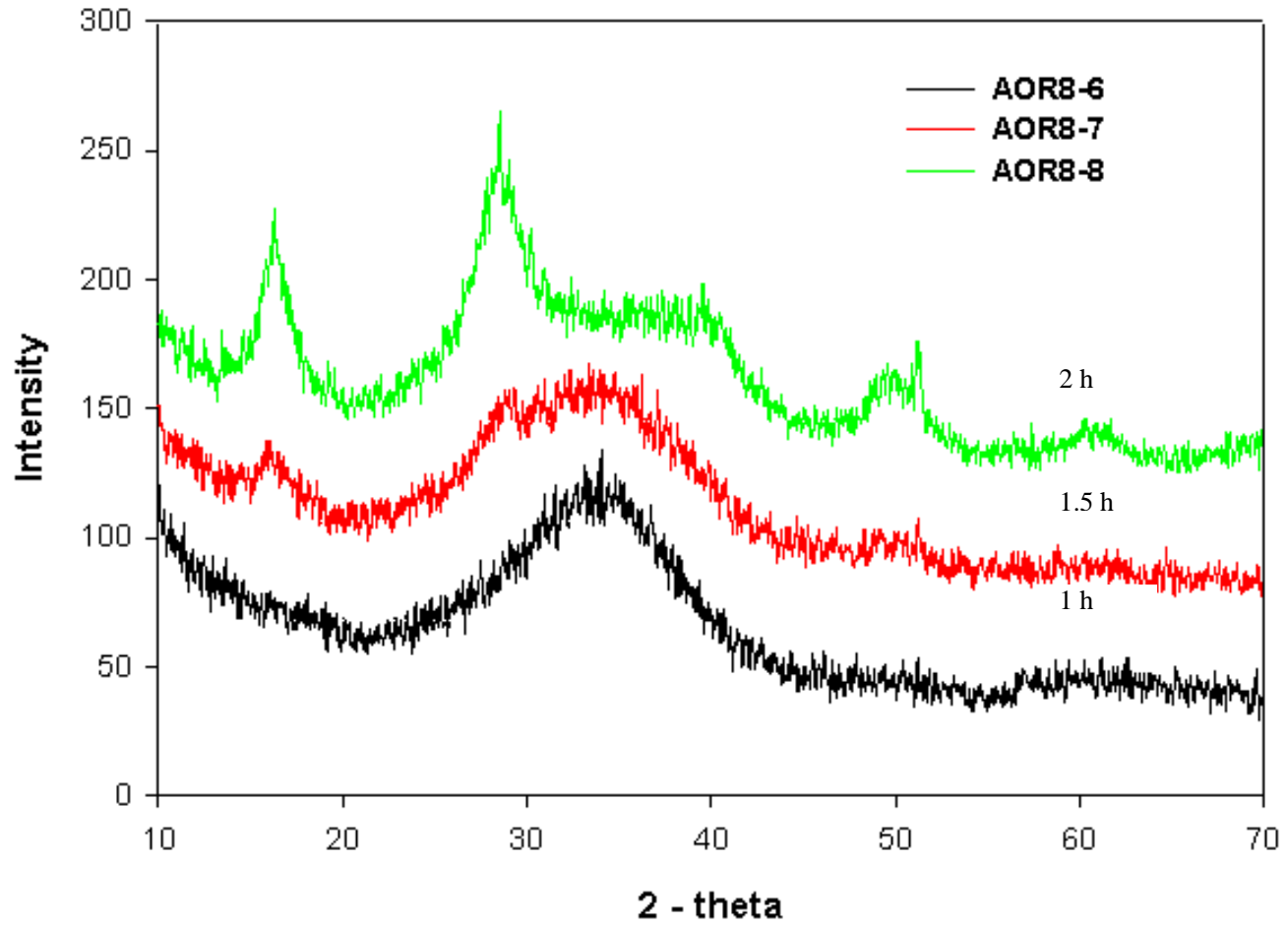

Figure $43 \quad \mathrm{XRD}$ analysis of the amorphous seed in $8 \mathrm{NaOH}, 2 \mathrm{NaNO}_{3}$ and $2 \mathrm{NaNO}_{2}$ and $0.45 \mathrm{Al}(\mathrm{III})$ solutions as a function of dissolution time at $30{ }^{\circ} \mathrm{C}$

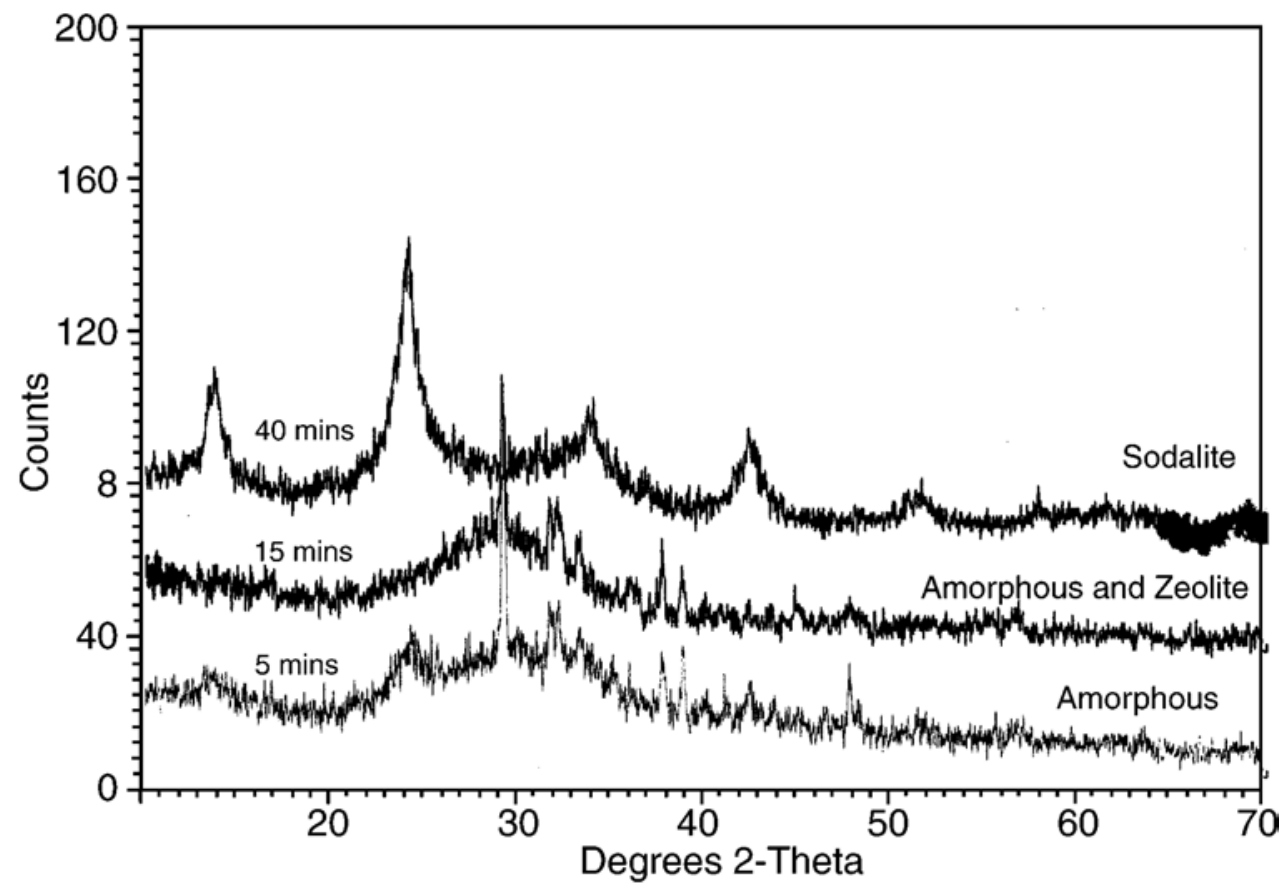

Figure $44 \quad \mathrm{XRD}$ analysis of amorphous seed in $6 \mathrm{NaOH}, 1 \mathrm{NaNO}_{3}$ and $1 \mathrm{NaNO}_{2}, 0.2$ $\mathrm{M} \mathrm{SiO}_{2}$ and $0.25 \mathrm{Al}$ (III) solutions as a function of dissolution time at $30{ }^{\circ} \mathrm{C}$ 


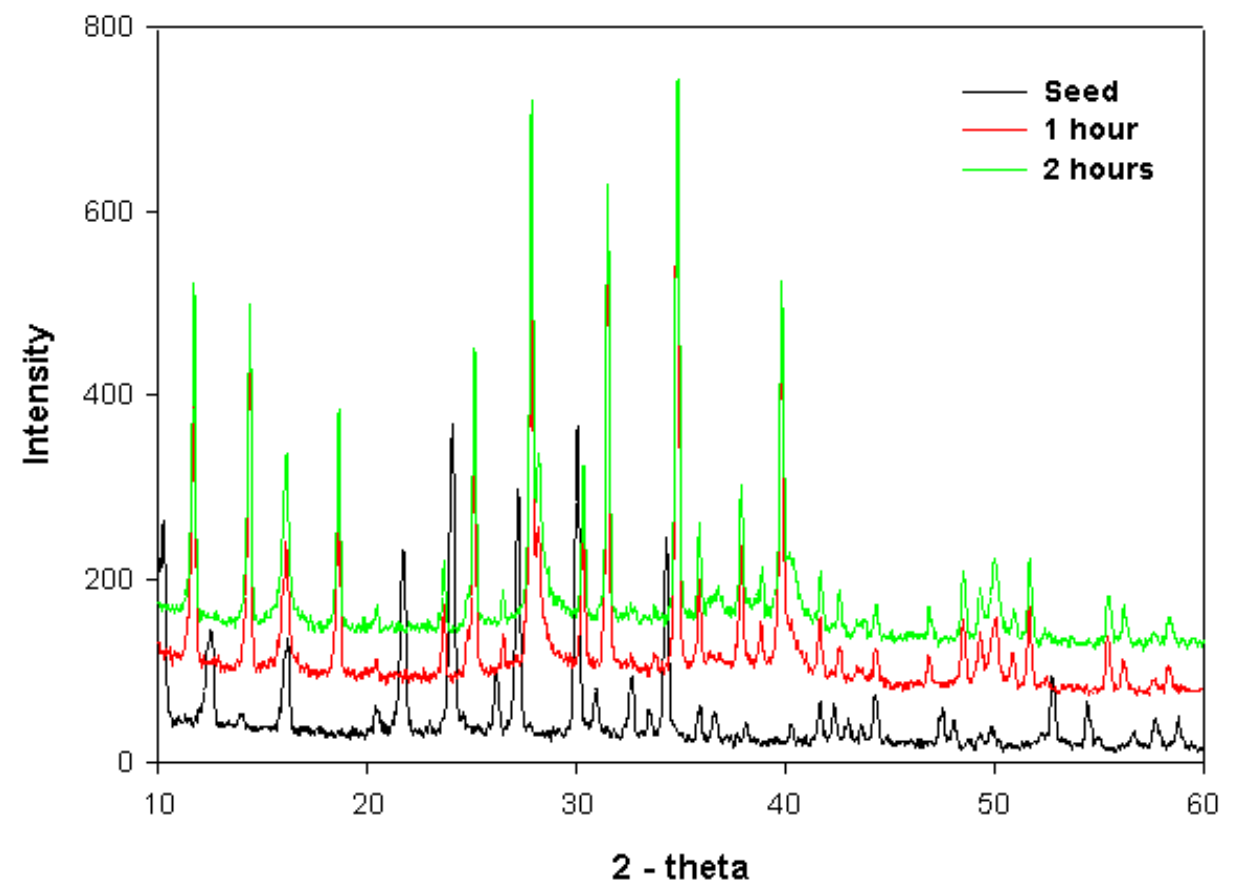

Figure 45 XRD analysis of the zeolite seed in $6 \mathrm{M} \mathrm{NaOH}$, and $4 \mathrm{M} \mathrm{NaOH}, 1 \mathrm{M}$ $\mathrm{NaNO}_{3}$ and $1 \mathrm{M} \mathrm{NaNO}_{2}$ solutions as a function of dissolution time at $65{ }^{\circ} \mathrm{C}$

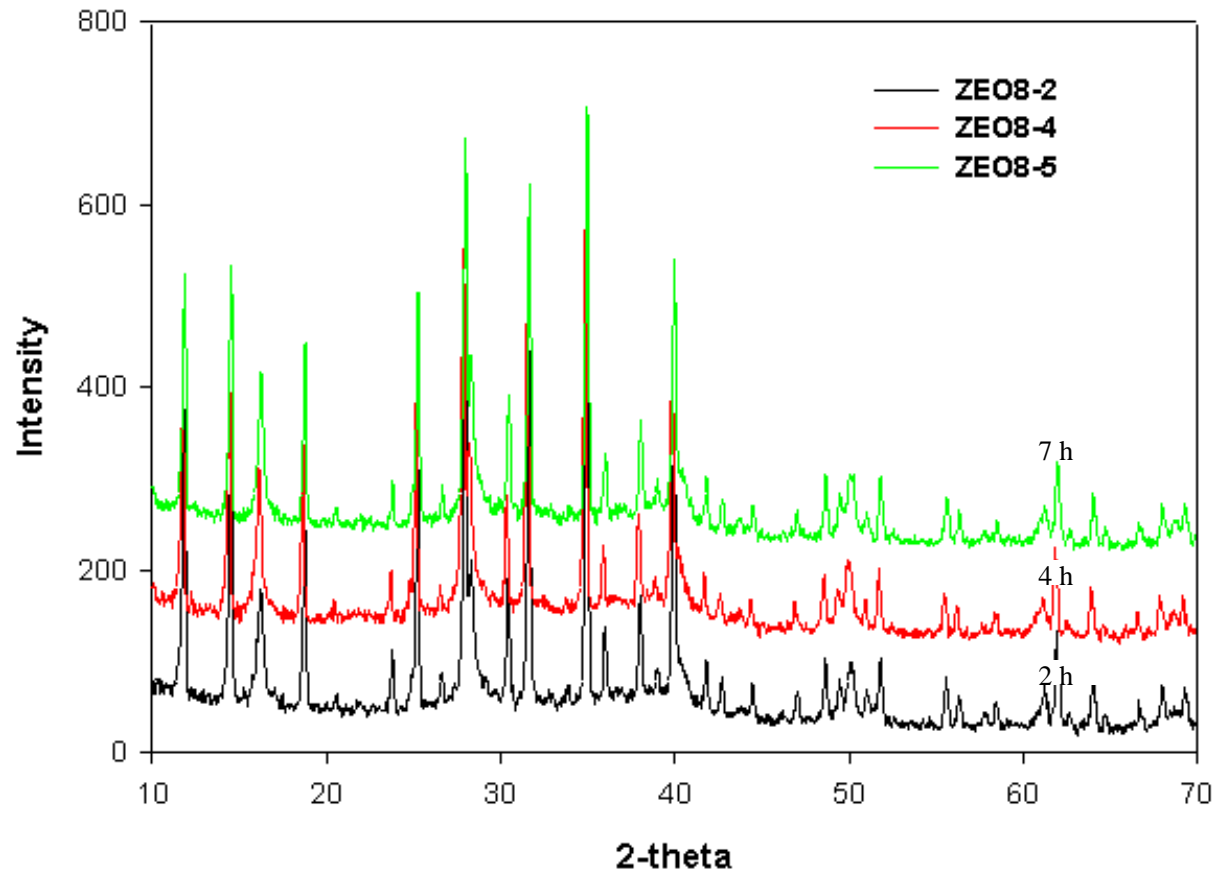

Figure 46 XRD analysis of zeolite $A$ seed in $8 \mathrm{M} \mathrm{NaOH}, 2 \mathrm{M} \mathrm{NaNO}{ }_{3}$ and $2 \mathrm{M}$ $\mathrm{NaNO}_{2}$ solution as a function of dissolution time at $30{ }^{\circ} \mathrm{C}$ 


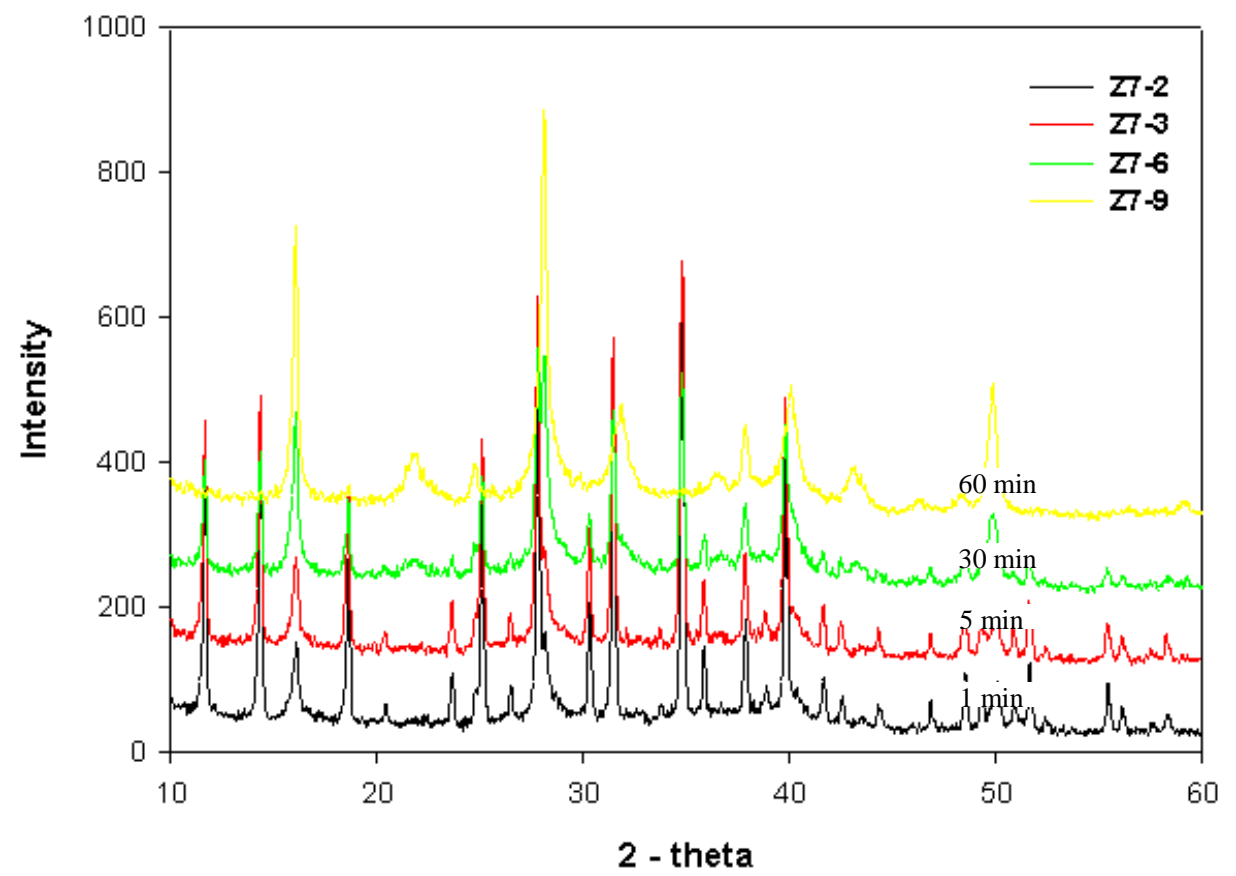

Figure 47 XRD analysis of the zeolite $\mathrm{A}$ seed in $8 \mathrm{M} \mathrm{NaOH}, 2 \mathrm{M} \mathrm{NaNO}_{3}, 2 \mathrm{M}$ $\mathrm{NaNO}_{2}$ and $0.15 \mathrm{M} \mathrm{Al}(\mathrm{III})$ solutions as a function of dissolution time at $65^{\circ} \mathrm{C}$

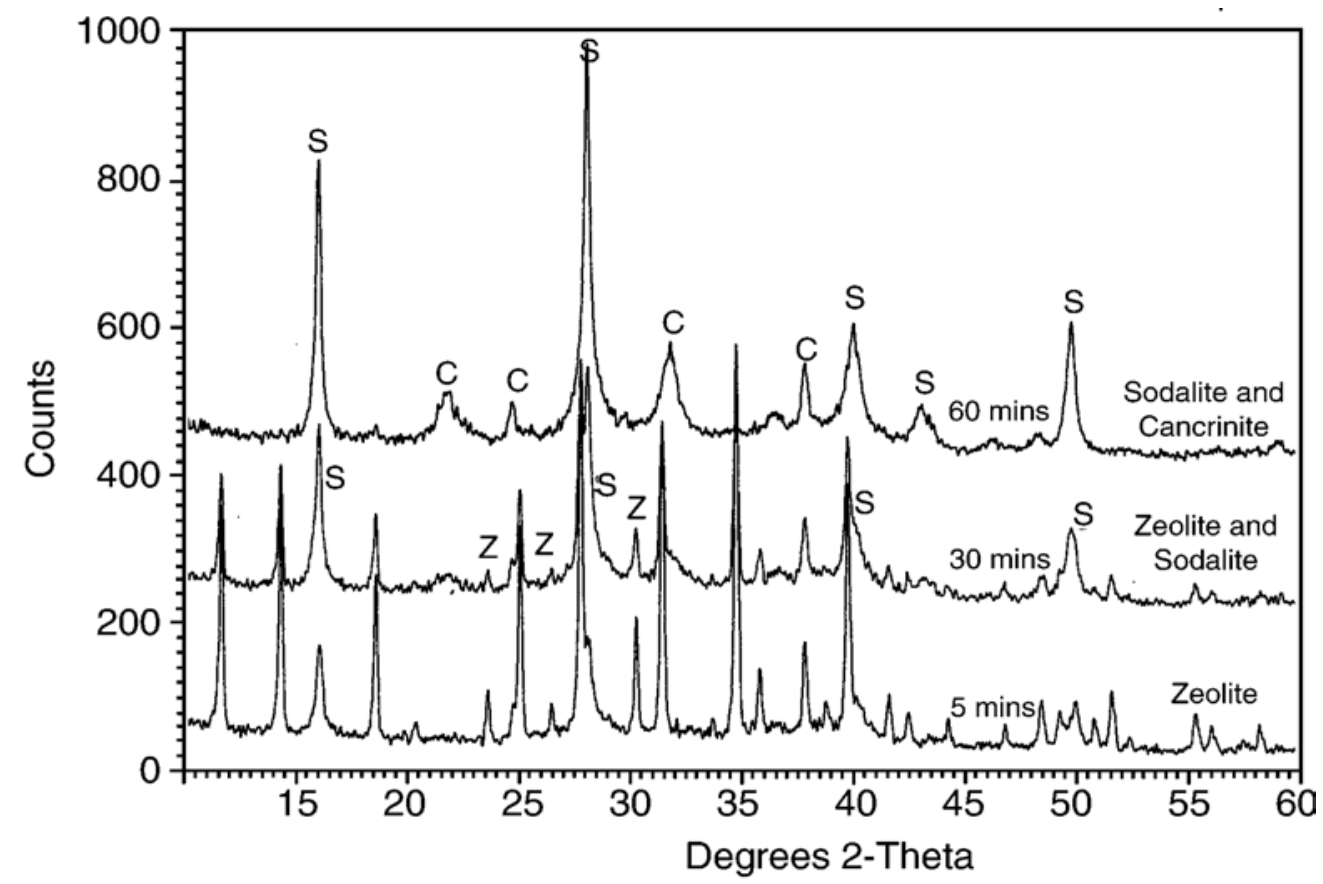

Figure 48 XRD analysis of the zeolite seed in $6 \mathrm{M} \mathrm{NaOH}, 2 \mathrm{M} \mathrm{NaNO}_{3}$ and $2 \mathrm{M}$ $\mathrm{NaNO}_{2}$ solution as a function of dissolution time at $65^{\circ} \mathrm{C}$ 


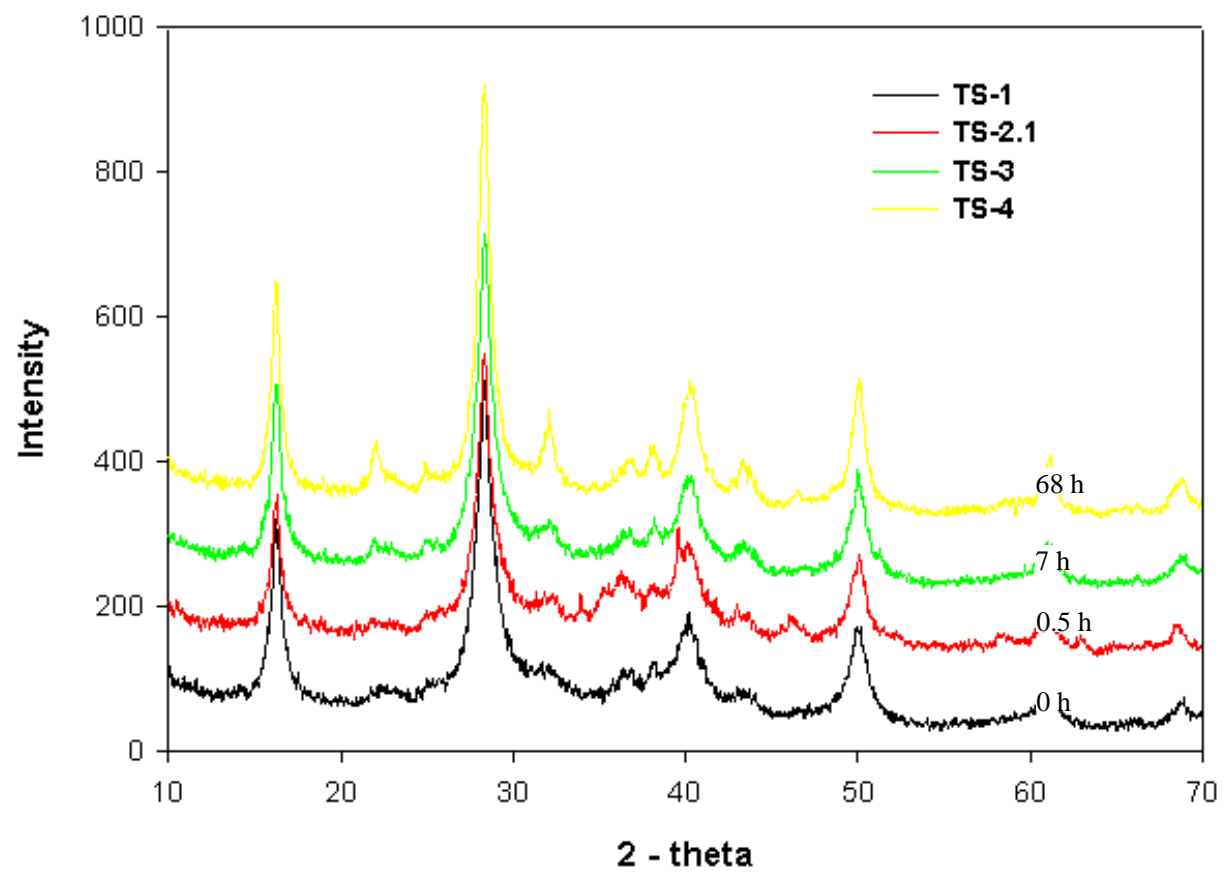

Figure $49 \quad \mathrm{XRD}$ analysis of the sodalite seed in $8 \mathrm{M} \mathrm{NaOH}, 2 \mathrm{M} \mathrm{NaNO}_{3}$ and $2 \mathrm{M}$ $\mathrm{NaNO}_{2}$ and $0.15 \mathrm{M}$ Al(III) solution as a function of dissolution time at $65^{\circ} \mathrm{C}$

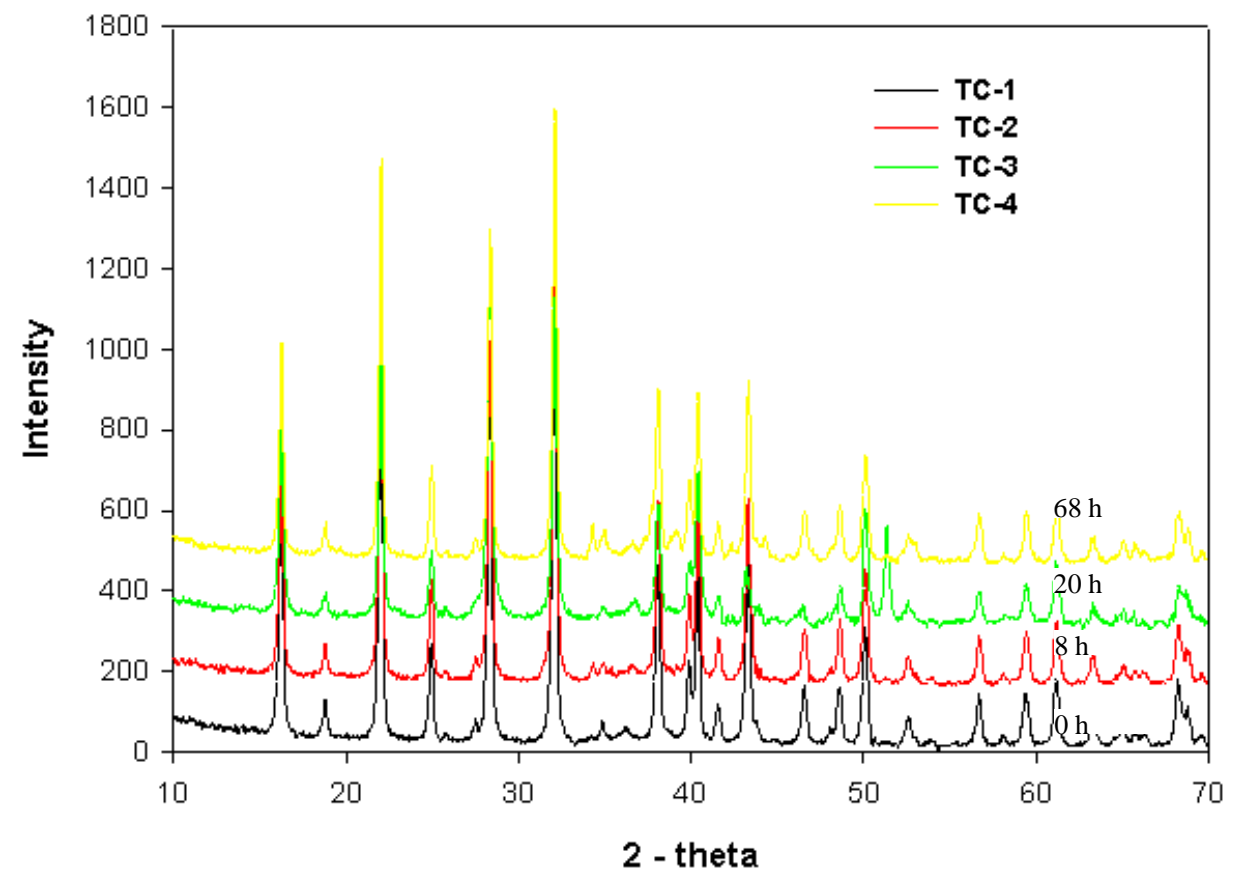

Figure $50 \quad \mathrm{XRD}$ analysis of the cancrinite seed in $8 \mathrm{M} \mathrm{NaOH}, 2 \mathrm{M} \mathrm{NaNO}$ and $2 \mathrm{M}$ $\mathrm{NaNO}_{2}, 0.15 \mathrm{M} \mathrm{Al}(\mathrm{III})$ solution as a function of dissolution time at $65{ }^{\circ} \mathrm{C}$ 


\subsection{SEEDED AND UNSEEDED CRYSTALLIZATION STUDIES}

\subsection{Seeded Crystallization: Secondary Nucleation and Particle Growth}

The main thrust of the work reported in this section was to investigate the mechanisms and kinetics of amorphous sodium aluminosilicate, zeolite A, sodalite and cancrinite seeded crystallization under conditions relevant to WSRC HLW evaporator processing and quantify kinetics of secondary nucleation and particle/crystal growth.

Isothermal seeded batch crystallizations were carried at 30,65 and $130{ }^{\circ} \mathrm{C}$ using wellcharacterized amorphous, zeolite A, sodalite and cancrinite seed particles of narrow size distribution. The seed charge and appropriate supersaturations were chosen such that either secondary nucleation or crystal growth substantially dominated the crystallization process over a specified period. For growth, the initial $\mathrm{SiO}_{2}$ relative supersaturation $(\sigma=(\mathrm{C}-$ $\mathrm{C}_{\text {equil }} / \mathrm{C}_{\text {equil }}$ ) was $<1$ for the zeolite $\mathrm{A}$, sodalite and cancrinite seed crystals and $\sim 0.5$ for the amorphous phase. For nucleation studies a $\sigma>1$ was characteristically used. Furthermore, appropriate crystallization times ranging from $1-4 \mathrm{~h}$ were used to suppress phase transformation. This ensures that the crystallographic characteristics of the seeds do not change during the experiment.

The seed crystal size analysis showed a unimodal size distribution with particles in $0.3-30.0$ $\mu \mathrm{m}$ range (Figure 51). Slurry samples periodically removed from the crystallizer were analyzed for $\mathrm{SiO}_{2}$ and $\mathrm{Al}$ (III) concentrations, magma density for crystal content, particle size distribution, BET surface area, XRD and SEM/TEM analyses.

\subsection{Results and Discussion}

\subsubsection{Secondary Nucleation}

Secondary nucleation phenomenon may be defined as the formation of sodium aluminosilicate nuclei (new colloidal size particles) through the interactions between sodium aluminosilicate solid seed or parent particles and solute species in supersaturated solutions. The secondary nuclei may be generated by a number of mechanisms including collision breeding, particle-particle contact nucleation, particle surface mediated-aluminosilicate clustering and dendritic attrition, all of which are facilitated by high degree of supersaturation (Li, Addai-Mensah and Prestidge, 2000). 
Typical results displaying secondary nucleation (dominant) and particle/crystal growth (minor) behavior are exemplified by solid-liquid heterogeneous crystallization runs carried out at an initial solution composition of $\mathrm{NaOH}=4 \mathrm{M}, \mathrm{NaNO}_{3}=1 \mathrm{M}, \mathrm{NaNO}_{2}=1 \mathrm{M}, \mathrm{SiO}_{2}=$ $0.175 \mathrm{M}, \mathrm{Al}(\mathrm{III})=0.188 \mathrm{M}$ and initial seed charge $=239.4 \mathrm{~m}^{2} / \mathrm{dm}^{-3}$ solution was used. This resulted in an initial relative supersaturation $\left(\mathrm{SiO}_{2}\right.$ or $\left.\mathrm{Al}(\mathrm{III})\right) \sigma=0.5$ for the amorphous particles at $65{ }^{\circ} \mathrm{C}$ and $\sim 5-20$ for zeolite, sodalite and cancrinite crystals. Characteristic product particle size analysis performed for sodalite seeded crystallization displayed the existence of bimodal particle size distributions after $3 \mathrm{~min}$, indicating the formation of secondary nuclei in the suspensions (Figure 51).

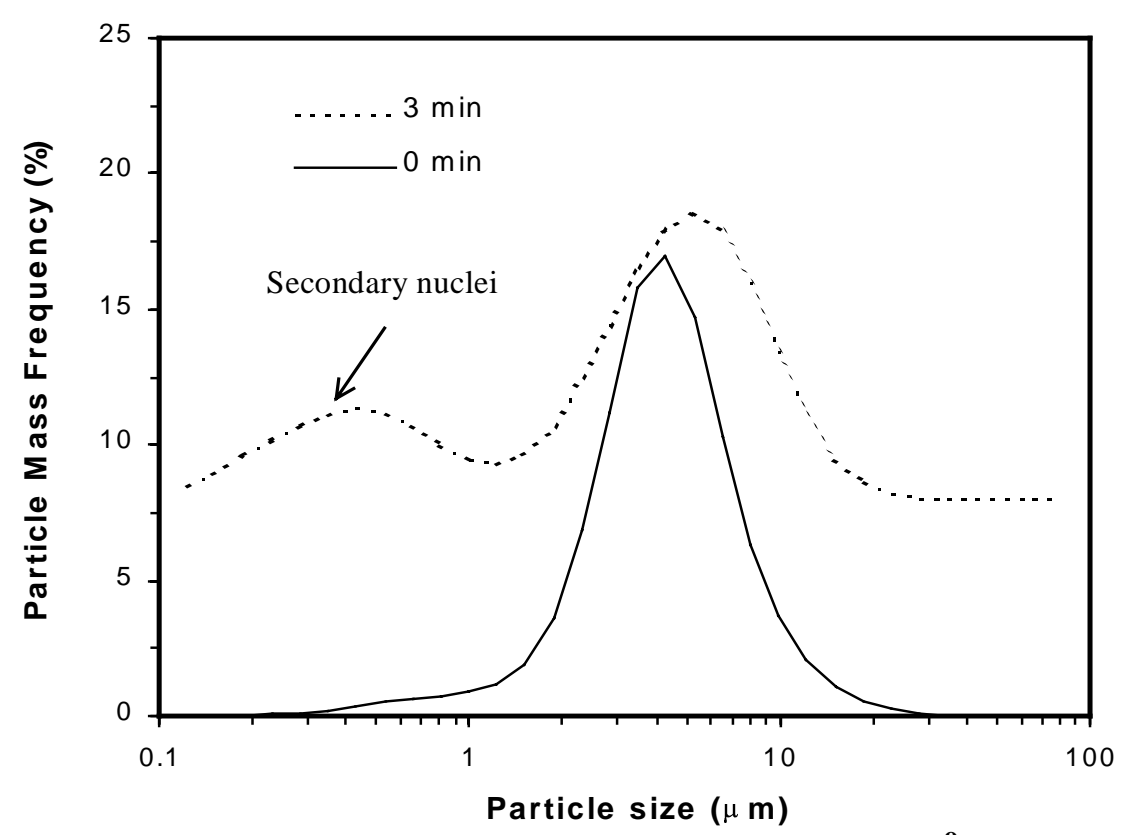

Figure 51 Size distributions for sodalite seeded suspensions at $65{ }^{\circ} \mathrm{C}$. Similar trend was observed for amorphous, zeolite $A$ and cancrinite seeded suspensions at 30, 65 and $130^{\circ} \mathrm{C}$

$\mathrm{SiO}_{2}$ and $\mathrm{Al}(\mathrm{III})$ concentrations decreased significantly at the very early stage of crystallization for all types of seeded liquors. Over long crystallization times $(>150 \mathrm{~h})$, the desilication of the liquors as reflected by $\mathrm{SiO}_{2}$ and $\mathrm{Al}(\mathrm{III})$ concentration profiles, indicated that the $\mathrm{SiO}_{2}$ and $\mathrm{Al}(\mathrm{III})$ species disappeared from solution at the same rate (Figure 52). 


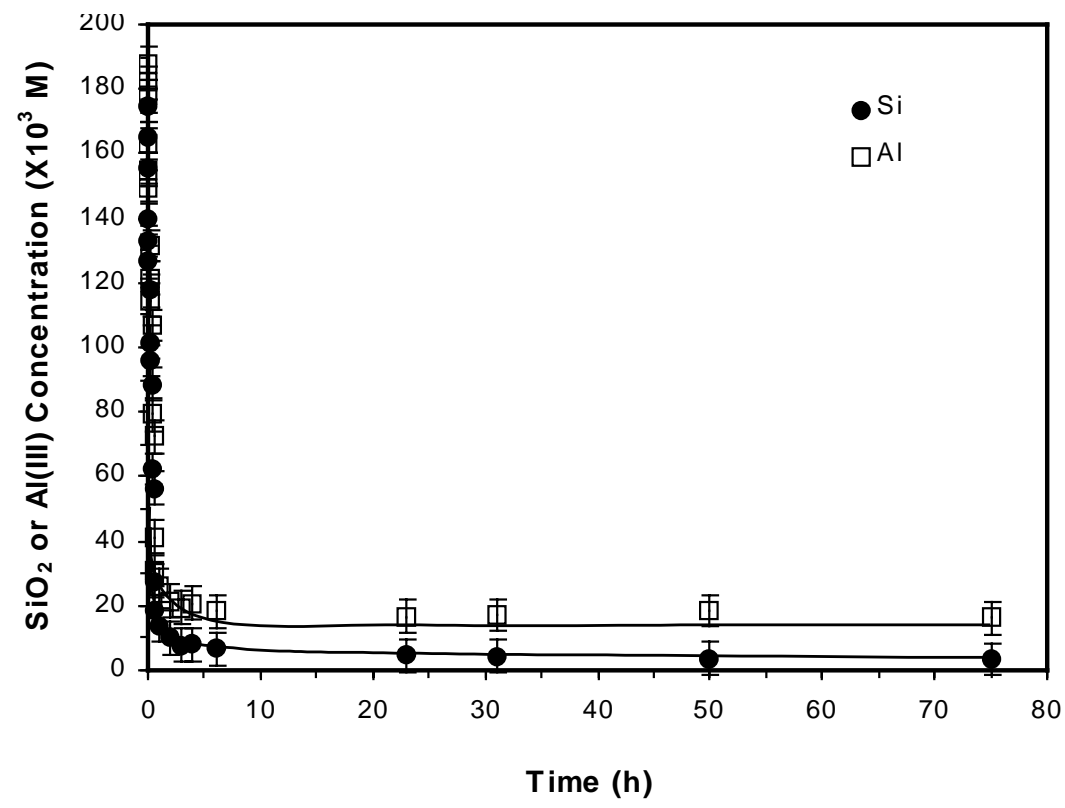

Figure 52 Desupersaturation for amorphous suspension at $65{ }^{\circ} \mathrm{C}$. Similar trends were observed for zeolite, sodalite and cancrinite seeded suspensions

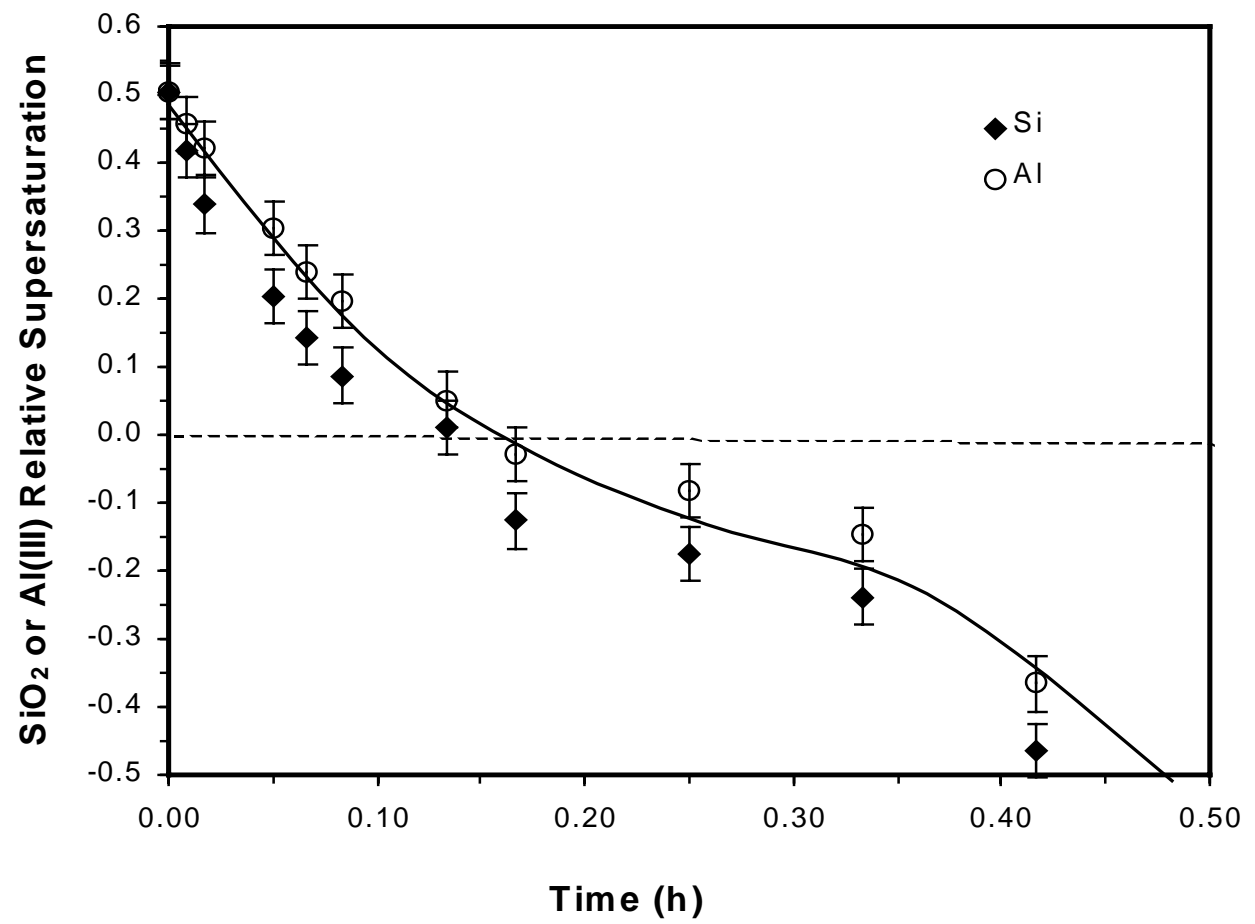

Figure 53 Desupersaturation of amorphous suspension at $65^{\circ} \mathrm{C}$ 


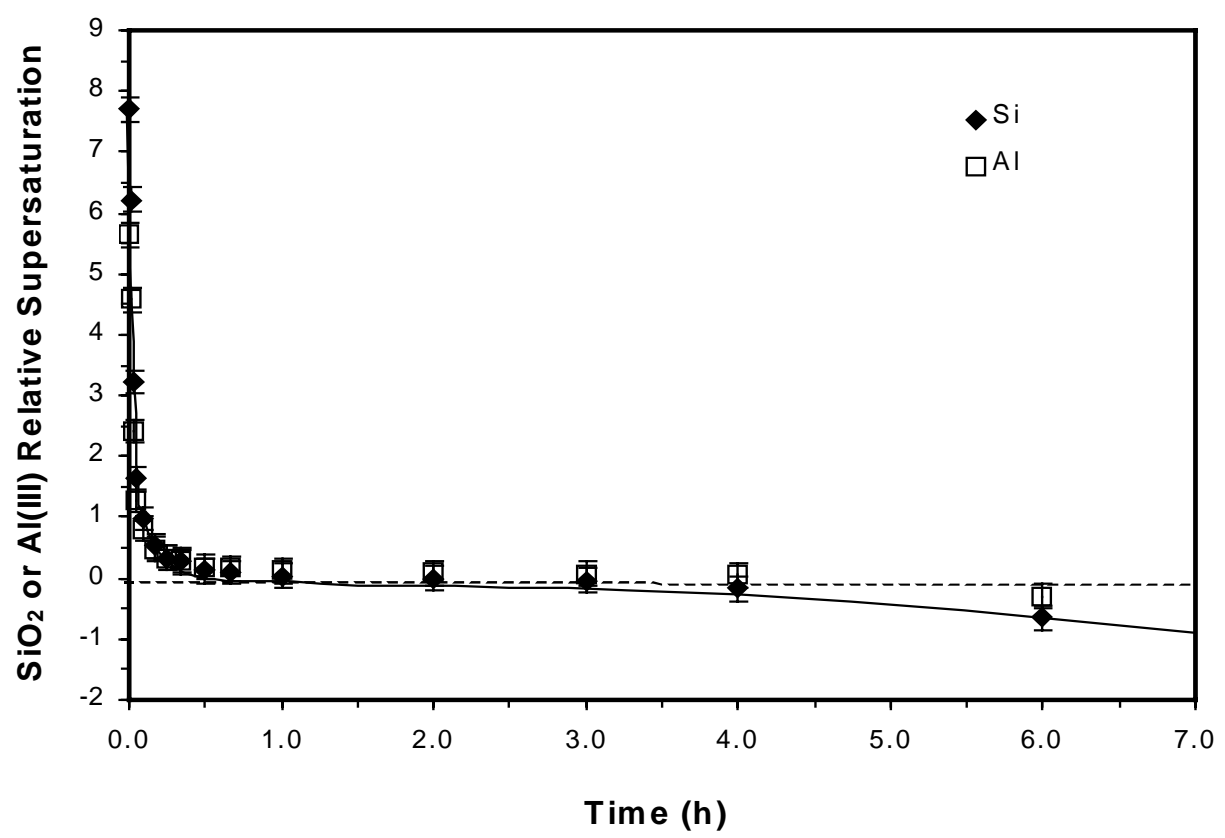

Figure 54 Relative supersaturation for zeolite A suspension at $65^{\circ} \mathrm{C}$

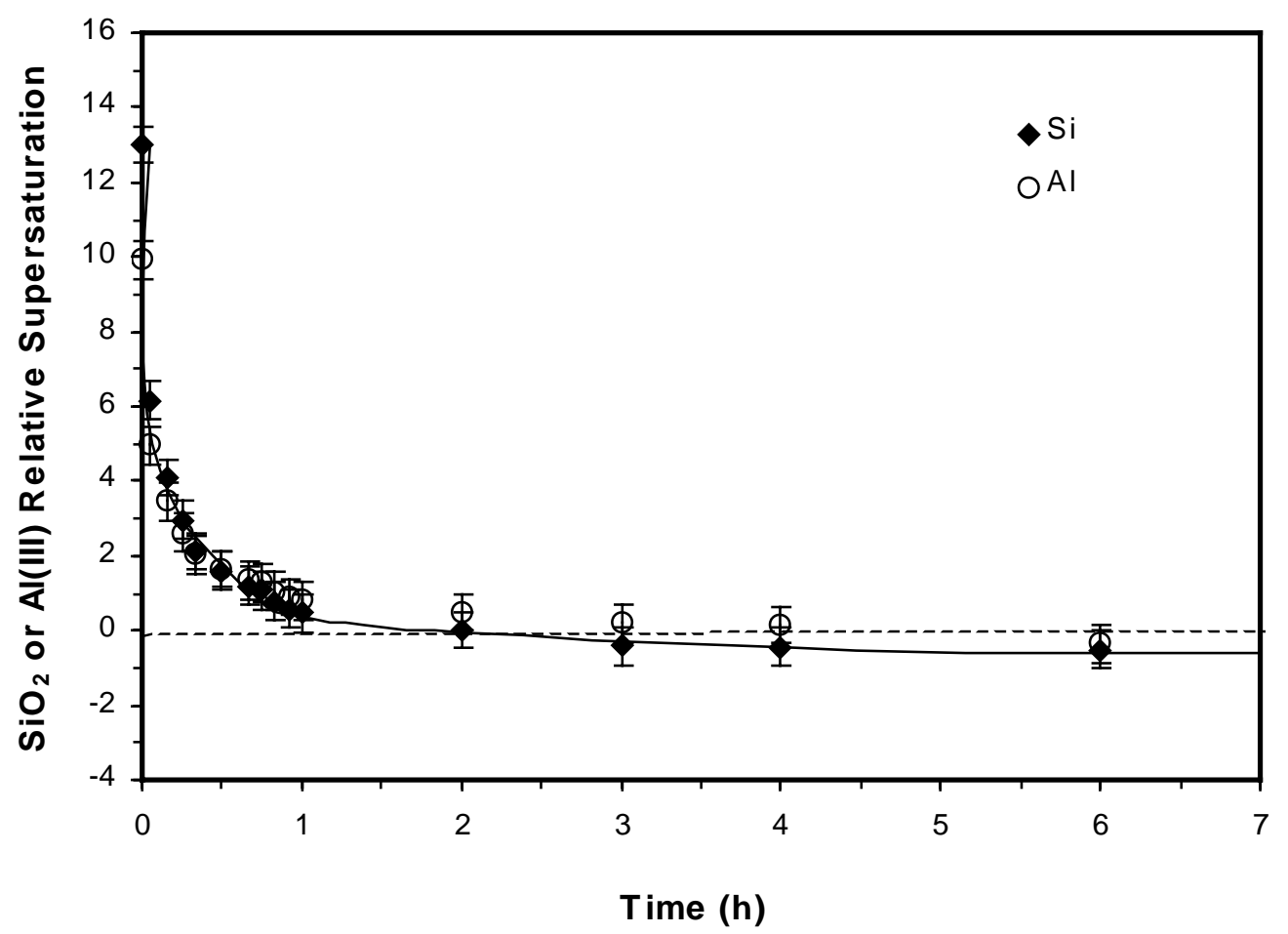

Figure 55 Relative supersaturation for sodalite solution at $65^{\circ} \mathrm{C}(\mathrm{NaOH}=4 \mathrm{M}$, $\mathrm{NaNO}_{3}=1 \mathrm{M}, \mathrm{NaNO}_{2}=1 \mathrm{M}$, initial $\mathrm{SiO}_{2}=0.175 \mathrm{M}, \mathrm{Al}(\mathrm{III})=0.188 \mathrm{M}, \sigma_{\mathrm{Si}}=13.0, \sigma_{\mathrm{Al}}=9.9$ and initial seed charge $=1.28 \mathrm{~g} \mathrm{dm}^{-3}=239.4 \mathrm{~m}^{2} \mathrm{dm}^{-3}$ ) which is same as previous figures 


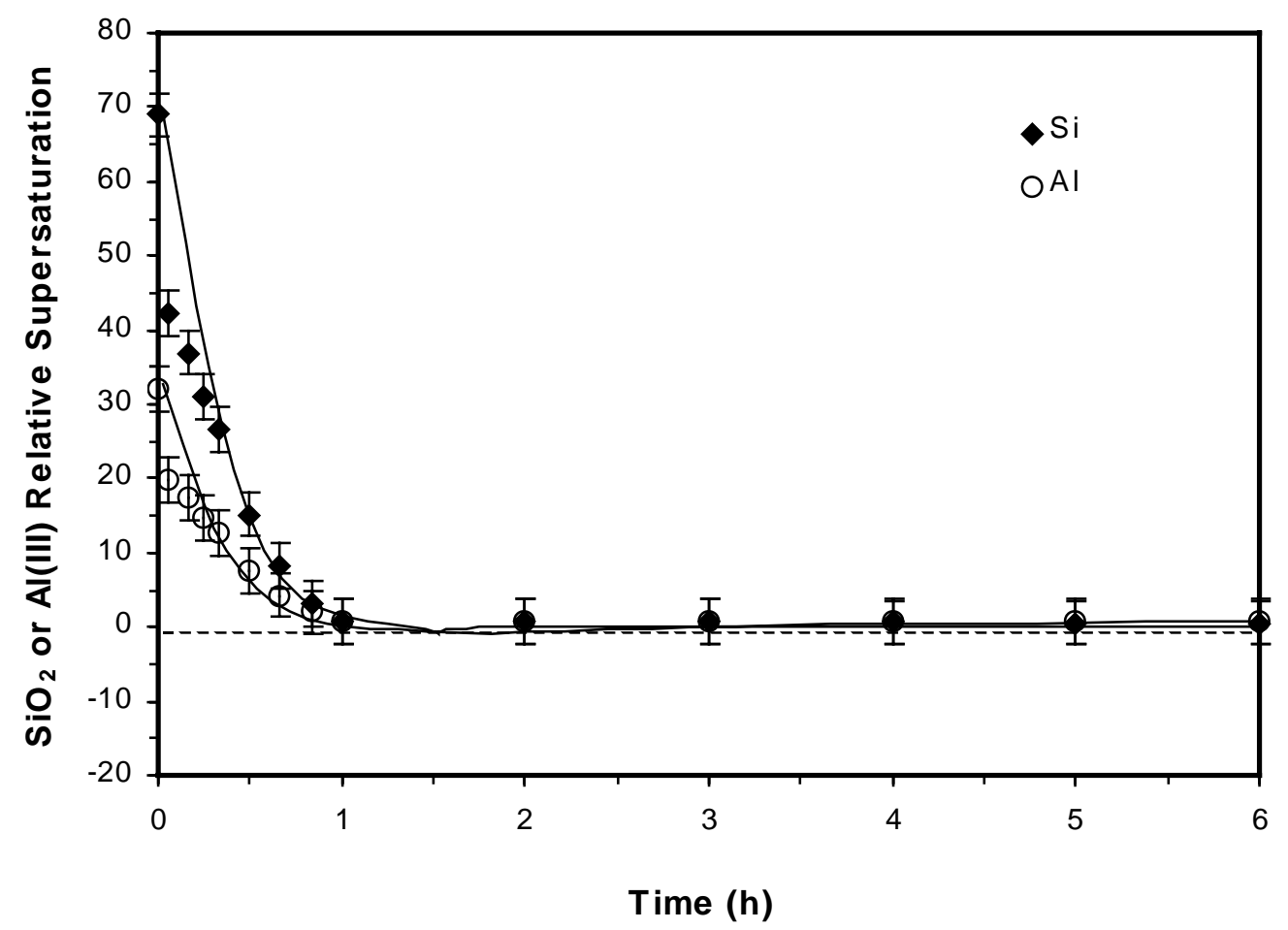

Figure 56 Relative supersaturation for cancrinite solution at $65^{\circ} \mathrm{C}$ and initial seed charge $=5.28 \mathrm{~g} \mathrm{dm}^{-3}=239.4 \mathrm{~m}^{2} \mathrm{dm}^{-3}$ )

Due to the differences in solubilities of the solid phases, the initial $\sigma$ was lowest for amorphous, followed by zeolite and then sodalite, and highest for cancrinite for all solutions at a constant ionic strength and solution composition. Typical variation of relative supersaturation with crystallization time for all four types of sodium aluminosilicate solid phases in identical solutions at $65^{\circ} \mathrm{C}$ is exhibited in Figure 57.

The results showed that the initial relative supersaturation decreased as follows: cancrinite > sodalite > zeolite A > amorphous solid. The rate of desupersaturation and approach to equilibrium solubility followed an opposite trend as: amorphous solid > zeolite A > sodalite $>$ cancrinite. This finding suggests that the under current sodium aluminosilicate crystallization conditions the chemical reaction kinetics or rate processes drive the crystallization mechanisms more strongly over a short time scale $(<8$ h) than the thermodynamics. 


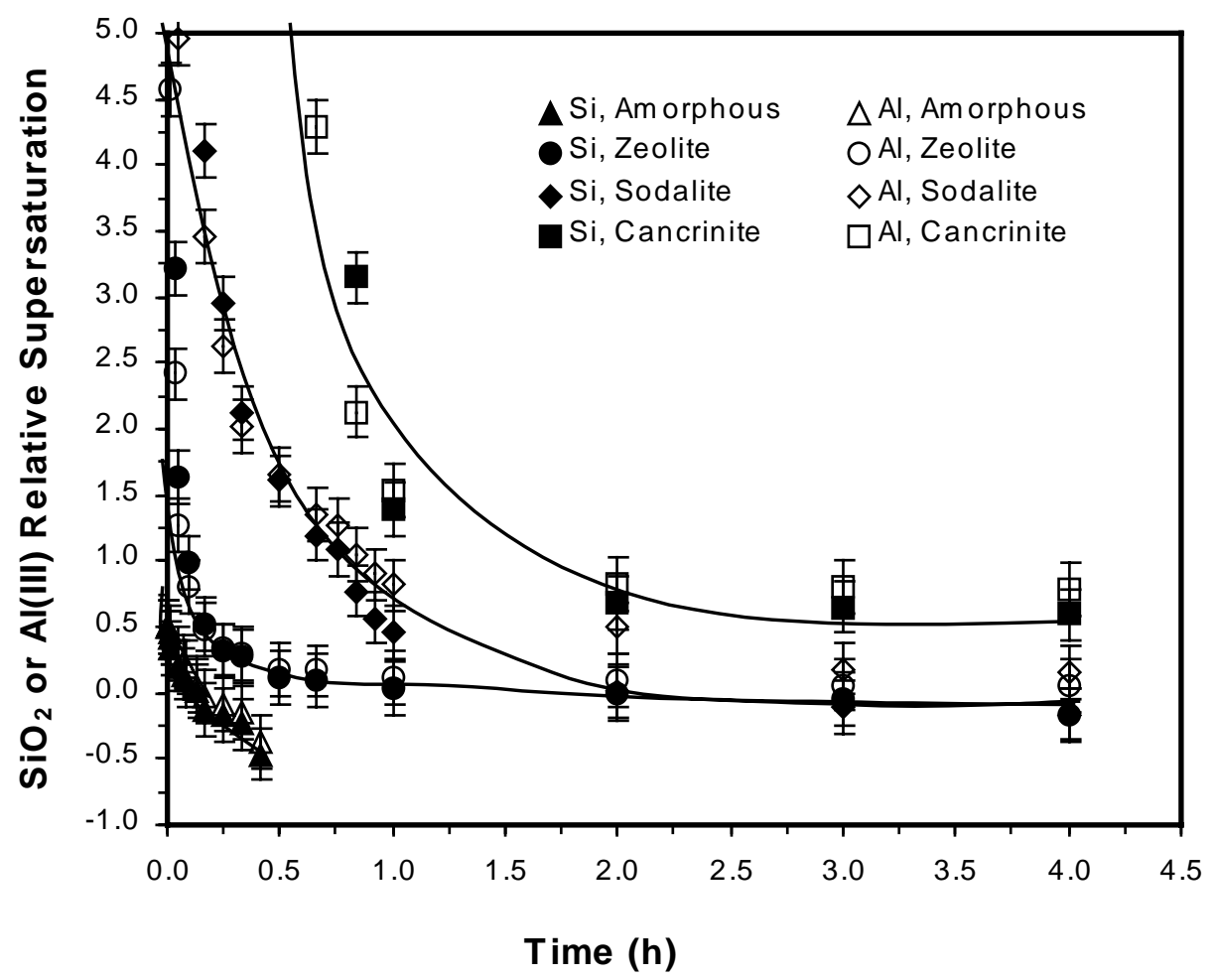

Figure $57 \quad$ Relative supersaturation as a function of solid phase in suspension at 65 ${ }^{\circ} \mathrm{C}\left(\mathrm{NaOH}=4 \mathrm{M}, \mathrm{NaNO}_{3}=1 \mathrm{M}, \mathrm{NaNO}_{2}=1 \mathrm{M}\right.$, initial $\mathrm{SiO}_{2}=0.175 \mathrm{M}, \mathrm{Al}(\mathrm{III})=0.188 \mathrm{M}$ and initial seed charge $=239.4 \mathrm{~m}^{2} \mathrm{dm}^{-3}$ )

The effect of temperature on the seeded desilication behavior are shown in Figures 58 and 59. The results indicate that the desilication reactions underpinning secondary nucleation and particle growth are strongly temperature dependent. The desilication rate increased considerably with increasing temperature as indicated in Figure 58 and Figure 59. 


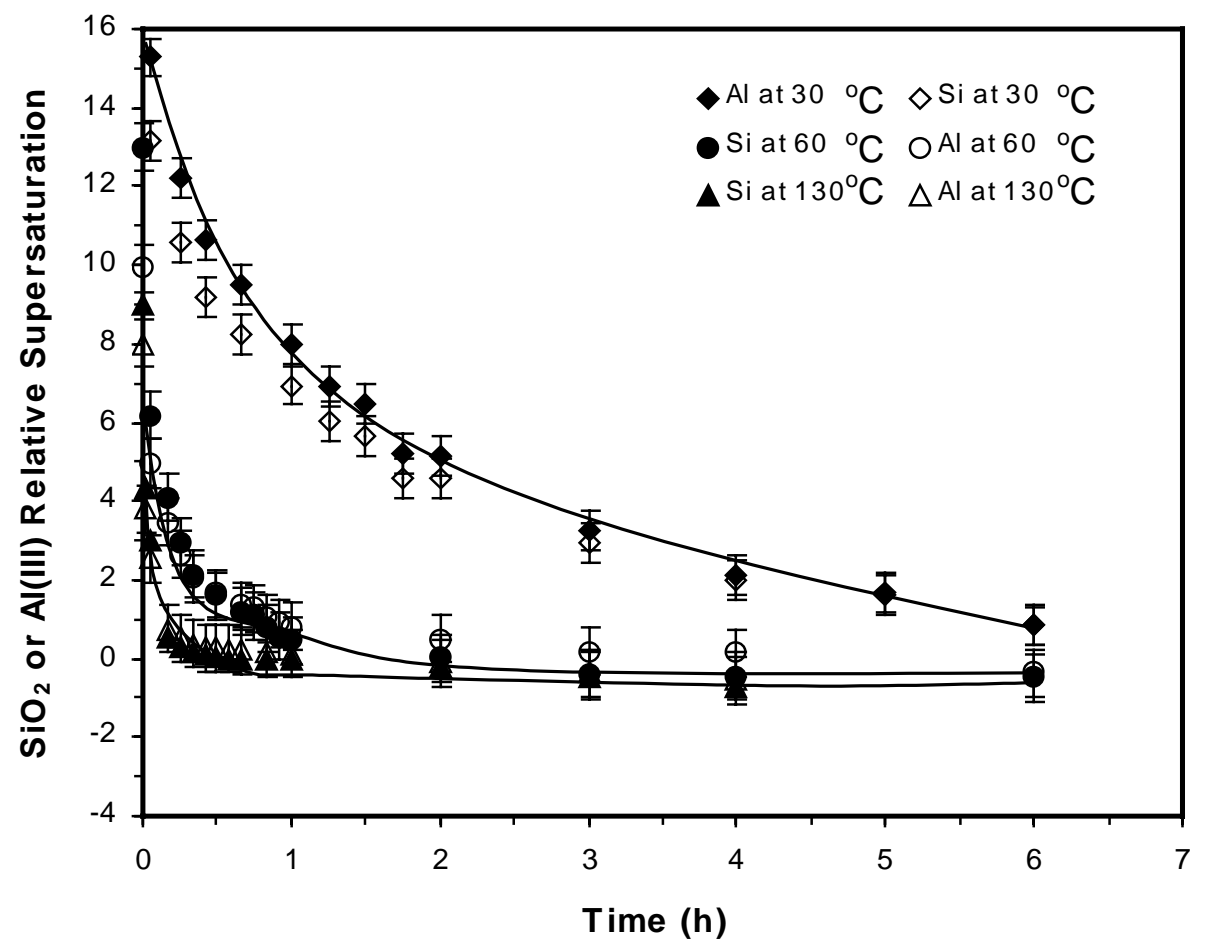

Figure 58 Relative supersaturation versus temperature for sodalite seeded solution

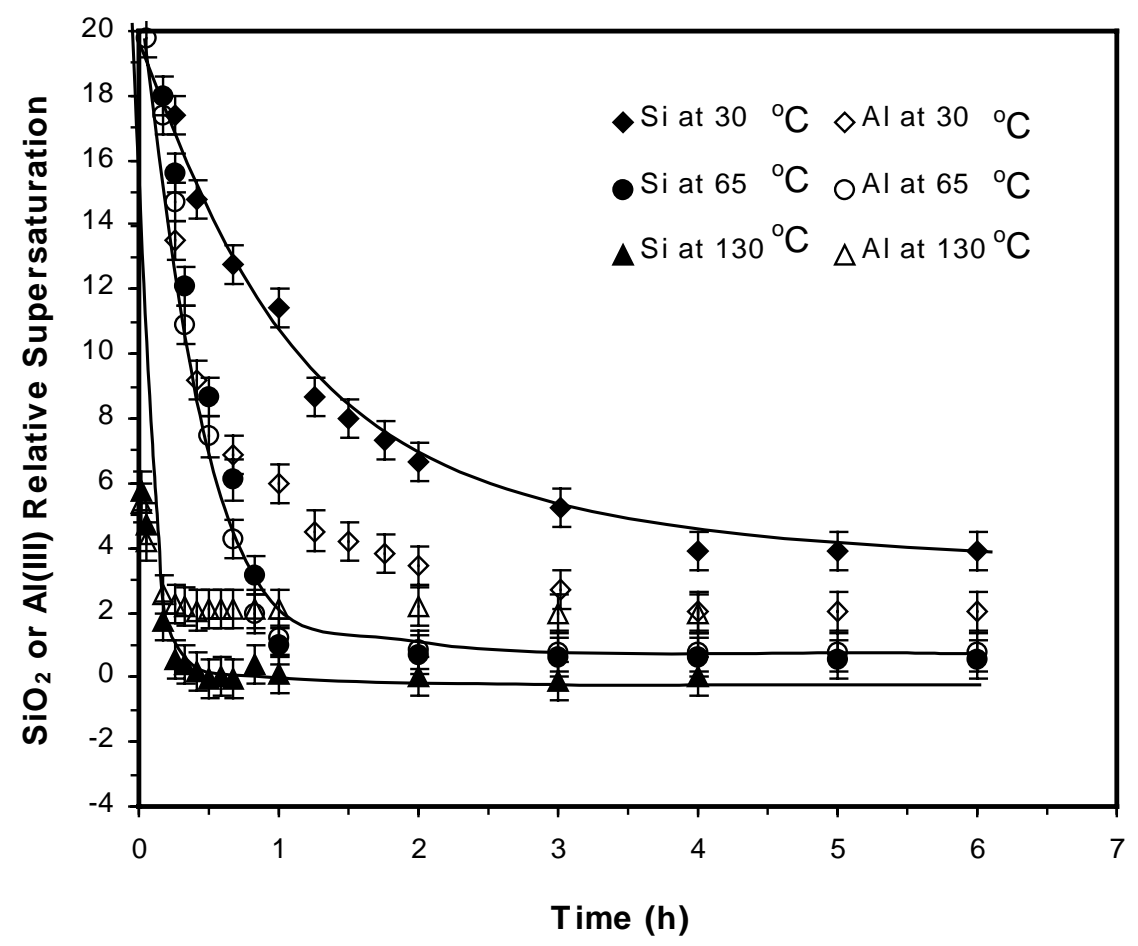

Figure 59 Relative supersaturation versus temperature for cancrinite system

As a consequence of the differences in the BET specific surface area of the seed particles different seed masses were used to achieve identical total particle surface area at the start of 
crystallization. Upon seeding the solid content changed at a rate which rapidly increased with increasing temperature as expected. In Figures 60-63 the initial and instantaneous magma densities are shown for crystallization at 3065 and $130{ }^{\circ} \mathrm{C}$, respectively. The change in solid content with time matched the liquor desupersaturation behavior very well during the seeded crystallization. The variation in seed mass and hence the number of primary particles may exert some influence on particle-particle interactions/collisions during secondary nucleation.

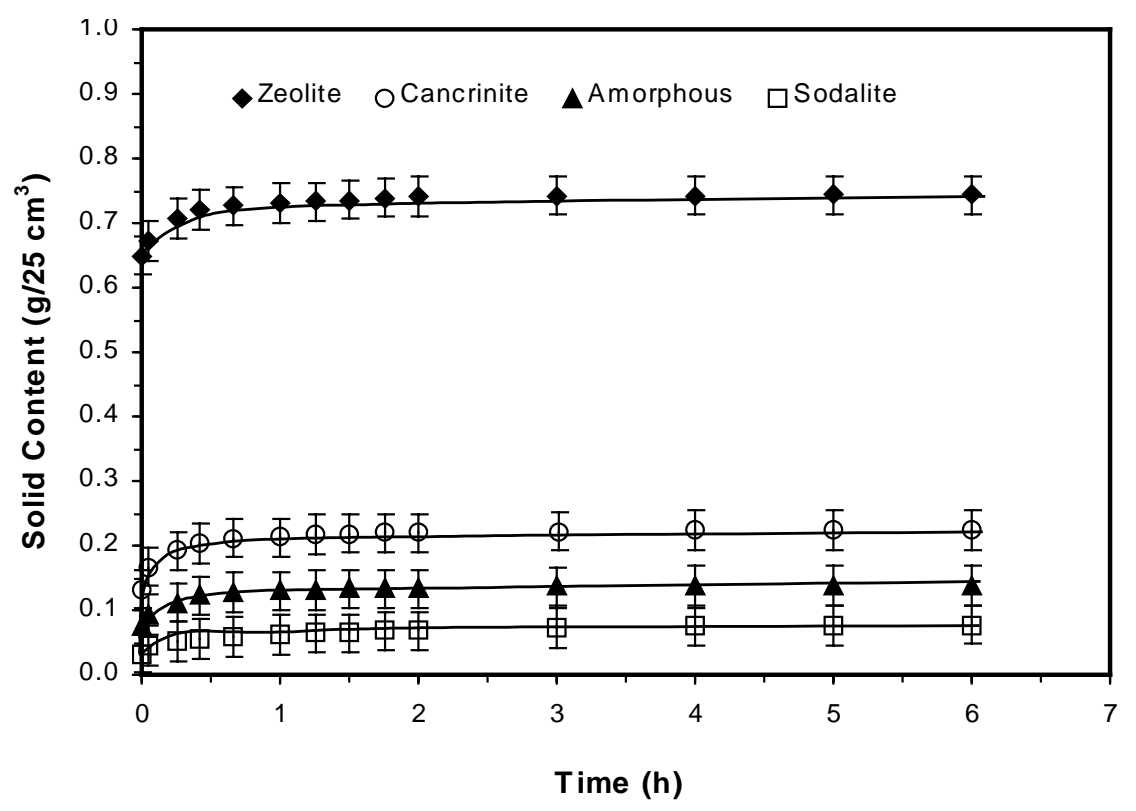

Figure 60 Solid content of seeded suspensions at $30^{\circ} \mathrm{C}$ as a function of aging time Differing seed charges were used to achieve similar total seed surface area for all solid phases

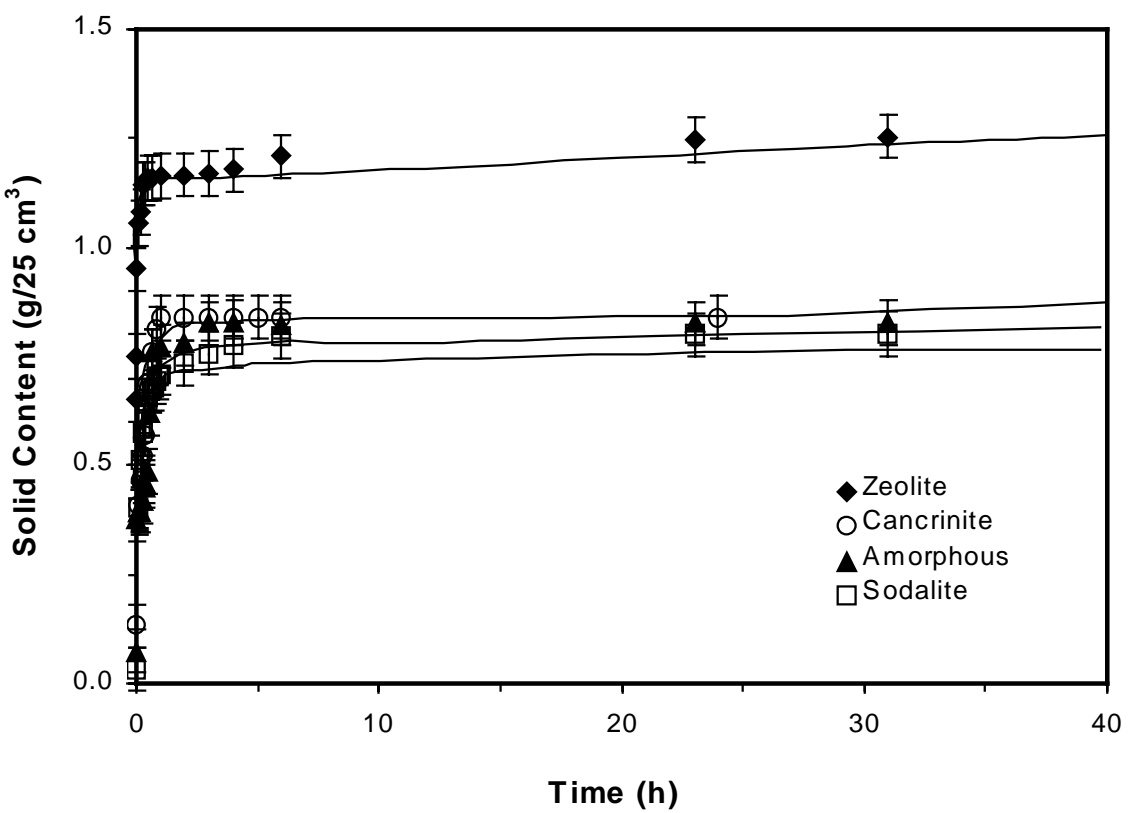

Figure 61 Solid content of seeded suspensions at $65^{\circ} \mathrm{C}$ 


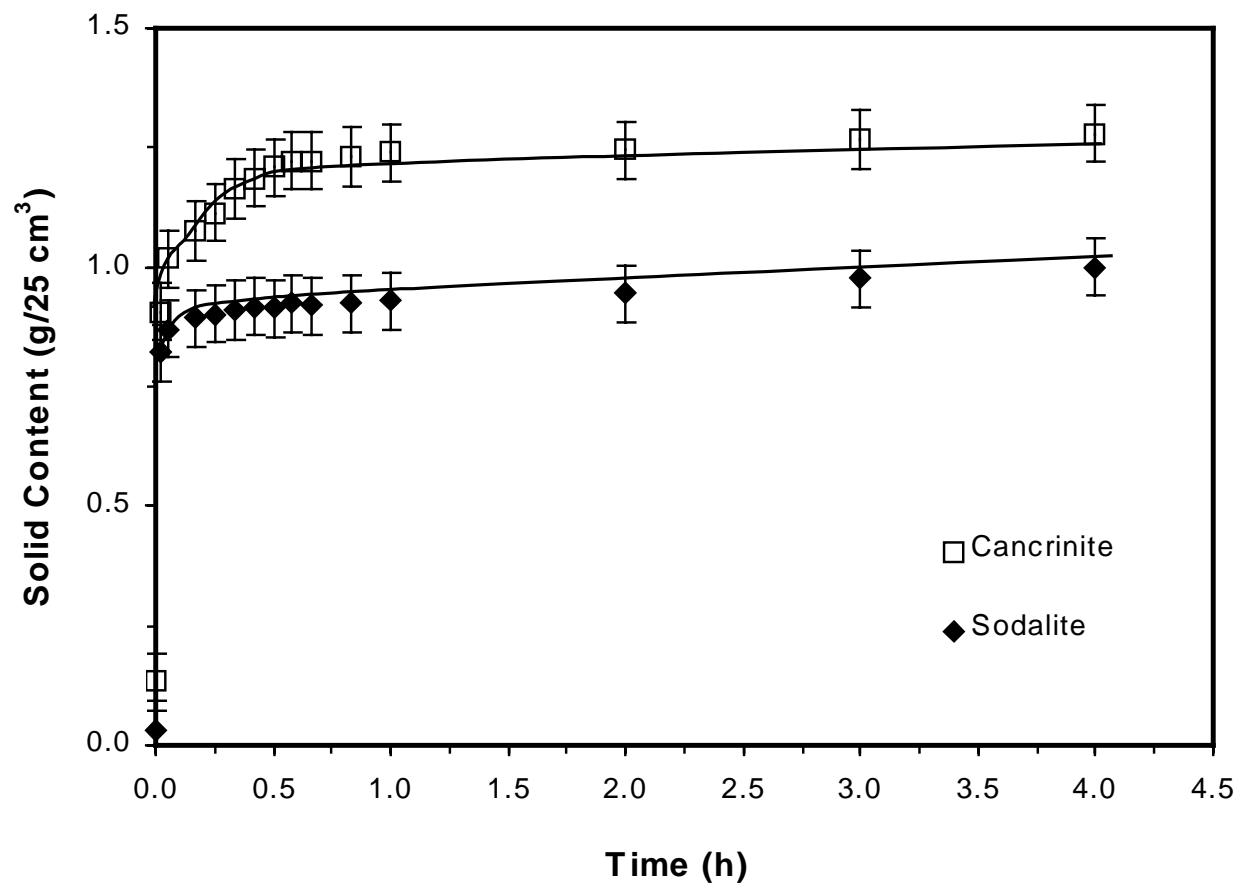

\section{Figure 62 Solid content of seeded suspensions at $130{ }^{\circ} \mathrm{C}$}

The evolution of solid particle surface area with time was characterized in all seeded crystallization runs. The net total crystal surface area significantly increased over an initial period as a consequence of secondary nucleation before reaching a plateau (Figure 63-65). At a specific and fixed suspension conditions the final total surface area (S) followed the sequence:

$$
\mathrm{S}_{\text {cancrinite }}>\mathrm{S}_{\text {sodalite }}>\mathrm{S}_{\text {zeolite }}>\mathrm{S}_{\text {amorphous }} \text {. }
$$

The same initial seed surface areas (e.g. $239.4 \mathrm{~m}^{2} \mathrm{dm}^{-3}$ ) were used under conditions where the relative supersaturation followed the same order as the solid product total surface area (i.e. $\sigma_{\text {cancrinite }}>\sigma_{\text {sodalite }}>\sigma_{\text {zeolite }}>\sigma_{\text {amorphous }}$ ). The increase in surface area reflecting the massive increase in ultra-fine particle number by secondary nucleation and the degree of supersaturation are directly linked. Namely, the change in relative $\mathrm{SiO}_{2}$ flux $(\sigma /$ total particle surface area) with time, indicative of supersaturation-influenced desilication kinetics (Figures 66-67), followed the sequence below:

$\Delta \mathrm{SiO}_{2}$ flux $_{\text {cancrinite }}>\Delta \mathrm{SiO}_{2}$ flux $_{\text {sodalite }}>\Delta \mathrm{SiO}_{2}$ flux $_{\text {zeolite }}>\Delta \mathrm{SiO}_{2}$ flux $_{\text {amorphous }}$ 
This indicates that at identical solution composition and ionic strength, the nucleation rate was highest in the presence of the least soluble phase, cancrinite, where the initial supersaturation was greatest. The rate was lowest for most soluble amorphous phase, where the initial supersaturation was also lowest. In the absence of solid phase transformation over 6h precipitation for all seeded systems, the increase in the total particle surface area was found to be considerably greater at the higher than lower temperature (e.g. 65 versus $30{ }^{\circ} \mathrm{C}$ ). This observation suggests the nucleation rate increased with increasing temperature. However, in some instances, the difference in the total particle surface area at 65 and $130{ }^{\circ} \mathrm{C}$ was quite subtle, indicating the possible impact of agglomeration at high temperatures. Particle agglomeration may occur at very high supersaturations and high temperatures where fast crystal/particle growth kinetics prevails, leading to a marked decrease in total surface area which offsets any increase caused by secondary nucleation.

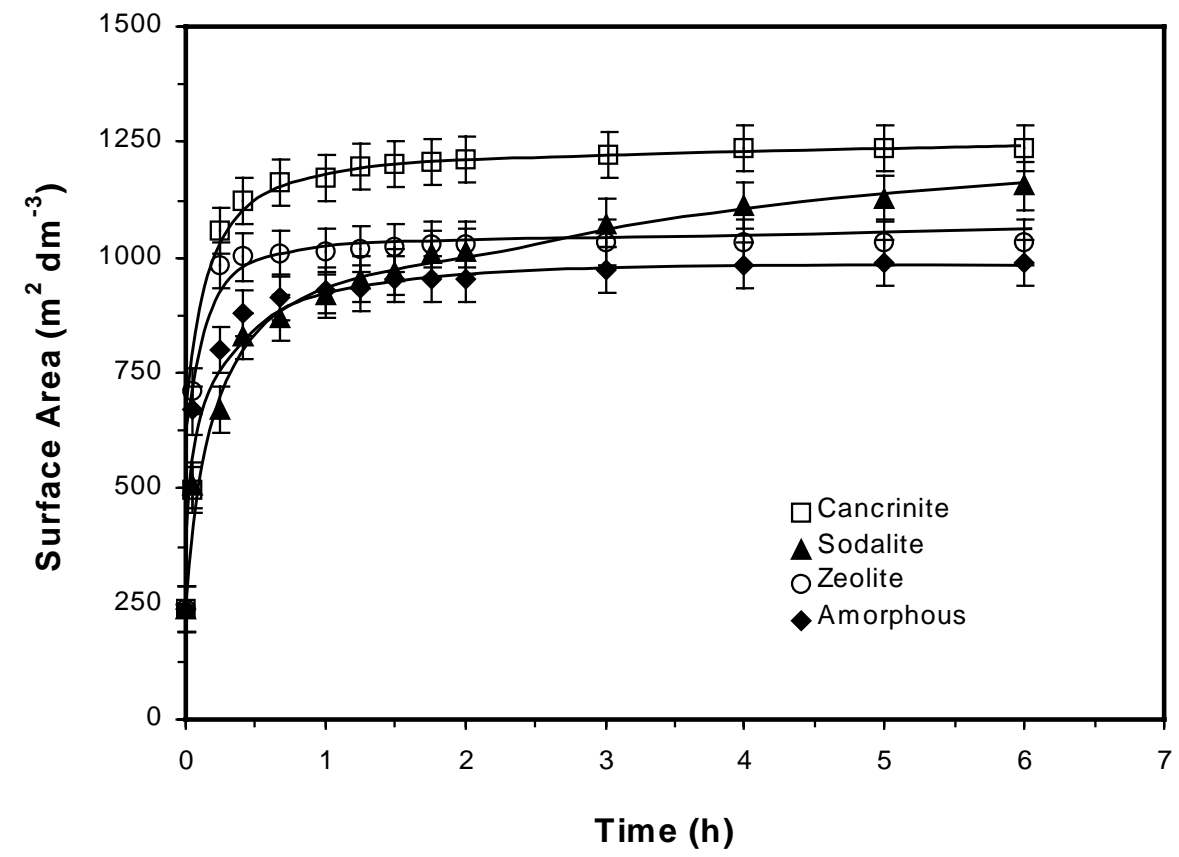

Figure 63 Surface area per unit volume of suspension in the crystallizer as a function of time at $30{ }^{\circ} \mathrm{C} 7$ 


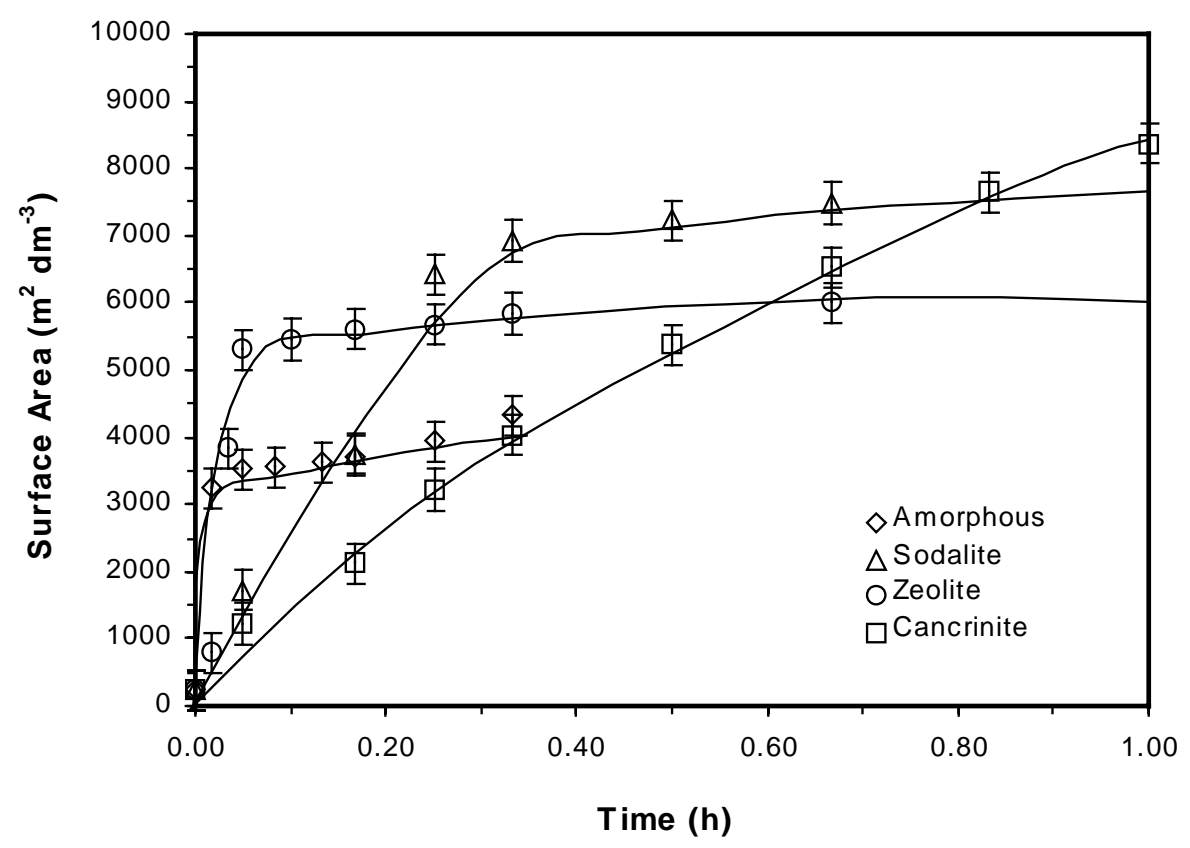

Figure 64 Surface area per unit volume of suspension in the crystallizer as a function of time at $65^{\circ} \mathrm{C}$

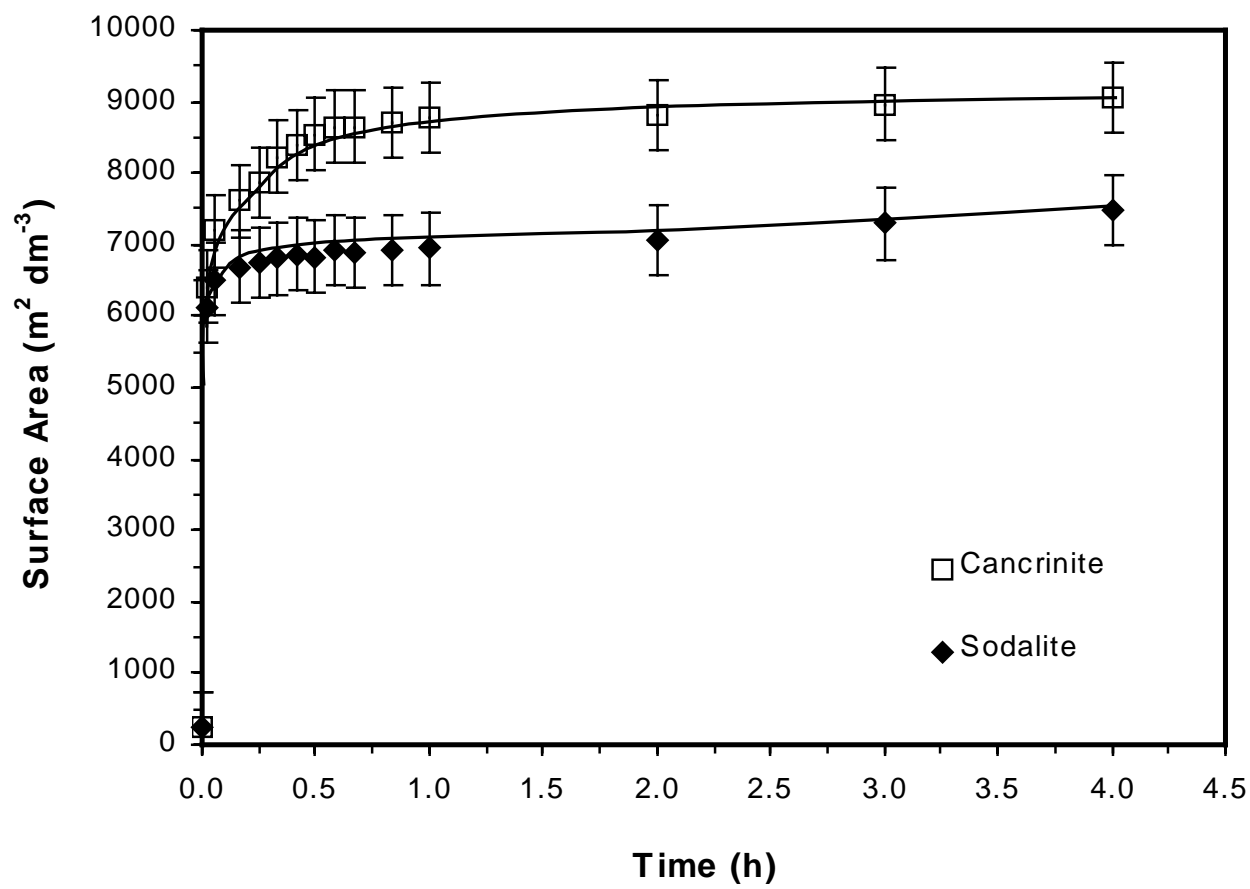

Figure 65 Surface area per unit volume of suspension in the crystallizer as a function of time at $130{ }^{\circ} \mathrm{C}$ 


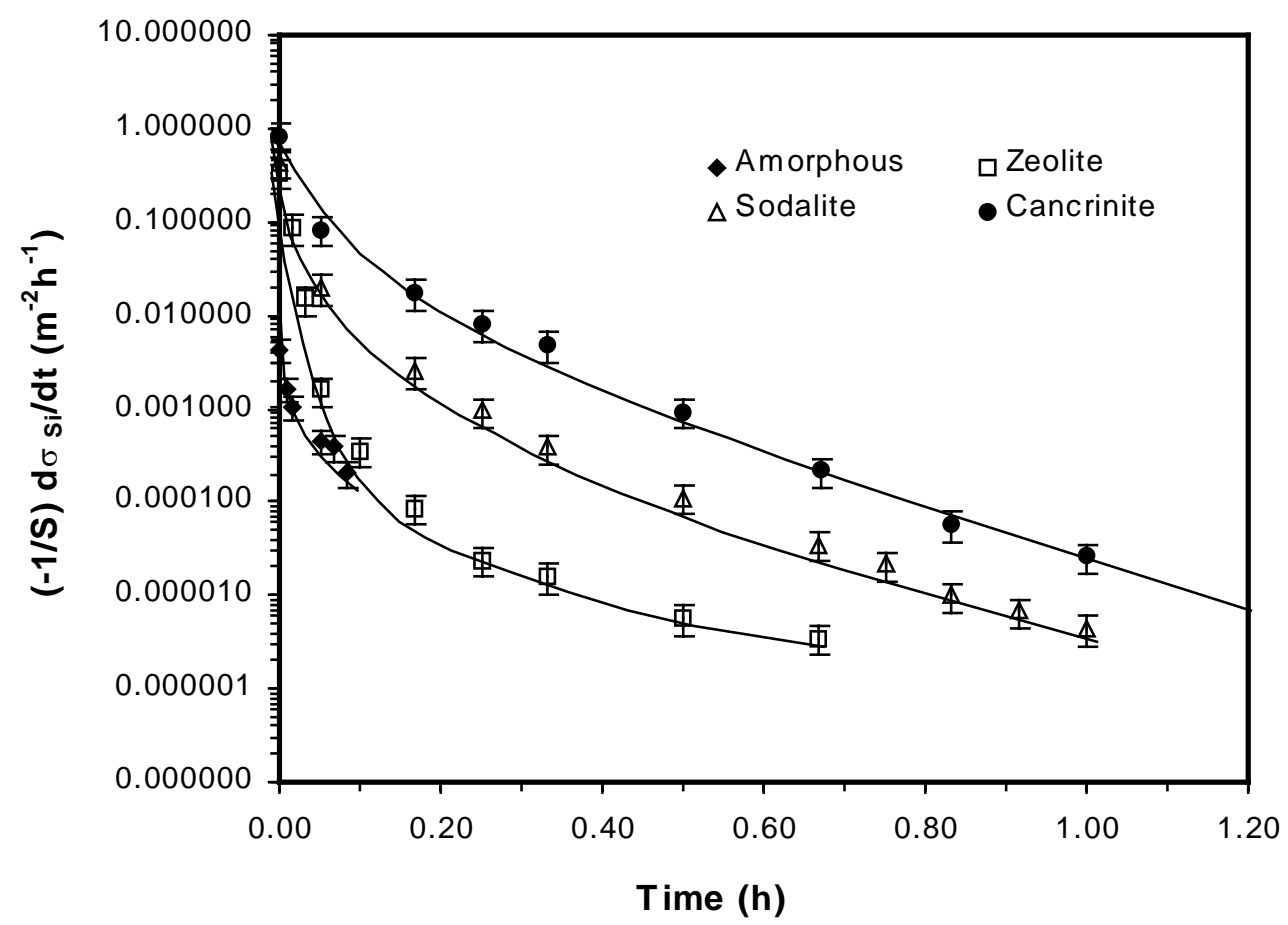

Figure 66 Flux change for different seeded crystallizations at $65{ }^{\circ} \mathrm{C}$

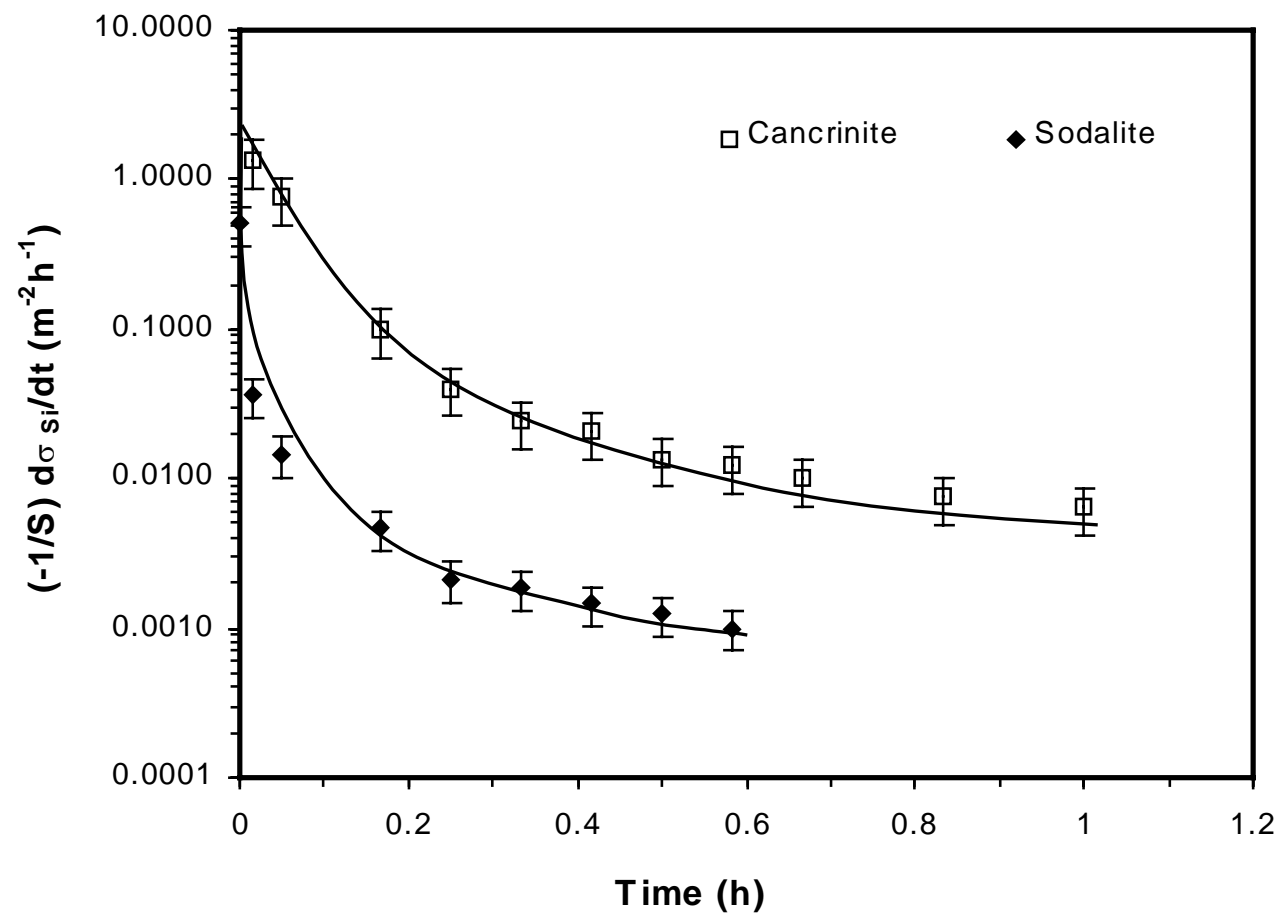

Figure 67 Flux change for different seeded crystallization at $130{ }^{\circ} \mathrm{C}$

\subsubsection{Growth of Amorphous and Crystalline Seed Particles}

Isothermal seeded batch crystallization during which pure growth (with no detectable secondary nucleation) of all phases occurred in solutions with similar initial $\sigma_{\mathrm{Si}}=0.5$ and $\sigma_{\mathrm{Al}}$ 
$=0.5,\left(\mathrm{NaOH}=4 \mathrm{M}, \mathrm{NaNO}_{3}=1 \mathrm{M}, \mathrm{NaNO}_{2}=1 \mathrm{M}\right.$, and initial seed charge $\left.=119.7 \mathrm{~m}^{2} \mathrm{dm}^{-3}\right)$ were performed at 30,65 and $130{ }^{\circ} \mathrm{C}$. The low initial driving force $\left(\sigma_{\mathrm{Si}}=0.5\right.$ and $\left.\sigma_{\mathrm{Al}}=0.5\right)$ used was sufficient for the suppression of both heterogeneous and secondary nucleation.

Growth is defined as size enlargement of a particulate matter resulting from surface integration or layering of ordered molecular size sodium aluminosilicate species or clusters via poly-condensation or cross-linking and ionic interactions. Particulate matter is referred to sodium aluminosilicate solid particles whose size is measurable (>25 nm) by present particle size measuring techniques. This particle growth mechanism excludes agglomeration involving aggregation and cementation of pre-existing particles that results in a decrease in particulate matter number density.

$\mathrm{SiO}_{2}$ and $\mathrm{Al}(\mathrm{III})$ concentration decreased with crystallization time at a similar rate (Figure 68) with a concomitant increase in solid content with time Figure 69. Zeolite A exhibited the highest crystal content in comparison with the other solid phases due to its higher initial seed mass (Figure 69). At constant initial supersaturation $(\sigma=0.5)$ solution, the desilication behavior due to seed particles growth was strongly seed phase dependent. For the crystalline particles the total crystal surface area increased due to crystal growth with the initial rate of increase in the surface area following the sequence: $\mathbf{S}_{\text {zeolite }}>\mathbf{S}_{\text {sodalite }}>\mathbf{S}_{\text {cancrinite }}$ (Figure 70). The amorphous seeded system showed the greatest desupersaturation rate whilst a cancrinite seeded system exhibited the slowest desupersaturation rate (Figure 71). 


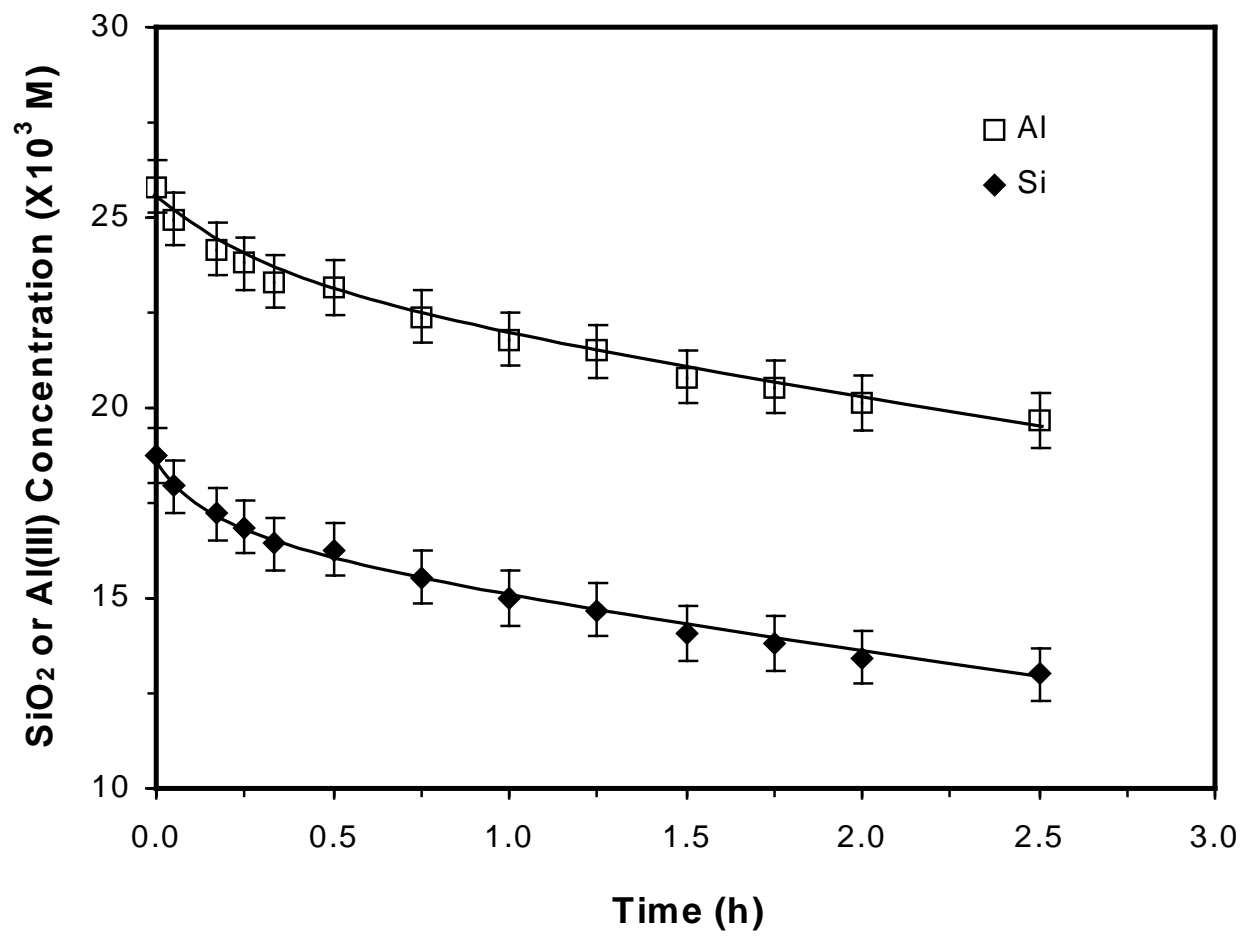

Figure 68 Desupersaturation for a sodalite seeded solution at $65{ }^{\circ} \mathrm{C}$

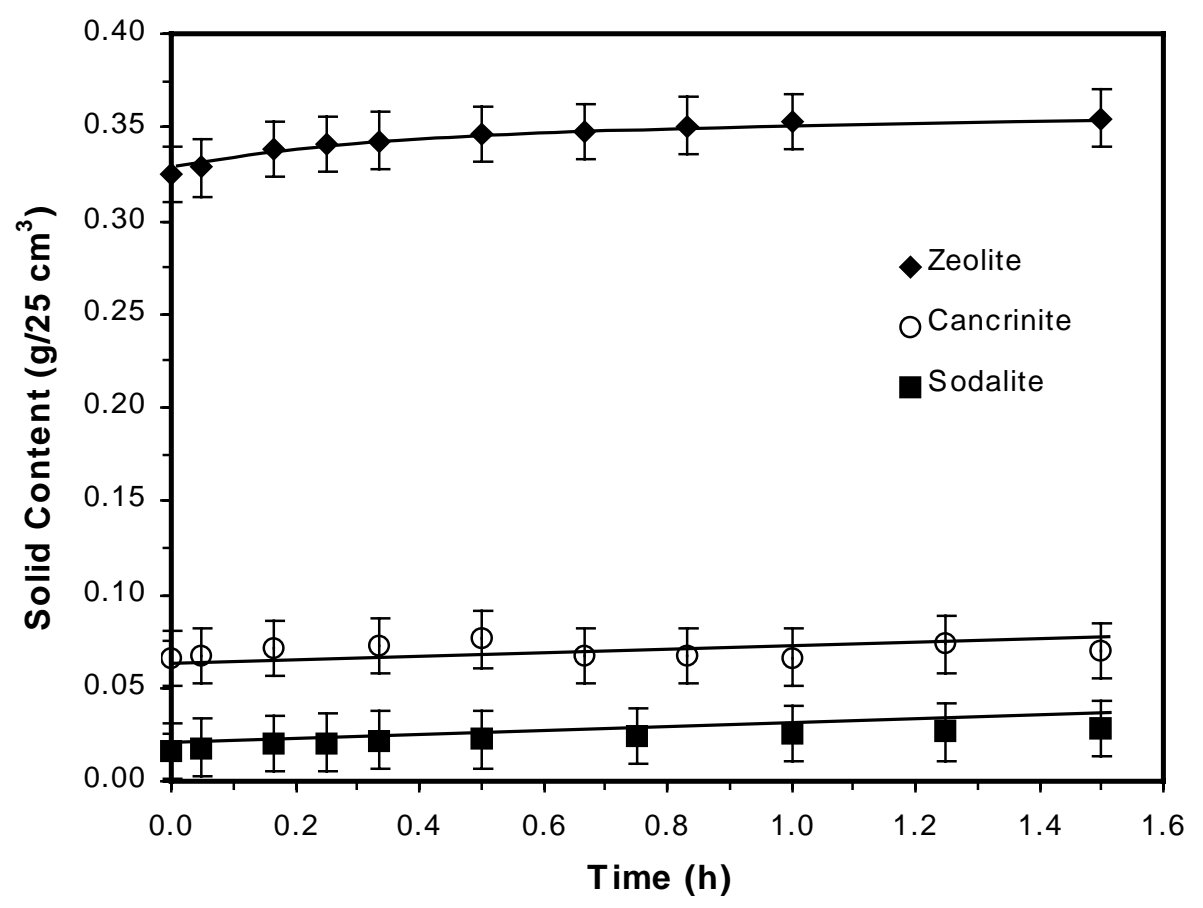

Figure 69 Solid content of seeded solutions at $65^{\circ} \mathrm{C}$ as a function of aging time 


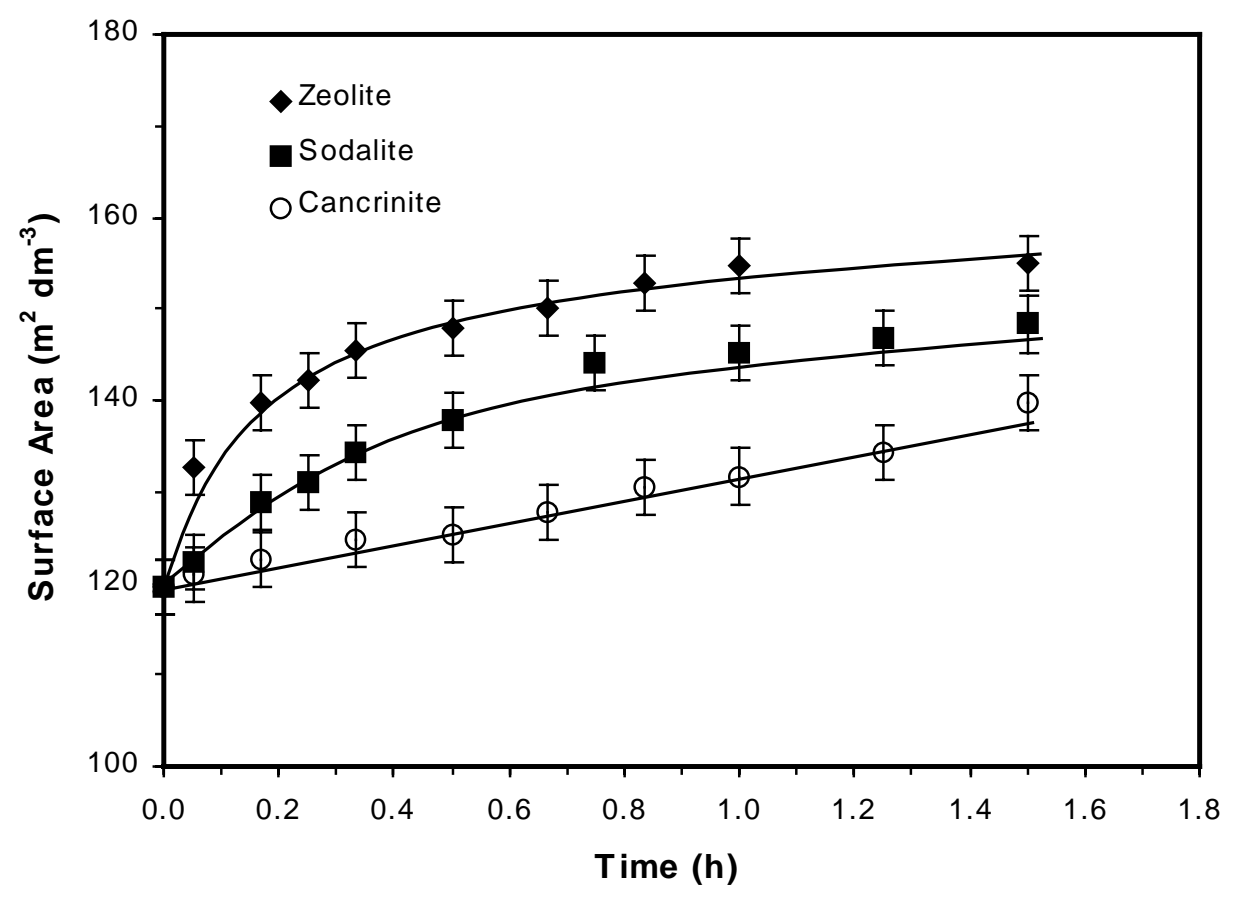

Figure 70 Surface area per unit volume of suspension in the crystallizer as a function of time at $65^{\circ} \mathrm{C}$

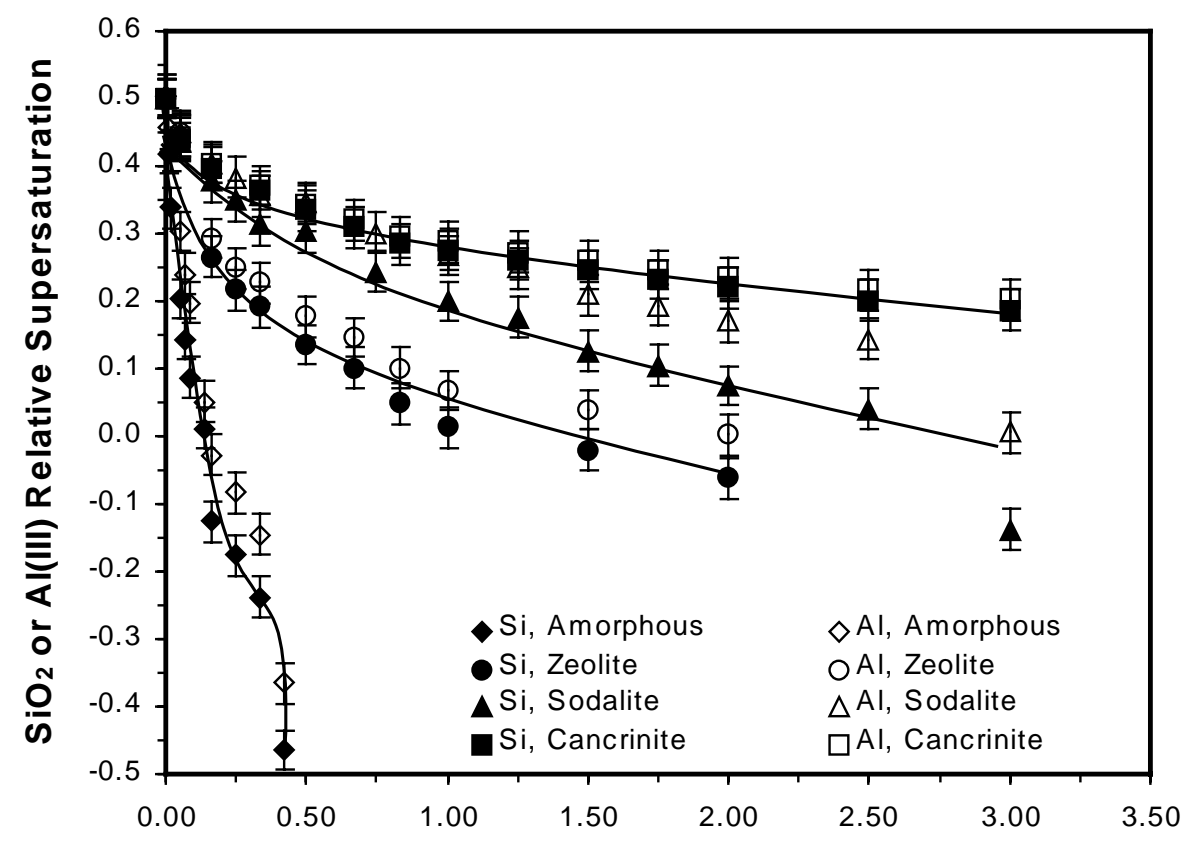

Time (h)

Figure 71 Relative supersaturation for seeded sodium aluminosilicate solutions as a function of solid phase at $65^{\circ} \mathrm{C}$

It is evident that in the presence of amorphous seed crystals that solubility can be reached and exceeded within a short time, e.g. $0.25 \mathrm{~h}$ at $65{ }^{\circ} \mathrm{C}$, as shown in Figure 71. The analysis of the data for the dependence of liquor desupersaturation on temperature indicated that the highest 
and lowest rates occurred at 130 and $30{ }^{\circ} \mathrm{C}$, respectively (Figure 72). This finding underscores the fact that the overall crystal growth process is strongly chemical reaction controlled requiring elevated temperatures to facilitate the rapid surface integration.

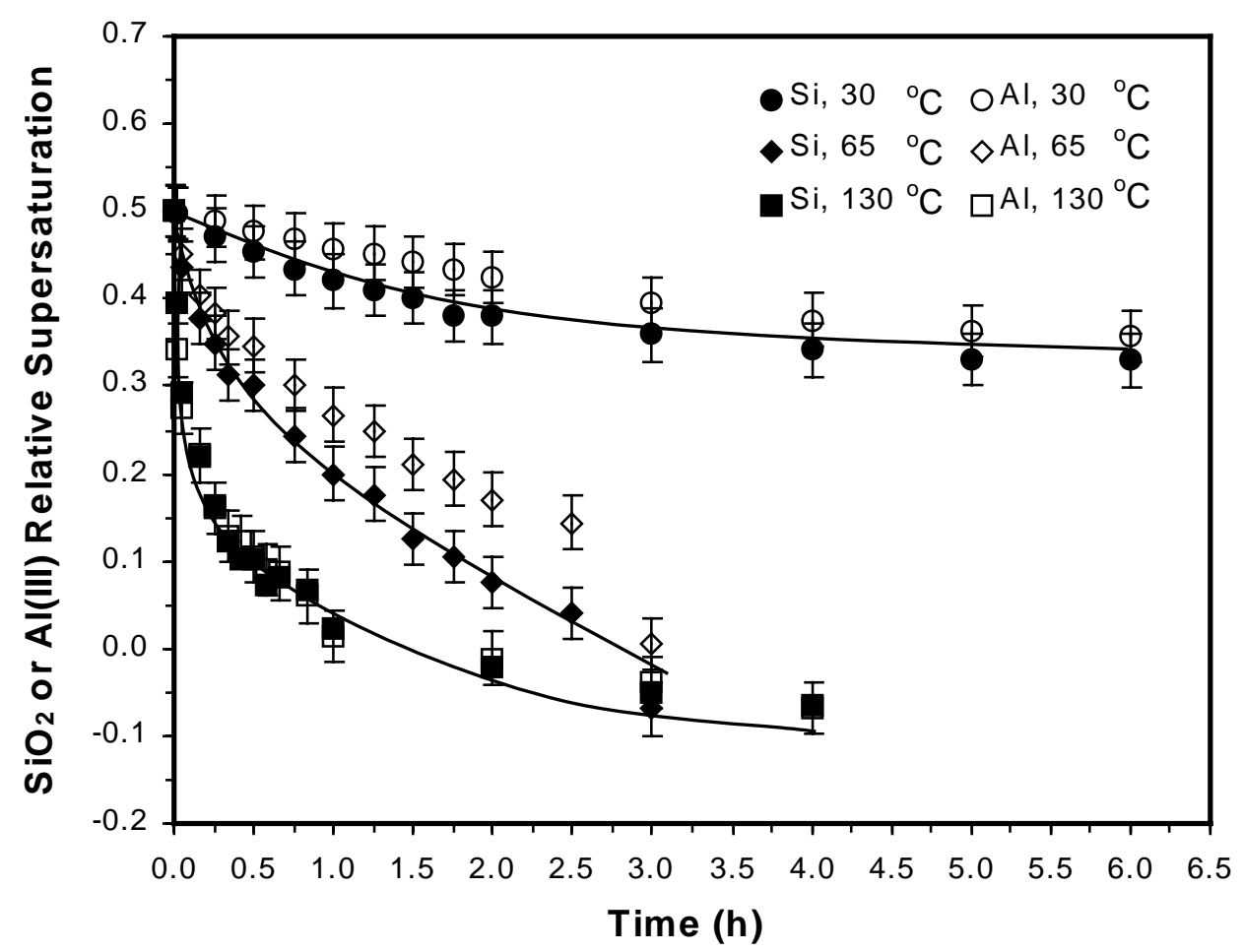

Figure 72 Relative supersaturation for sodalite seeded sodium aluminosilicate solution as function of temperature and time

Typical cumulative number-size distributions of solid particles obtained from all seeded precipitation indicated that no gross breakage of solid crystals occurred during desilication (Figures 73-76). A constancy of the total particle number was established through particle sizing-number count (population balance) analysis. This analysis also showed that secondary nucleation and agglomeration were not significant. Furthermore, no noticeable spread of particle size distribution with crystallization time (indicative of growth rate dispersion or size dependent growth effects) was observed. Consequently, the present kinetics data may be modeled for pure crystal and amorphous particle size-independent growth consistent with the fact that all particles grow at substantially similar rate, regardless of their individual sizes. Any increase in size is therefore ascribed solely to variation in and influence of temperature, supersaturation and the total, exposed particle surface area.

An average particle linear growth rate of $3.76 \mu \mathrm{m} \mathrm{h}^{-1}$ was determined from cumulative number-size distribution of amorphous particles of seeded precipitation at $30{ }^{\circ} \mathrm{C}(\mathrm{NaOH}=$ 
$4 \mathrm{M}, \mathrm{NaNO}_{3}=1 \mathrm{M}, \mathrm{NaNO}_{2}=1 \mathrm{M}$, initial $\mathrm{NaOH}=4 \mathrm{M}, \mathrm{NaNO}_{3}=1 \mathrm{M}, \mathrm{NaNO}_{2}=1 \mathrm{M}$. Similarly, an average linear growth rate of $0.86 \mu \mathrm{m} \mathrm{h}^{-1}$ for zeolite, $0.54 \mu \mathrm{m} \mathrm{h}^{-1}$ for sodalite and $0.03 \mu \mathrm{m}$ $\mathrm{h}^{-1}$ for cancrinite crystals were estimated from seeded precipitation involving similar solutions at $130{ }^{\circ} \mathrm{C}$. These data suggest that for primary particle growth, the rate was highest for amorphous phase, followed by zeolite A, and then sodalite, with cancrinite being the slowest growing phase. This is supported by the analyses of solution $\mathrm{SiO} 2$ flux decline with time of crystallization (Figures 77-79).

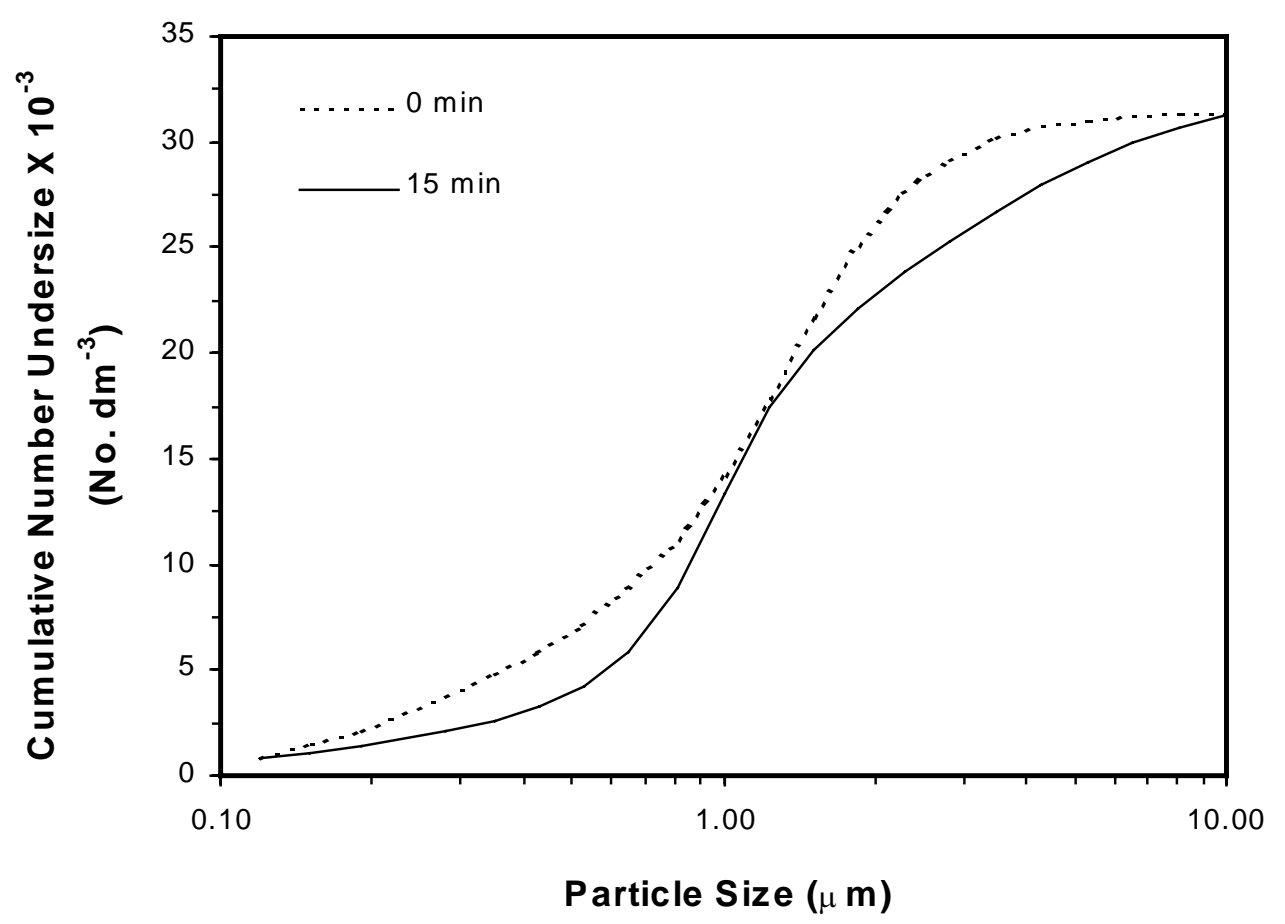

Figure 73 Typical cumulative number-size distribution of amorphous particles obtained from seeded precipitation at $30{ }^{\circ} \mathrm{C}$ 


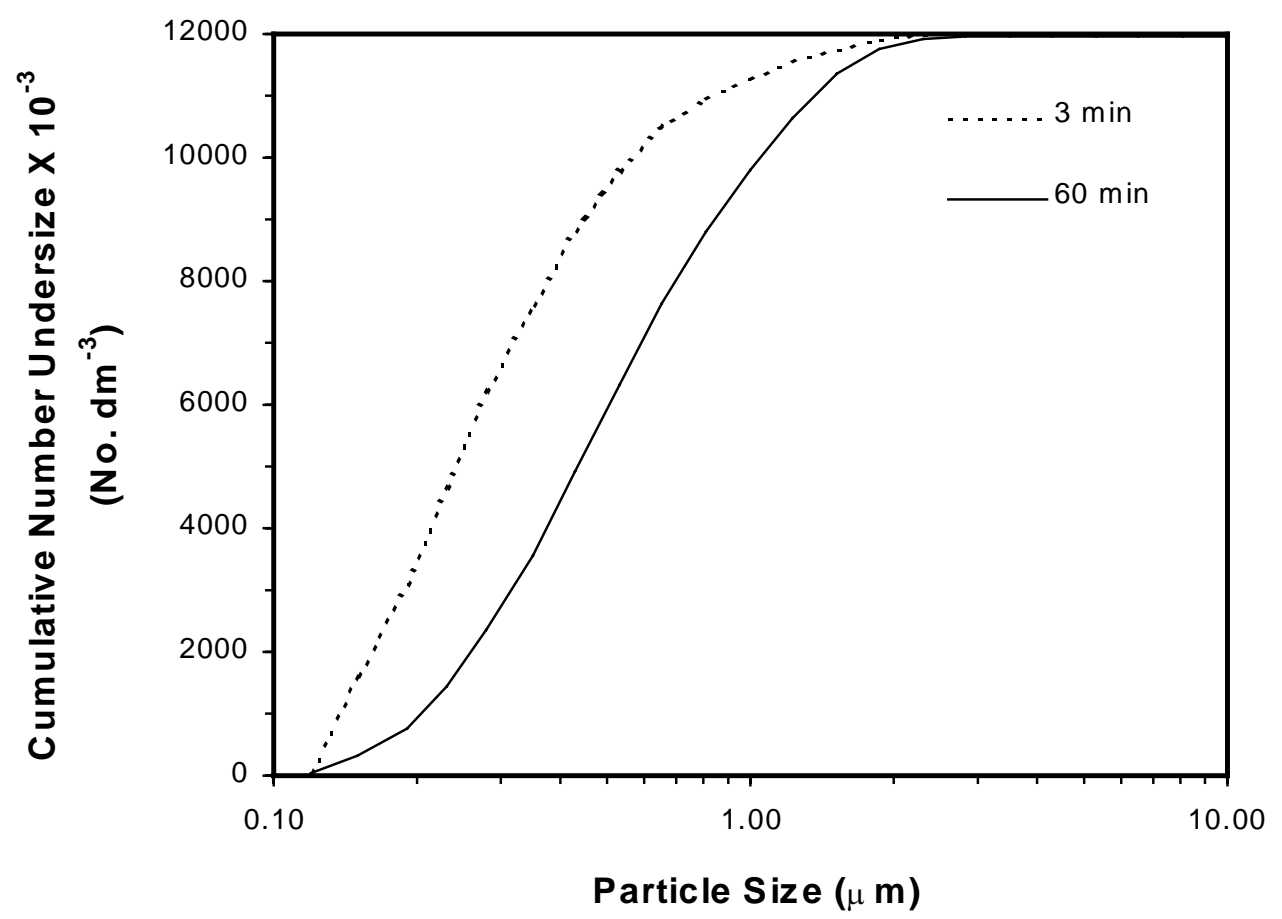

Figure 74 Typical cumulative number-size distribution of zeolite particles obtained from seeded precipitation at $65^{\circ} \mathrm{C}$

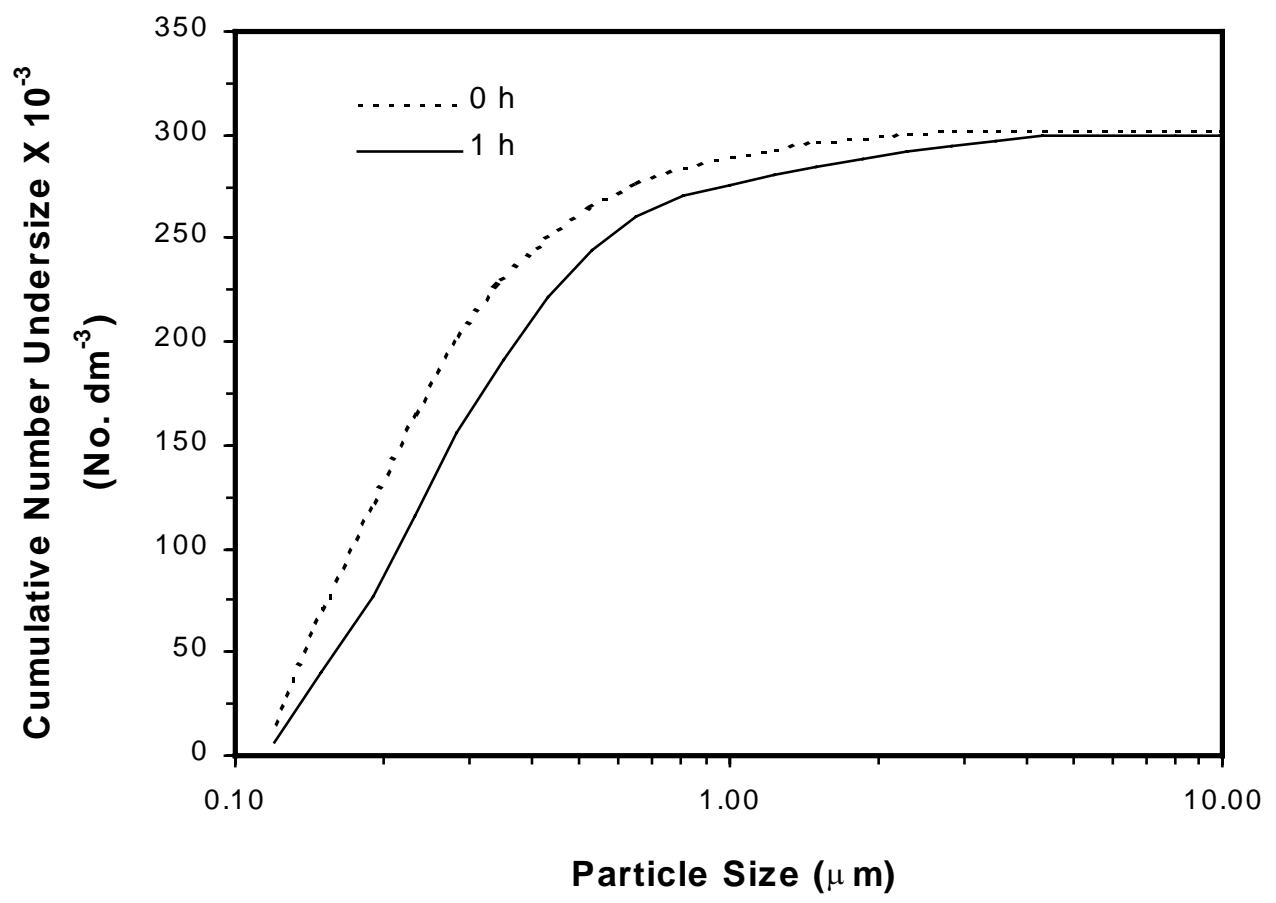

Figure 75 Typical cumulative number-size distribution of sodalite particles obtained from seeded precipitation at $130{ }^{\circ} \mathrm{C}$ 


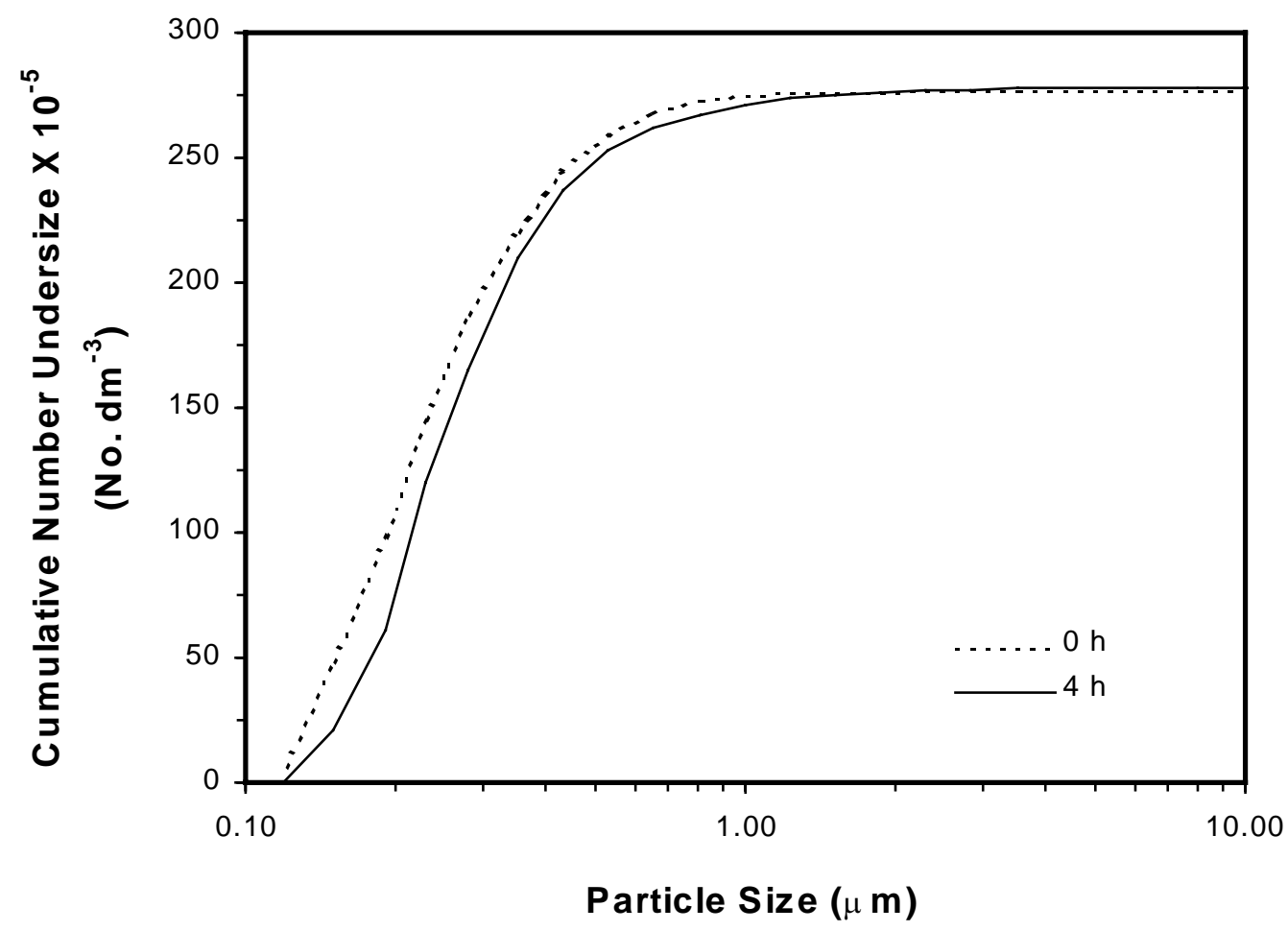

Figure 76 Typical cumulative number-size distribution of cancrinite particles obtained from seeded precipitation at $130{ }^{\circ} \mathrm{C}$

The change in relative $\mathrm{SiO}_{2}$ flux with time due to pure crystal/particle at similar initial relative supersaturation and similar seed surface area was seed phase type dependent and followed the sequence (Figure 77-79):

$$
\Delta\left(\mathrm{SiO}_{2} \text { flux }\right)_{\text {amorphous }}>\Delta\left(\mathrm{SiO}_{2} \text { flux }_{\text {zeolite }}\right)>\Delta\left(\mathrm{SiO}_{2} \text { flux }_{\text {sodalite }}\right)>\Delta\left(\mathrm{SiO}_{2} \text { flux }_{\text {cancrinite }}\right) .
$$

The data in Figures 77-79 indicate that under similar suspension conditions crystallization via particle growth was kinetically more favourably in the presence of a less stable sodium aluminosilicate solid phase. Thus, the amorphous solid, grows at a much faster rate than the most stable cancrinite crystals. The activation energies for the growth mechanism determined from isothermal growth studies performed at different temperatures $\left(30,65\right.$ and $\left.130{ }^{\circ} \mathrm{C}\right)$ are consistent with the trends indicated by the solid phase dependent-SiO${ }_{2}$ flux changes. 
WSRC-MS-2002-00907

Page 90 of 141

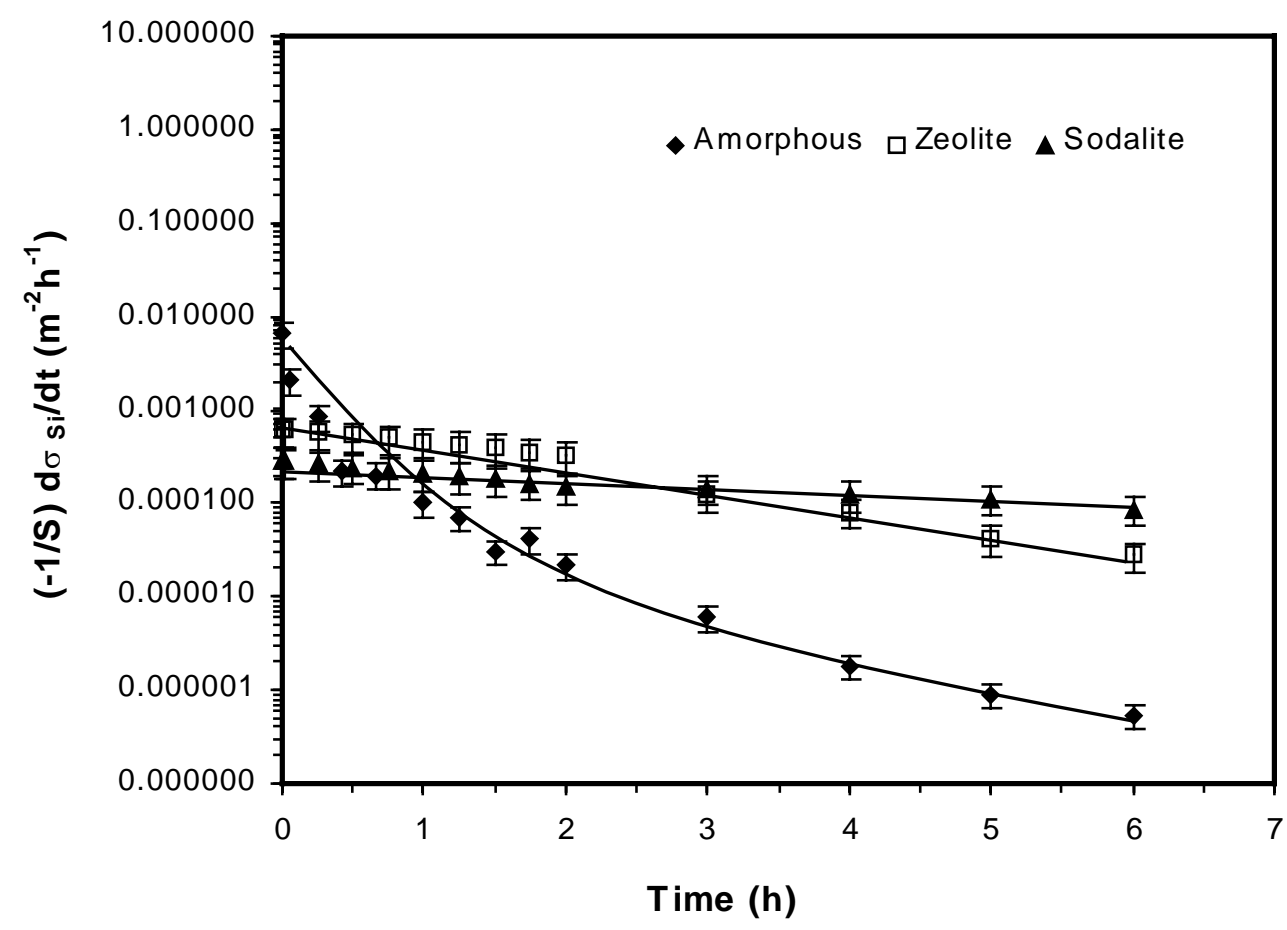

Figure 77 Flux change for different seeded crystallizations at $30{ }^{\circ} \mathrm{C}$

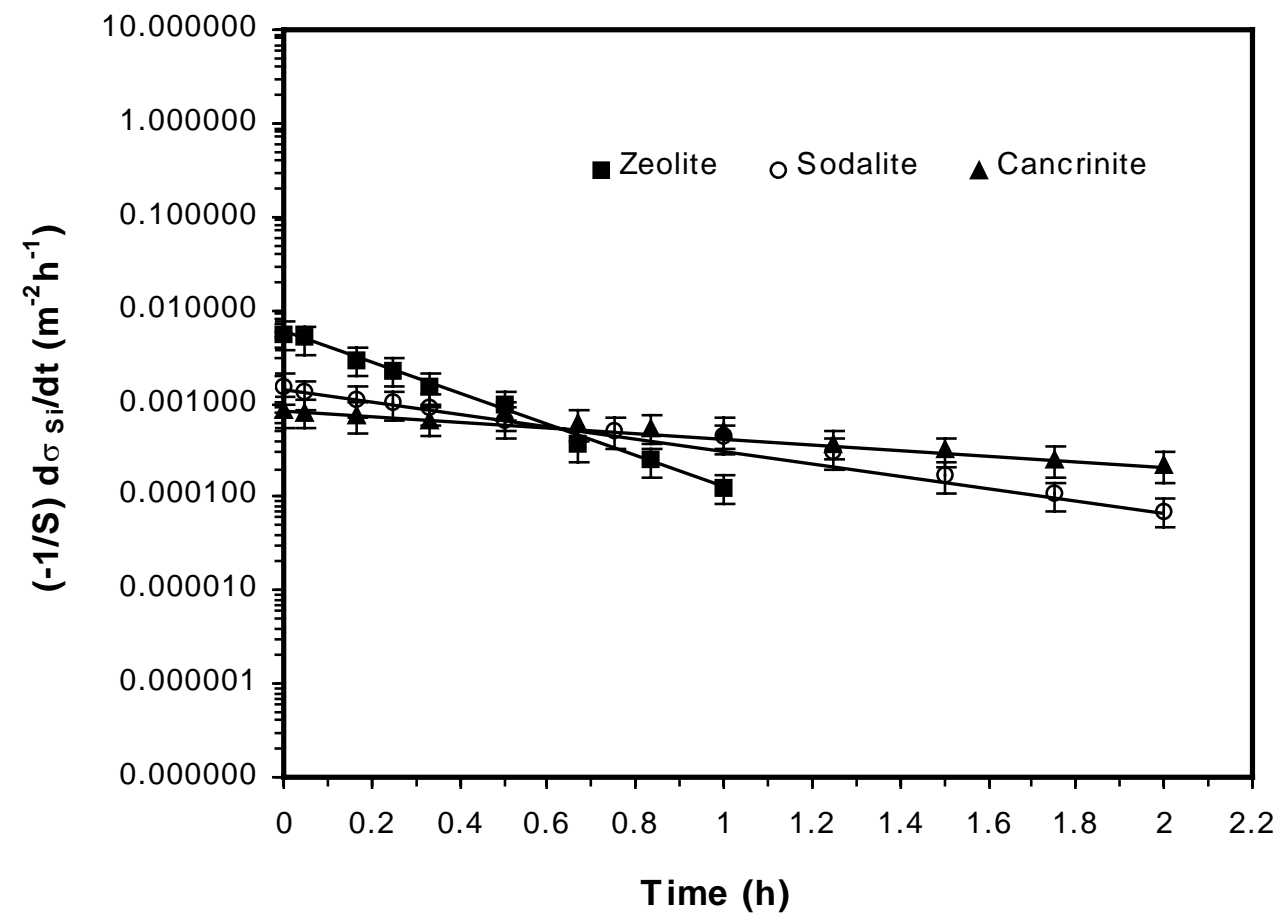

Figure 78 Flux change for different seeded crystallization at $65^{\circ} \mathrm{C}$ 


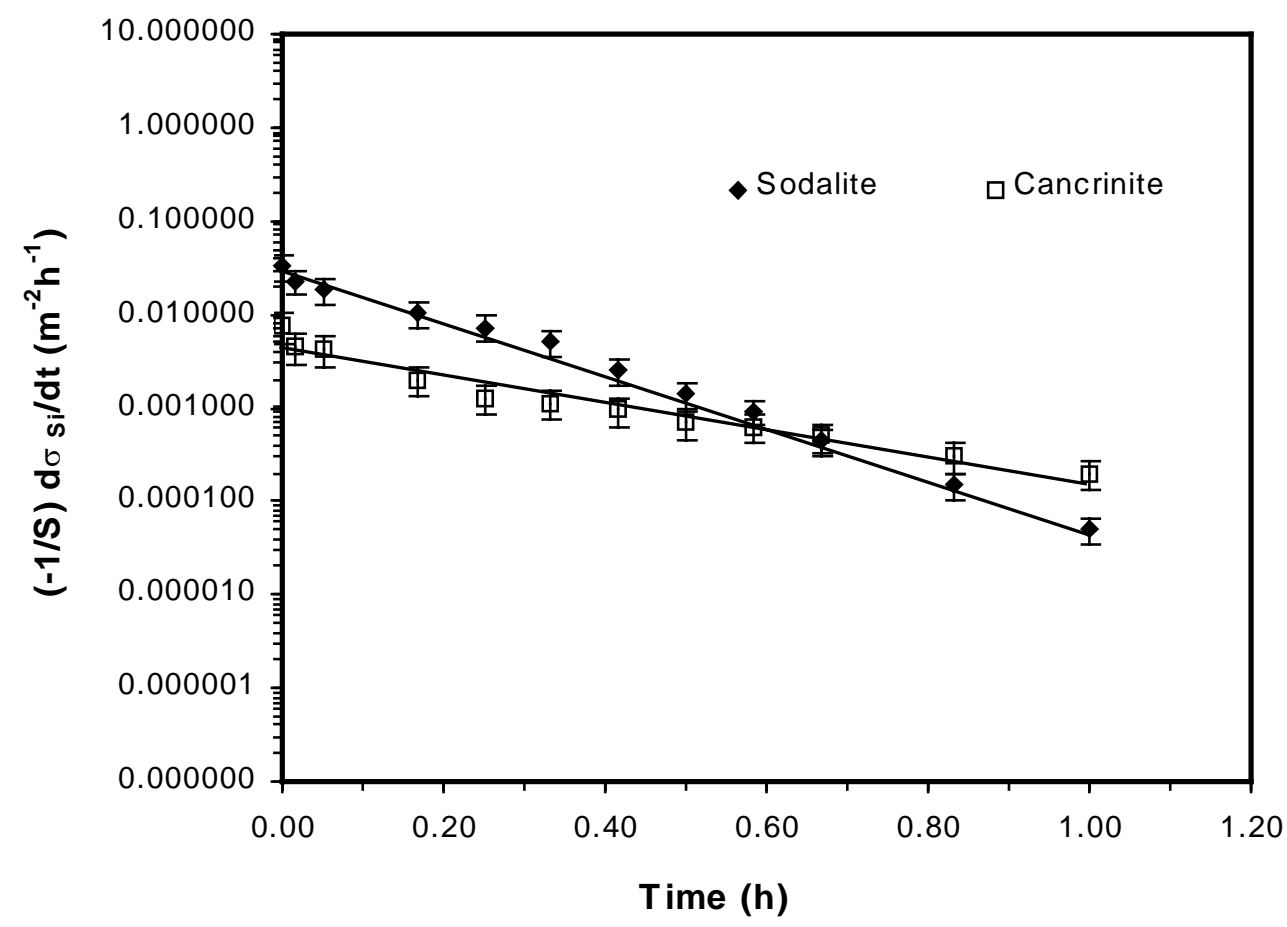

Figure 79 Flux change for different seeded crystallization at $130{ }^{\circ} \mathrm{C}$

\subsubsection{Modeling Secondary Nucleation and Crystal Growth Kinetics}

The crystallization kinetics data produced from the seeded crystallization at high initial supersaturations were analysed and quantified using a semi empirical power law model (Equation 1) involving $\mathrm{SiO}_{2}$ and $\mathrm{Al}(\mathrm{III})$ relative supersaturations $\left(\sigma_{\mathrm{SiO} 2}\right.$ and $\sigma_{\mathrm{Al}}$ ), total particle surface area (S) and an exponent of relative supersaturation (n) and temperature (T).

$$
\begin{array}{ll}
-\frac{1}{\mathrm{~S}} \frac{\mathrm{d} \sigma_{\mathrm{SiO}_{2}}}{\mathrm{dt}}=\mathrm{k}\left(\sigma_{\mathrm{SiO}_{2}} \sigma_{\mathrm{Al}}\right)^{n} & \text { Equation 1 } \\
\mathrm{k}=\mathrm{k}_{\mathrm{o}} \exp \left(-\frac{\mathrm{E}_{\mathrm{a}}}{\mathrm{RT}}\right) & \text { Equation 2 }
\end{array}
$$

\section{Secondary Nucleation and Particle Growth}

Plots of $\operatorname{In}\left[(-1 / \mathrm{S}) d \sigma_{\mathrm{Si}} / \mathrm{dt}\right]$ versus In $\left(\sigma_{\mathrm{Si}} \sigma_{\mathrm{Al}}\right)$ yield linear relationships of two distinct regions (slopes) for the four solid phase seed suspensions (Figure 80-82). The transition from secondary nucleation to growth crystallization generally occurred at relative 
supersaturations $(\sigma)$ in the range $0.8-1.0$ for the Zeolite A, Sodalite and Cancrinite crystalline phases at 65 and $130^{\circ} \mathrm{C}$. At $30^{\circ} \mathrm{C}$ the critical $\sigma$ values were considerably higher. Namely, they were 1.91 for zeolite A, 6.46 for sodalite and 12.41 for cancrinite crystals. For the amorphous seeded system the transition occurred at $\sim \sigma=0.45$. These relative supersaturations are the critical values above which substantial secondary nucleation occurred in tandem with crystal/particle growth. The increased metastable limit for nucleation at $30{ }^{\circ} \mathrm{C}$ is consistent with the existence of the relation of temperature and relative supersaturation.

From the slopes of the plots the secondary nucleation dominated-reaction order (n) was reproducibly found to $\sim 2$ with respect to individual $\mathrm{SiO}_{2}$ and $\mathrm{Al}(\mathrm{III})$ relative supersaturations (Table 17). For pure particle or crystal growth a dependence of $\mathrm{SiO}_{2}$ and Al(III) relative supersaturations to the power of unity was observed. These indicate an overall $4^{\text {th }}$ and $2^{\text {nd }}$ order dependence of secondary nucleation and growth rates, respectively, on relative supersaturation. The dependence of growth rate upon the combined $\mathrm{SiO}_{2}$ and Al(III) relative supersaturation to the power of 2 is in strong agreement with the results obtained from seeded liquors for which desupersaturation occurred purely by growth as shown below.

Activation energies of 47,48 and $82 \mathrm{kJmol}^{-1}$ for zeolite, sodalite and cancrinite secondary nucleation, respectively, were estimated from Arrhenius plots (Equation 2 and Figure 83). For the amorphous phase, no reliable activation energy for nucleation has been successfully estimated as yet. The nucleation of the amorphous phase was almost always instantaneous, and the integrity of solid usually ephemeral due to rapid phase transformation, making reliable estimates of nucleation kinetics parameters at high supersaturations nearly intractable. Although the activation energy obtained for secondary nucleation of zeolite crystals was marginally lower than that for sodalite crystals, the values of the pre-exponential factors were noticeably higher for the sodalite seeded system. It appears that the collision frequency between the nuclei forming species was enhanced for sodalite as a result of the templating effect of nitrate and nitrite ions which are incorporated into the sodalite (and cancrinite) structure but not the zeolite phase. 


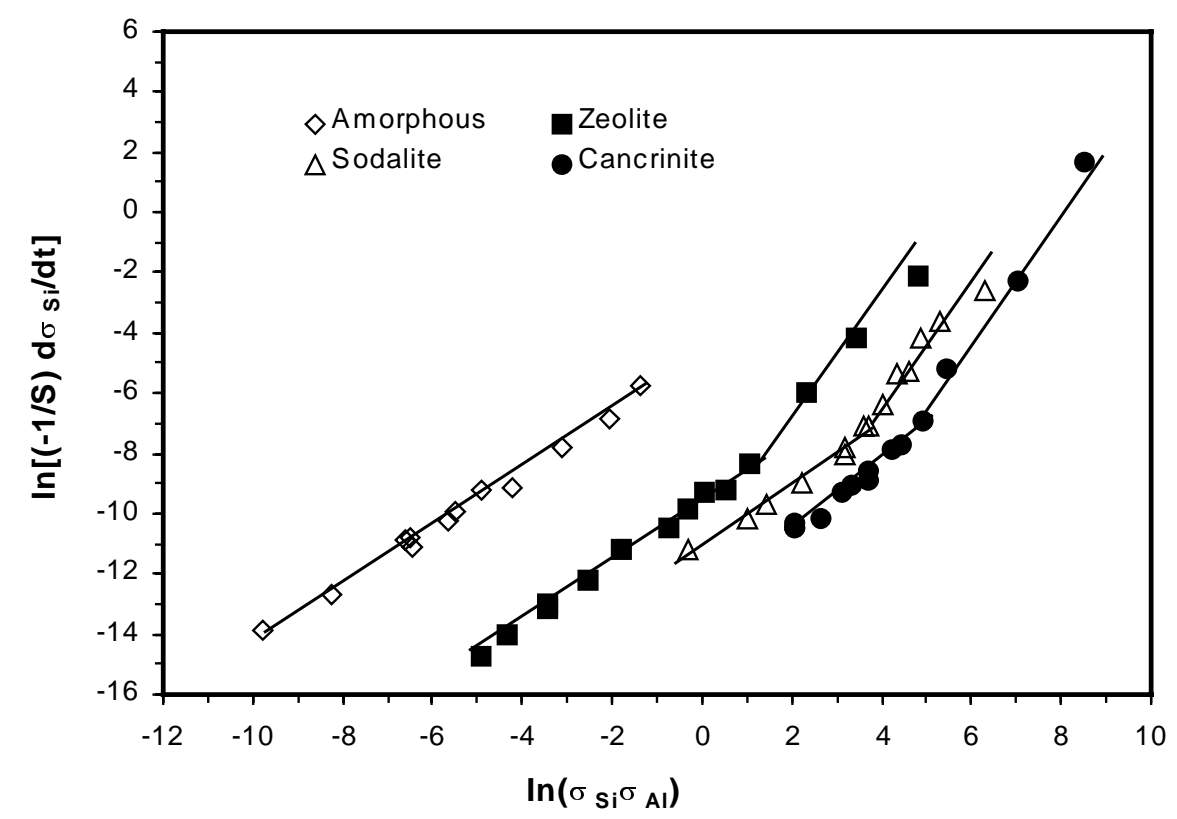

Figure 80 Plots of $\operatorname{In}\left[(-1 / \mathrm{S}) \mathbf{d} \sigma_{\mathrm{Si}} / \mathbf{d t}\right.$ ] versus $\operatorname{In}\left(\sigma_{\mathrm{Si}} \sigma_{\mathrm{Al}}\right)$ [showing a second order dependency (slope $=2$ ) and a first order dependency (slope $=1$ ) on the $\mathrm{SiO}_{2}$ relative supersaturation] for secondary nucleation and growth of amorphous, zeolite, sodalite and cancrinite particles respectively from sodium aluminosilicate solution at $30^{\circ} \mathrm{C}$

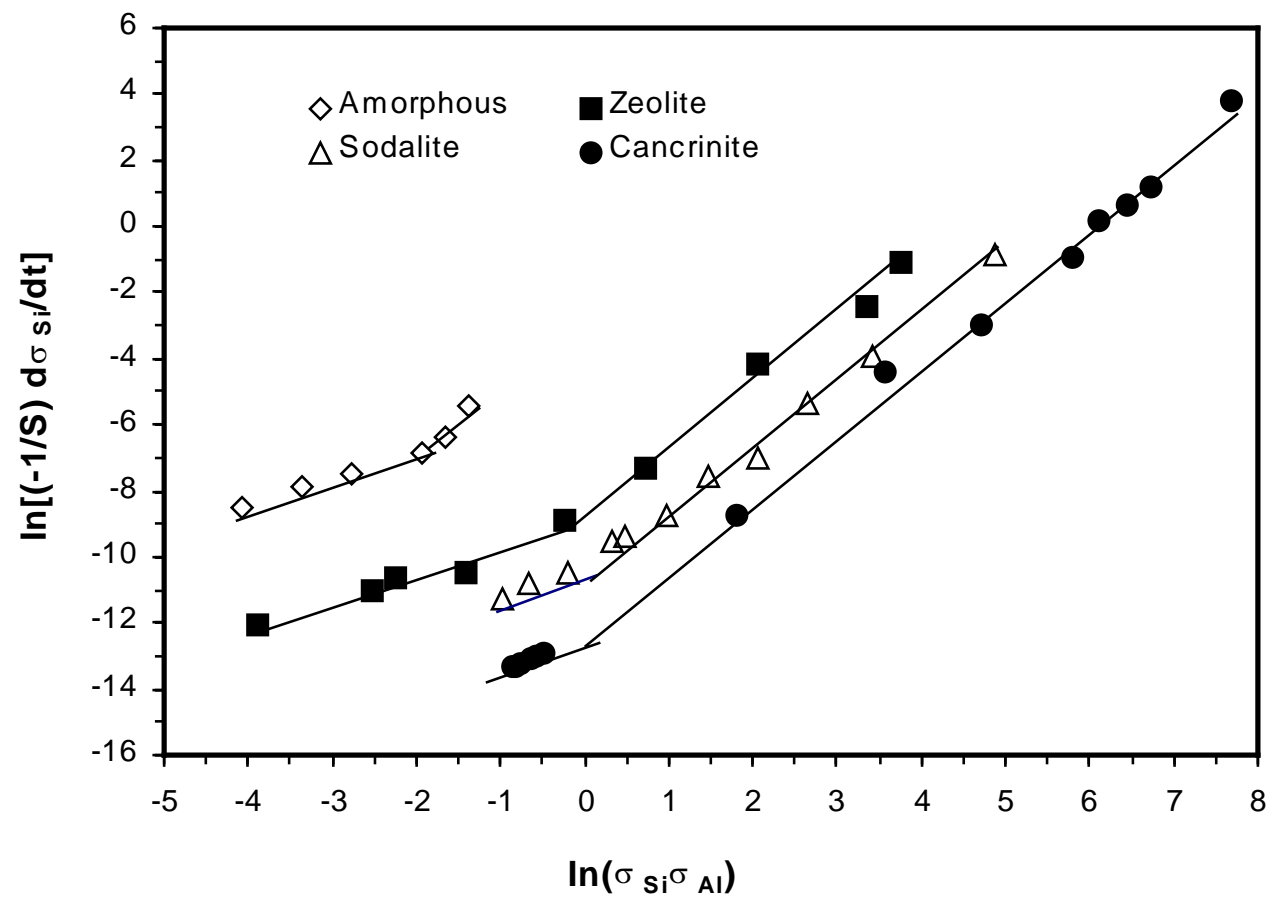

Figure 81 Plots of $\operatorname{In}\left[(-1 / \mathrm{S}) \mathrm{d} \sigma_{\mathrm{Si}} / \mathbf{d t}\right]$ versus $\operatorname{In}\left(\sigma_{\mathrm{Si}} \sigma_{\mathrm{Al}}\right)$ [showing a second order dependency (slope $=2$ ) and a first order dependency (slope $=1$ ) on the $\mathrm{SiO}_{2}$ relative supersaturation] for secondary nucleation and growth of amorphous, zeolite, sodalite and cancrinite particles respectively from sodium aluminosilicate solution at $65^{\circ} \mathrm{C}$ 


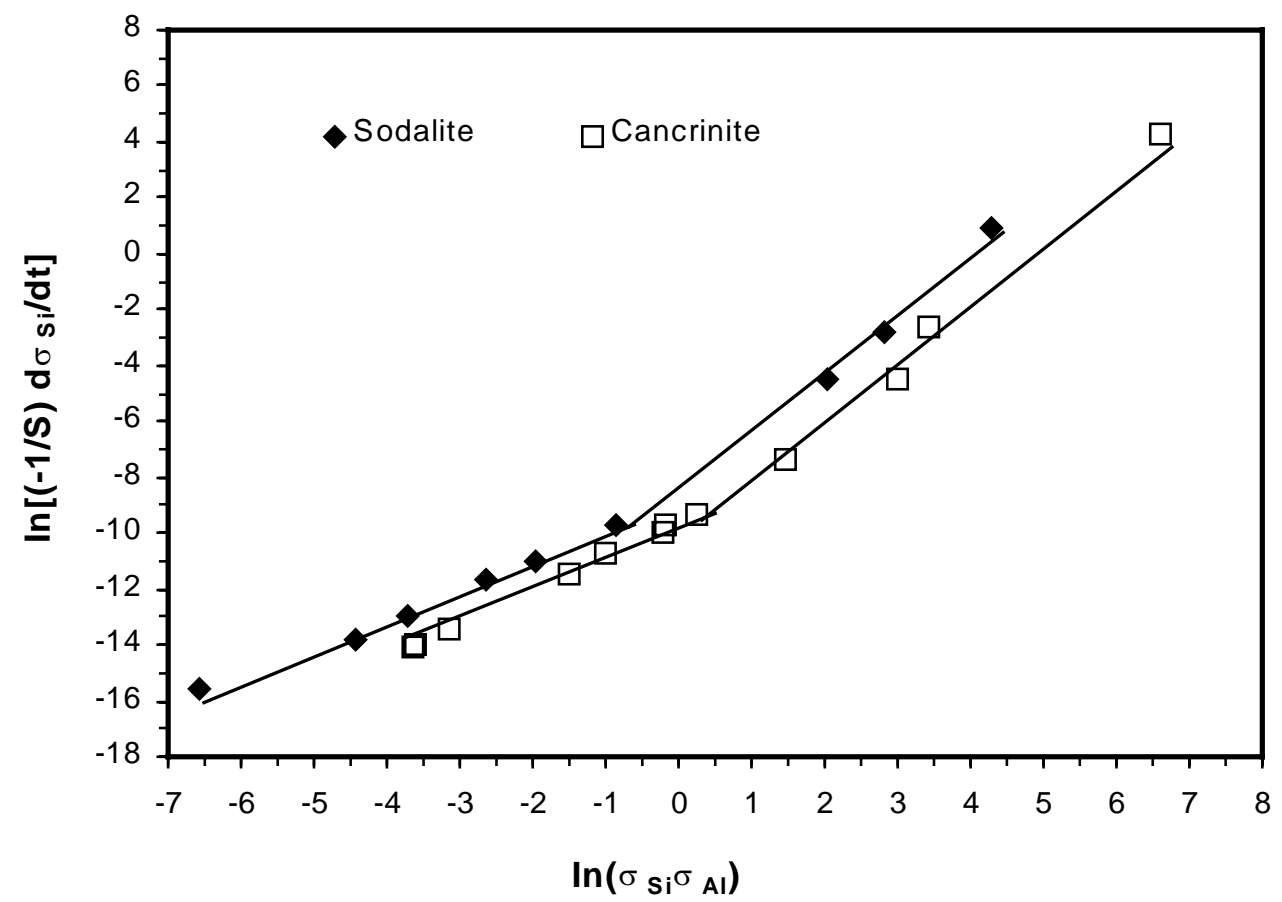

Figure 82 Plots of $\operatorname{In}\left[(-1 / S) d \sigma_{\mathrm{Si}} / \mathbf{d t}\right]$ versus $\operatorname{In}\left(\sigma_{\mathrm{Si}} \sigma_{\mathrm{Al}}\right)$ [showing a second order dependency (slope $=2$ ) and a first order dependency (slope $=1$ ) on the $\mathrm{SiO}_{2}$ relative supersaturation] for secondary nucleation and growth of sodalite and cancrinite particles respectively from sodium aluminosilicate solution at $130{ }^{\circ} \mathrm{C}$

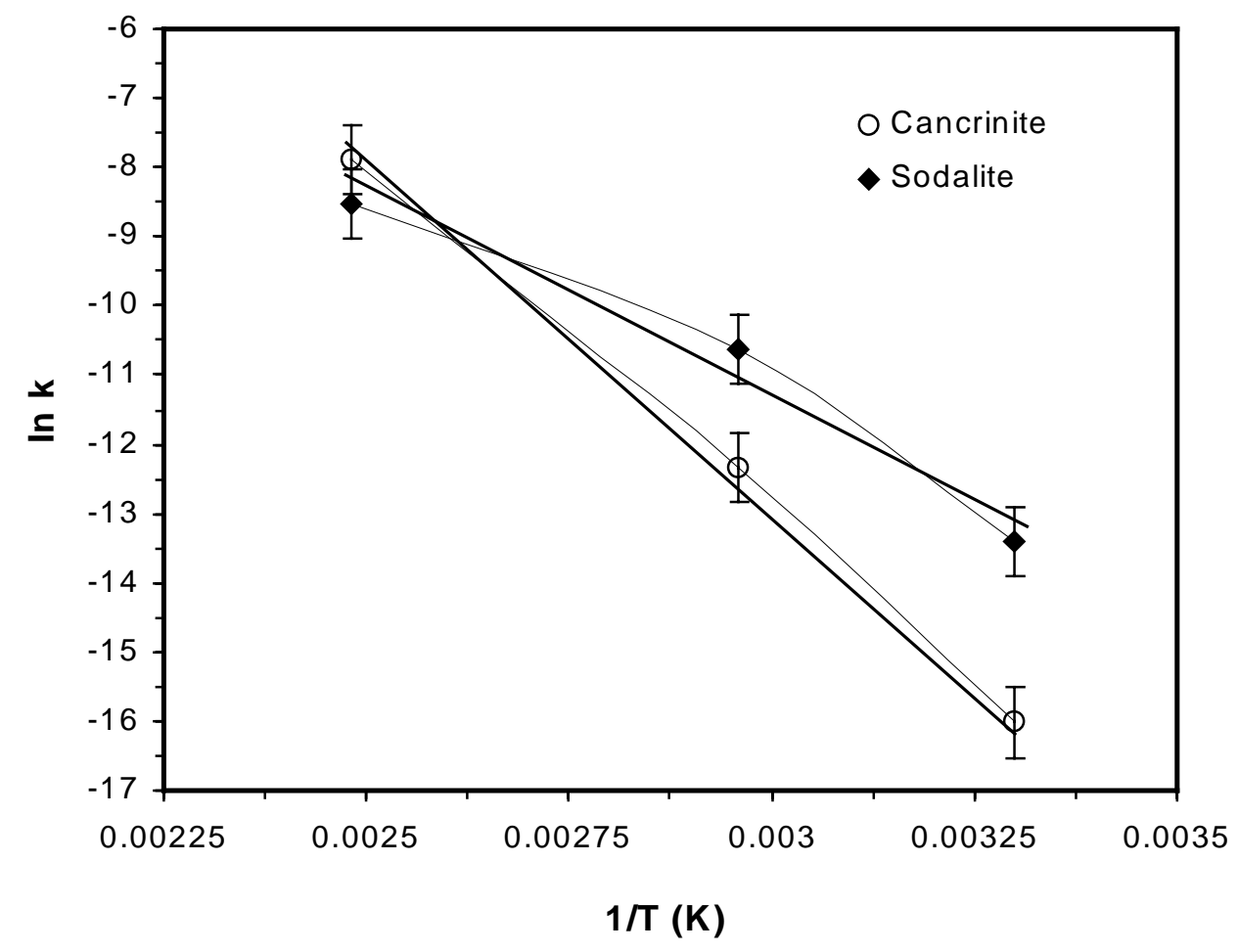

Figure 83 Arrhenius plots using the second order rate constants for sodalite and cancrinite secondary nucleation 


\subsubsection{Growth Kinetics}

Kinetics parameters for pure growth in solutions of the initial composition: $\mathrm{NaOH}=4 \mathrm{M}$, $\mathrm{NaNO}_{3}=1 \mathrm{M}, \mathrm{NaNO}_{2}=1 \mathrm{M}$, the same initial $\sigma_{\mathrm{Si}}=0.5$ and $\sigma_{\mathrm{Al}}=0.5$, and initial seed charge $=$ $119.7 \mathrm{~m}^{2} \mathrm{dm}^{-3}$ ) at 30,65 and $130{ }^{\circ} \mathrm{C}$ were estimated from the data as shown in Figures 84-87. Linear relationships were obtained from plots of $\operatorname{In}\left[(-1 / \mathrm{S}) \mathrm{d} \sigma_{\mathrm{Si}} / \mathrm{dt}\right]$ versus $\operatorname{In}\left(\sigma_{\mathrm{Si}} \sigma_{\mathrm{Al}}\right)$ for the different seeded systems. A reaction order of 1 was obtained for growth of the particles (Table 17).

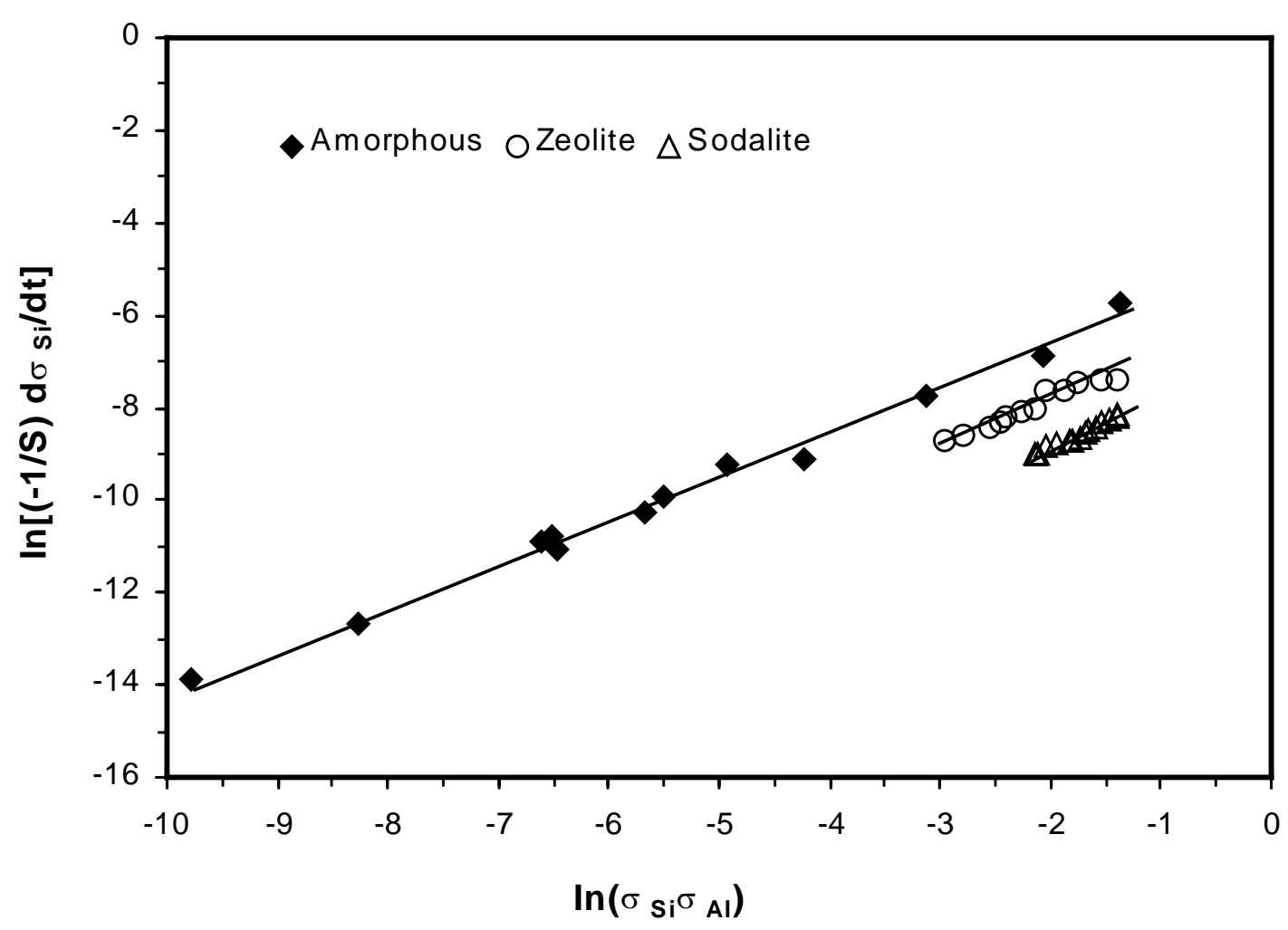

Figure 84 Plots of $\operatorname{In}\left[(-1 / S) d \sigma_{\mathrm{Si}} / \mathbf{d t}\right]$ versus $\operatorname{In}\left(\sigma_{\mathrm{Si}} \sigma_{\mathrm{Al}}\right)$ [showing a first order dependency (slope $=1$ ) on the $\mathrm{SiO}_{2}$ relative supersaturation] for growth of amorphous, zeolite and sodalite particles from sodium aluminosilicate solution at $30^{\circ} \mathrm{C}$

Arrhenius plots using the first order rate constants and the temperature yield linear relations as exemplified by Figure 87 for sodalite crystal growth. Activation energies of $2.5 \pm 0.5,22.9$ \pm 1.0 and $31.1 \pm 2.0$ and $66.6 \pm 3.0 \mathrm{kJmol}^{-1}$ were calculated from Arrhenius plots for the amorphous solid particles, zeolite, sodalite and cancrinite crystal growth, respectively. The very low activation energy barrier estimated for the growth of the amorphous solid phase indicates that integration of growth units is fast and involves relatively low interaction energy. Furthermore, the growth process of the amorphous solid appears to be volume diffusion 
controlled at low temperatures $\left(30^{\circ} \mathrm{C}\right)$. The higher values of activation energy observed the crystalline solid phases and overall reaction order of 2 both indicate that the bimolecular reactions underpinning crystal growth process are likely chemical-reaction controlled.

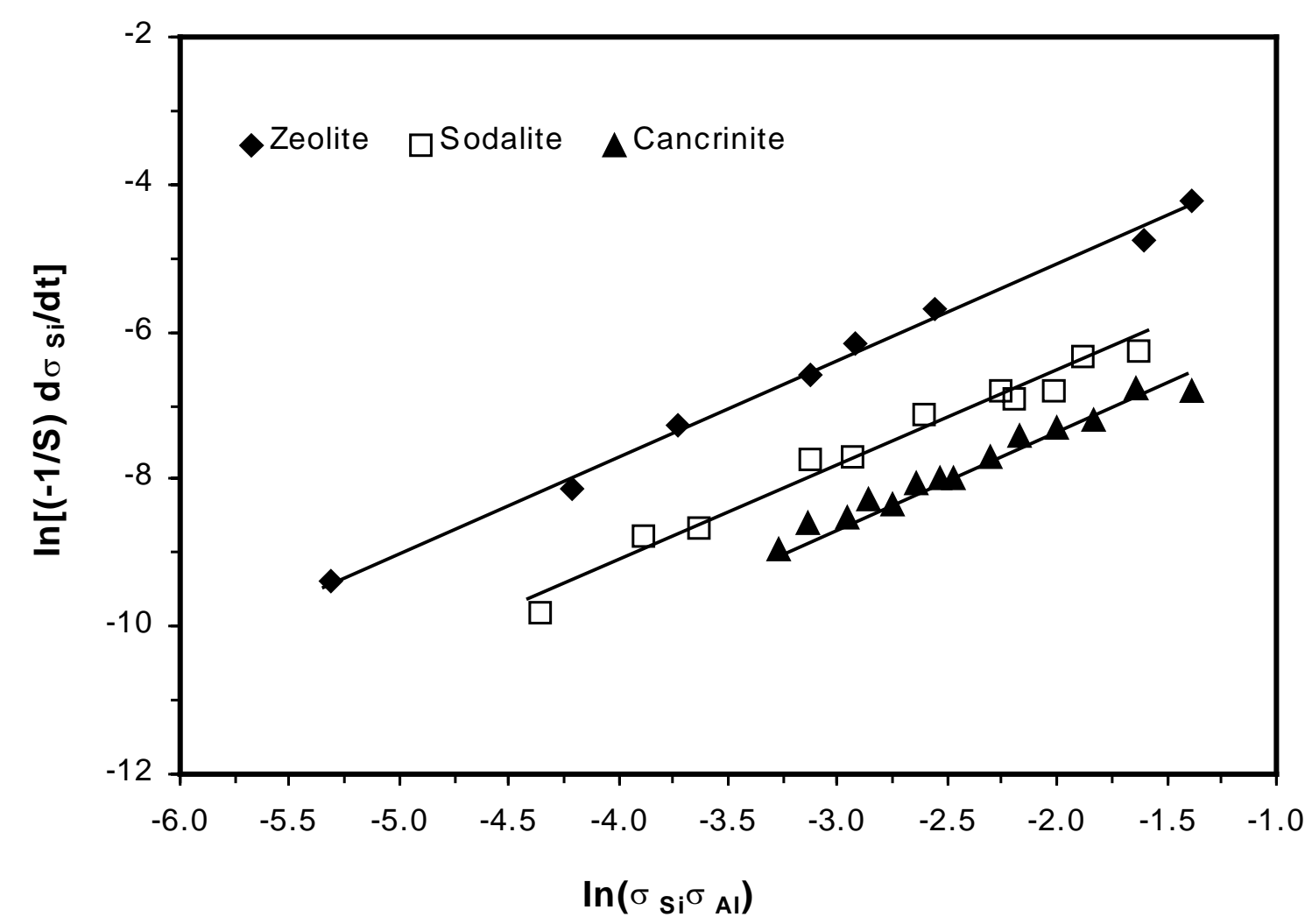

Figure 85 Plots of $\operatorname{In}\left[(-1 / S) d \sigma_{\mathrm{Si}} / \mathbf{d t}\right]$ versus $\operatorname{In}\left(\sigma_{\mathrm{Si}} \sigma_{\mathrm{Al}}\right)$ [showing a first order dependency (slope $=1$ ) on the $\mathrm{SiO}_{2}$ relative supersaturation] for growth of zeolite sodalite and cancrinite particles from sodium aluminosilicate solution at $65{ }^{\circ} \mathrm{C}$

The pre-exponential factors increased significantly (> an order of magnitude) with increasing thermodynamic stability of the solid phase. This reflects thermodynamic-influenced energetics which drive the sodium aluminosilicate phase to the most stable solid phase (after sufficiently long time). Cancrinite with the largest pre-exponential factor and largest activation energy is demonstrated to be more stable while exhibiting the largest energy barrier to growth. At the other extreme, the amorphous solid is shown to be the least thermodynamically stable is kinetically predisposed to grow the fastest. Zeolite A and sodalite crystals fall between the two extremes.

The present results for crystal growth kinetics $\left(\mathrm{n}=2\right.$ and $\mathrm{Ea}>20 \mathrm{~kJ} \mathrm{~mol}^{-1}$ ) suggest that theoretical treatment of the mechanisms underpinning crystal formation may be achieved using surface integration-controlled crystal growth theories. The BCF spiral growth model or the nuclei upon nuclei (birth and spread) model of the 2-dimensional surface nucleation 
theory. Both of these models assume that there is no volume diffusion limitation or barrier for transport of the growth units to the particle surface sites and that growth of the crystal occurs by the emergence and propagation of spiral screw dislocation (BCF theory) or by surface nucleation and spread of 2-dimensional islands.

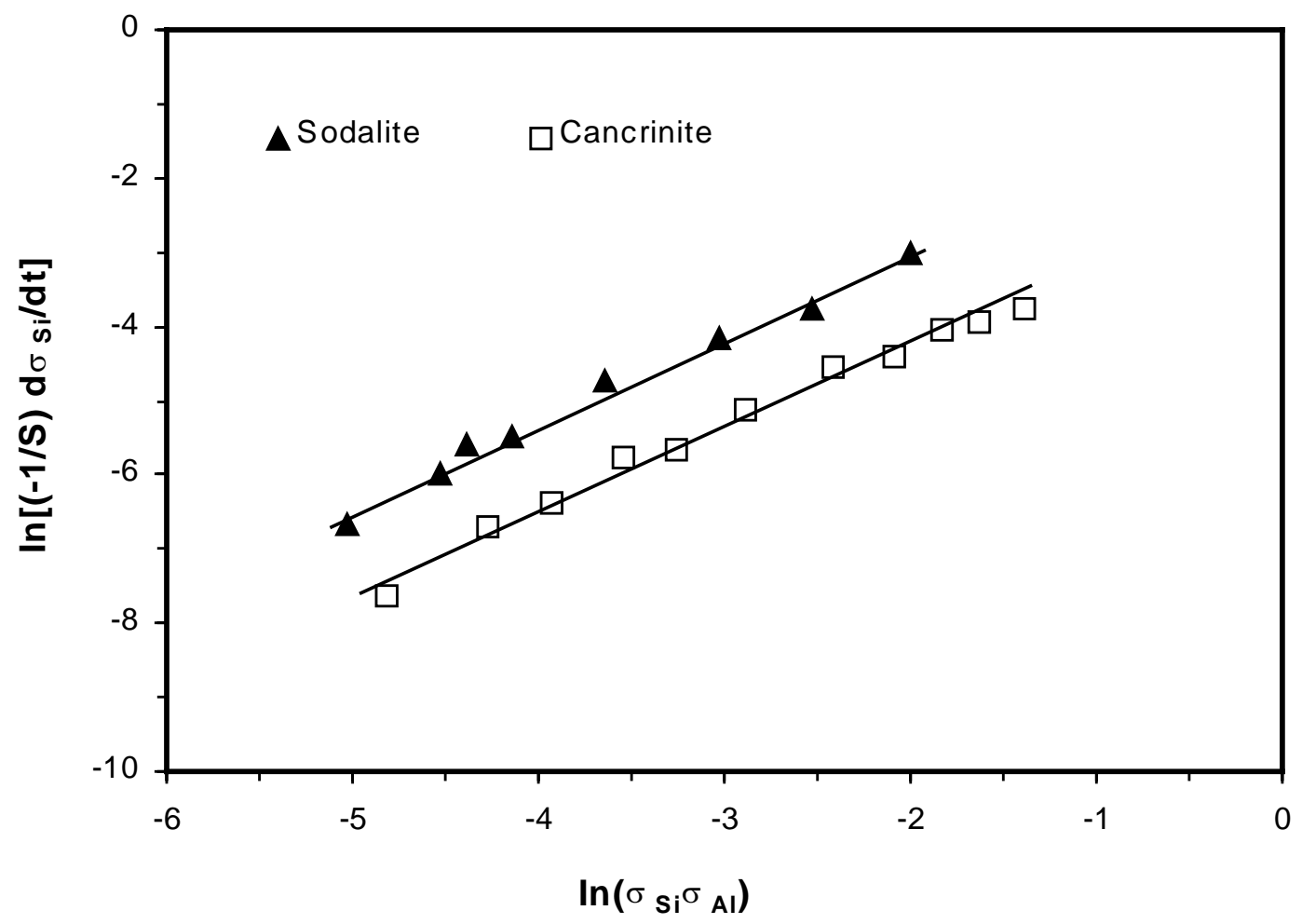

Figure 86 Plots of $\operatorname{In}\left[(-1 / S) d \sigma_{\mathrm{Si}} / \mathbf{d t}\right]$ versus $\operatorname{In}\left(\sigma_{\mathrm{Si}} \sigma_{\mathrm{Al}}\right)$ [showing a first order dependency (slope $=1$ ) on the $\mathrm{SiO}_{2}$ relative supersaturation] for growth of sodalite and cancrinite crystals from sodium aluminosilicate solution at $130{ }^{\circ} \mathrm{C}$ 
WSRC-MS-2002-00907

Page 98 of 141

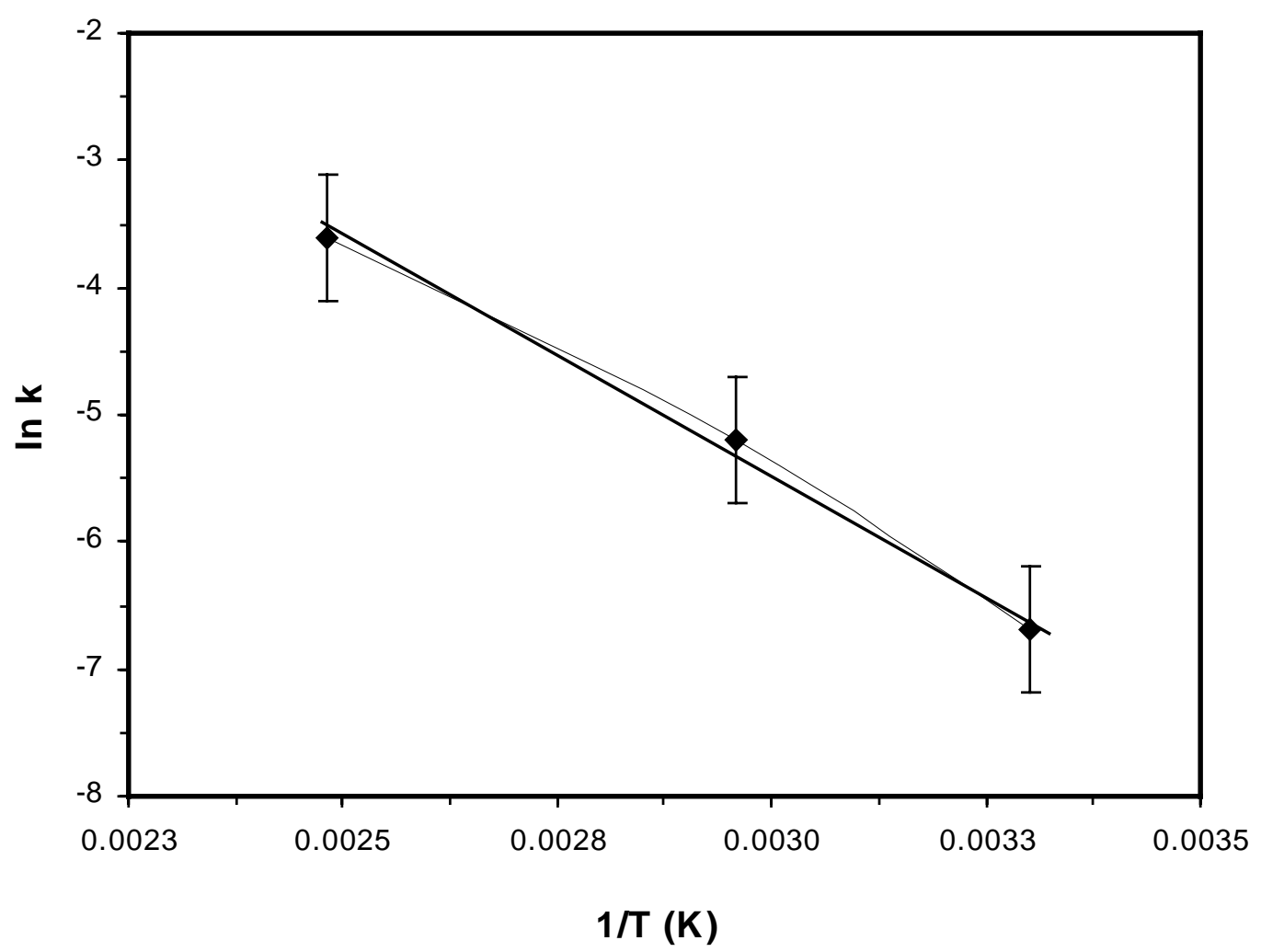

Figure 87 Arrhenius plot for sodalite crystal growth 



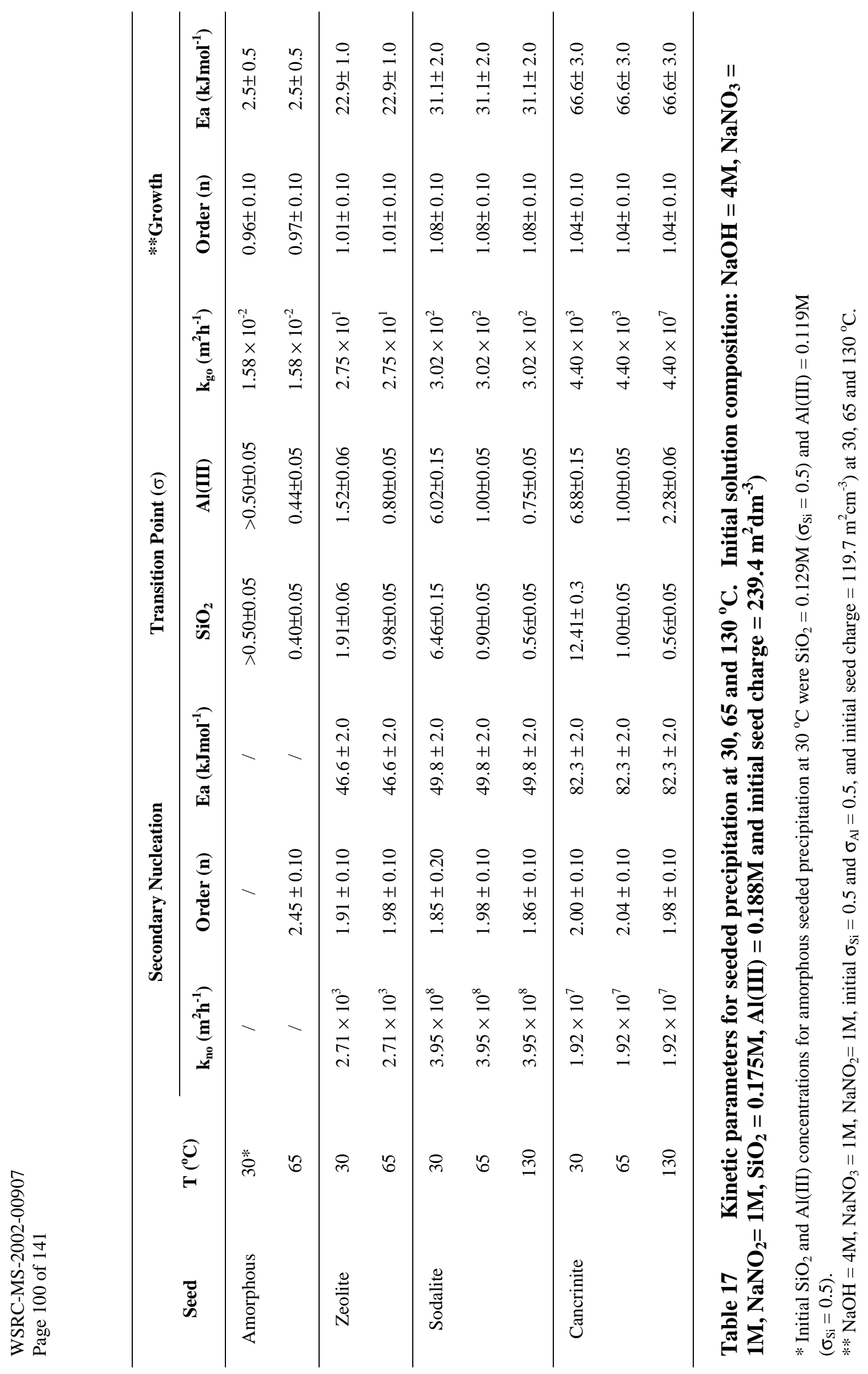

8 


\subsection{Unseeded Crystallization Studies}

\subsubsection{Homogeneous/Heterogeneous Nucleation at $130{ }^{\circ} \mathrm{C}$}

Self-nucleation behavior of unseeded supersaturated optically-clear liquors was investigated at $130{ }^{\circ} \mathrm{C}$ for 2 types of liquors of which the $\mathrm{SiO}_{2}$ and $\mathrm{Al}(\mathrm{III})$ concentrations were $[\mathrm{Si}][\mathrm{Al}]=4 \times 10^{-3} \mathrm{M}^{2}$ and $[\mathrm{Si}][\mathrm{Al}]=2 \times 10^{-3} \mathrm{M}^{2} . \mathrm{SiO}_{2}$ concentration decreased significantly with time for both solutions with the reduction being more pronounced at the higher initial $\mathrm{SiO}_{2}$ (Figure 88).

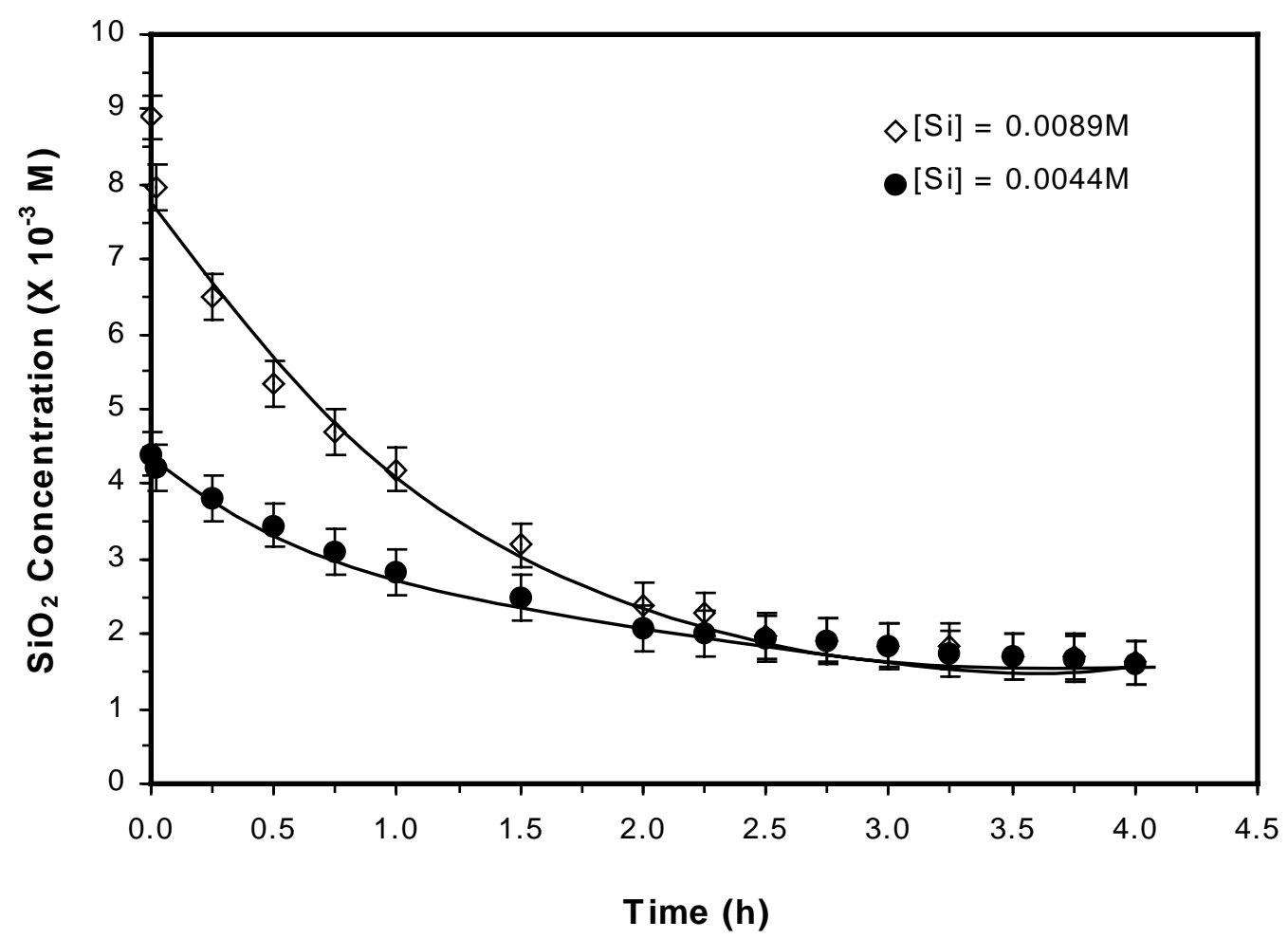

Figure $88 \quad \mathrm{SiO}_{2}$ concentration for unseeded solutions at $130{ }^{\circ} \mathrm{C}$ and constant $\mathrm{Al}(\mathrm{III})=0.45 \mathrm{M}, \mathrm{NaOH}=4 \mathrm{M}, \mathrm{NaNO}_{3}=1 \mathrm{M}, \mathrm{NaNO}_{2}=1 \mathrm{M}$

Self-nucleation desilication reactions resulted in an approach to sodalite solubility after $2.0 \mathrm{~h}$ and $1.5 \mathrm{~h}$ at the high and low supersaturations, respectively (Figure 89). Thereafter, phase transformation of sodalite to cancrinite occurred leading to $\sigma_{\mathrm{Si}}<0$ with respect to sodalite. The proliferation of sodium aluminosilicate particles (sodalite and cancrinite) as a result of the desilication reactions was confirmed by solid content 
and SEM analyses carried out on suspensions and steel substrates periodically removed from the crystallizer.

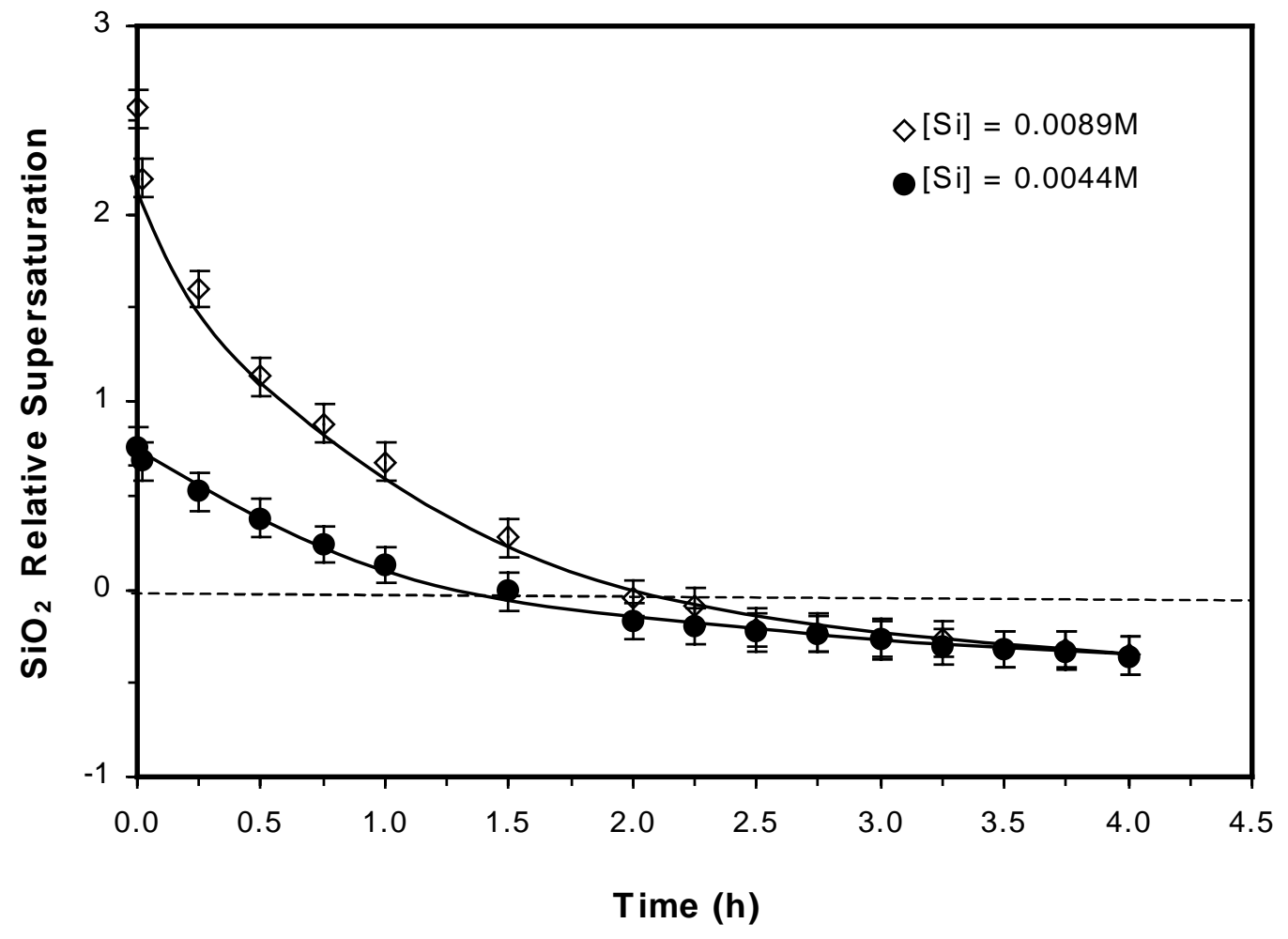

Figure 89 Relative supersaturation (with respect to sodalite) for unseeded solutions at $130{ }^{\circ} \mathrm{C}$ and constant $\mathrm{Al}(\mathrm{III})=0.45 \mathrm{M}, \mathrm{NaOH}=4 \mathrm{M}, \mathrm{NaNO}_{3}=1 \mathrm{M}$, $\mathrm{NaNO}_{2}=1 \mathrm{M}$

The crystal/solid content was greater at the higher initial supersaturation as expected (Figure 90). The total solid surface area per unit volume of suspension exhibited behaviour contrary to the solid content (Figure 91) suggesting the occurrence of agglomeration. Typical size distributions (Figure 92) of the crystals produced after $4 \mathrm{~h}$ strongly support the above observation. The particles crystallized at the higher supersaturation were coarser (dominant particle size $=50 \mu \mathrm{m}$ ) than those formed at the lower supersaturation (dominant particle size $=20 \mu \mathrm{m}$ ). The presence of these aluminosilicate particles in the crystallizer suspensions shows that nucleation and crystal growth occurred under the aforementioned conditions at $130{ }^{\circ} \mathrm{C}$.

Linear relationships of two distinct regions were obtained from plots of $\operatorname{In}\left[(-1 / \mathrm{S}) \mathrm{d} \sigma_{\mathrm{Si}} / \mathrm{dt}\right]$ versus In $\left(\sigma_{\mathrm{Si}}\right)$ for the two systems (Figure 93-94). The transition between these two 
linear regions generally occurred at $\sigma=0.67$ (Table 18) which is higher than the value 0.56 previously estimated for the secondary nucleation sodalite and cancrinite crystals. The reaction order $(\mathrm{n})$ of $4.35-5.45$ and $\sim 2$ were obtained for data at $\sigma>0.67$ and $\sigma<$ 0.67, respectively (Table 18). This observation indicates that homogeneous/ heterogeneous nucleation occurred at $\sigma>0.67$ whilst crystal growth, and possibly secondary nucleation, predominantly prevailed at $\sigma<0.67$. The metastable supersaturation limit $\left(\sigma_{\mathrm{c}}\right)$ for all the observed crystallization mechanisms may be stated as:

$\sigma_{\mathbf{c}}$-homogeneous/heterogeneous nucleation $>\sigma_{\mathbf{c}}$-Secondary nucleation $>\sigma_{\mathbf{c}}$-crystal growth

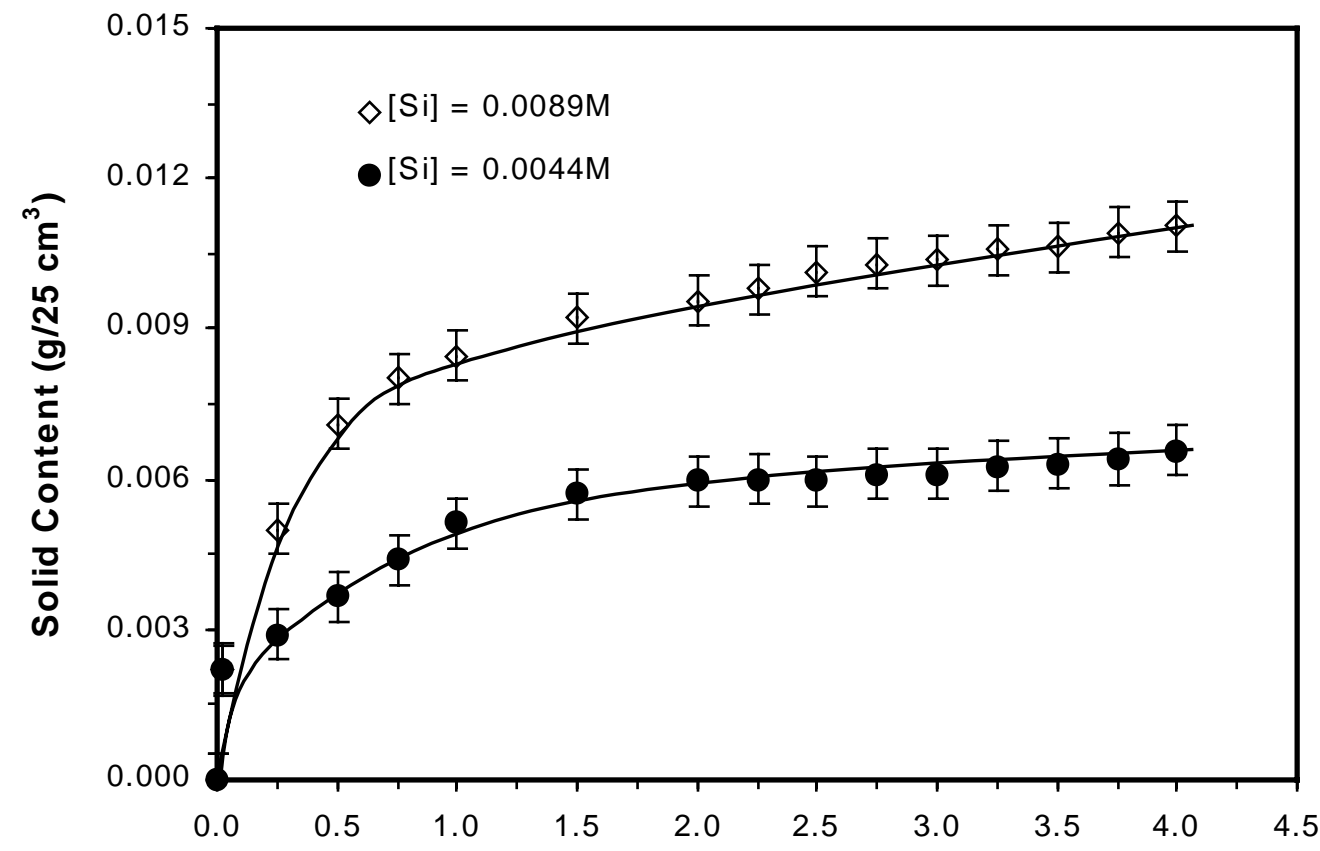

Time (h)

Figure 90 Solid content of unseeded solutions as a function of time at $130{ }^{\circ} \mathrm{C}$ and constant $\mathrm{Al}(\mathrm{III})=0.45 \mathrm{M}, \mathrm{NaOH}=4 \mathrm{M}, \mathrm{NaNO}_{3}=1 \mathrm{M}, \mathrm{NaNO}_{2}=1 \mathrm{M}$ 


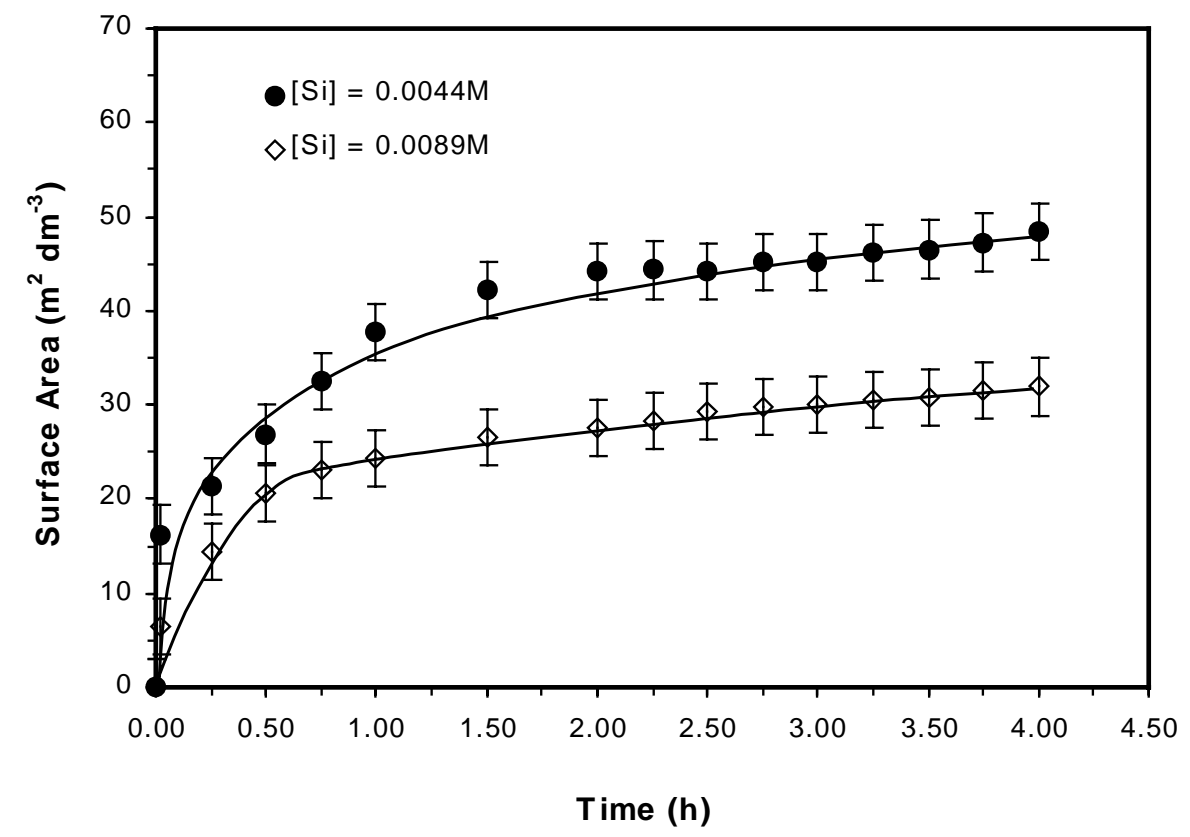

Figure 91 Total solid surface area per unit volume of suspension in the autoclave as a function of time at $130{ }^{\circ} \mathrm{C}$ and constant $\mathrm{Al}(\mathrm{III})=0.45 \mathrm{M}, \mathrm{NaOH}=$ $4 \mathrm{M}, \mathrm{NaNO}_{3}=1 \mathrm{M}, \mathrm{NaNO}_{2}=1 \mathrm{M}$

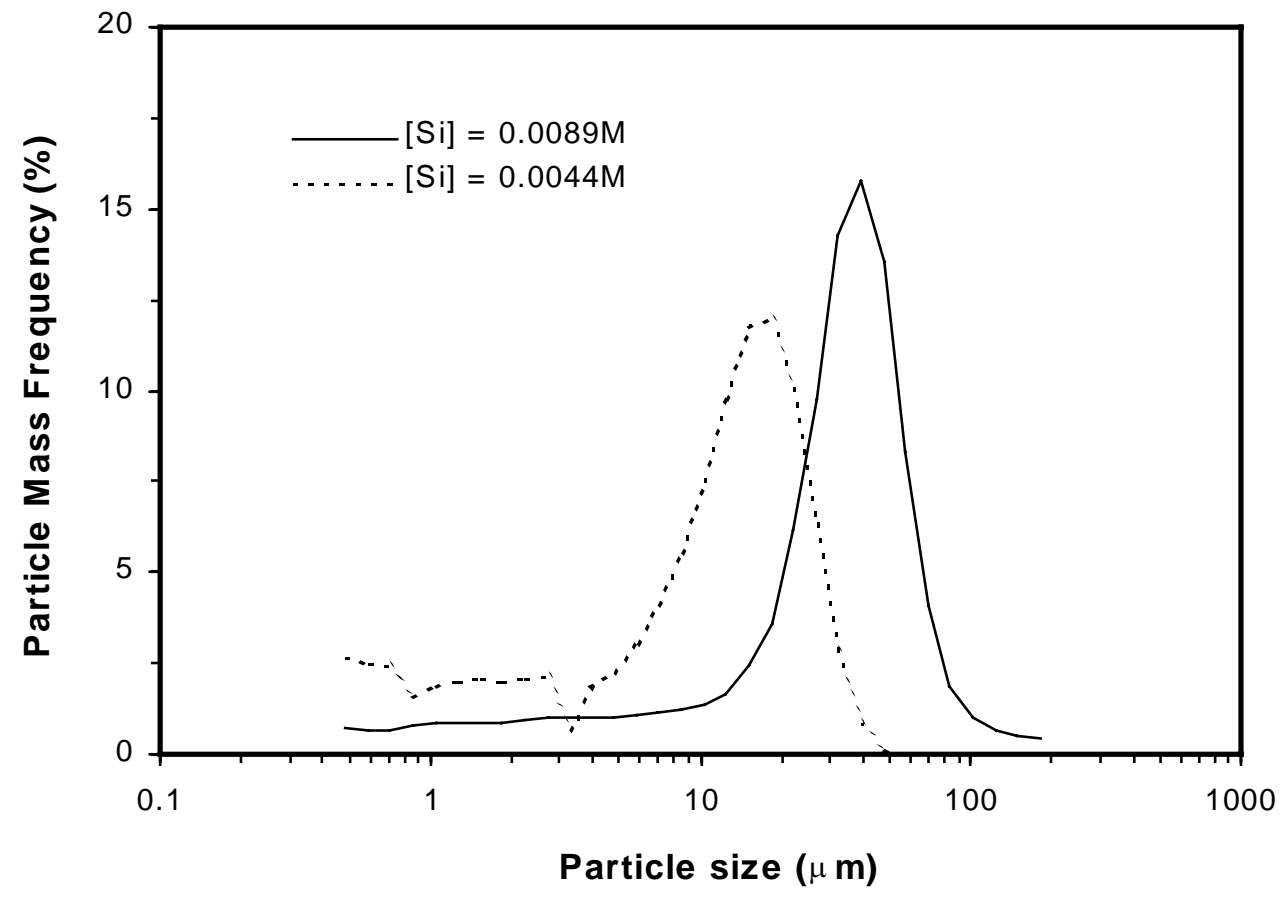

Figure 92 Crystal size distributions of solid particles obtained at $4 \mathrm{~h}$ from unseeded sodium aluminosilicate precipitation at $130{ }^{\circ} \mathrm{C}$ 


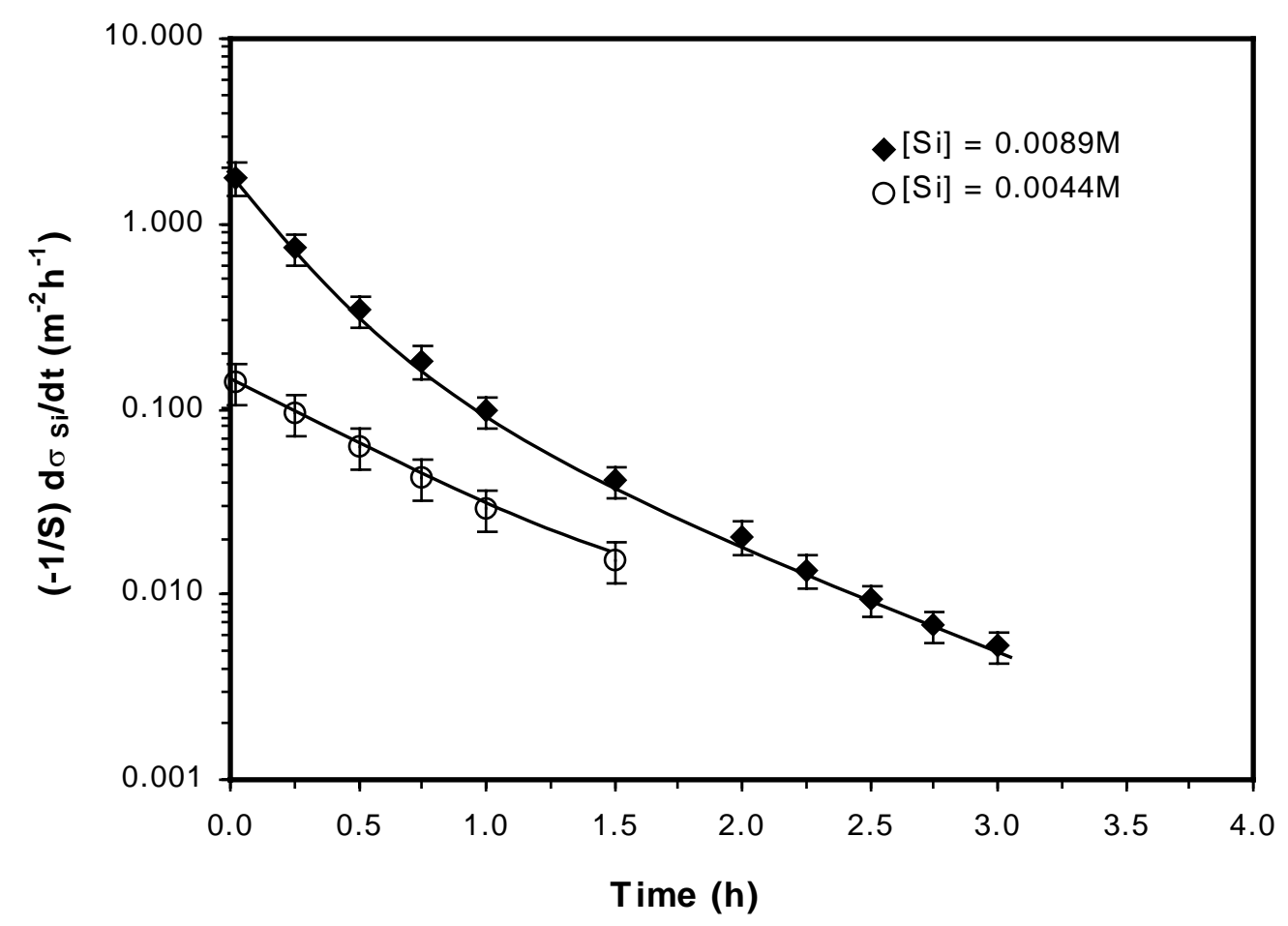

Figure 93 Desupersaturation flux at $130{ }^{\circ} \mathrm{C}$ and constant $\mathrm{Al}(\mathrm{III})=0.45 \mathrm{M}$, $\mathrm{NaOH}=4 \mathrm{M}, \mathrm{NaNO}_{3}=1 \mathrm{M}, \mathrm{NaNO}_{2}=1 \mathrm{M}$

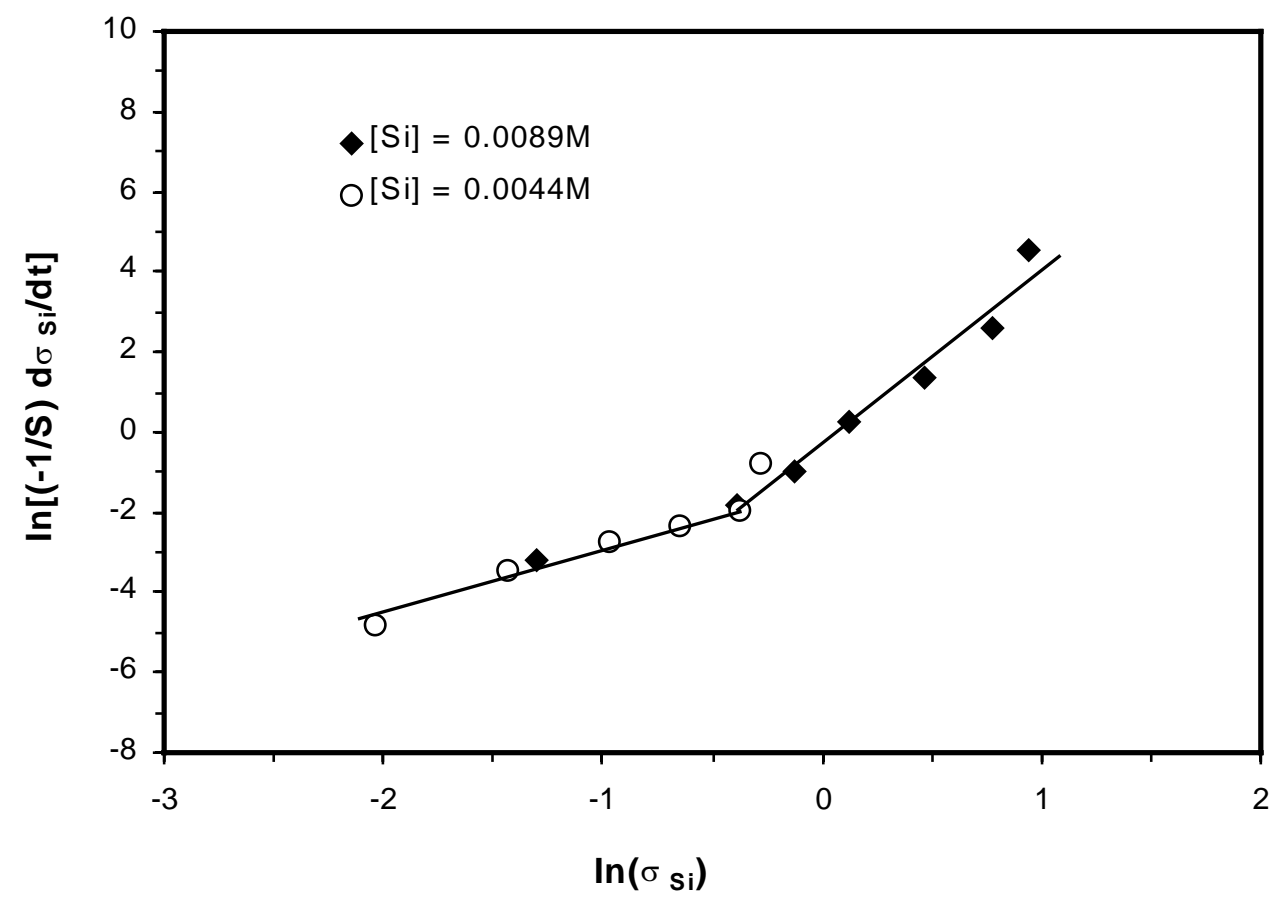

Figure $94 \quad \operatorname{In}\left[(-1 / \mathbf{S}) \mathbf{d} \sigma_{\mathrm{Si}} / \mathbf{d t}\right]$ versus $\operatorname{In}\left(\sigma_{\mathrm{Si}}\right)$ for homogeneous/heterogeneous nucleation and growth sodalite from solution at $130{ }^{\circ} \mathrm{C}$ and Constant $\mathrm{Al}$ (III) = $0.45 \mathrm{M}, \mathrm{NaOH}=4 \mathrm{M}, \mathrm{NaNO}_{3}=1 \mathrm{M}, \mathrm{NaNO}_{2}=1 \mathrm{M}$ 


\begin{tabular}{lcccccc}
\hline $\begin{array}{l}{[\mathbf{S i}][\mathbf{A I}]} \\
\left(\mathbf{M}^{\mathbf{2}}\right)\end{array}$ & \multicolumn{2}{c}{$\begin{array}{c}\text { Heterogeneous } \\
\text { Nucleation }\end{array}$} & \multicolumn{2}{c}{ Growth } & \multicolumn{2}{c}{ Transition Point $(\sigma)$} \\
\cline { 2 - 6 } & In k & Order $(\mathbf{n})$ & In k & Order $(\mathbf{n})$ & $\mathbf{S i O 2}$ & $\mathbf{A l}(\mathbf{I I I})$ \\
\hline $2 \times 10^{-3}$ & $/$ & $4.35 \pm 0.25$ & -1.07 & $1.97 \pm 0.20$ & $0.67 \pm 0.05$ & $/$ \\
$4 \times 10^{-3}$ & -0.68 & $5.45 \pm 0.25$ & -0.98 & $1.96 \pm 0.20$ & $0.67 \pm 0.05$ & $/$ \\
\hline
\end{tabular}

Table 18 Parameters for unseeded precipitation $\left(\left(\mathrm{NaOH}=4 \mathrm{M}, \mathrm{NaNO}_{3}=1 \mathrm{M}\right.\right.$, $\left.\mathrm{NaNO}_{2}=1 \mathrm{M}\right)$ at constant $\mathrm{Al}(\mathrm{III})=0.45 \mathrm{M}$ and $130{ }^{\circ} \mathrm{C}$

Comparisons of the parameters obtained in the present studies (Tables 17 and 18) with reported literature values (Tables 19 and 20) indicate good agreement in some cases and significant differences in others. Note that the literature values are quite variable. The relation between the current work and previous literature may be rationalized in terms of specific differences in solution composition, ionic strength and solid phase crystallographic characteristics. 


\begin{tabular}{|c|c|c|c|c|}
\hline \multirow[t]{2}{*}{ Authors } & \multirow[t]{2}{*}{ Experimental Conditions } & \multicolumn{3}{|c|}{ Nucleation } \\
\hline & & $\mathbf{n}$ & $\mathbf{k}_{\mathrm{no}}$ & $\begin{array}{c}\mathbf{E a} \\
(\mathbf{k J m} \\
\left.\mathbf{o l}^{-1}\right)\end{array}$ \\
\hline $\begin{array}{l}\text { Zhdanov } \\
\text { (1990) }\end{array}$ & $\begin{array}{l}\text { Zeolite A nucleation from a high } \mathrm{SiO}_{2} \text { and } \mathrm{Al}(\mathrm{OH})_{3} \\
\text { concentration via formation of an amorphous. }\end{array}$ & / & / & 44 \\
\hline $\begin{array}{l}\text { Antonic et } \\
\text { al. } 1994\end{array}$ & Zeolite A nucleation & l & l & $\begin{array}{c}12- \\
14\end{array}$ \\
\hline $\begin{array}{l}\text { Marui et } \\
\text { al., (2002) }\end{array}$ & $\begin{array}{l}\text { Zeolite A nucleation from a clear solution: } 6 \mathrm{M} \\
\mathrm{NaOH}, 3000-7000 \mathrm{ppm} \mathrm{SiO}_{2}, \mathrm{Al}(\mathrm{OH})_{3} \text { at } 65-80{ }^{\circ} \mathrm{C}\end{array}$ & I & l & 88 \\
\hline $\begin{array}{l}\text { Barnes } \\
(1999)\end{array}$ & $\begin{array}{l}\text { Sodalite nucleation from: } 3.87 \mathrm{M} \mathrm{NaOH}, 0.38 \mathrm{M} \\
\mathrm{Na}_{2} \mathrm{CO}_{3}, 0.1 \mathrm{M} \mathrm{SiO}_{2}, 1.67 \mathrm{M} \mathrm{Al}(\mathrm{OH})_{3}, 90-240{ }^{\circ} \mathrm{C} \text {. }\end{array}$ & / & / & 95 \\
\hline $\begin{array}{l}\text { Gualtieri } \\
\text { et al., } \\
(1997)\end{array}$ & $\begin{array}{l}\text { Sodalite nucleation from a clear solution: } 1 \mathrm{M} \mathrm{NaOH} \\
\text { (dissolved kaolinites in } 4 \mathrm{M} \mathrm{NaOH} \text {, then diluted into } \\
1 \mathrm{M} \mathrm{NaOH} \text { concentration) at } 100-130^{\circ} \mathrm{C} \text {. }\end{array}$ & 4.7 & $\begin{array}{c}2 \times 10^{9} \\
\min ^{-1}-1 \times \\
10^{18} \min ^{-1}\end{array}$ & $\begin{array}{l}71- \\
142\end{array}$ \\
\hline $\begin{array}{l}\text { Grujic et } \\
\text { al., (1989) }\end{array}$ & $\begin{array}{l}\text { Sodalite nucleation from a zeolite } \mathrm{A} \text { seeded } \\
\text { solution: } 8 \mathrm{M} \mathrm{NaOH} \text { at } 70-85^{\circ} \mathrm{C} \text {. }\end{array}$ & / & / & 104 \\
\hline $\begin{array}{l}\text { Barnes } \\
(1999)\end{array}$ & $\begin{array}{l}\text { Cancrinite nucleation from a sodalite seeded } \\
\text { solution: } 3.87 \mathrm{M} \mathrm{NaOH}, 0.38 \mathrm{M} \mathrm{Na}_{2} \mathrm{CO}_{3}, 0.05 \mathrm{M} \mathrm{SiO}_{2} \\
\text { and } 1.67 \mathrm{M} \mathrm{Al}(\mathrm{OH})_{3} \text { at } 180-240{ }^{\circ} \mathrm{C} .\end{array}$ & 2 & $\begin{array}{c}2.68 \times 10^{13} \\
\mathrm{~h}^{-1}\end{array}$ & 133 \\
\hline $\begin{array}{l}\text { Duncan et } \\
\text { al., (1995) }\end{array}$ & Scale formation in pilot plant size heat exchangers. & 2 & $5.1 \times 10^{4}$ & 77 \\
\hline $\begin{array}{l}\text { O’Neill } \\
\text { (1986) }\end{array}$ & Heat exchanger scaling plant liquor. & 2 & $2.4 \times 10^{5}$ & 51 \\
\hline This study & $\begin{array}{l}\text { Zeolite nucleation from a zeolite seeded solution: } \\
4 \mathrm{M} \mathrm{NaOH}, 1 \mathrm{M} \mathrm{NaNO}, 0.175 \mathrm{M} \mathrm{SiO}_{2} \text { and } 0.188 \mathrm{M} \\
\mathrm{Al}(\mathrm{III}) \text { at } 30 \text { and } 65^{\circ} \mathrm{C} \text {. }\end{array}$ & 4 & $\begin{array}{l}2.7 \times 10^{3} \\
\mathrm{~m}^{-2} \mathrm{~h}^{-1}\end{array}$ & 47 \\
\hline This study & $\begin{array}{l}\text { Sodalite nucleation from a sodalite seeded solution: } \\
4 \mathrm{M} \mathrm{NaOH}, 1 \mathrm{M} \mathrm{NaNO}, 0.175 \mathrm{M} \mathrm{SiO}_{2} \text { and } 0.188 \mathrm{M} \\
\mathrm{Al}(\mathrm{III}) \text { at } 30-130{ }^{\circ} \mathrm{C} \text {. }\end{array}$ & 4 & $\begin{array}{c}4.0 \times 10^{8} \\
\mathrm{~m}^{-2} \mathrm{~h}^{-1}\end{array}$ & 49 \\
\hline This study & $\begin{array}{l}\text { Cancrinite nucleation from a cancrinite seeded } \\
\text { solution: } 4 \mathrm{M} \mathrm{NaOH}, 1 \mathrm{M} \mathrm{NaNO}_{2}, 0.175 \mathrm{M} \mathrm{SiO}_{2} \text { and } \\
0.188 \mathrm{M} \mathrm{Al}(\mathrm{III}) \text { at } 30-130{ }^{\circ} \mathrm{C} .\end{array}$ & 4 & $\begin{array}{l}1.9 \times 10^{7} \\
\mathrm{~m}^{-2} \mathrm{~h}^{-1}\end{array}$ & 82 \\
\hline
\end{tabular}

Table 18 Literature reported parameters for nucleation of sodium aluminosilicate 


\begin{tabular}{|c|c|c|c|c|}
\hline \multirow[t]{2}{*}{ Authors } & \multirow[t]{2}{*}{ Experimental Conditions } & \multicolumn{3}{|l|}{ Growth } \\
\hline & & $\begin{array}{c}\text { Order } \\
\text { (n) }\end{array}$ & $\mathbf{k}_{\mathrm{go}}$ & $\underset{\left(\mathrm{kJJmol}^{-1}\right)}{\mathbf{E a}}$ \\
\hline $\begin{array}{l}\text { Zhdanov } \\
(1971)\end{array}$ & Growth of Zeolite A. & I & I & 44 \\
\hline $\begin{array}{l}\text { Schoeman } \\
\text { et al., } \\
(1994)\end{array}$ & $\begin{array}{l}\text { Growth of Silicalite-1: a clear solution } \\
\text { with molar composition of 9TPAOH : } \\
0.1 \mathrm{Na}_{2} \mathrm{O}: 25 \mathrm{SiO}_{2}: 480 \mathrm{H}_{2} \mathrm{O}: 100 \mathrm{EtOH} \\
\text { at } 80-98{ }^{\circ} \mathrm{C} .\end{array}$ & 1 & / & 42 \\
\hline $\begin{array}{l}\text { Zhdanov et } \\
\text { al., (1980) }\end{array}$ & Growth of zeolite X. & I & I & 63 \\
\hline $\begin{array}{l}\text { Kacirek et } \\
\text { al., (1975) } \\
(1976)\end{array}$ & Growth of zeolite Y. & / & I & $49-65$ \\
\hline $\begin{array}{l}\text { Grujic et } \\
\text { al., (1989) }\end{array}$ & $\begin{array}{l}\text { Growth of sodalite: } 8 \mathrm{M} \mathrm{NaOH} \text { at } 70-85 \\
{ }^{\circ} \mathrm{C} \text {. }\end{array}$ & I & I & 102 \\
\hline $\begin{array}{l}\text { Barnes et } \\
\text { al., (1999) }\end{array}$ & $\begin{array}{l}\text { Growth of sodalite: } 3.87 \mathrm{M} \mathrm{NaOH} \text {, } \\
0.38 \mathrm{M} \mathrm{Na} \mathrm{CO}_{3}, 0.1 \mathrm{M} \mathrm{SiO}_{2} \text { and } 1.67 \mathrm{M} \\
\mathrm{Al}(\mathrm{OH})_{3} \text { at } 90-220^{\circ} \mathrm{C} \text {. }\end{array}$ & 2 & $\begin{array}{l}26.8 \mathrm{~m}^{-2} \\
\min ^{-1}\end{array}$ & 30 \\
\hline $\begin{array}{l}\text { Barnes et } \\
\text { al., (1999) }\end{array}$ & $\begin{array}{l}\text { Growth of cancrinite: } 3.87 \mathrm{M} \mathrm{NaOH} \text {, } \\
0.38 \mathrm{M} \mathrm{Na} \mathrm{CO}_{3}, 0.1 \mathrm{M} \mathrm{SiO} \text { and } 1.67 \mathrm{M} \\
\mathrm{Al}(\mathrm{OH})_{3} \text { at } 120-180{ }^{\circ} \mathrm{C} \text {. }\end{array}$ & 3 & $\begin{array}{l}1.2 \times 10^{7} \\
\mathrm{~m}^{-2} \min ^{-1}\end{array}$ & 80 \\
\hline This study & $\begin{array}{l}\text { Growth of amorphous: } 4 \mathrm{M} \mathrm{NaOH}, 1 \mathrm{M} \\
\mathrm{NaNO}_{2}, \sigma_{\mathrm{Si}}=0.5 \text { and } \sigma_{\mathrm{Al}}=0.5 \text { at } 30 \text { and } \\
65^{\circ} \mathrm{C} \text {. }\end{array}$ & 2 & $\begin{array}{l}1.6 \times 10^{-2} \\
\mathrm{~m}^{-2} \mathrm{~h}^{-1}\end{array}$ & 2.5 \\
\hline This study & $\begin{array}{l}\text { Growth of zeolite: } 4 \mathrm{M} \quad \mathrm{NaOH}, 1 \mathrm{M} \\
\mathrm{NaNO}_{2}, \sigma_{\mathrm{Si}}=0.5 \text { and } \sigma_{\mathrm{Al}}=0.5 \text { at } 30 \text { and } \\
65^{\circ} \mathrm{C} \text {. }\end{array}$ & 2 & $\begin{array}{l}2.8 \times 10^{1} \\
\mathrm{~m}^{-2} \mathrm{~h}^{-1}\end{array}$ & 23 \\
\hline This study & $\begin{array}{l}\text { Growth of sodalite: } 4 \mathrm{M} \mathrm{NaOH}, 1 \mathrm{M} \\
\mathrm{NaNO}_{2}, \sigma_{\mathrm{Si}}=0.5 \text { and } \sigma_{\mathrm{Al}}=0.5 \text { at } 30- \\
130{ }^{\circ} \mathrm{C} .\end{array}$ & 2 & $\begin{array}{l}3.0 \times 10^{2} \\
\mathrm{~m}^{-2} \mathrm{~h}^{-1}\end{array}$ & 31 \\
\hline This study & $\begin{array}{l}\text { Growth of cancrinite: } 4 \mathrm{M} \mathrm{NaOH}, 1 \mathrm{M} \\
\mathrm{NaNO}_{2}, \sigma_{\mathrm{Si}}=0.5 \text { and } \sigma_{\mathrm{Al}}=0.5 \text { at } 65 \text { and } \\
130{ }^{\circ} \mathrm{C} \text {. }\end{array}$ & 2 & $\begin{array}{l}4.4 \times 10^{7} \\
\mathrm{~m}^{-2} \mathrm{~h}^{-1}\end{array}$ & 67 \\
\hline
\end{tabular}

Table 19 Literature reported kinetics parameters for sodium aluminosilicate crystal growth 


\subsection{Sodium Aluminosilicate Solid Phase Transformations}

\subsection{Overview}

The crystallographic characteristics and kinetic behavior of sodium aluminosilicate solid phases have been investigated as a function of solution conditions and temperature by $\mathrm{X}$ ray powder diffraction analysis of products periodically removed from the suspension. Specifically, hydrothermal transformation of amorphous solid, zeolite, sodalite and cancrinite crystalline phases were studied at 30,65 and $130{ }^{\circ} \mathrm{C}$ in caustic aluminate liquors.

\subsection{Results and Discussions}

The results reveal that in the presence of nitrate and nitrite ions the transformation of amorphous seed particles in $\mathrm{SiO}_{2}$-free caustic solutions $(4 \mathrm{M} \mathrm{NaOH}, 1 \mathrm{M} \mathrm{NaNO}$ and $1 \mathrm{MNaNO}_{2}$ ) at $65{ }^{\circ} \mathrm{C}$ (Figure 95) proceeded to the sodalite phase over a period of $1 \mathrm{~h}$ without detection of zeolite phase. After $3 \mathrm{~h}$ a very small concentration of cancrinite was also observed and increased with time. 


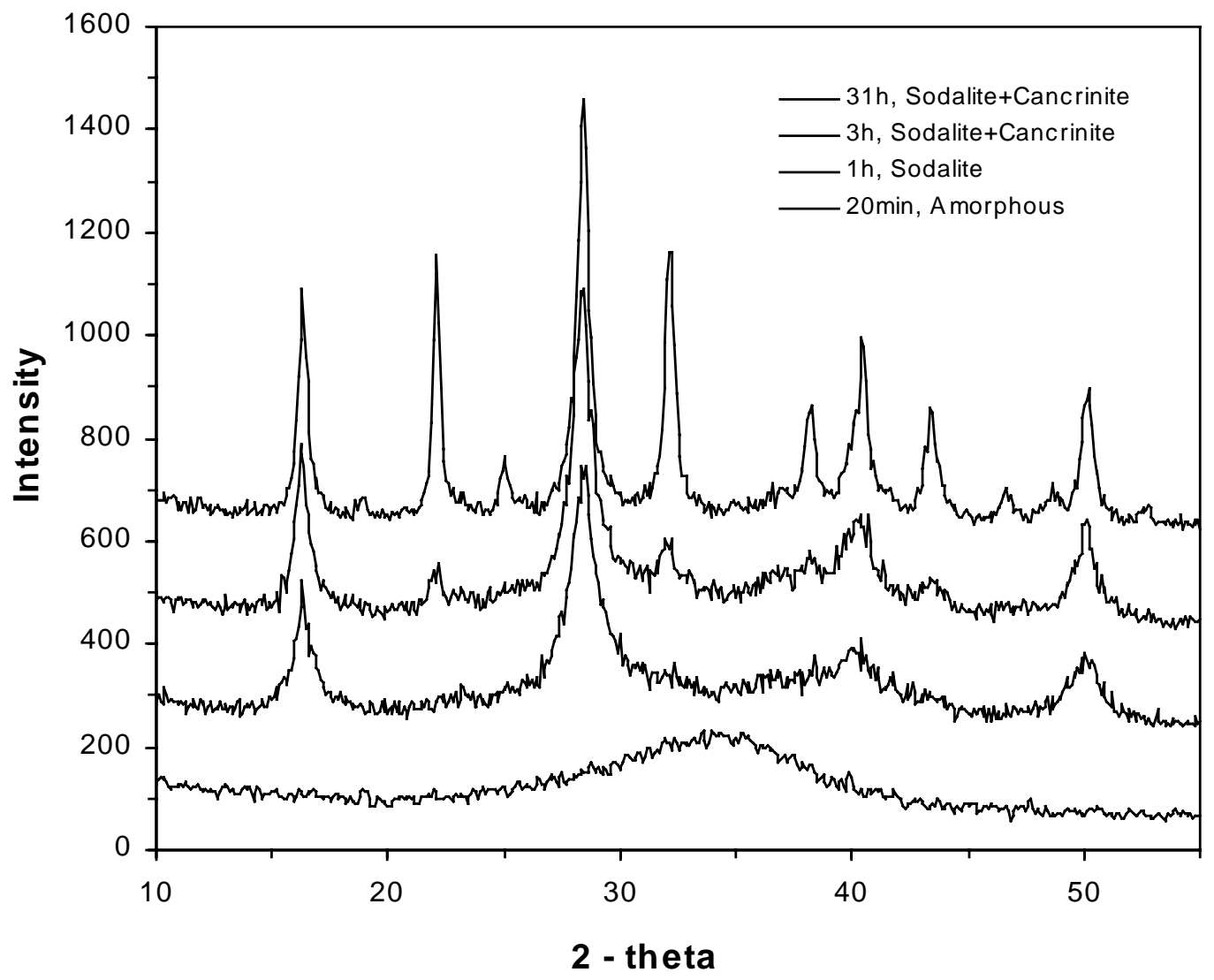

Figure $95 \quad \mathrm{XRD}$ analysis of the amorphous seed in $4 \mathrm{M} \mathrm{NaOH}, 1 \mathrm{M} \mathrm{NaNO}_{3}$ and $1 \mathrm{MNaNO}_{2}$ solution as a function of time at $65^{\circ} \mathrm{C}$

Similar phase transformation behaviour was observed for the following initial supersaturated conditions: $4.0 \mathrm{M} \mathrm{NaOH}, 1.0 \mathrm{M} \mathrm{NaNO}_{3}, 1.0 \mathrm{M} \mathrm{NaNO}_{2}, 0.175 \mathrm{M} \mathrm{SiO}_{2}$ and $0.188 \mathrm{M} \mathrm{Al}(\mathrm{III})$ ) at $65{ }^{\circ} \mathrm{C}$ (Figure 96). The amorphous - sodalite transformation rate appeared to be faster in undersaturated than supersaturated solution.

Transformation of zeolite A phase to sodalite in a solution of $8.0 \mathrm{M} \mathrm{NaOH}, 2.0 \mathrm{M}$ $\mathrm{NaNO}_{3}, 2.0 \mathrm{M} \mathrm{NaNO}_{2}$ and $0.15 \mathrm{M} \mathrm{Al}(\mathrm{III})$ ) at $30{ }^{\circ} \mathrm{C}$ occurred after $8 \mathrm{~h}$ (Figure 97). Upon further aging to $17 \mathrm{~h}$ the cancrinite phase appeared alongside with zeolite and sodalite. A mixture of sodalite and cancrinite phases formed with the disappearance of the zeolite phase over $336 \mathrm{~h}$. 


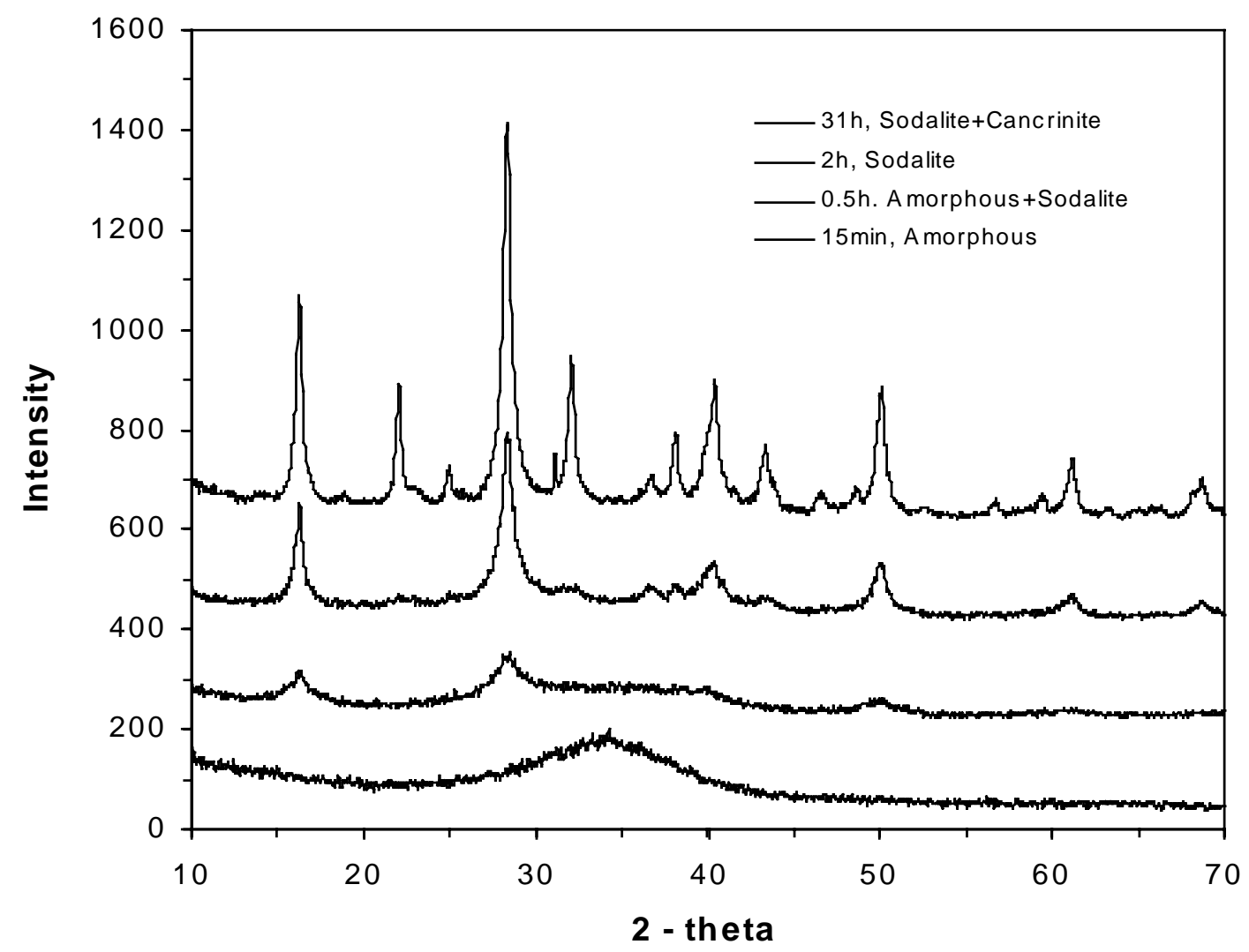

Figure 96 XRD analysis of crystals obtained from an amorphous seeded precipitation as a function of time at $65{ }^{\circ} \mathrm{C}$ and initial concentration: $4 \mathrm{M} \mathrm{NaOH}$,

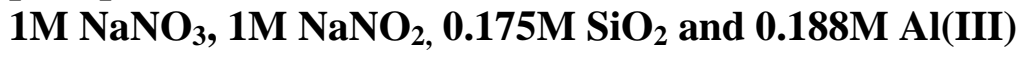




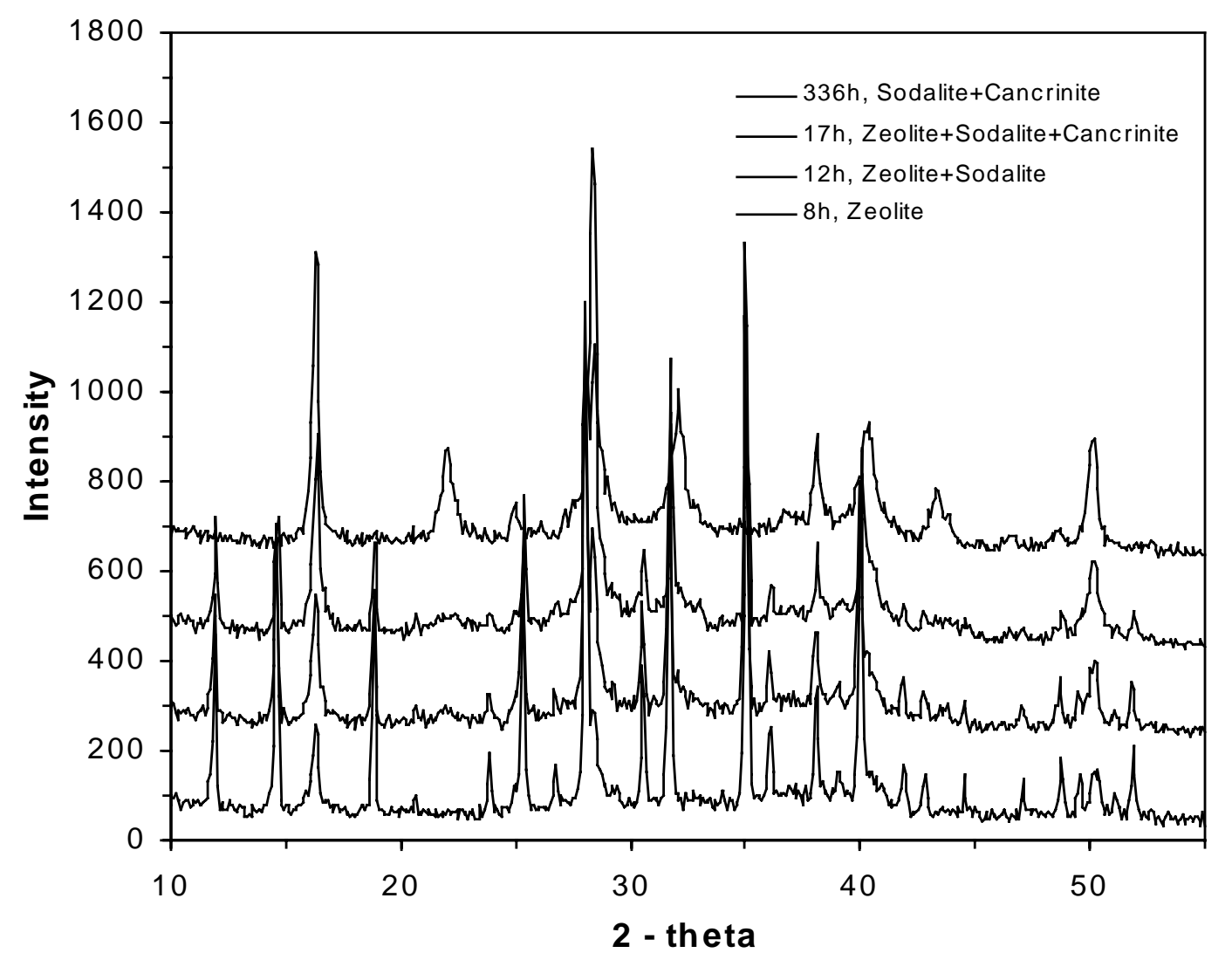

Figure $97 \quad \mathrm{XRD}$ analysis of the zeolite seed in $8 \mathrm{M} \mathrm{NaOH}, 2 \mathrm{M} \mathrm{NaNO} \mathbf{2}_{3} \mathbf{2 M N a N O}_{2}$ and $0.15 \mathrm{M} \mathrm{Al}(\mathrm{III})$ solutions as a function of dissolution time at $30^{\circ} \mathrm{C}$

Similar phase transformation behaviour of zeolite to sodalite then to cancrinite was observed under supersaturated or precipitation conditions over $23 \mathrm{~h}$ (Figure 98). 


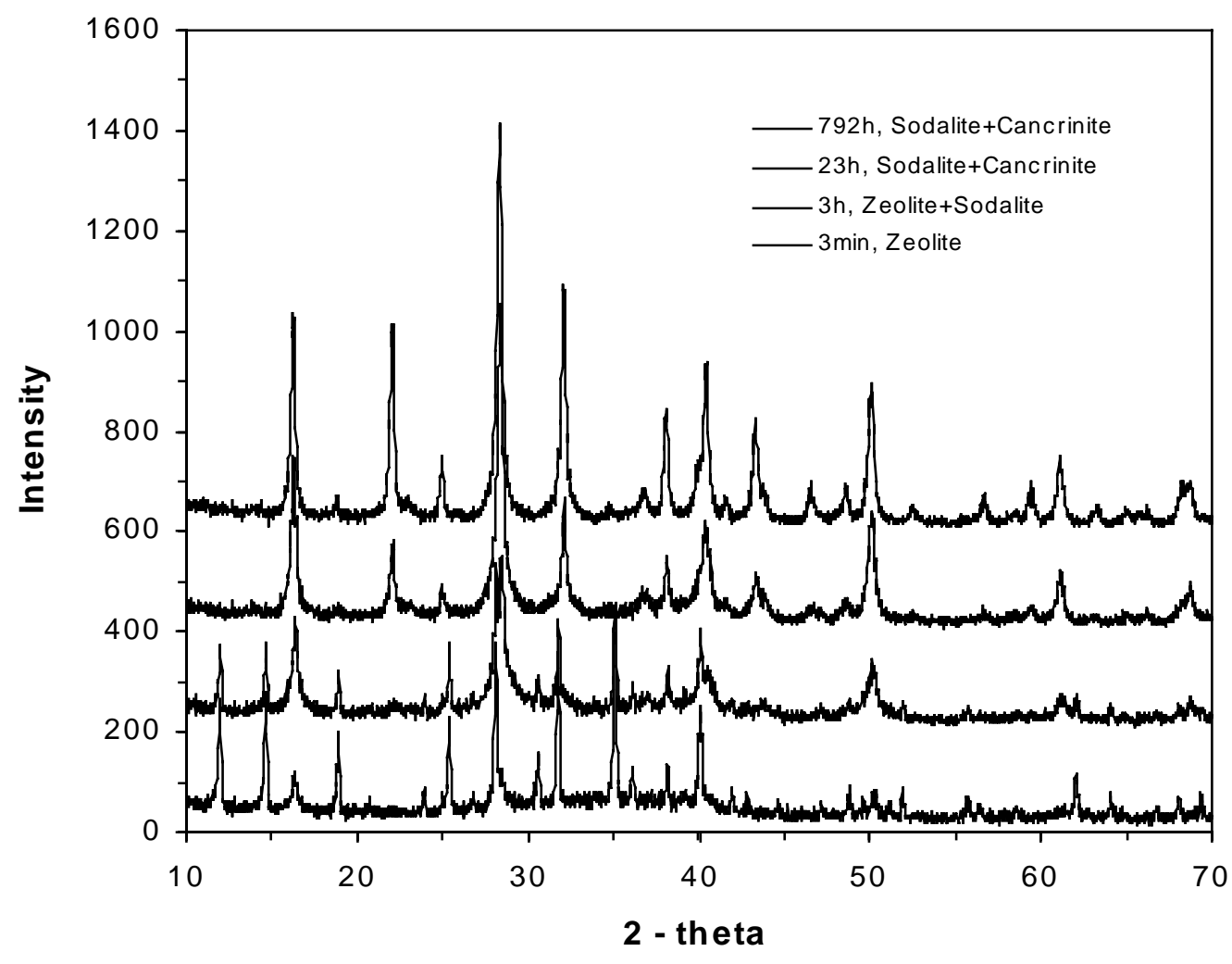

Figure 98 XRD analysis of crystals obtained from a zeolite A seeded precipitation as a function of time at $65^{\circ} \mathrm{C}$ and concentration: $4 \mathrm{M} \mathrm{NaOH}, 1 \mathrm{M}$ $\mathrm{NaNO}_{3}, 1 \mathrm{M} \mathrm{NaNO}, \mathrm{O}_{2} .175 \mathrm{M} \mathrm{SiO}_{2}$ and $0.188 \mathrm{M} \mathrm{Al}(\mathrm{III})$

The sodalite to cancrinite phase transformation was observed over 2 to $31 \mathrm{~h}$ for sodalite seeded in undersaturated $\left(\mathrm{SiO}_{2}\right.$ and $\mathrm{Al}(\mathrm{III})$-free) solution (Figure 99). A similar trend was obtained under supersaturated conditions at $65{ }^{\circ} \mathrm{C}$ over $6-768 \mathrm{~h}$ (Figure 100). Thus the transformation from sodalite to cancrinite was significantly faster in the undersaturated than supersaturated conditions.

Based on the results of synthesis, transformation and characterization studies, the amorphous $\rightarrow$ zeolite $\mathrm{A} \rightarrow$ sodalite phase transformation in nitrate/nitrite rich liquors at $65{ }^{\circ} \mathrm{C}$ or higher temperatures appears to be so rapid that the zeolite A solid phase in the product was practically undetectable by XRD (i.e. $<4 \mathrm{wt} \%$ ). 


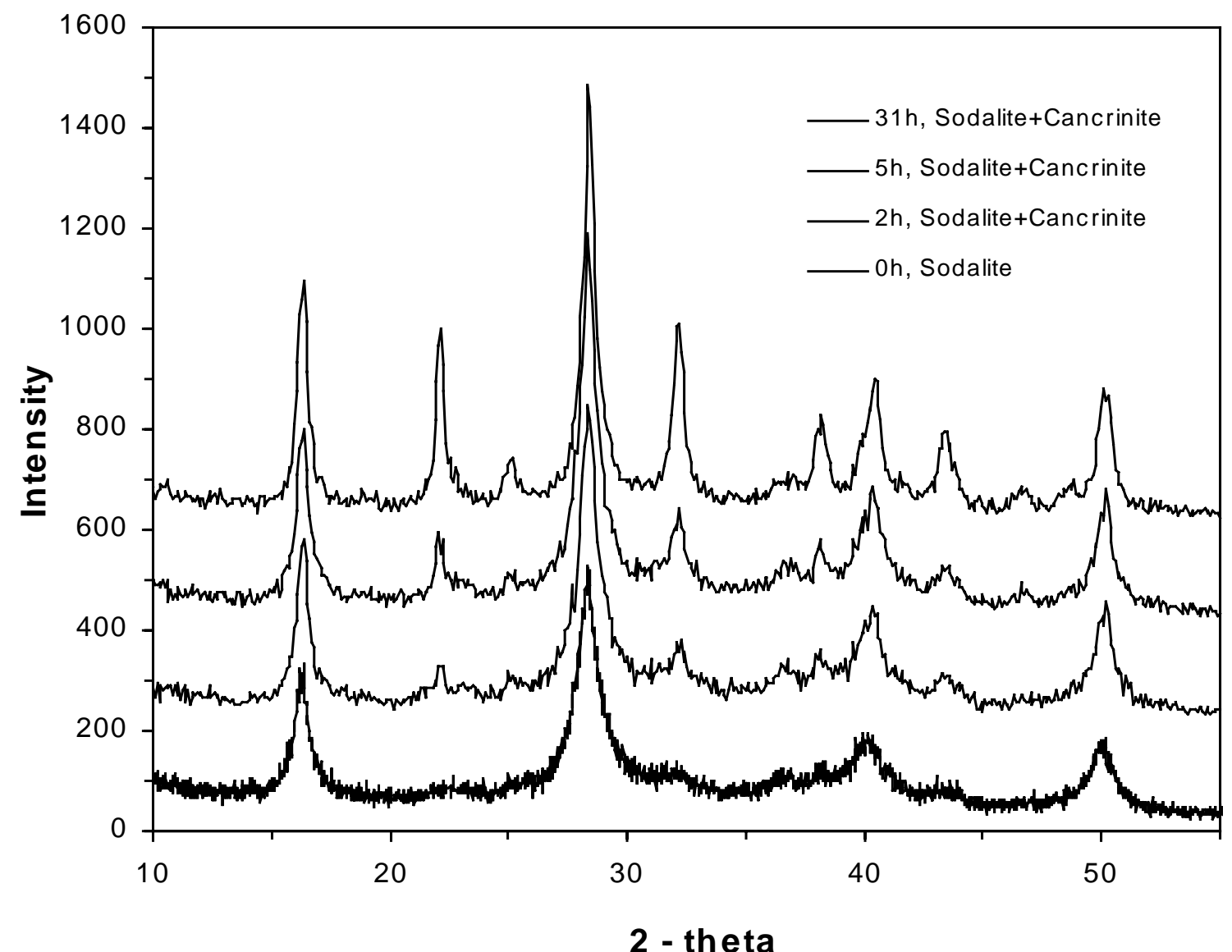

Figure 99 XRD analysis of the sodalite seed in $4 \mathrm{M} \mathrm{NaOH}, 1 \mathrm{M} \mathrm{NaNO} \mathrm{Na}_{3}$ and $1 \mathrm{MNaNO}_{2}$ solutions at $65^{\circ} \mathrm{C}$ 


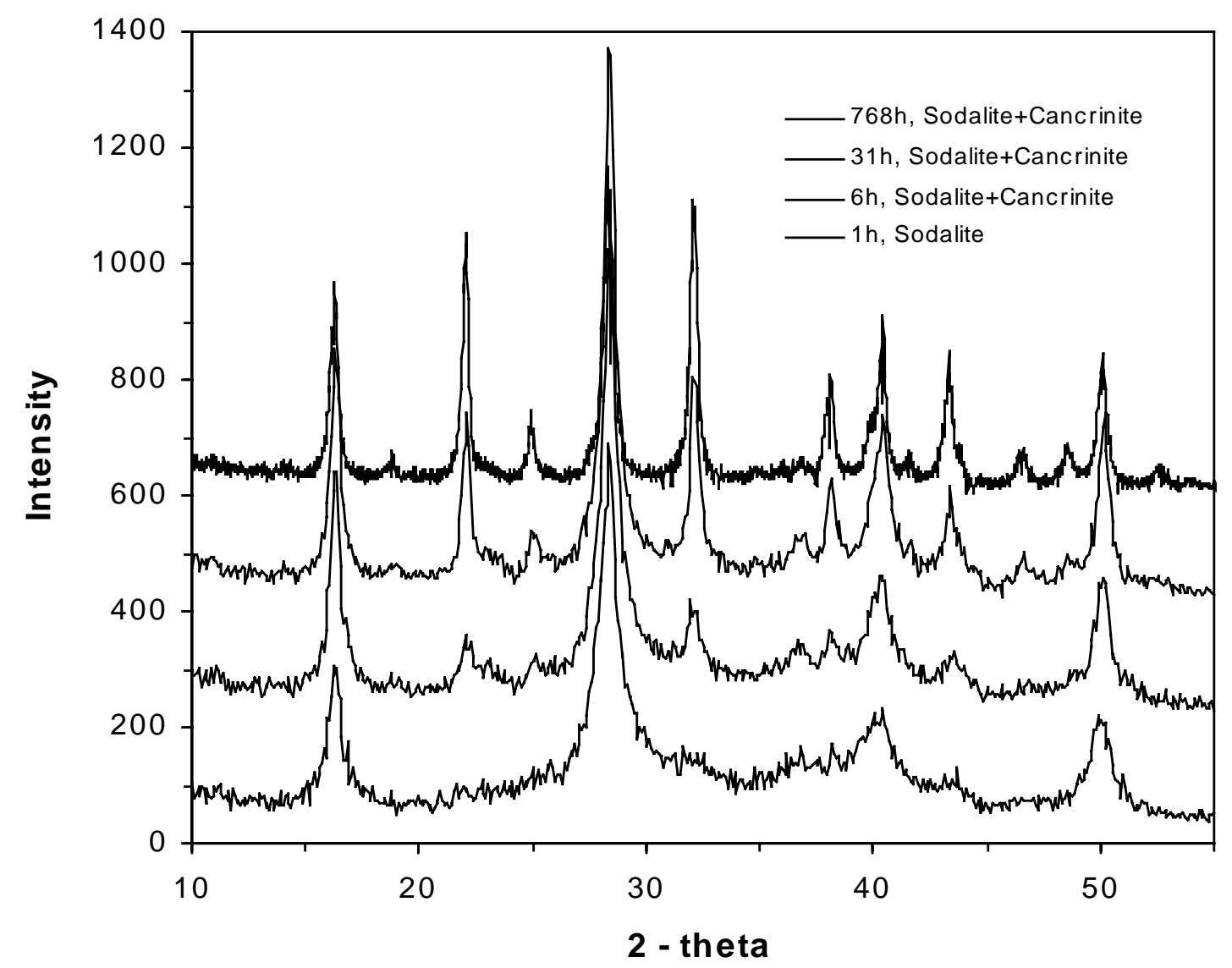

Figure 100 XRD analysis of crystals obtained from a sodalite seeded precipitation at $65{ }^{\circ} \mathrm{C}$ and initial solution concentration of $4 \mathrm{M} \mathrm{NaOH}, 1 \mathrm{M} \mathrm{NaNO} \mathrm{N}_{3}$, $1 \mathrm{M} \mathrm{NaNO}, \mathrm{N.175} \mathrm{MiO}_{2}$ and $0.188 \mathrm{M} \mathrm{Al}(\mathrm{III})$

Increasing relative concentrations of sodalite/cancrinite phase were observed with time regardless of the initial seed phase (Figures 101-108). Amorphous transformed to sodalite with the greatest rate while sodalite transformed to cancrinite at the lowest rate. It is worth noting that complete sodalite to cancrinite transformation cannot be achieved at $130{ }^{\circ} \mathrm{C}$ even with time of up to $400 \mathrm{~h}$.

It is apparent that there is a very strong dependence of the rate of transformation on temperature (Figures 101-102). After $70 \mathrm{~min}$ at $65^{\circ} \mathrm{C}$ there is almost $100 \%$ conversion of amorphous phase to sodalite but only 2 min required for a similar conversion at 130 ${ }^{\circ} \mathrm{C}$ (Figure 101). At $65{ }^{\circ} \mathrm{C}$ after $31 \mathrm{~h}$ only $38 \%$ of sodalite transformed to cancrinite while only $2 \mathrm{~h}$ was required for a similar level of transformation at $130{ }^{\circ} \mathrm{C}$ (Figure 102). 


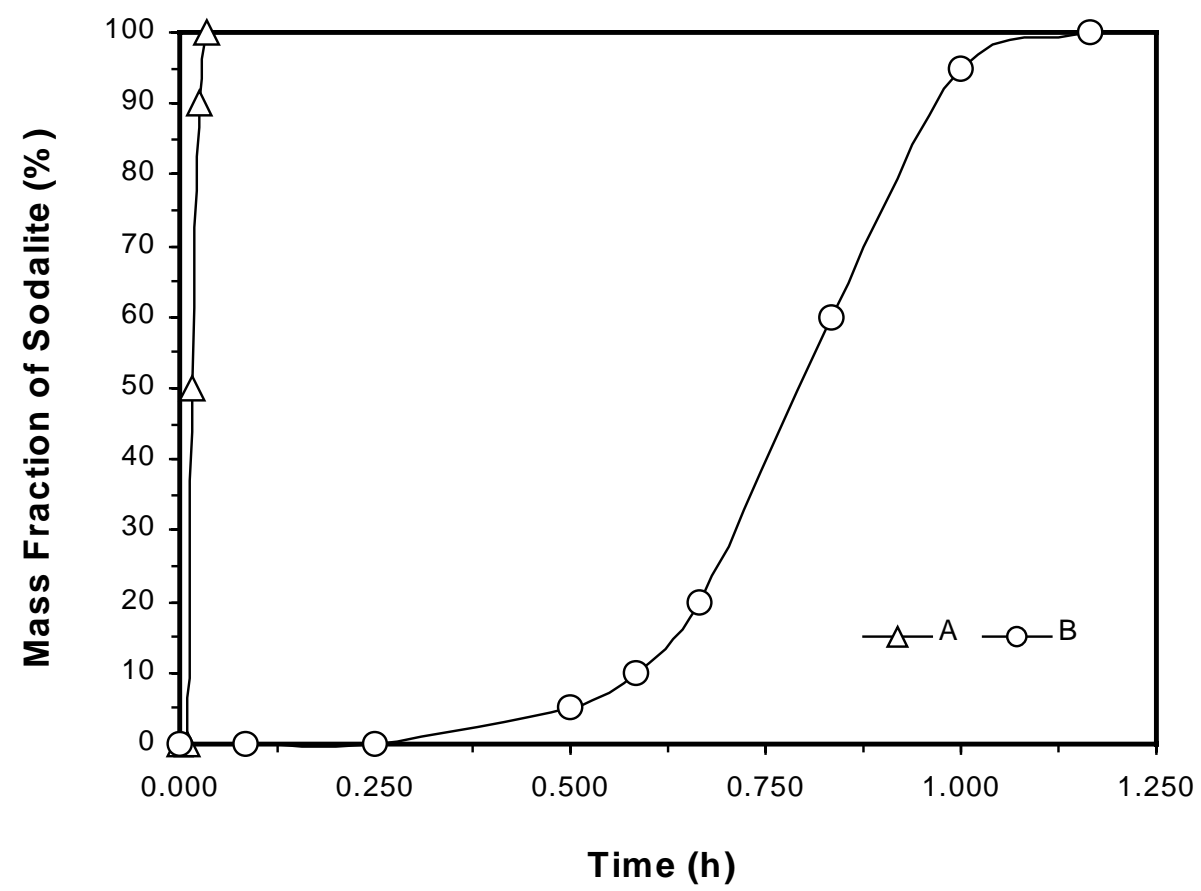

Figure 101 Mass fraction of sodalite in solid samples obtained from amorphous seed in $4 \mathrm{M} \mathrm{NaOH}, 1 \mathrm{M} \mathrm{NaNO}$ and $1 \mathrm{MNaNO}_{2}$ solutions at 130 (A) and $65^{\circ} \mathrm{C}(\mathrm{B})$

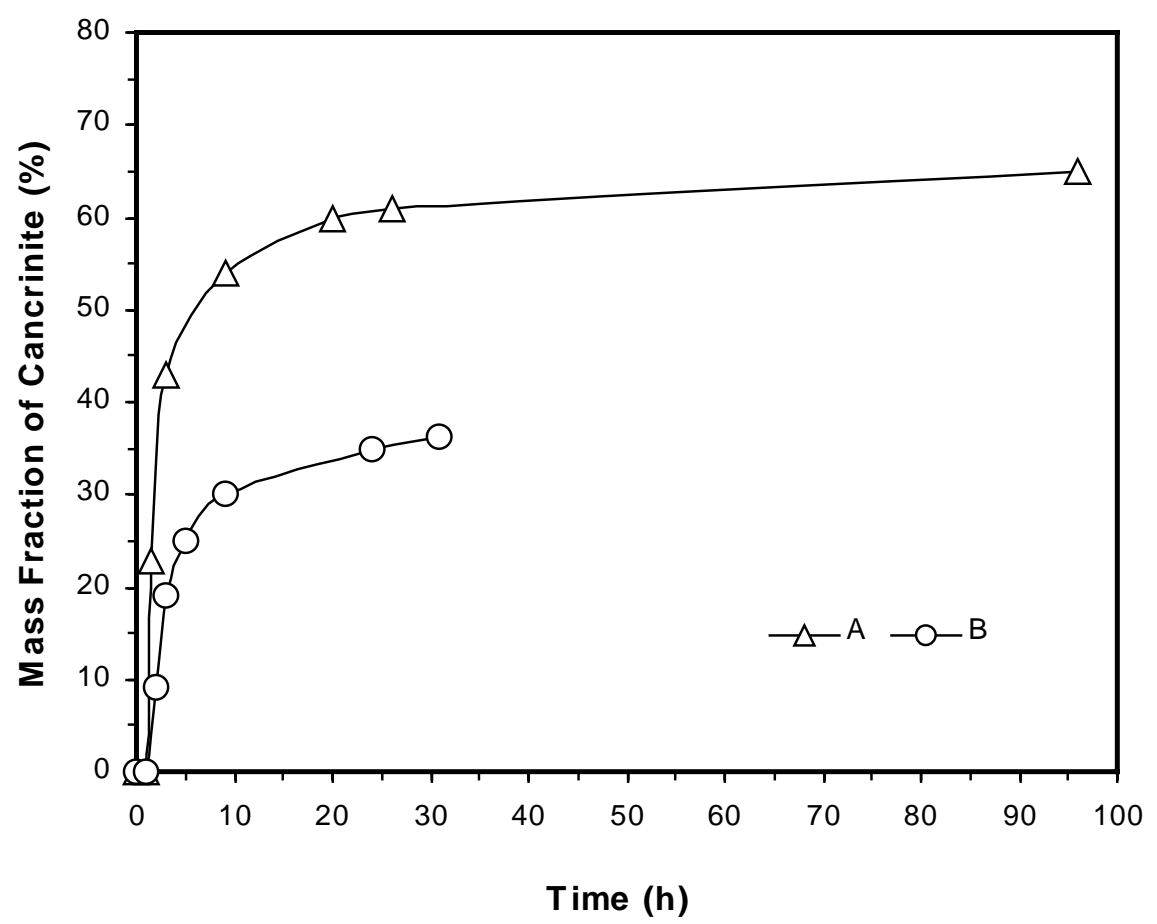

Figure 102 Mass fraction of cancrinite in solid samples obtained from sodalite seed in $4 \mathrm{M} \mathrm{NaOH}, 1 \mathrm{M} \mathrm{NaNO}{ }_{3}$ and $1 \mathrm{MNaNO}_{2}$ solutions at $130(\mathrm{~A})$ and $65^{\circ} \mathrm{C}(\mathrm{B})$ 


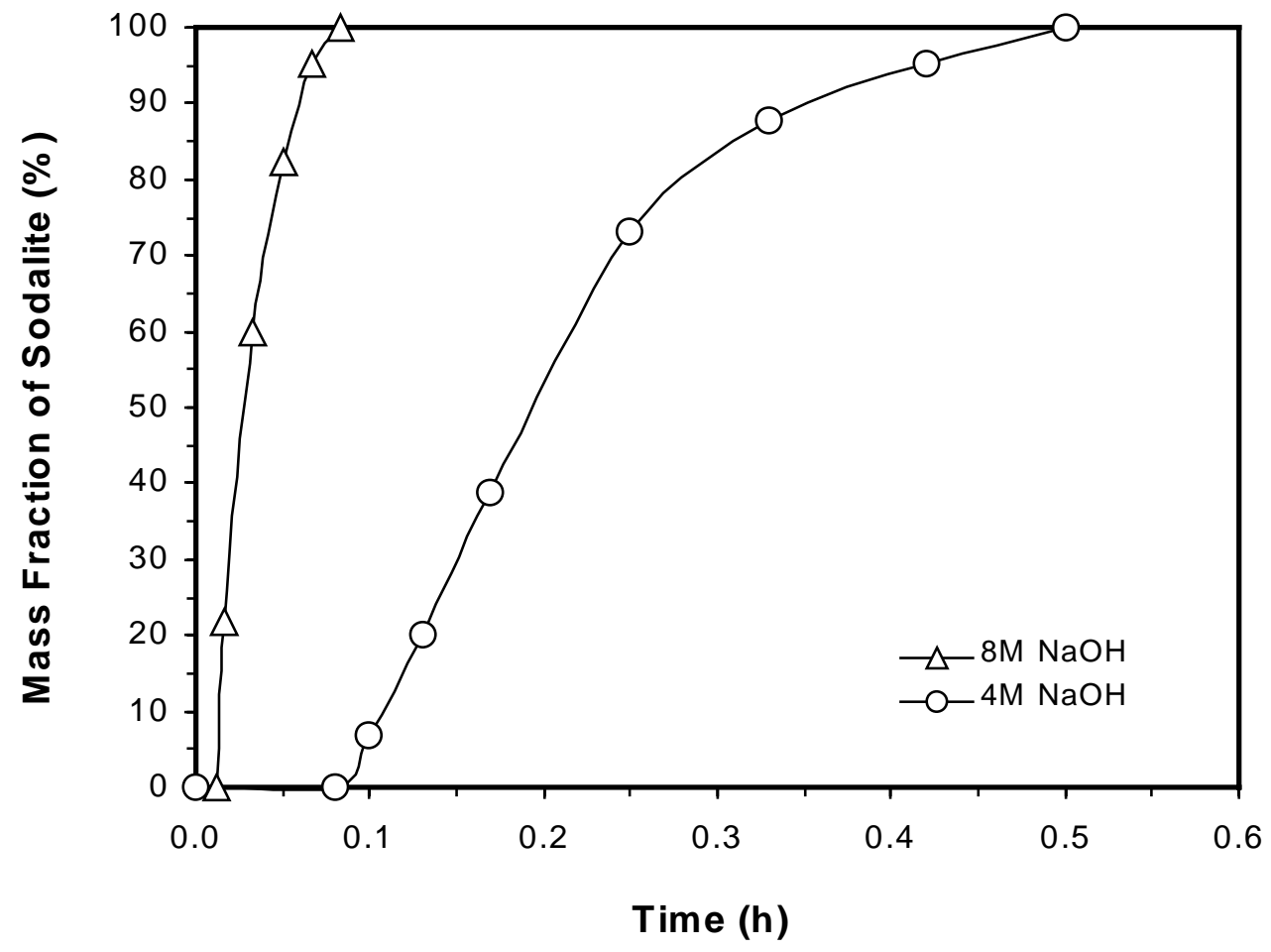

Figure 103 Mass fraction of sodalite in solid samples obtained from zeolite seed in different solutions (initial $\mathrm{Al}(\mathrm{III})=0 \mathrm{M}$ ) as a function of time at $130{ }^{\circ} \mathrm{C}$

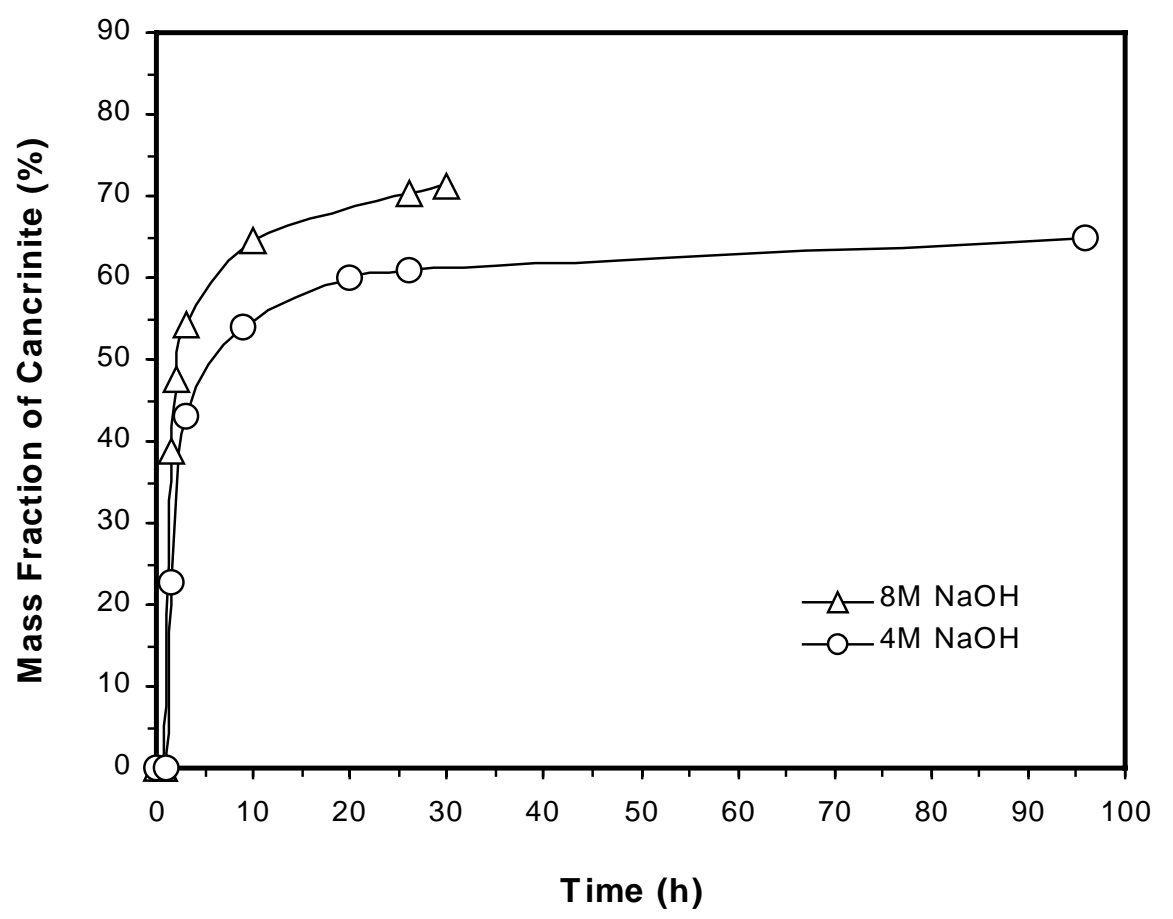

Figure 104 Mass fraction of cancrinite in solid samples obtained from sodalite seed in different solutions (initial $\mathrm{Al}(\mathrm{III})=0 \mathrm{M}$ ) as a function of time at $130{ }^{\circ} \mathrm{C}$ 
After 30 min at a low caustic and low nitrate/nitrite concentration there is almost $100 \%$ conversion form zeolite to sodalite but only $5 \mathrm{~min}$ is required for a similar conversion at a high caustic and high nitrate/nitrite concentration and $130{ }^{\circ} \mathrm{C}$ (Figure 103). At a low caustic and low nitrate/nitrite concentration and $130{ }^{\circ} \mathrm{C}$ after $96 \mathrm{~h} 65 \%$ sodalite transformed to cancrinite yet only $10 \mathrm{~h}$ is needed for a similar lever of transformation to occur at a high caustic and high nitrate/nitrite concentration and $130{ }^{\circ} \mathrm{C}$ (Figure 104).

The level of initial $\mathrm{Al}(\mathrm{III})$ concentration significantly affects the rate of phase transformation (Figures 105-108). A higher Al(III) concentration resulted in a lower rate of transformation while a lower A(III) concentration resulted in a higher rate of transformation under experimental conditions investigated in the study. It was found that at an initial $\mathrm{Al}(\mathrm{III})$ concentration of $0.45 \mathrm{M}$ that during either amorphous or zeolite to sodalite transformations the zeolite-sodalite intermediate structure was observalbe. In contrast at low initial $\mathrm{Al}(\mathrm{III})$ concentrations $(0-0.15 \mathrm{M})$ a nitrite-bearing cubic structure of sodalite formed was only detected.

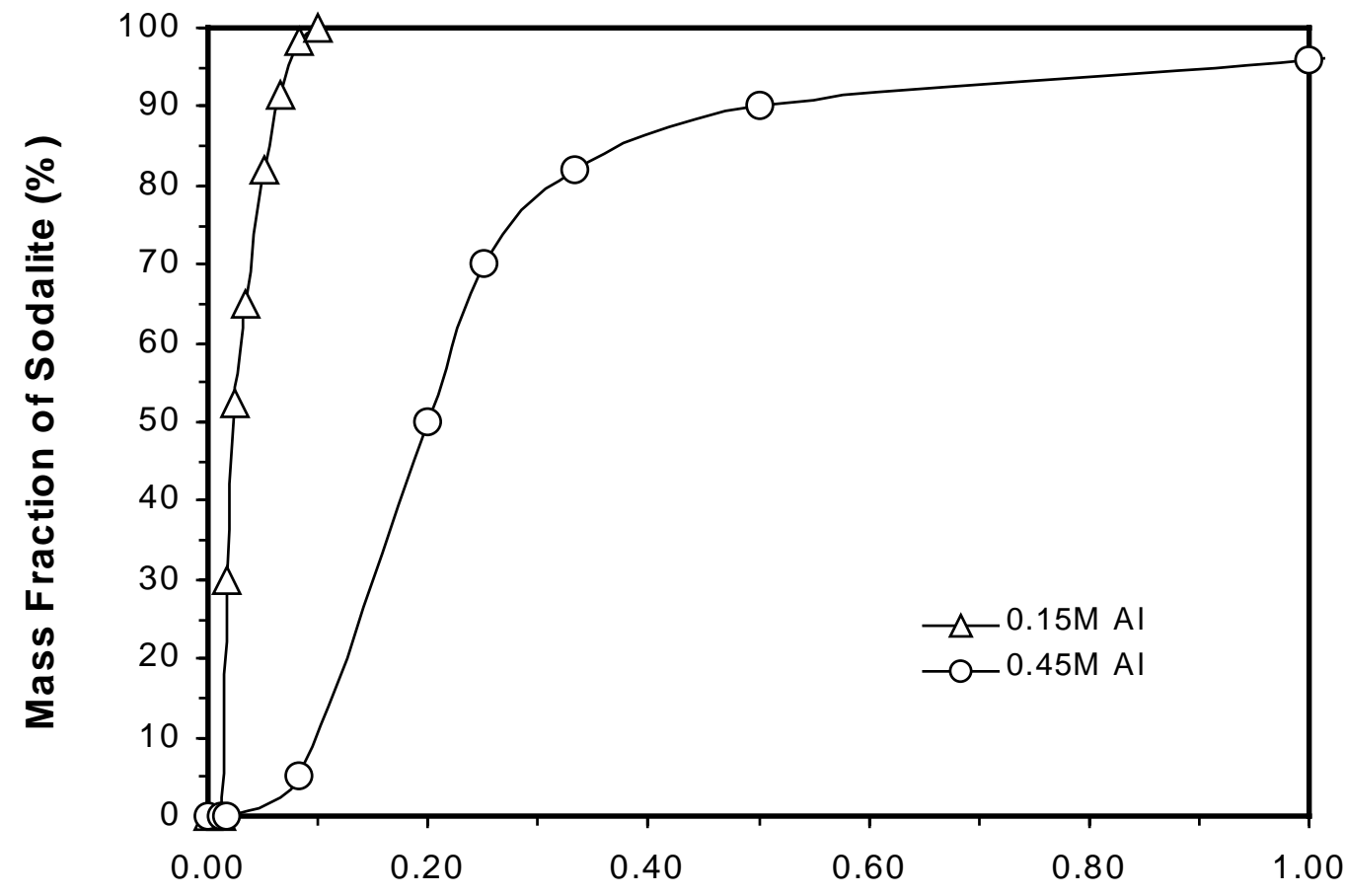

Time (h)

Figure 105 Mass fraction of sodalite obtained from amorphous seed in $8 \mathrm{M}$ $\mathrm{NaOH}, 2 \mathrm{M} \mathrm{NaNO}, 2 \mathrm{MNaNO}_{2}$ solutions at different $\mathrm{Al}(\mathrm{III})$ concentrations at $65^{\circ} \mathrm{C}$ 


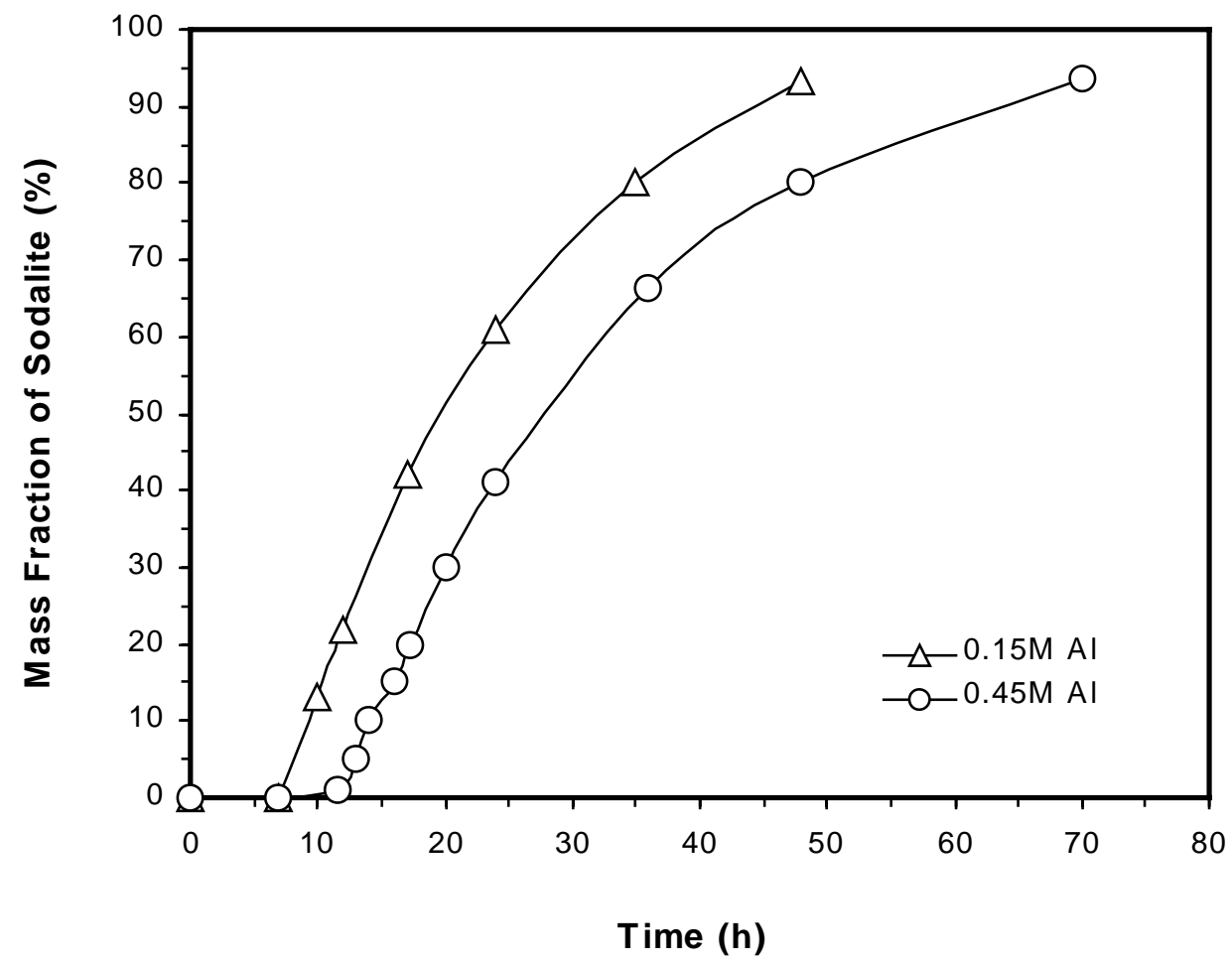

Figure 106 Mass fraction of sodalite obtained from zeolite seed in $8 \mathrm{M} \mathrm{NaOH}, 2 \mathrm{M}$ $\mathrm{NaNO}_{3}$ and $2 \mathrm{MNaNO}_{2}$ solution at different $\mathrm{Al}(\mathrm{III})$ concentrations and $30{ }^{\circ} \mathrm{C}$

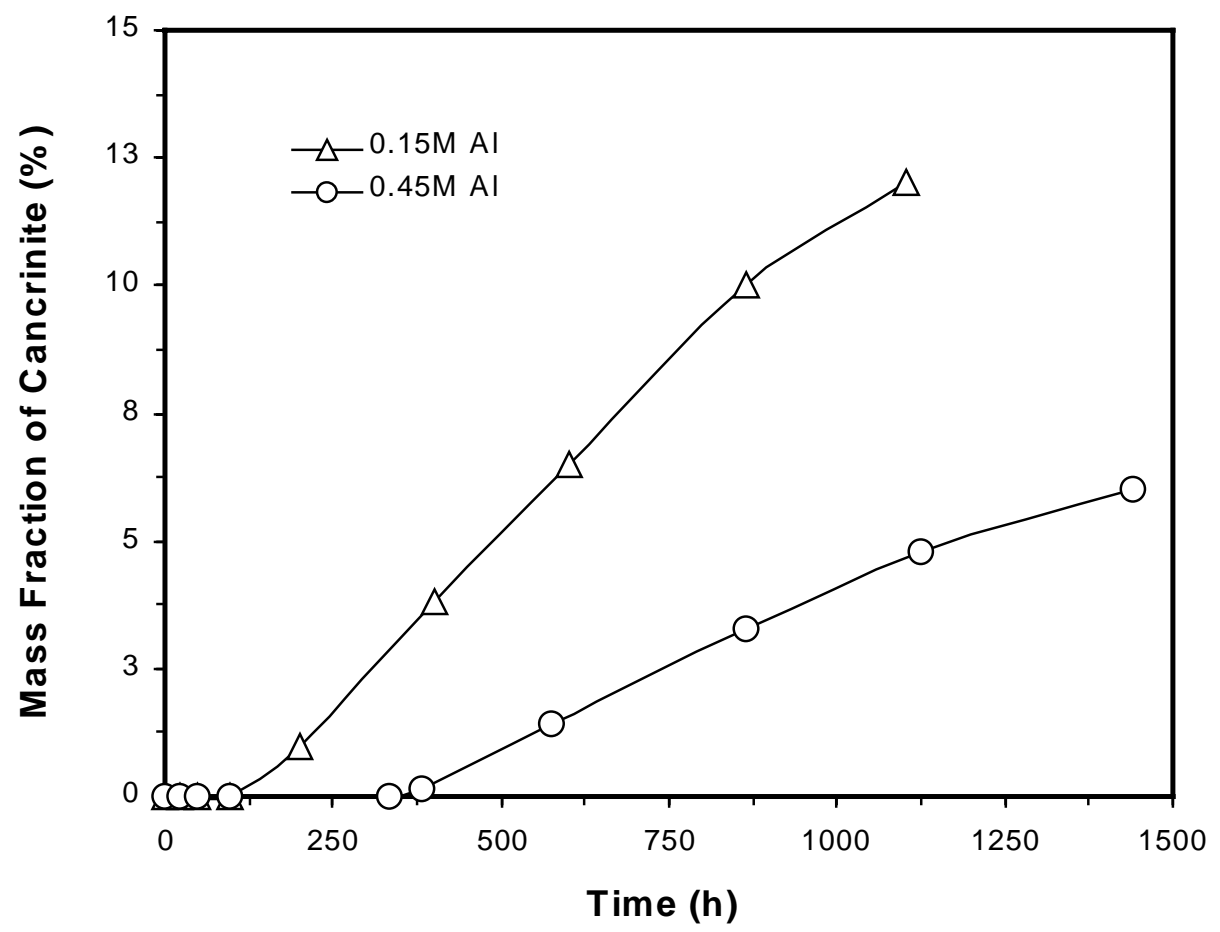

Figure 107 Mass fraction of cancrinite obtained from sodalite seed in $8 \mathrm{M} \mathrm{NaOH}$, $2 \mathrm{M} \mathrm{NaNO}_{3}$ and $2 \mathrm{MNaNO}_{2}$ solution at different $\mathrm{Al}(\mathrm{III})$ concentrations and $30{ }^{\circ} \mathrm{C}$ 


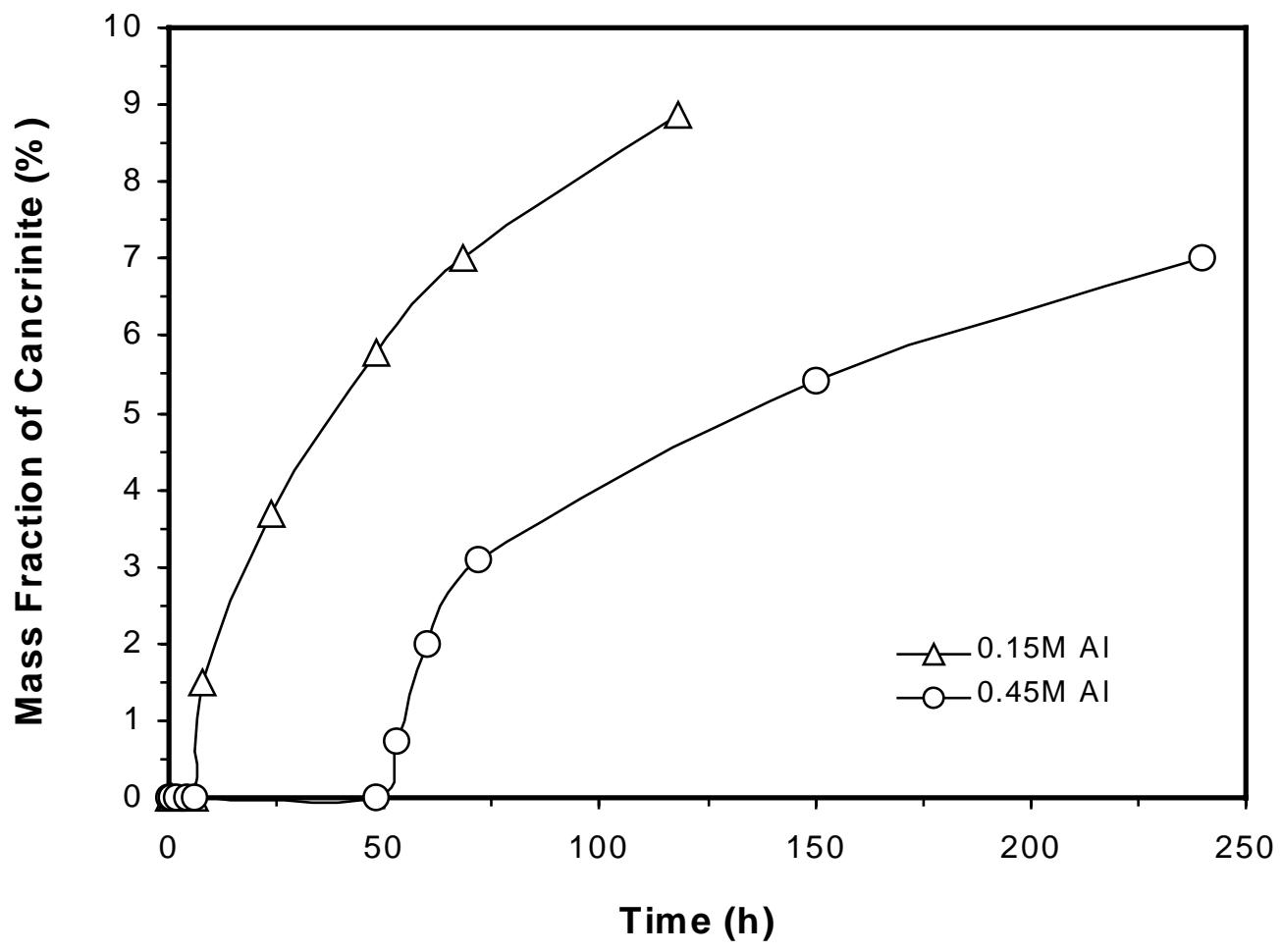

Figure 108 Mass fraction of cancrinite obtained from sodalite seed in $8 \mathrm{M} \mathbf{~ N a O H}$, $2 \mathrm{M} \mathrm{NaNO}{ }_{3}$ and $2 \mathrm{MNaNO}_{2}$ solution at different $\mathrm{Al}(\mathrm{III})$ concentrations and $65{ }^{\circ} \mathrm{C}$

Linear relationships were obtained from plots of $\operatorname{In}[\mathrm{d}($ Relative sodalite/Relative cancrinite concentration)dt] versus In[Relative amorphous/zeolite/sodalite concentration] for the three different seeded systems (Figures 109-111). Reaction orders of 0.5 and 1 were observed for amorphous/zeolite to sodalite and sodalite to cancrinite phase transformation, respectively (Table 21).

The results suggest that the molar flux of solution species dissipated in the formation of sodalite shows a 0.5 -to- 1 correspondence with the molar flux of sodium aluminosilicate species created by the dissolution of amorphous and zeolite. The transformation of cancrinite shows a one to one correspondence with the molar flux of the species created by sodalite dissolution. These observations are highly consistent with the chemical structures of the 4 aluminosilicate solid phases (amorphous/zeolite $\mathrm{A}=$ $\mathrm{Na}_{12} \mathrm{Al}_{12} \mathrm{Si}_{12} \mathrm{O}_{48} \cdot 27 \mathrm{H}_{2} \mathrm{O}$ ) and (sodalite/cancrinite $=\mathrm{Na}_{8} \mathrm{Al}_{6} \mathrm{~S}_{6} \mathrm{O}_{12} \cdot 2 \mathrm{NO}_{3}{ }^{*} 2-3.4 \mathrm{H}_{2} \mathrm{O}$ ). 
Activation energies of $49 \pm 4 \mathrm{~kJ} \mathrm{~mol}^{-1}, 71 \pm 4 \mathrm{~kJ} \mathrm{~mol}^{-1}$ and $102 \pm 4 \mathrm{~kJ} \mathrm{~mol}^{-1}$ were calculated from the 0.5 th and 1 st order rate laws, and a simple Arrhenius-rate constant relationship for temperature dependency for amorphous, zeolite and sodalite phase transformations. The calculated pre-exponential factors as shown in Table 21 indicate a strong dependence upon initial aluminium concentration. The kinetic models were found to fit experimental data very well and are shown in Figures 112-114.

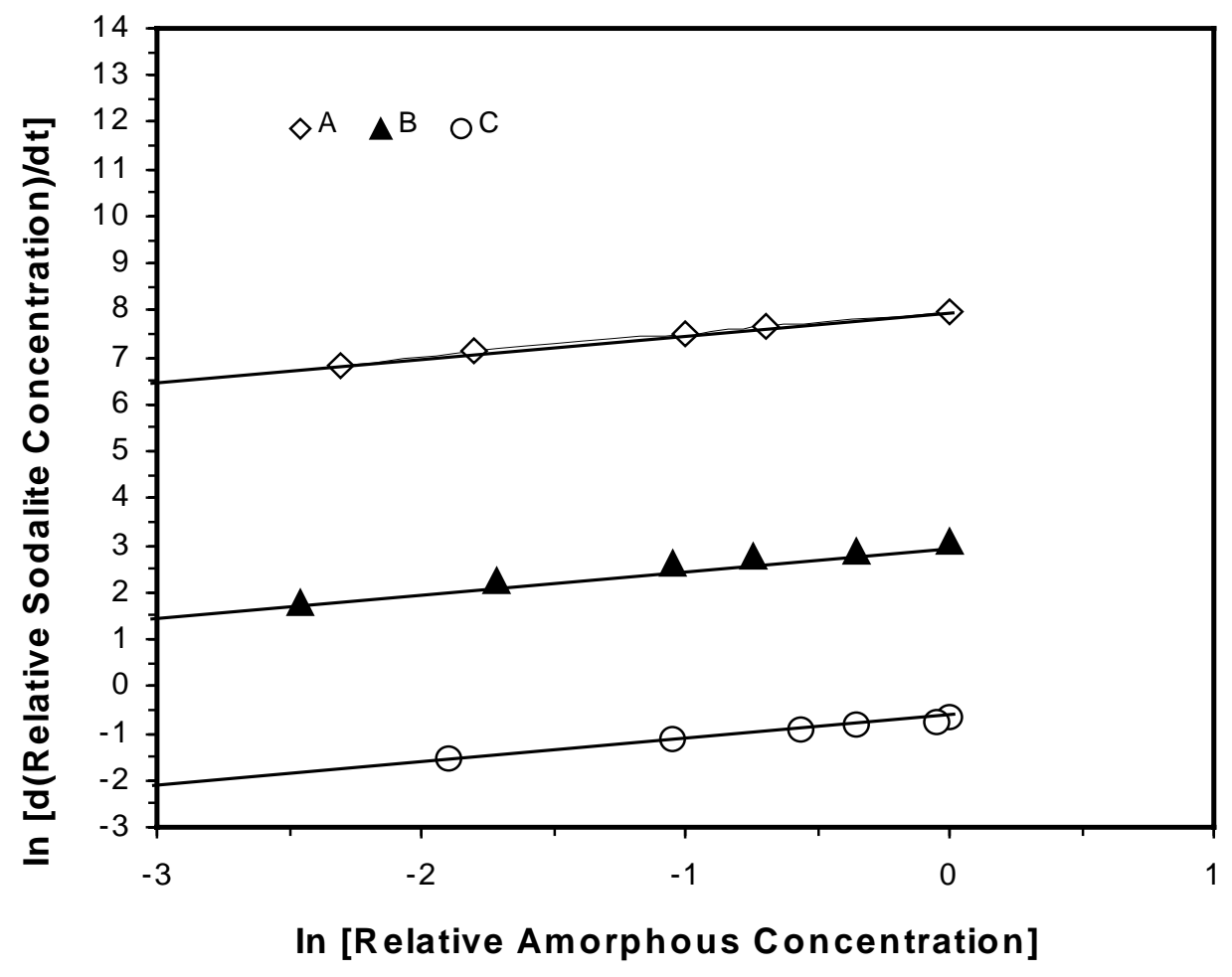

Figure 109 Amorphous-sodalite transformation kinetics plot showing a linear near $0.5^{\text {th }}$ order dependence at: $\mathrm{A}-130{ }^{\circ} \mathrm{C}\left(4 \mathrm{M} \mathrm{NaOH}, 1 \mathrm{M} \mathrm{NaNO} \mathrm{NaNaNO}_{3}, 1 \mathrm{MNa}^{2}\right.$ ) and $\mathrm{B}-65^{\circ} \mathrm{C}$ and $\mathrm{C}-30{ }^{\circ} \mathrm{C}\left(8 \mathrm{M} \mathrm{NaOH}, 2 \mathrm{M} \mathrm{NaNO}_{3}, 2 \mathrm{MNaNO}_{2}\right.$ and $0.15 \mathrm{M} \mathrm{Al}$ (III) 


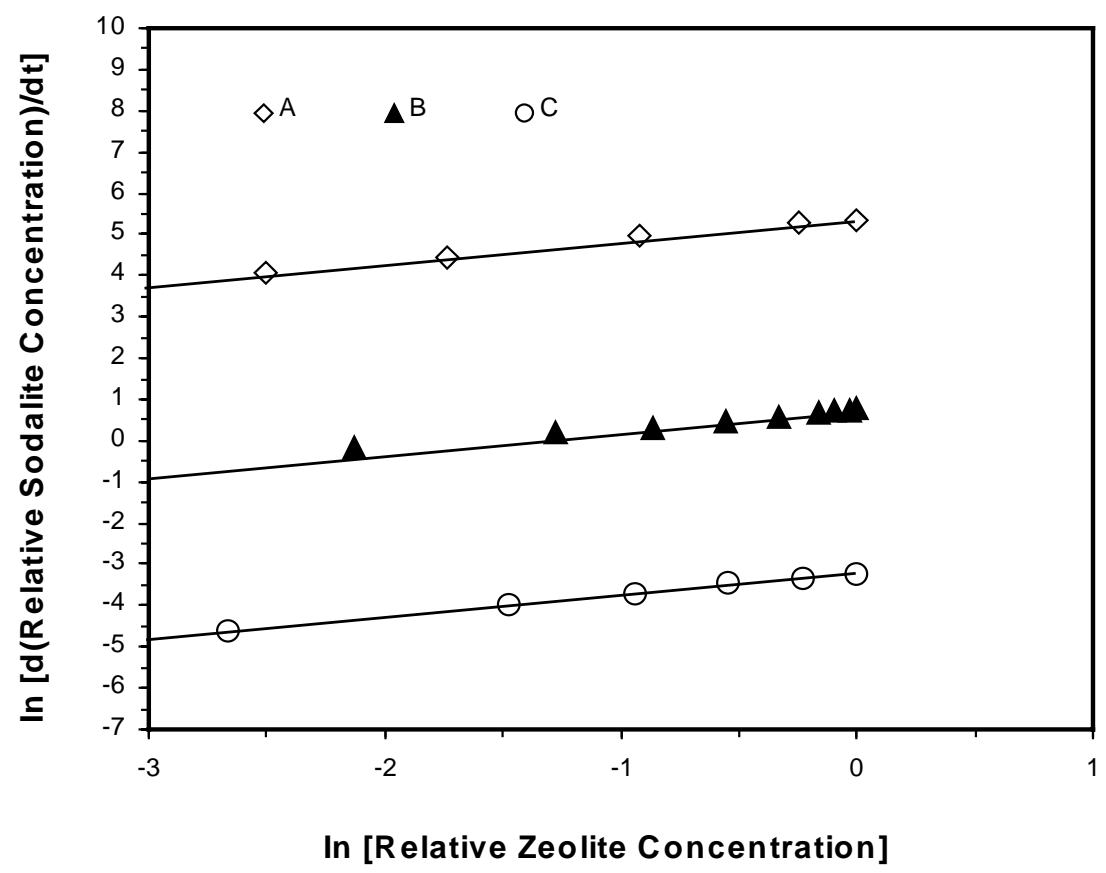

Figure 110 Zeolite-sodalite transformation kinetics plot showing a linear $0.5^{\text {th }}$ order dependence at $\mathrm{A}-130{ }^{\circ} \mathrm{C}\left(8 \mathrm{M} \mathrm{NaOH}, 2 \mathrm{M} \mathrm{NaNO}{ }_{3}, 2 \mathrm{MNaNO}_{2}\right) \mathrm{B}-65^{\circ} \mathrm{C}$ and $\mathrm{C}$ $30{ }^{\circ} \mathrm{C}\left(8 \mathrm{M} \mathrm{NaOH}, 2 \mathrm{M} \mathrm{NaNO}_{3}, 2 \mathrm{MNaNO}_{2}\right.$ and $0.15 \mathrm{M} \mathrm{Al}(\mathrm{III})$

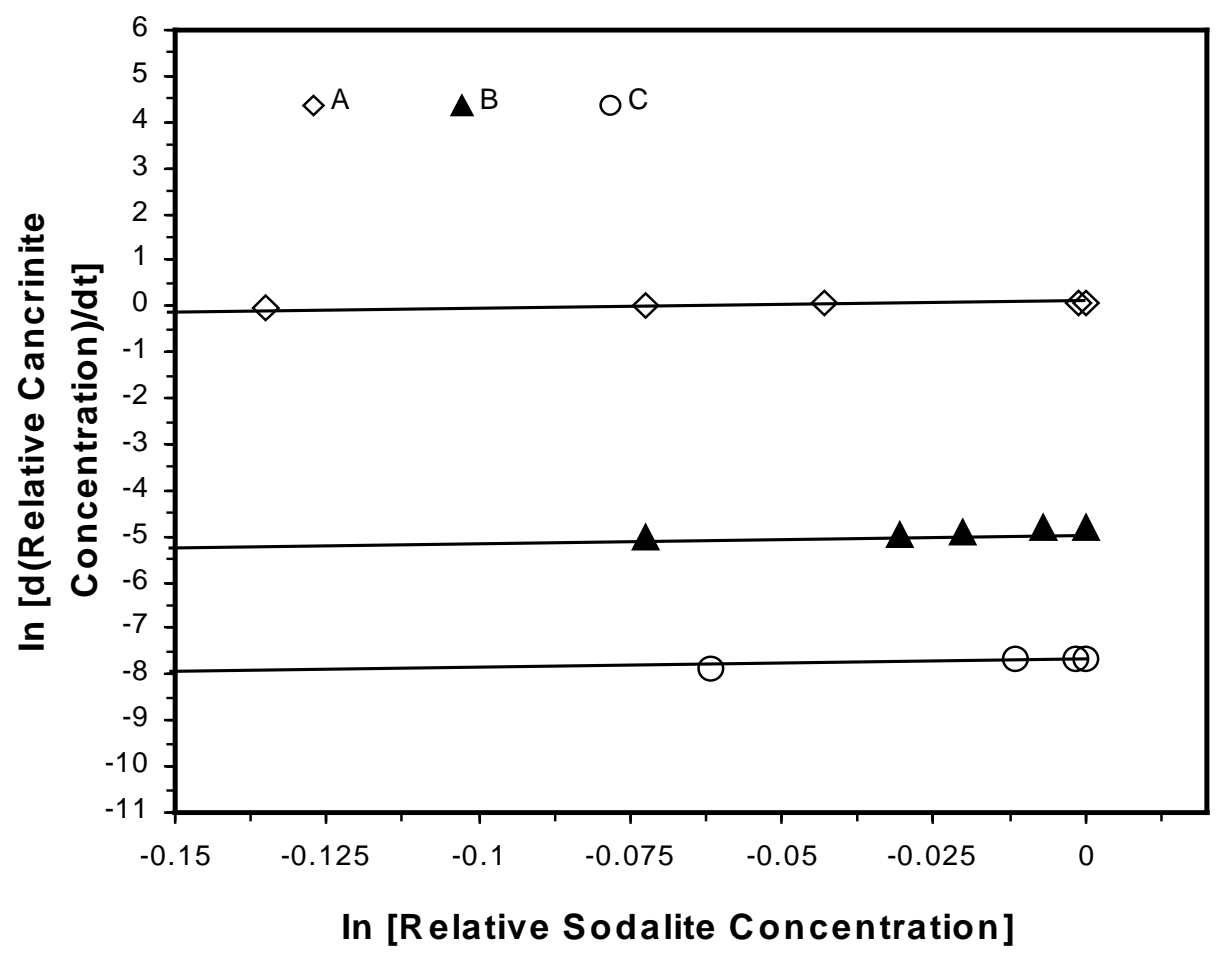

Figure 111 Sodalite-cancrinite transformation kinetics plot showing a linear first order dependence at $\mathrm{A}-130{ }^{\circ} \mathrm{C}\left(8 \mathrm{M} \mathrm{NaOH}, 2 \mathrm{M} \mathrm{NaNO}{ }_{3}, 2 \mathrm{MNaNO}_{2}\right) \mathrm{B}-65^{\circ} \mathrm{C}$ and $\mathrm{C}$ $30{ }^{\circ} \mathrm{C}\left(8 \mathrm{M} \mathrm{NaOH}, 2 \mathrm{M} \mathrm{NaNO}_{3}, 2 \mathrm{MNaNO}_{2}\right.$ and $0.45 \mathrm{M} \mathrm{Al}(\mathrm{III})$ 


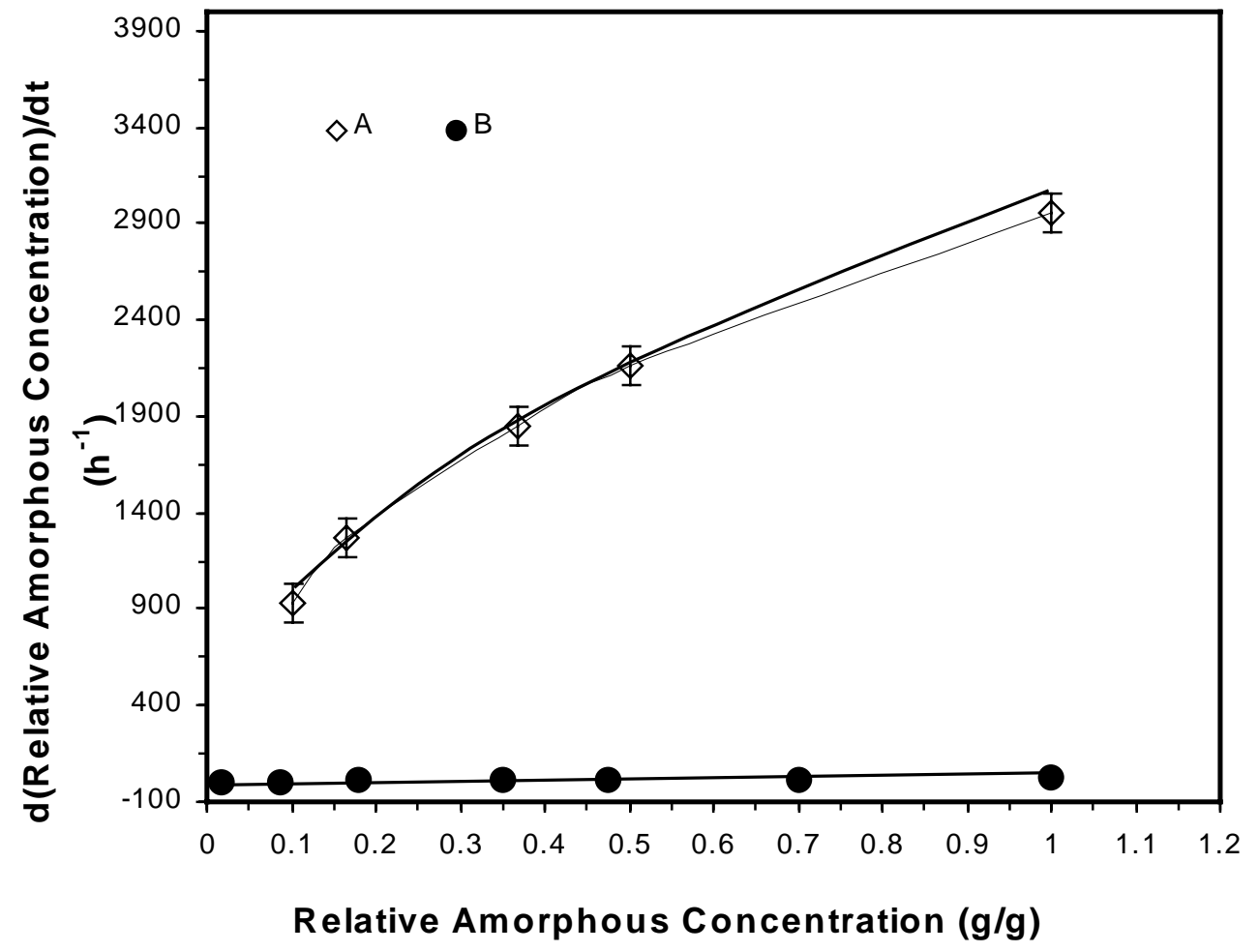

Figure 112 Experimentally determined amorphous fluxes versus the relative amorphous concentration at $\mathrm{A}-130{ }^{\circ} \mathrm{C}\left(4 \mathrm{M} \mathrm{NaOH}, 2 \mathrm{M} \mathrm{NaNO}_{3}, 2 \mathrm{MNaNO}_{2}\right) \mathrm{B}-65$ ${ }^{\circ} \mathrm{C}\left(8 \mathrm{M} \mathrm{NaOH}, 2 \mathrm{M} \mathrm{NaNO}_{3}, 2 \mathrm{MNaNO}_{2}\right.$ and $0.15 \mathrm{M} \mathrm{Al}$ (III)

The activation energies for both the amorphous and zeolite phase transformations to sodalite are higher than that for zeolite nucleation $\left[12-14 \mathrm{~kJ} \mathrm{~mol}^{-1}\right.$ (Antonic et al., 1994)] and pure sodalite crystal growth [30 $\mathrm{kJ} \mathrm{mol}^{-1}$ (Barnes et al., 1999)], and lower than that for pure cancrinite crystal growth $\left[80 \mathrm{~kJ} \mathrm{~mol}^{-1}\right.$ (Barnes et al., 1999)] and reported zeolite to sodalite phase transformation [100 kJ mol${ }^{-1}$ (Grujic et al., 1989)]. The activation energy for amorphous to sodalite is lower than that for zeolite to sodalite indicating that less energy is needed to break and reform bonds in an amorphous to sodalite transformation as compared with a zeolite transformation toward sodalite.

The activation energy obtained for the sodalite to cancrinite transformation is $30 \%$ lower than that reported by Barnes et al. (133 $\left.\mathrm{kJ} \mathrm{mol}^{-1}\right)$ for carbonate containing sodalite/cancrinite. The lower value observed in the present work reflects the nitrate/nitrite ions templating effect which facilitated the formation of sodalite and cancrinite. 


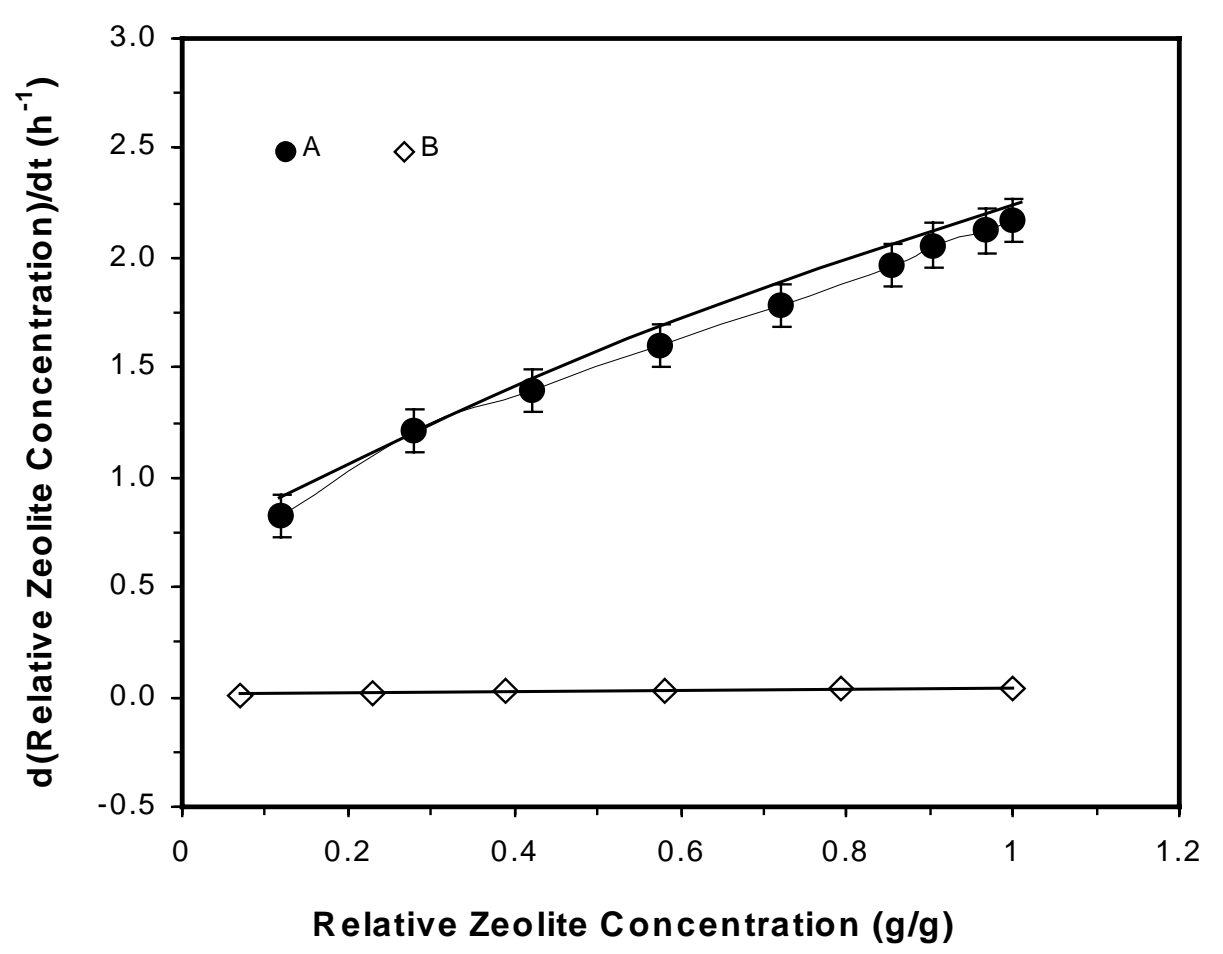

Figure 113 Experimentally determined zeolite fluxe versus the relative zeolite concentration at $\mathrm{A}-65^{\circ} \mathrm{C}$ and $\mathrm{B}-30{ }^{\circ} \mathrm{C}\left(8 \mathrm{M} \mathrm{NaOH}, 2 \mathrm{M} \mathrm{NaNO}_{3}, 2 \mathrm{MNaNO}_{2}\right.$ and 0.15M Al(III)

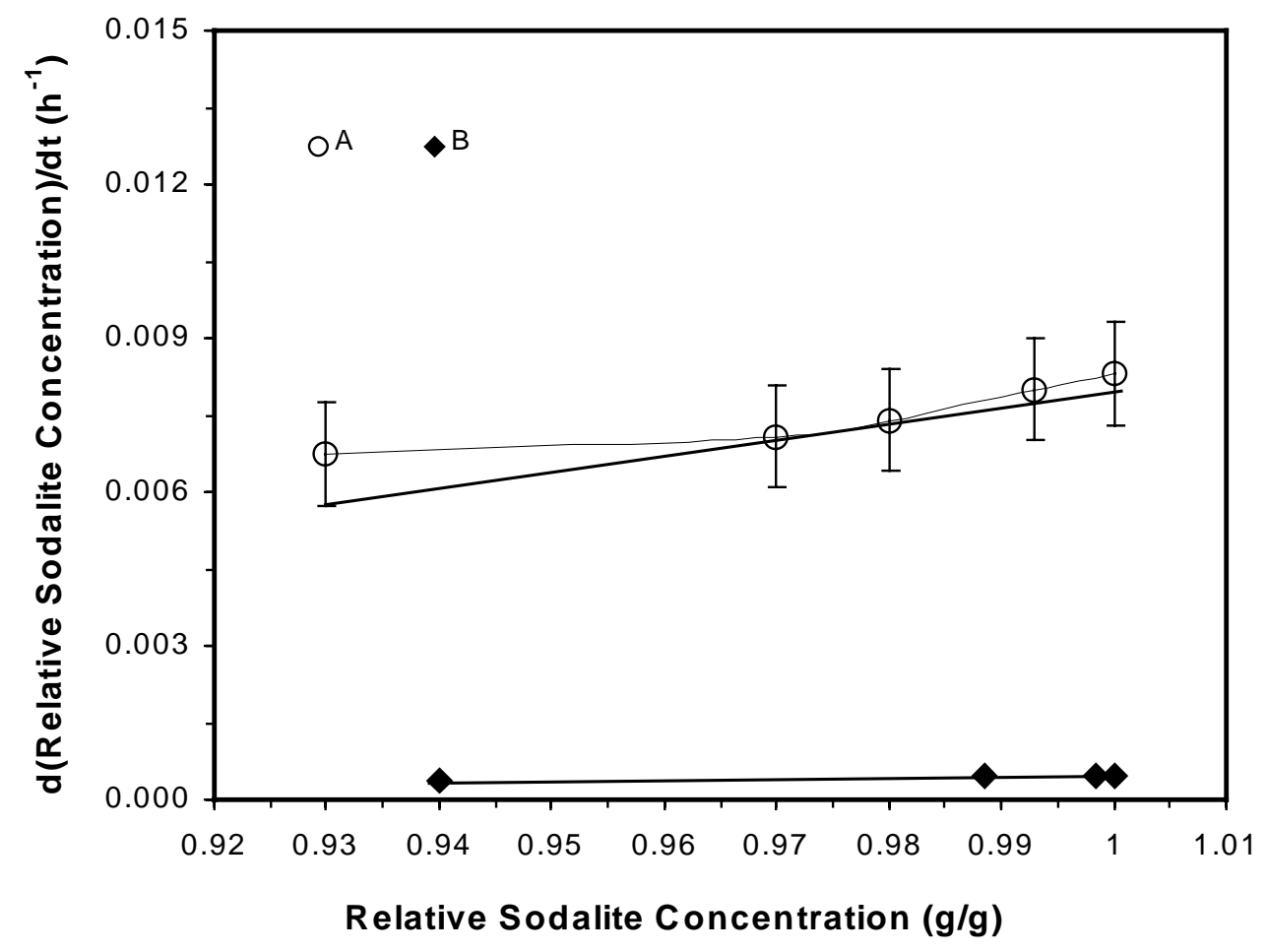

Figure 114 Experimentally determined sodalite fluxes versus relative sodalite at $\mathrm{A}-65^{\circ} \mathrm{C}$ and $\mathrm{B}-30{ }^{\circ} \mathrm{C}\left(8 \mathrm{M} \mathrm{NaOH}, 2 \mathrm{M} \mathrm{NaNO}_{3}, 2 \mathrm{MNaNO}_{2}\right.$ and $0.45 \mathrm{M} \mathrm{Al}$ (III) 


\begin{tabular}{|c|c|c|c|c|c|c|c|c|c|}
\hline \multirow{2}{*}{ Phase } & \multicolumn{4}{|c|}{$\begin{array}{l}\text { Initial solution } \\
\text { composition (M) }\end{array}$} & \multirow{2}{*}{$\begin{array}{c}\mathrm{T} \\
\left({ }^{\mathbf{0}} \mathbf{C}\right)\end{array}$} & \multirow{2}{*}{$\begin{array}{l}\text { Induction } \\
\text { time (h) }\end{array}$} & \multirow{2}{*}{$\begin{array}{c}\mathrm{k}_{\mathrm{O}} \\
\left(\mathbf{h}^{-1}\right)\end{array}$} & \multirow{2}{*}{$\underset{\left.(\mathbf{k J ~ m o l})^{-1}\right)}{\mathbf{E}_{\mathrm{a}}}$} & \multirow{2}{*}{$\begin{array}{l}\text { Order } \\
\text { (n) }\end{array}$} \\
\hline & $\mathrm{NaOH}$ & $\mathrm{NO}_{3}$ & $\mathrm{NO}_{2}^{-}$ & Al(III) & & & & & \\
\hline \multirow{3}{*}{ Amorphous } & 4 & 1 & 1 & 0 & 65 & 0.33 & $1.84 \times 10^{8}$ & 51 & 0.45 \\
\hline & 4 & 1 & 1 & 0 & 130 & $30 \mathrm{~s}$ & $1.84 \times 10^{8}$ & 51 & 0.48 \\
\hline & 4 & 1 & 1 & 0.19 & 65 & 0.25 & I & I & 0.48 \\
\hline \multirow[t]{3}{*}{ to } & 8 & 2 & 2 & 0 & 130 & $<1 \mathrm{~s}$ & I & I & I \\
\hline & 8 & 2 & 2 & 0.15 & 30 & 1.10 & $3.95 \times 10^{8}$ & 48 & 0.54 \\
\hline & 8 & 2 & 2 & 0.15 & 65 & $45 \mathrm{~s}$ & $3.95 \times 10^{8}$ & 48 & 0.49 \\
\hline \multirow[t]{3}{*}{ Sodalite } & 8 & 2 & 2 & 0.45 & 30 & 1.10 & $2.81 \times 10^{8}$ & 48 & 0.47 \\
\hline & 8 & 2 & 2 & 0.45 & 65 & $45 \mathrm{~s}$ & $2.81 \times 10^{8}$ & 48 & 0.52 \\
\hline & 4 & 1 & 1 & 0 & 65 & 1.70 & $2.56 \times 10^{10}$ & 73 & 0.51 \\
\hline \multirow[t]{2}{*}{ Zeolite } & 4 & 1 & 1 & 0 & 130 & 0.08 & $2.56 \times 10^{10}$ & 73 & 0.53 \\
\hline & 4 & 1 & 1 & 0.19 & 65 & 0.83 & I & I & 0.49 \\
\hline \multirow[t]{3}{*}{ to } & 8 & 2 & 2 & 0 & 130 & $45 \mathrm{~s}$ & I & I & 0.50 \\
\hline & 8 & 2 & 2 & 0.15 & 30 & 7.00 & $4.28 \times 10^{10}$ & 70 & 0.53 \\
\hline & 8 & 2 & 2 & 0.15 & 65 & 0.06 & $4.28 \times 10^{10}$ & 70 & 0.48 \\
\hline \multirow[t]{3}{*}{ Sodalite } & 8 & 2 & 2 & 0.45 & 30 & 10.00 & $3.32 \times 10^{10}$ & 70 & 0.52 \\
\hline & 8 & 2 & 2 & 0.45 & 65 & 0.08 & $3.32 \times 10^{10}$ & 70 & 0.48 \\
\hline & 4 & 1 & 1 & 0 & 65 & 2.00 & $1.34 \times 10^{14}$ & 101 & 1.04 \\
\hline \multirow[t]{2}{*}{ Sodalite } & 4 & 1 & 1 & 0 & 130 & 1.00 & $1.34 \times 10^{14}$ & 101 & 0.98 \\
\hline & 4 & 1 & 1 & 0.19 & 65 & 2.50 & I & I & 1.03 \\
\hline \multirow[t]{3}{*}{ to } & 8 & 2 & 2 & 0 & 130 & 0.75 & I & I & 1.01 \\
\hline & 8 & 2 & 2 & 0.15 & 30 & 96.0 & $4.06 \times 10^{14}$ & 104 & 1.04 \\
\hline & 8 & 2 & 2 & 0.15 & 65 & 6.0 & $4.06 \times 10^{14}$ & 104 & 1.01 \\
\hline \multirow[t]{2}{*}{ Cancrinite } & 8 & 2 & 2 & 0.45 & 30 & 348 & $2.53 \times 10^{14}$ & 104 & 0.98 \\
\hline & 8 & 2 & 2 & 0.45 & 65 & 48 & $2.53 \times 10^{14}$ & 104 & 1.05 \\
\hline
\end{tabular}

Table 21 Kinetic parameters for the phase transformation of nitrate/nitritefree particles in different solutions at 30,65 and $130{ }^{\circ} \mathrm{C}$ 


\subsection{Interfacial Chemistry and Particle Interactions}

\subsection{Zeta Potentials}

Electrokinetic zeta potentials of the precipitated fine size $(<10 \mu \mathrm{m})$ particles of the amorphous, zeolite A, sodalite and cancrinite phases were determined at $25^{\circ} \mathrm{C}$ (Figure 115). The results show that in a $10^{-2} \mathrm{M} \mathrm{NaNO}_{3}$ solution that all four phases were positively charged $(\sim+40-+60 \mathrm{mV})$ in the acidic $\mathrm{pH}$ range $(0-6)$. The magnitude of the electrokinetic potential/charge decreased with increasing $\mathrm{pH}$. As the $\mathrm{pH}$ increased the potential eventually became zero. These isoelectric points were at $\mathrm{pH}$ values of $8,8,8.5$, and 7.2 for amorphous and zeolite A, for sodalite and cancrinite, respectively. Upon further increase in the suspension $\mathrm{pH}$ the zeta potentials decreased steadily becoming -40 $\mathrm{mV}$ at $\mathrm{pH} \approx 13$ for the amorphous phase and $-50--70 \mathrm{mV}$ for the zeolite A, sodalite and cancrinite phases. Higher caustic levels could not be analyzed due to instrumental limitations with respect to caustic. 


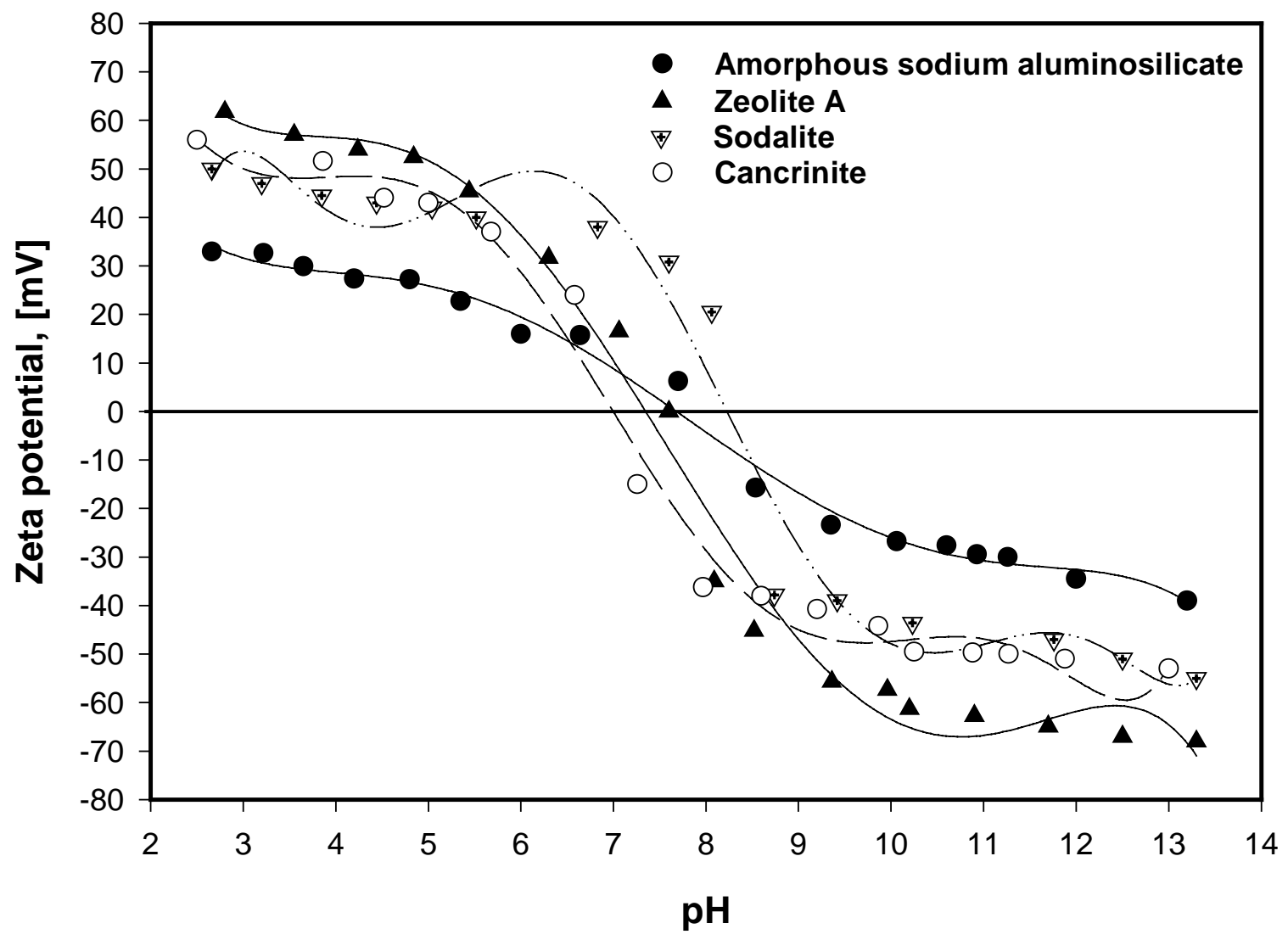

Figure115 Electrokinetic zeta potentials in $10^{-2} \mathrm{M} \mathrm{NaNO}_{3}$ solution versus $\mathrm{pH}$

The indication of the isoelectric point (IEP) in $\mathrm{pH}$ range 7- 8.5 for sodium aluminosilicate solid phases is that the alumina $\left(\mathrm{Al}_{2} \mathrm{O}_{3}\right)$-like tetrahedral sites are more dominant than silica/silicate cluster sites in determining the charging behaviour and the electrical double layer properties of the particles in aqueous environment. This observation is consistent with the fact that the IEP values of acidic $\mathrm{SiO}_{2}$ sodium-exchanged aluminosilicates (kaolinite and smectite) occur at $\sim \mathrm{pH} 2$ while those of the basic $\mathrm{Al}_{2} \mathrm{O}_{3} / \mathrm{Al}(\mathrm{OH})_{3}$ particles are at typically at $\mathrm{pH} 8-10$. The results also suggest that the protonation and deprotonation behaviour is strongly $\mathrm{pH}$ dependent. It appears that at higher caustic concentration where the $\mathrm{pH} \gg>13$ that the particles will be highly deprotonated in solution. Therefore under WSRC evaporator processing conditions the highly negatively charged particles will possibly lead to specific ion adsorption in the stern layer of the electrical double layer thereby causing a reduction in zeta potential. 
Furthermore, under the condition of high solution ionic strength ( $>4 \mathrm{M})$ used in this work the thickness of the electrical double layer / Debye length will be $<<1 \mathrm{~nm}$. Thus, in spite of the moderate zeta potential at high $\mathrm{pH}$, the high ionic strength of the solution will result in the compression of the double layer and effectively screen the repulsive electrostatic particle interactions with significant upon colloidal stability. In the absence of other (non-DLVO) forces, the highly compressed electric double layer could be conducive to attractive particle-particle interactions and lead to particle aggregation and eventually agglomeration as evidenced by the morphological behaviour observed in the SEM photomicrographs below.

\subsection{Fouling Behavior-Unseeded and Seeded Systems}

\subsubsection{Unseeded Systems}

SEM micrographs reveal that various sodium aluminosilicate particles display phasedependent morphological and steel substrate fouling behavior. Suspended solid and fouled stainless steel samples obtained from unseeded crystallizations at $130{ }^{\circ} \mathrm{C}$ and constant $\mathrm{Al}(\mathrm{III})=0.45 \mathrm{M}, \mathrm{NaOH}=4 \mathrm{M}, \mathrm{NaNO}_{3}=1 \mathrm{M}, \mathrm{NaNO}_{2}=1 \mathrm{M}$, initial $[\mathrm{Si}][\mathrm{Al}]=4$ $\times 10^{-3} \mathrm{M}^{2}\left(\sigma_{\mathrm{Si}}=2.56, \mathrm{SiO}_{2}=0.0089 \mathrm{M}\right)$ and $[\mathrm{Si}][\mathrm{Al}]=2 \times 10^{-3} \mathrm{M}^{2}\left(\sigma_{\mathrm{Si}}=0.76 \mathrm{SiO}_{2}=\right.$ 0.0044 M) are shown below in Figures 116-122.

A typical morphology of particles formed under the higher supersaturation $\left(\sigma_{\mathrm{Si}}=2.56\right)$ is shown in Figure 116 while Figure 117 reveals the extent of massive fouling at the steel substrate surface. A similar trend was observed for the runs which were performed at lower supersaturation $\left(\sigma_{\mathrm{Si}}=0.76\right)$ (Figures 118 and 119). 


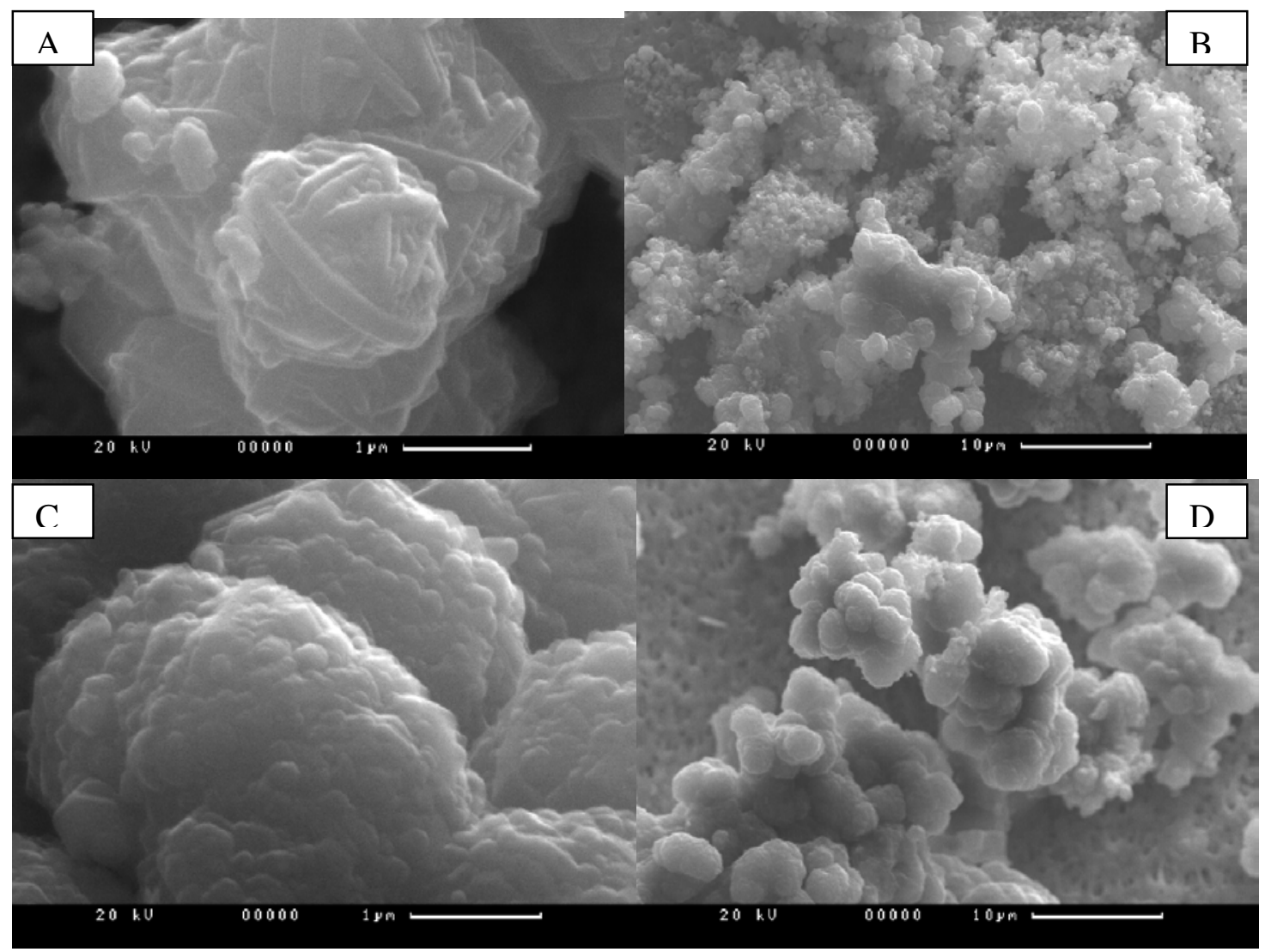

Figure 116 SEM micrographs of crystals formed from high supersaturation selfnucleating liquors $\left(\mathrm{Al}(\mathrm{III})=0.45 \mathrm{M}, \mathrm{NaOH}=4 \mathrm{M}, \mathrm{NaNO}_{3}=1 \mathrm{M}, \mathrm{NaNO}_{2}=1 \mathrm{M}\right.$, initial $\left.[\mathrm{Si}][\mathrm{Al}]=4 \times 10^{-3} \mathrm{M}^{2}\left(\sigma_{\mathrm{Si}}=2.56, \mathrm{SiO}_{2}=0.0089 \mathrm{M}\right)\right)$ at $130{ }^{\circ} \mathrm{C}$ removed from suspension after $30 \mathrm{~min}$ (And $B$ ) and $4 \mathrm{~h}(\mathrm{C}$ and $\mathrm{D})$

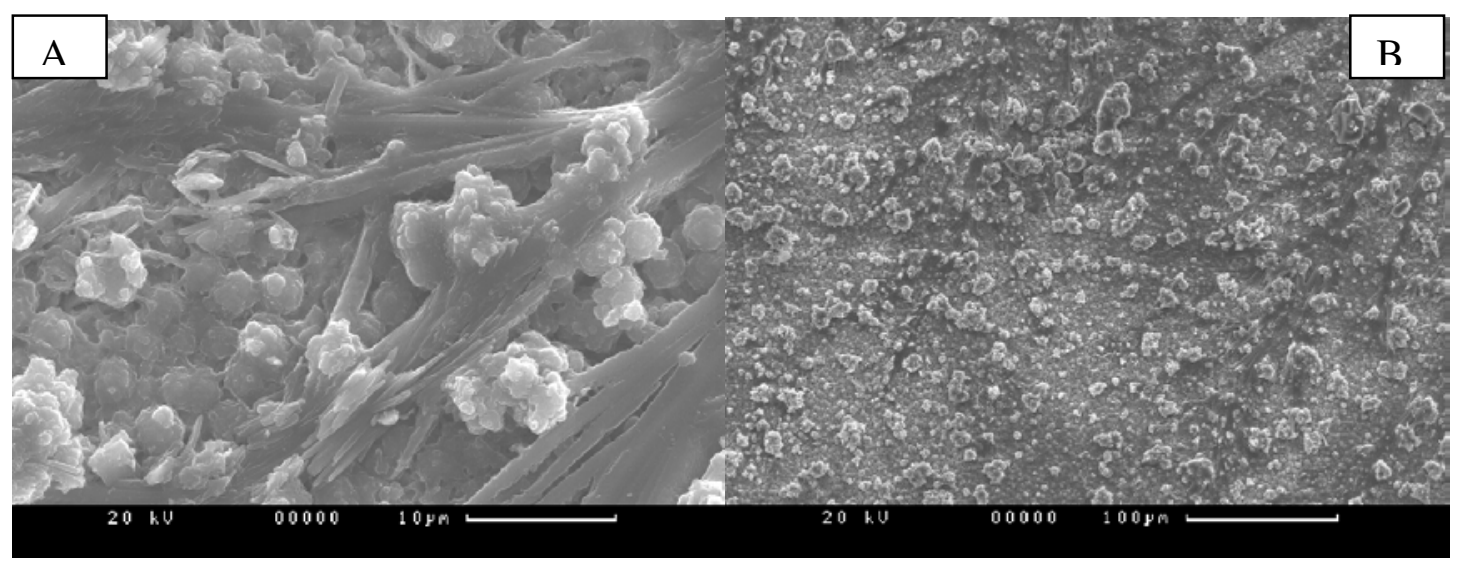

Figure 117 SEM micrographs of stainless steel substrates fouled by crystals formed from high supersaturation self-nucleating liquors at $130{ }^{\circ} \mathrm{C}$ removed from suspension after $4 \mathrm{~h}$ (A and $B)$ 


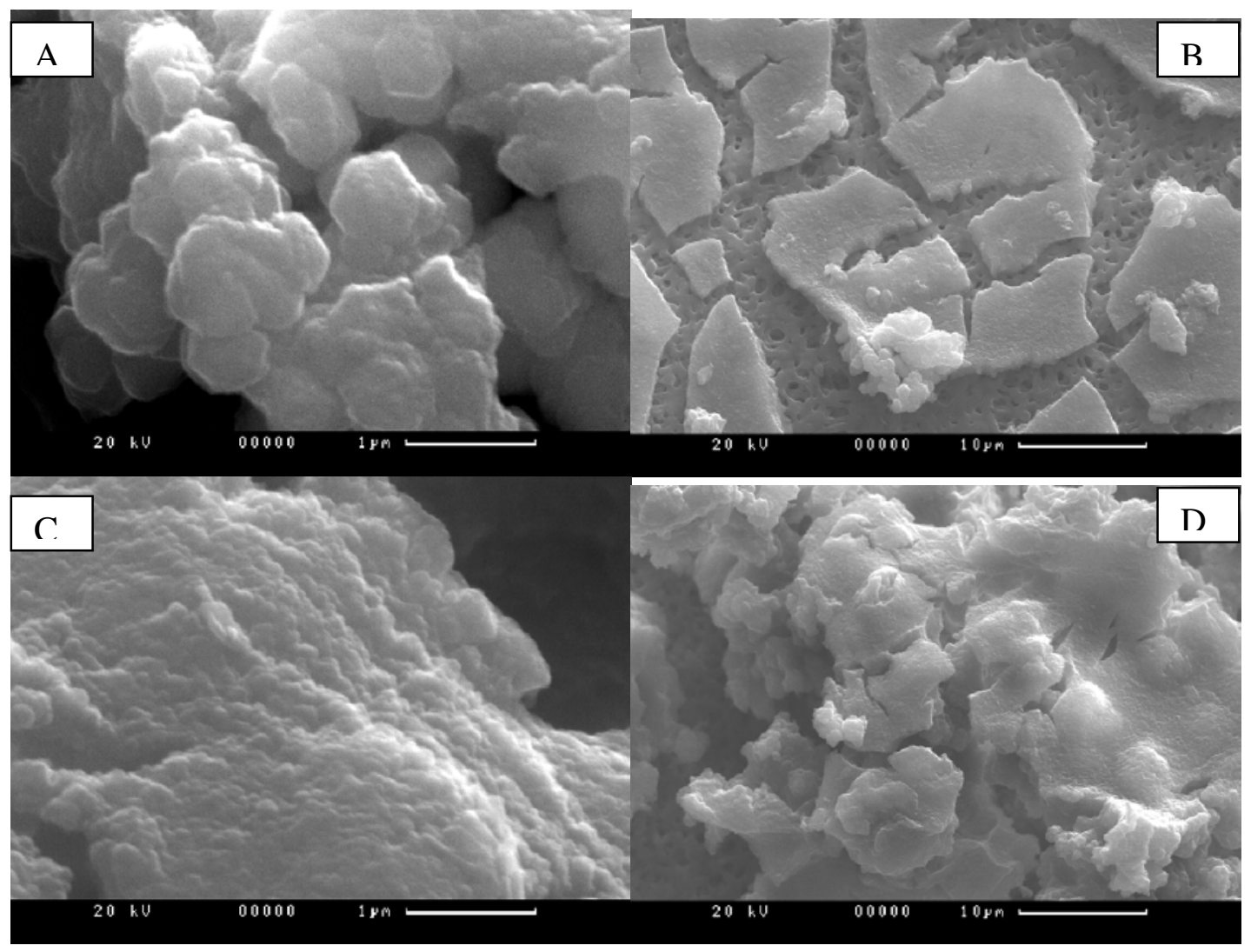

Figure 118 SEM micrographs of crystals formed from low supersaturation selfnucleating liquors $\left(\mathrm{Al}(\mathrm{III})=0.45 \mathrm{M}, \mathrm{NaOH}=4 \mathrm{M}, \mathrm{NaNO}_{3}=1 \mathrm{M}, \mathrm{NaNO}_{2}=1 \mathrm{M}\right.$, initial $[\mathrm{Si}][\mathrm{Al}]=2 \times 10^{-3} \mathrm{M}^{2}\left(\sigma_{\mathrm{Si}}=0.76 \mathrm{SiO}_{2}=0.0044 \mathrm{M}\right)$ at $130{ }^{\circ} \mathrm{C}$ removed from suspension after 30 min (And $B$ ) and $4 h(C$ and $D)$

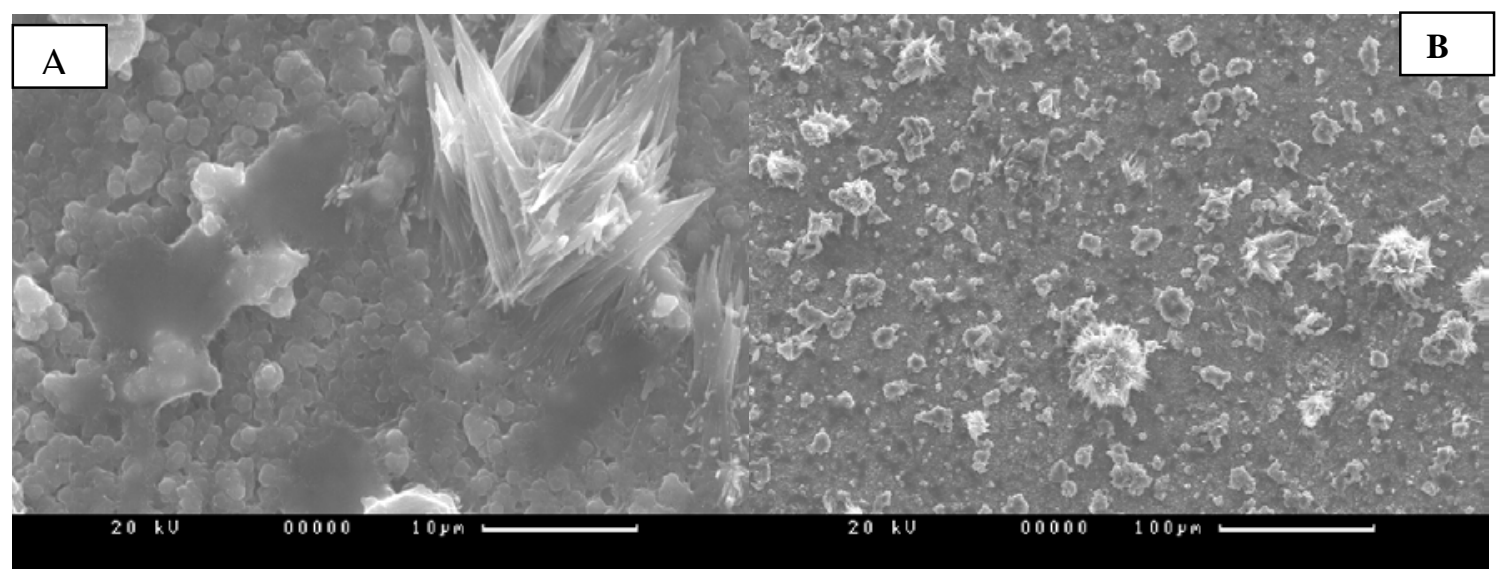

Figure 119 SEM micrographs of stainless steel substrates fouled from low supersaturation self-nucleating liquors $\left(\mathrm{Al}(\mathrm{III})=0.45 \mathrm{M}, \mathrm{NaOH}=4 \mathrm{M}, \mathrm{NaNO}_{3}=\right.$ $1 \mathrm{M}, \mathrm{NaNO}_{2}=1 \mathrm{M}$, initial $\left.[\mathrm{Si}][\mathrm{Al}]=2 \times 10^{-3} \mathrm{M}^{2}\left(\sigma_{\mathrm{Si}}=0.76 \mathrm{SiO}_{2}=0.0044 \mathrm{M}\right)\right)$ at 130 ${ }^{\circ} \mathrm{C}$ removed from suspension after $4 \mathrm{~h}(\mathrm{C}$ and $\mathrm{D})$ 
SEM micrographs of crystals formed at steel substrate surface from low $\left(119.5 \mathrm{~m}^{2} / \mathrm{dm}^{-3}\right)$ and high sodalite $\left(239 \mathrm{~m}^{2} / \mathrm{dm}^{-3}\right)$ seeded liquors $\left(\mathrm{Al}(\mathrm{III})=0.45 \mathrm{M}, \mathrm{NaOH}=4 \mathrm{M}, \mathrm{NaNO}_{3}\right.$ $=1 \mathrm{M}, \mathrm{NaNO}_{2}=1 \mathrm{M}$, initial $\left.[\mathrm{Si}][\mathrm{Al}]=2 \times 10^{-3} \mathrm{M}^{2}\left(\sigma_{\mathrm{Si}}=0.76 \mathrm{SiO}_{2}=0.0044 \mathrm{M}\right)\right)$ at 130 ${ }^{\circ} \mathrm{C}$ are shown below in Figures 120 and 121, respectively. They indicate that seeding considerably reduced the fouling behaviour, the extent of which directly depended upon the seed surface used. Thus, the higher the surface area loading, the greater the suppression of fouling, as the growing crystals effectively dissipate the available supersaturation.

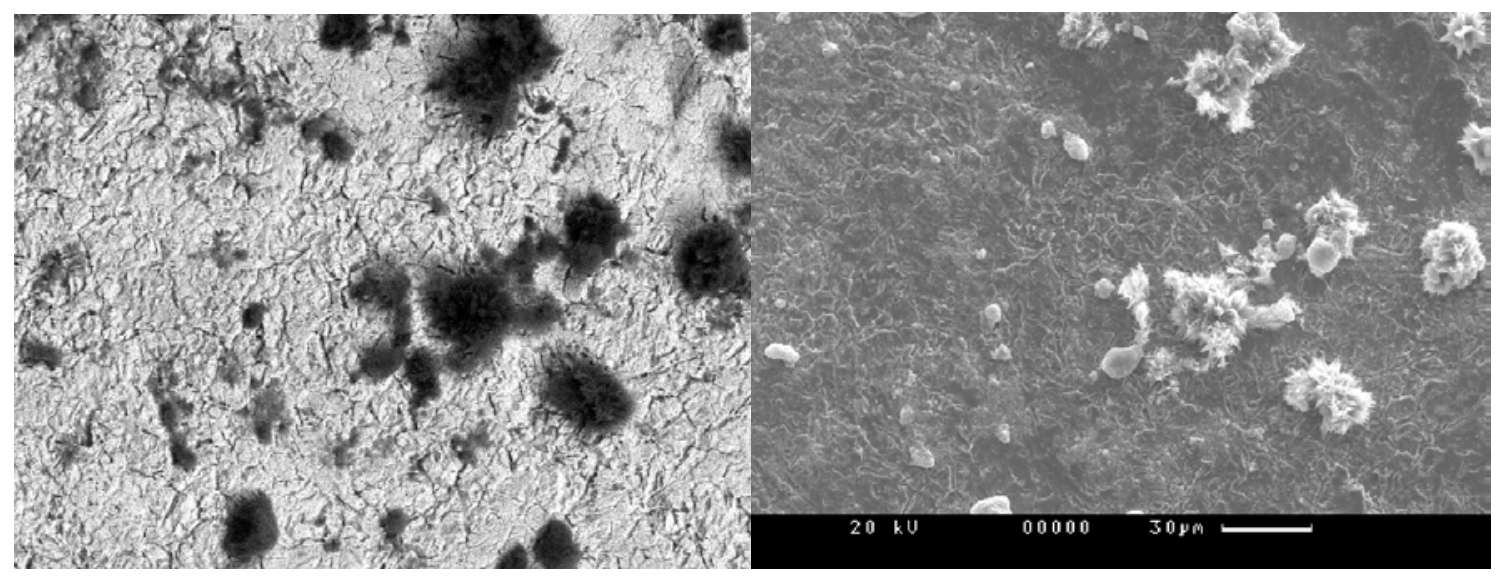

Figure 120 SEM micrographs of crystals formed at steel substrate surface from low sodalite seeding supersaturated liquors $\left(\mathrm{Al}(\mathrm{III})=0.45 \mathrm{M}, \mathrm{NaOH}=4 \mathrm{M}, \mathrm{NaNO}_{3}=\right.$ $1 \mathrm{M}, \mathrm{NaNO}_{2}=1 \mathrm{M}$, initial [Si][Al] $=2 \times 10^{-3} \mathrm{M}^{2}$ at $130{ }^{\circ} \mathrm{C}$ removed from suspension after $30 \mathrm{~min}$ (And $\mathrm{B}$ ) and $4 \mathrm{~h}(\mathrm{C}$ and $\mathrm{D})$ 


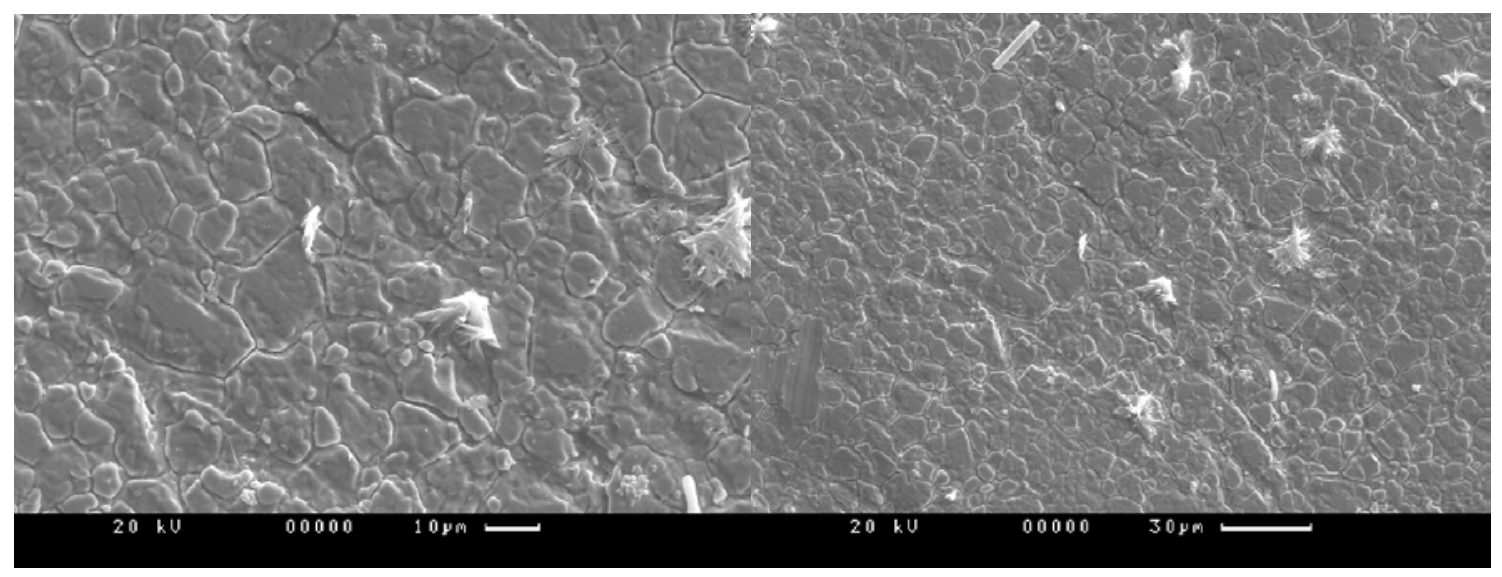

Figure 121 SEM micrographs of crystals formed at steel substrate surface from high sodalite seeding supersaturated liquors $\left(\mathrm{Al}(\mathrm{III})=0.45 \mathrm{M}, \mathrm{NaOH}=4 \mathrm{M}, \mathrm{NaNO}_{3}\right.$ $=1 \mathrm{M}, \mathrm{NaNO}_{2}=1 \mathrm{M}$, initial $\left.[\mathrm{Si}][\mathrm{AI}]=2 \times 10^{-3} \mathrm{M}^{2}\left(\sigma_{\mathrm{Si}}=0.76 \mathrm{SiO}_{2}=0.0044 \mathrm{M}\right)\right)$ at 130 ${ }^{\circ} \mathrm{C}$ removed from suspension after $30 \mathrm{~min}(\mathrm{And} \mathrm{B})$ and $4 \mathrm{~h}(\mathrm{C}$ and $\mathrm{D})$

SEM micrographs of crystals formed at steel substrate surface from low $\left(119.5 \mathrm{~m}^{2} / \mathrm{dm}^{-3}\right)$ and high cancrinite seeding $\left(239 \mathrm{~m}^{2} / \mathrm{dm}^{-3}\right)$ supersaturated liquors $(\mathrm{Al}(\mathrm{III})=0.45 \mathrm{M}$, $\mathrm{NaOH}=4 \mathrm{M}, \mathrm{NaNO}_{3}=1 \mathrm{M}, \mathrm{NaNO}_{2}=1 \mathrm{M}$, initial $[\mathrm{Si}][\mathrm{Al}]=2 \times 10^{-3} \mathrm{M}^{2}$ at $130{ }^{\circ} \mathrm{C}$ are shown below in Figures 122 and 123, respectively. They indicate that seeding considerably reduced the fouling behaviour, with higher seed surface area loading leading profound suppression of the fouling behaviour.

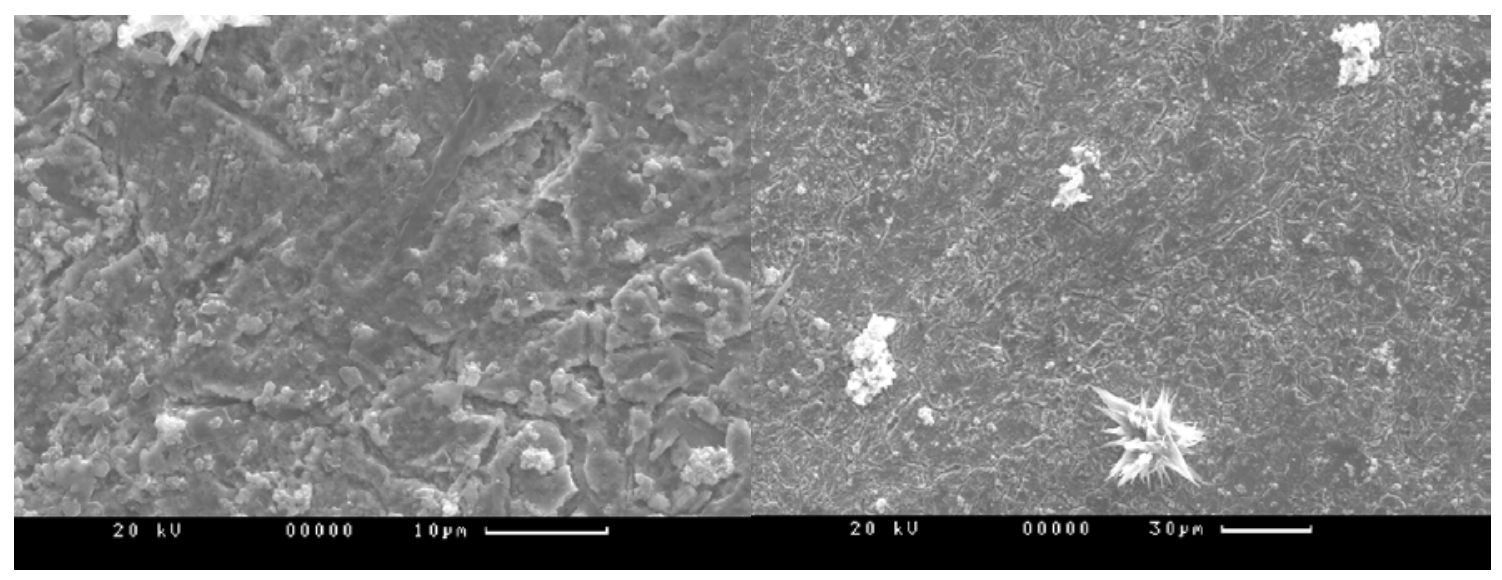

Figure 122 SEM micrographs of crystals formed at steel substrate surface from low cancrinite seeding supersaturated liquors $(\mathrm{Al}(\mathrm{III})=0.45 \mathrm{M}, \mathrm{NaOH}=4 \mathrm{M}$, $\mathrm{NaNO}_{3}=1 \mathrm{M}, \mathrm{NaNO}_{2}=1 \mathrm{M}$, initial $[\mathrm{Si}][\mathrm{AI}]=2 \times 10^{-3} \mathrm{M}^{2}$ at $130{ }^{\circ} \mathrm{C}$ removed from suspension after 30 min (And B) and $4 \mathrm{~h}(\mathrm{C}$ and $\mathrm{D})$ 


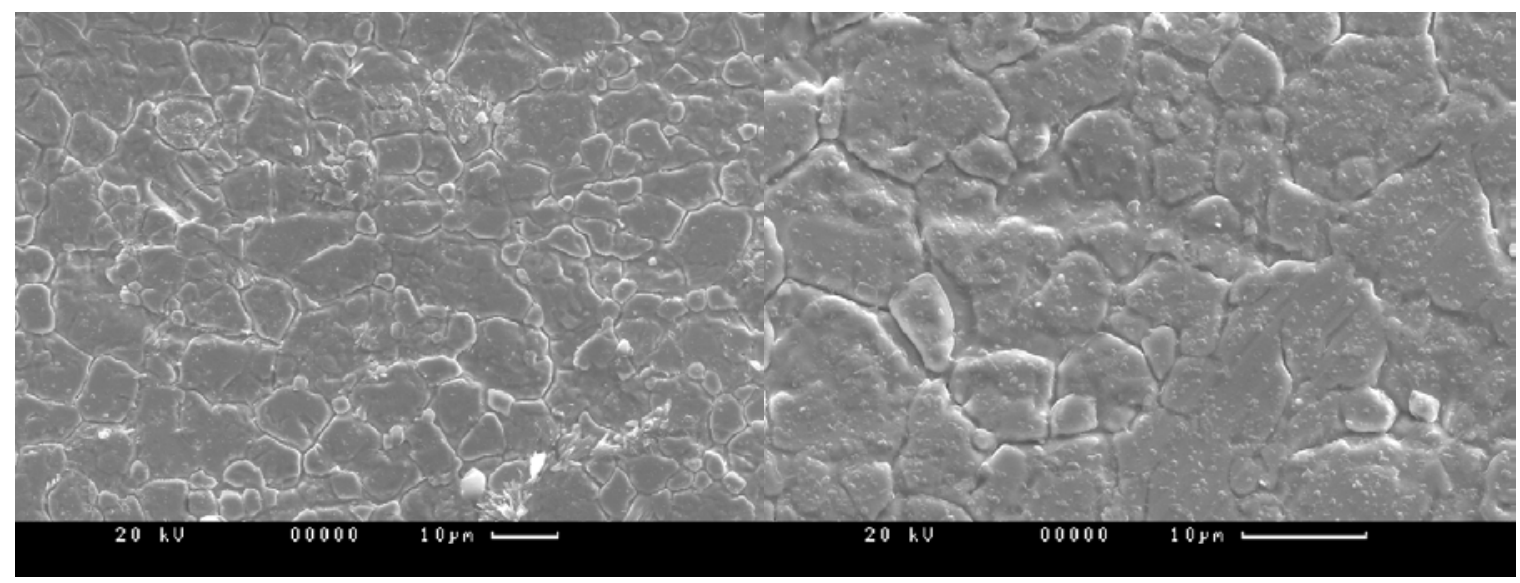

Figure 123 SEM micrographs of crystals formed at steel substrate surface from high cancrinite seeding supersaturated liquors $(\mathrm{Al}(\mathrm{III})=0.45 \mathrm{M}, \mathrm{NaOH}=4 \mathrm{M}$, $\mathrm{NaNO}_{3}=1 \mathrm{M}, \mathrm{NaNO}_{2}=1 \mathrm{M}$, initial) at $130{ }^{\circ} \mathrm{C}$ removed from suspension after $30 \mathrm{~min}$ (And $B)$ and $4 \mathrm{~h}(\mathrm{C}$ and $\mathrm{D})$

SEM micrographs of steel substrate surface removed from high sodalite seeding $\left(239 \mathrm{~m}^{2} /\right.$ $\left.\mathrm{dm}^{-3}\right)$ supersaturated liquors $\left(\mathrm{Al}(\mathrm{III})=0.45 \mathrm{M}, \mathrm{NaOH}=4 \mathrm{M}, \mathrm{NaNO}_{3}=1 \mathrm{M}, \mathrm{NaNO}_{2}=1 \mathrm{M}\right.$, initial $\left.[\mathrm{Si}][\mathrm{Al}]=2 \times 10^{-3} \mathrm{M}^{2}\left(\sigma_{\mathrm{Si}}=0.76 \mathrm{SiO}_{2}=0.0044 \mathrm{M}\right)\right)$ at $65{ }^{\circ} \mathrm{C}$ is shown below in Figure 124. It can be clearly seen that at lower temperature (in contrast with high temperature) the presence of high surface area of sodalite seed crystals completely suppressed fouling over the entire $4 \mathrm{~h}$ crystallization period. The pivotal synergistic role played by temperature and active seed growth behaviour is clearly demonstrated.

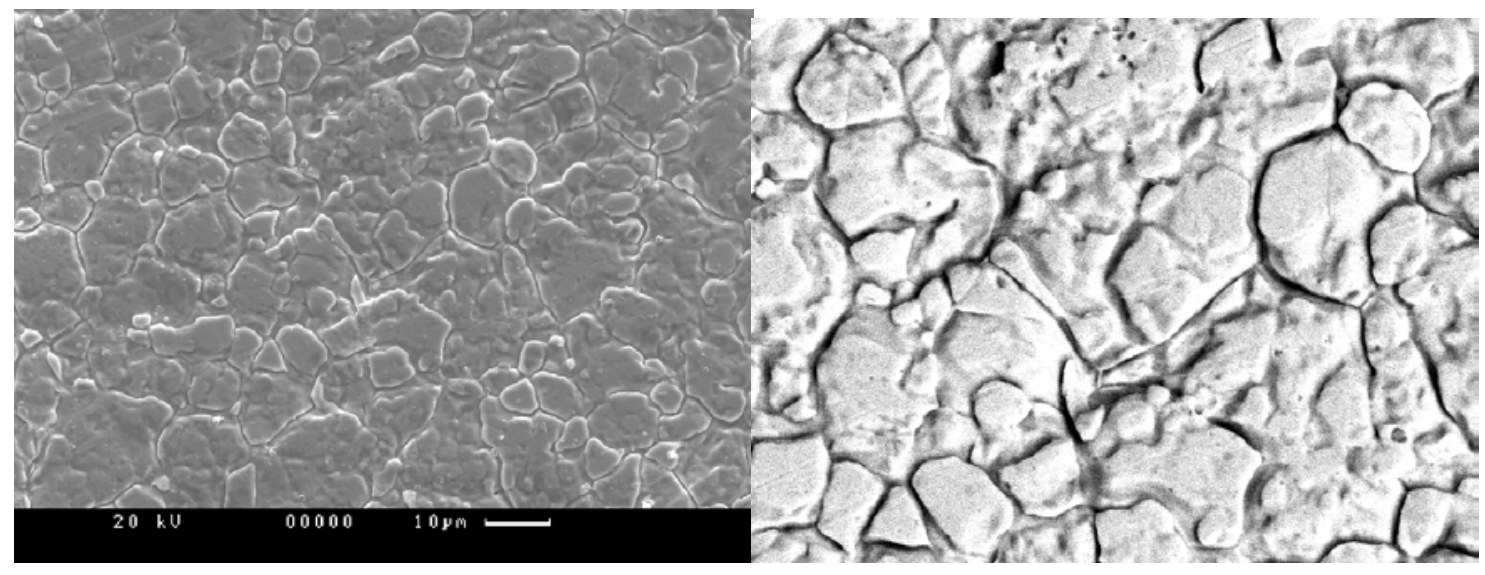

Figure 124 SEM micrographs of steel substrate surface at high sodalite seeding supersaturated liquors $\left(\mathrm{Al}(\mathrm{III})=0.45 \mathrm{M}, \mathrm{NaOH}=4 \mathrm{M}, \mathrm{NaNO}_{3}=1 \mathrm{M}, \mathrm{NaNO}_{2}=1 \mathrm{M}\right.$, initial $[\mathrm{Si}][\mathrm{Al}]=2 \times 10^{-3} \mathrm{M}^{2}$ ) at $65^{\circ} \mathrm{C}$ removed from suspension after $30 \mathrm{~min}$ (And B) and $4 \mathrm{~h}(\mathrm{C}$ and $\mathrm{D})$ 


\subsubsection{Seeded Systems}

Sodium aluminosilicate (cancrinite) fouled stainless steel samples removed from cancrinite seeded crystallization system operating $65^{\circ} \mathrm{C}$ were investigated as a function time of reaction in SEM microscope. Samples were investigated on the steel token surface. All tokens, prior to SEM investigation, were marked by line traced $5 \mathrm{~mm}$ from the (Figure 125). Two areas marked on the tokens were studied by SEM imaging and were analyzed using the STIMAN program. Samples were examined on a field emission FESEM $(20 \mathrm{kV})$ after coating them in vacuum by $3 \mathrm{~nm}$ thick gold-palladium film, (Smart and Tovey (1982)).

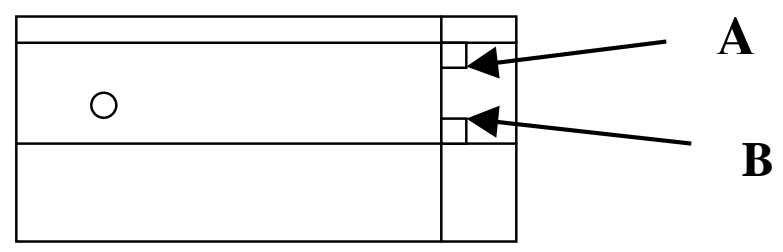

\section{Figure 125 Marked regions stainless steel token subjected to SEM investigations}

Standard secondary electron (SE) mode images that are commonly used for morphological study were not suitable for image analysis (Fig. 126a). To enhance the contrast between the aluminosilicate particles and the steel substrate, images were collected using the backscattered electron (BE) mode. In this mode the sodium aluminosilicate crystals appear in regions of dark contrast on the bright background of the stainless steel substrate (Fig. 126b). The resulting micrographs are almost binary in color (black and white). This allows for a good discrimination between sodium aluminosilicate scale fouling and the unfouled steel substrate areas by the STIMAN image analysis program.

The fouled steel tokens (Figures 127-132) removed from the cancrinite-seeded solution at $65{ }^{\circ} \mathrm{C}\left(\mathrm{NaOH}=4 \mathrm{M}, \mathrm{NaNO}_{3}=1 \mathrm{M}, \mathrm{NaNO}_{2}=1 \mathrm{M}\right.$, initial $\mathrm{SiO}_{2}=0.175 \mathrm{M}, \mathrm{Al}(\mathrm{III})=$ $0.188 \mathrm{M}$, seed charge $=239.4 \mathrm{~m}^{2} \mathrm{dm}^{-3}$ ) were investigated. This was designed to provide information on a system in which a stable crystalline phase fouling proceeds with no 
phase transformation complexities. STIMAN calculations revealed that the relative particle area increased with reaction time. This increase to more than $90 \%$ after 60 minutes. As shown on Figure 127 and Table 22 the surface coverage gradually increased for the first 15 minutes of reaction time and then rapidly increased in coverage to $\sim 94 \%$ after 60 minutes.

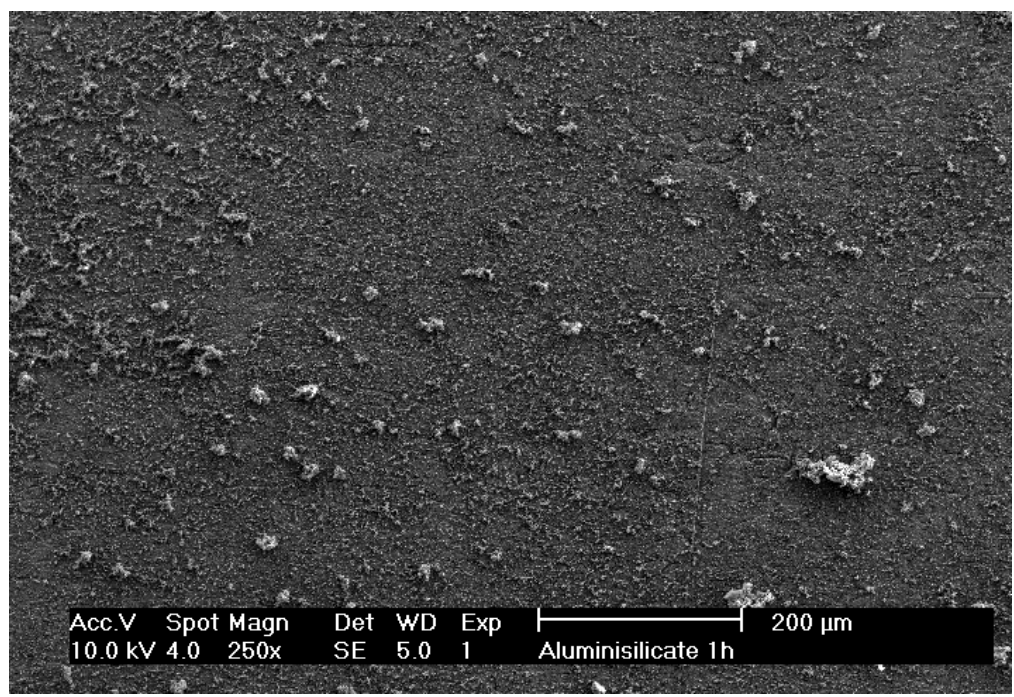

Figure 126a SEM of steel substrate sample imaged in SE mode and magnified 250 times for a cancrinite-seeded solution at $65^{\circ} \mathrm{C}\left(\mathrm{NaOH}=4 \mathrm{M}, \mathrm{NaNO}_{3}=1 \mathrm{M}, \mathrm{NaNO}_{2}=\right.$ $1 \mathrm{M}, \mathrm{SiO}_{2}=0.175 \mathrm{M}, \mathrm{Al}(\mathrm{III})=0.188 \mathrm{M}$, and initial seed charge $=239.4 \mathrm{~m}^{2} \mathrm{dm}^{-3}$ )

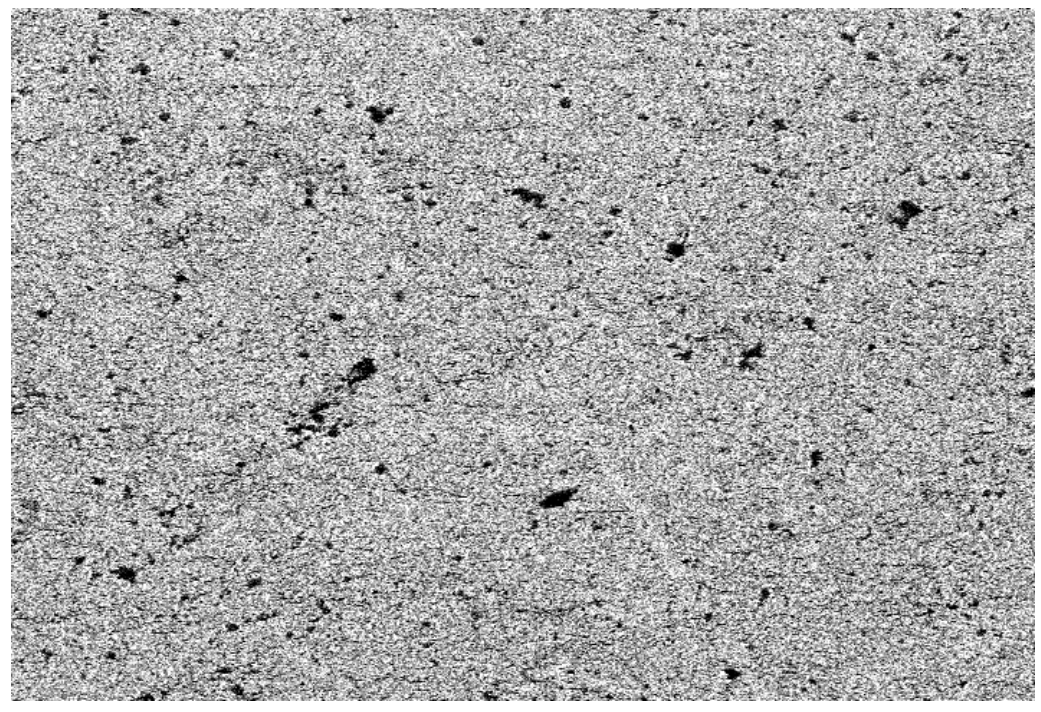

Figure 126b SEM of steel substrate sample imaged in BSE mode after 3 min of reaction time and magnified 250 times for a cancrinite-seeded solution at $65{ }^{\circ} \mathrm{C}$ $\left(\mathrm{NaOH}=4 \mathrm{M}, \mathrm{NaNO}_{3}=1 \mathrm{M}, \mathrm{NaNO}_{2}=1 \mathrm{M}, \mathrm{SiO}_{2}=0.175 \mathrm{M}, \mathrm{Al}(\mathrm{III})=0.188 \mathrm{M}\right.$, initial seed charge $=239.4 \mathrm{~m}^{2} \mathrm{dm}^{-3}$ ) 


\section{Cancrinite seeds}

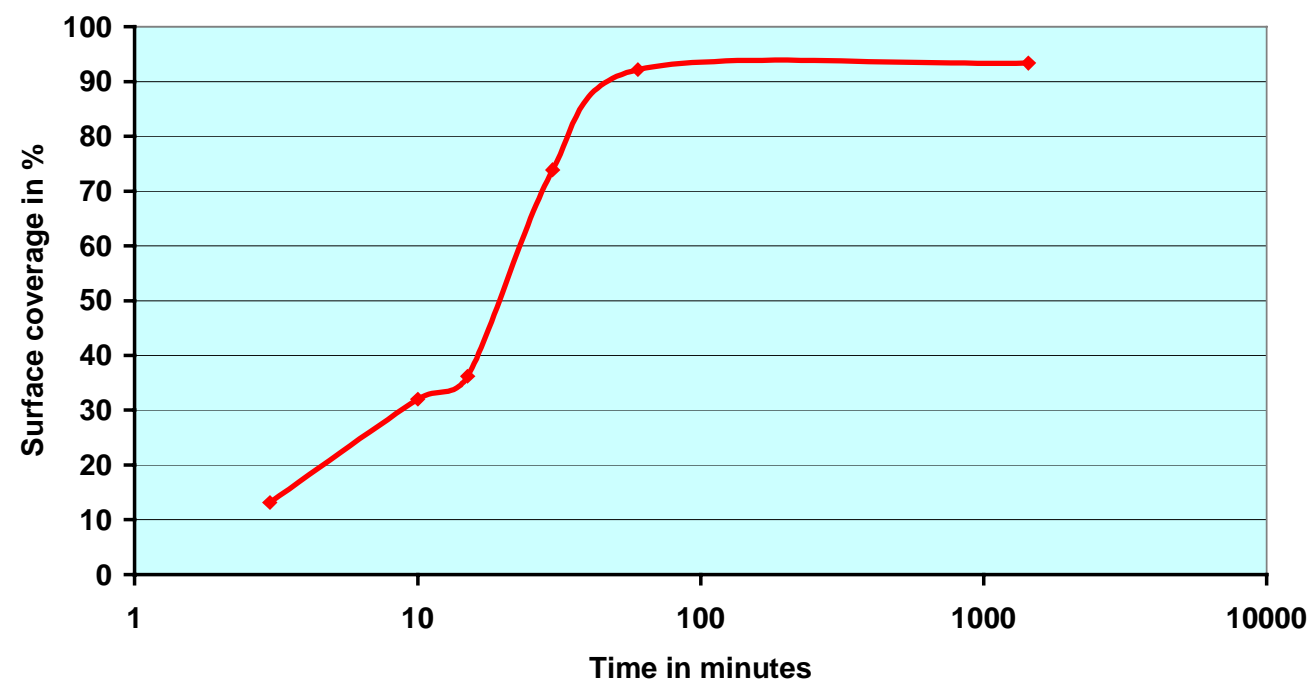

Fig. 127 Steel substrate fouling as function of time for a cancrinite-seeded solution at $65^{\circ} \mathrm{C}\left(\mathrm{NaOH}=4 \mathrm{M}, \mathrm{NaNO}_{3}=1 \mathrm{M}, \mathrm{NaNO}_{2}=1 \mathrm{M}\right.$, initial $\mathrm{SiO}_{2}=0.175 \mathrm{M}$, $\mathrm{Al}(\mathrm{III})=0.188 \mathrm{M}$, and initial seed charge $\left.=239.4 \mathrm{~m}^{2} \mathrm{dm}^{-3}\right)$

\begin{tabular}{|l|c|c|c|c|c|c|}
\hline Reaction time in hours & 3min & 10min & 15min & 30min & 60min & $\begin{array}{c}\mathbf{1 4 4 0} \\
\text { min }\end{array}$ \\
\hline Relative particle area \% & 13.16 & 32.03 & 36.21 & 73.87 & 92.14 & 93.38 \\
\hline Average diameter $(\mu \mathrm{m})$ & 0.77 & 0.79 & 0.82 & 0.74 & 0.59 & 0.57 \\
\hline Average area $\left(\mu \mathrm{m}^{2}\right)$ & 1.04 & 1.34 & 1.75 & 2.1 & 1.02 & 0.34 \\
\hline Average perimeter $(\mu \mathrm{m})$ & 4.95 & 5.47 & 5.47 & 5.24 & 4.31 & 4.13 \\
\hline Specific surface area $(1 / \mu \mathrm{m})$ & 0.54 & 1.06 & 0.96 & 0.28 & 0.005 & 0.016 \\
\hline
\end{tabular}

Table 22 Results of image analysis

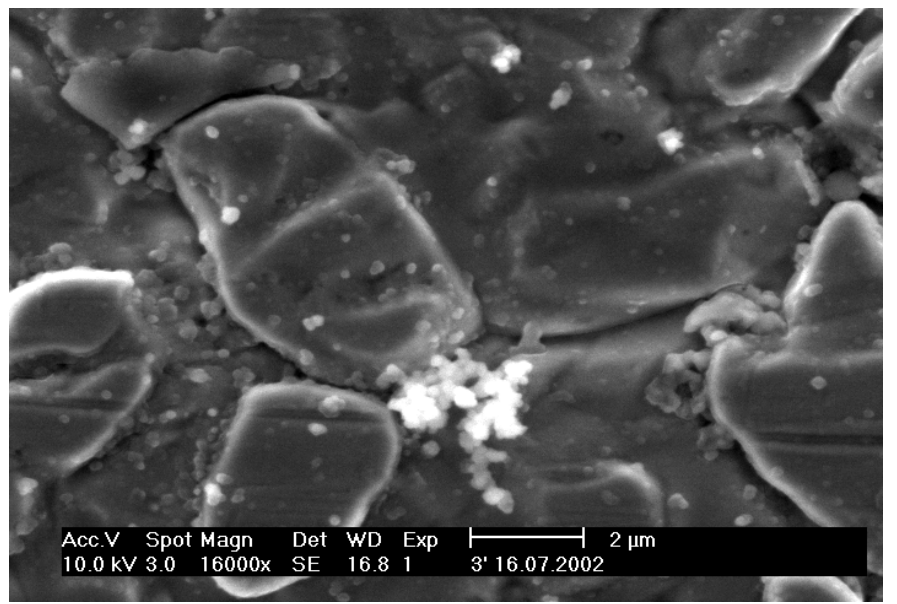

Figure 128 SEM showing cancrinite coverage after 3min of reaction 


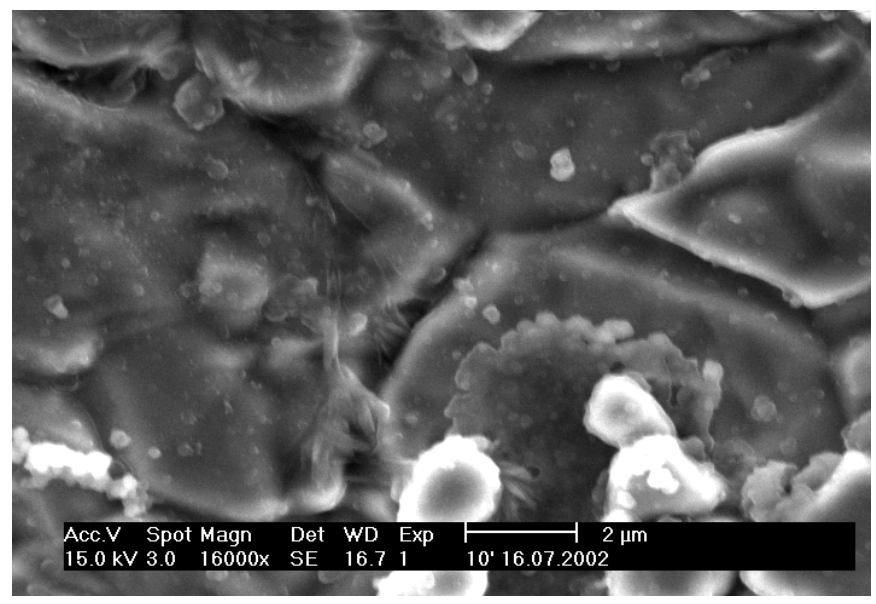

Figure 129 SEM showing cancrinite coverage after 10min of reaction

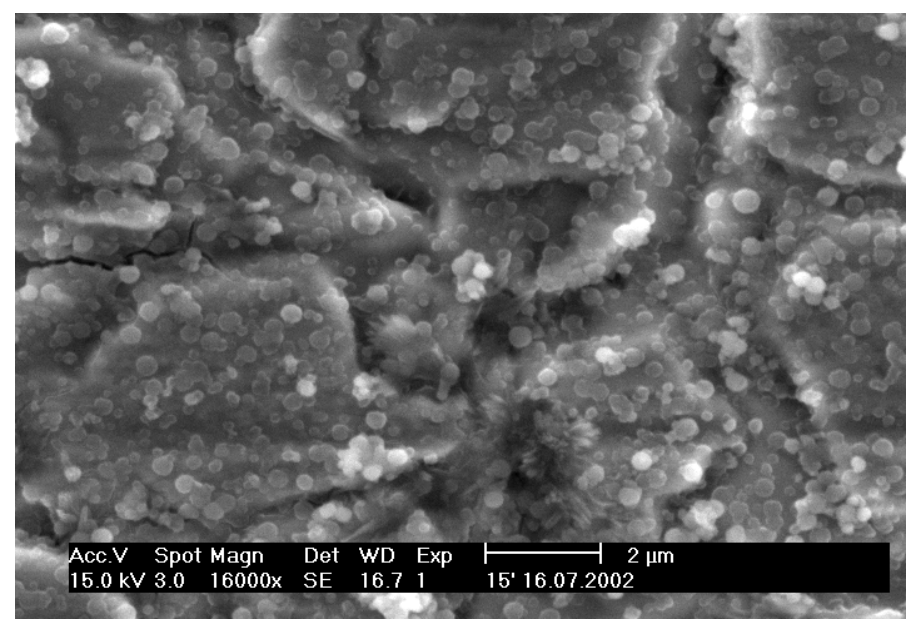

Figure 130 SEM showing cancrinite coverage after $15 \mathrm{~min}$ of reaction

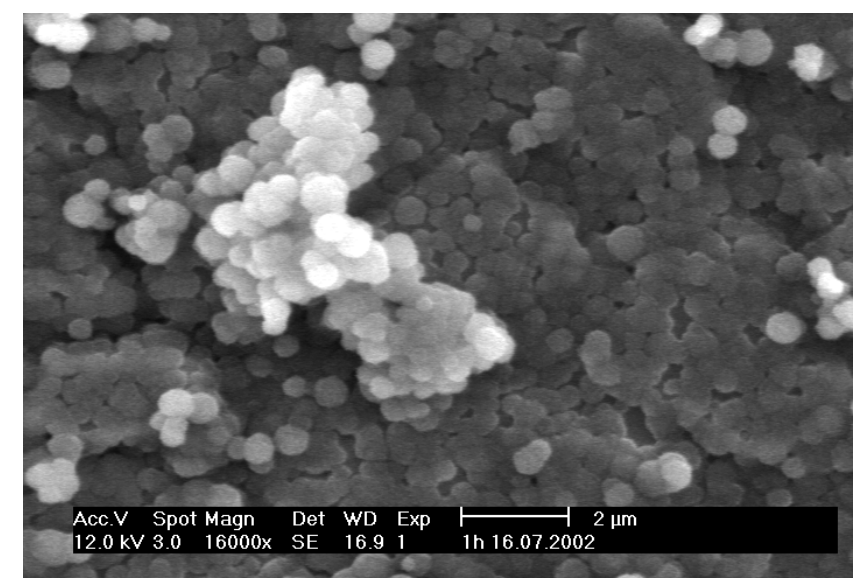

Figure 131 SEM showing cancrinite coverage after 1 hour of reaction 


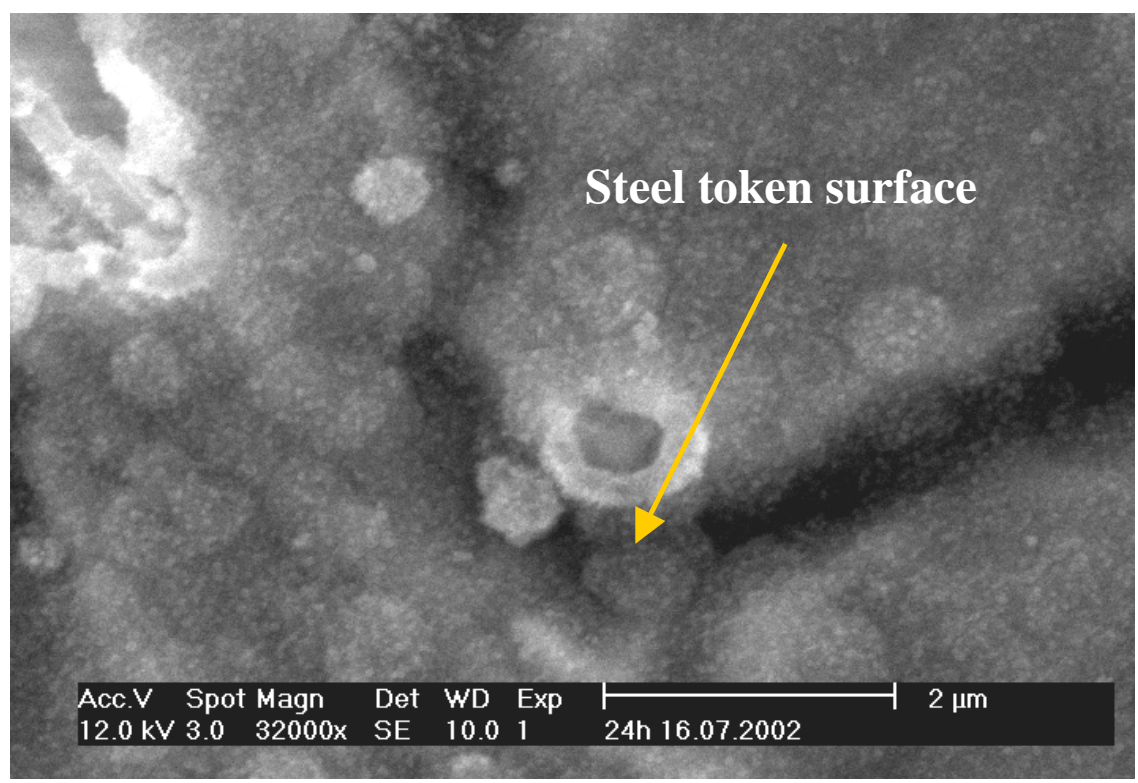

Figure 132 SEM showing cancrinite coverage after 24 hours of reaction.

\subsubsection{Amorphous Seeded Fouling}

The fouling of steel tokens removed from an amorphous seeded suspension as function of crystallization time at $65{ }^{\circ} \mathrm{C}\left(\mathrm{NaOH}=4 \mathrm{M}, \mathrm{NaNO}_{3}=1 \mathrm{M}, \mathrm{NaNO}_{2}=1 \mathrm{M}\right.$, initial $\mathrm{SiO}_{2}=$ $0.175 \mathrm{M}, \mathrm{Al}(\mathrm{III})=0.188 \mathrm{M}$, and initial seed charge $=239.4 \mathrm{~m}^{2} \mathrm{dm}^{-3}$ ) was investigated results are shown in the following figure. These results have been reproduced but are not currently understood. It is quite possible that for a system of high seed charge that some small portion of particles adhere or cement to the substrate. The presence of these attached particles could be fascilitated by a minor cementation that subsequently gives way during solution mediated phase transformation. The Mensah group continues to work in this area to increase understanding as part of the central research interests in the area of aluminosilicates. 


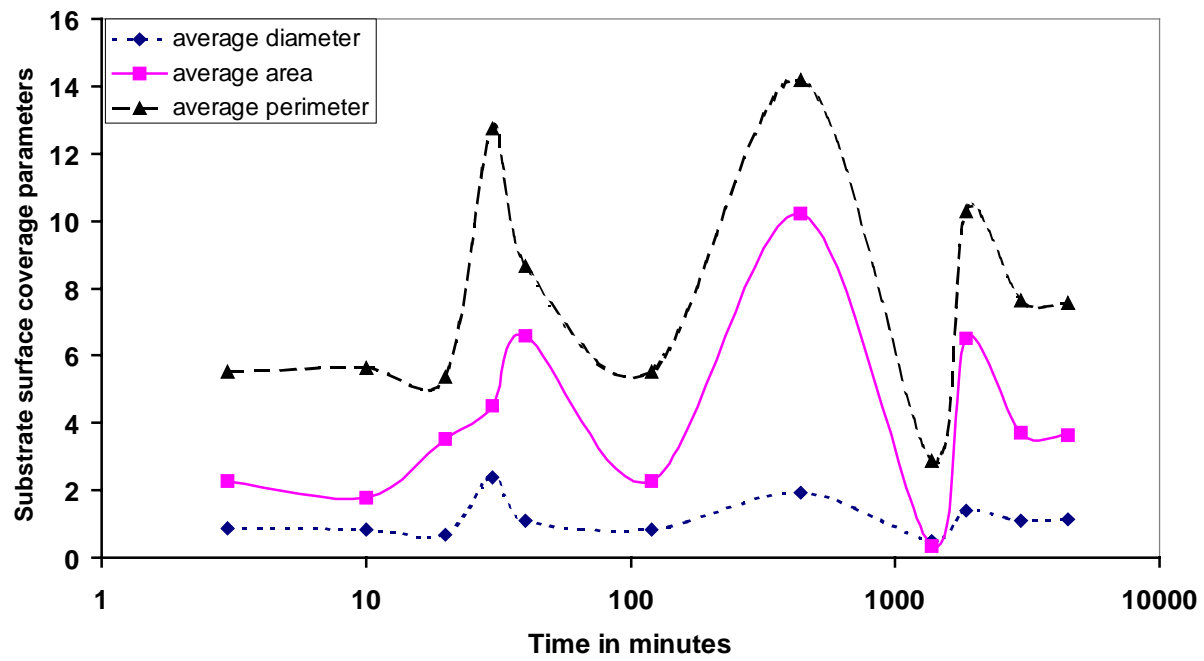

Figure 133 Estimated fractional coverage of steel substrate 


\subsection{Conclusion}

In the present work the four primary aluminosilicate phases of interest to WSRC have been synthesized and characterized. Furthermore evaluation of solubility, crystallization mechanisms, and phase transformations of the phases has been performed.

More specifically, a comprehensive structural and crystallographic characterization of the all four sodium aluminosilicate solid phases has been performed. Reliable equilibrium solubility data have been determined under a range of solution compositions at 30, 65 and $130{ }^{\circ} \mathrm{C}$. The equilibrium $\mathrm{SiO}_{2}$ solubility decreased in the order of amorphous/gel > zeolite A > sodalite > cancrinite.

The mechanisms of nucleation (homogeneous, heterogeneous and secondary) and particle/crystal growth as well as phase transformation have been investigated. Clear links between nucleation and crystal/particle growth and supersaturation/temperature have been established. Semi-empirical power law models have been obtained for the quantification and prediction of the crystallization and phase transformation behavior. 


\subsection{REFERENCES}

\subsection{References for sections 1.0-6.0}

1. Breck, D.W., Eversole, W.G., Milton, R.M., Reed, T.B. and Thomas, T.L., J. American Chem Soc. 78(23) 563 (1956).

2. Gramlich, V. and Meier, W.M. Z. Krystallogr. Kristallgeom., Kristallphys., Kristallchem., 133, 134 (1971).

3. Barrer, RM., Baynam, J.W. Bultitude, F.W., Meier, W.M., J. Chem Soc. 195 (1961).

4. Reed, T.B. and Breck, D.W., J. American Chem. Soc. 78 (23) 5972 (1956)

5. Buhl, J.-Ch., J. Crystal Growth, Vol. 108 143-149 (1991).

6. Buhl, J.-Ch. And Leons, J., JCRGAE, Vol. 108143 (1991). SodNo3

7. Hund, F., Z. Anorg. Allg. Chem., 511225 (1984).

8. Hund, F., Z. Anorg. Allg. Chem., 509153 (1984).

9. Ni L.P, Khalyapini O.B , Bunchuck L.V and Goldman M.M., 'Crystallisation of Cancrinite Under Low Temperature Conditions of the Bayer Process.', Zhurnal Prikladroi Khimii.(translated), 48 (1975) 2117.

10. Hermelar G, Buhl J Ch, Hoffman W., 'Influence of Carbonate on the Synthesis of an Intermediate Phase Between Sodalite and Cancrinite.', Catalysis Today, 8 (1991) 415.

11. Farmer V.C.(ed.), 'The Infra-Red Spectra Of Minerals', Mineralogical Society Monograph 4, (1974) 372.

12. Porotnikova T.P. and Derevyankin V.A., 'Infrared Absorption Spectra of Equilibrium Solid Phases of the $\mathrm{Na}_{2} \mathrm{O}-\mathrm{Al}_{2} \mathrm{O}_{3}-\mathrm{SiO}_{2}-\mathrm{H}_{2} \mathrm{O}$ system.', Soviet J. Of Non Ferrous Metals, 8 (1975) 38.

13. Avdeeva T.I and Vorsina I.A., 'Infra-red Spectra of Hydroaluminosilicates Formed During the Desiliconizing of Sodium Aluminate Solutions.', Soviet J. of Non-ferrous Metals, 42 (1969) 53.

14. Flanigen E.M., Khatami H., Syzmanski H.A., 'Infrared Structural Studies of Zeolite Frameworks.', Advances in Chemistry Series, 16 (1971) 201.

15. Leiteizen M.G., Pashkevich L.A., Firfarova I.B. and Tsekhovol'skaya D. N., 'Characteristics of Sodium Hydroaluminosilicates Formed Under Alumina Production Conditions.', Tsvetnye Metally, (1974) 23.

16. Baker, M.D., Godber, J. and Ozin, G.A., Perspectives in Molecular Sieve Science (Ed. W.H. Flank and T.E. Whyte Jr.) ACS Symposium Series,.Vol 368137.

17. Ozin, G.A., Baker, M.D. and Godber, J., J. Am. Chem. Soc. 1073033 (1985).

18. Brunauer S. Emmett P.H. and Teller J., J. Am. Chem. Soc., 60 (1938) 309.

19. Antonic T., Cizmek A. and Subotic B., "Dissolution of Amorphous Aluminosilicate Zeolite Precursors in Alkaline Solutions", Chem. Soc. Faraday Trans., 9024 (1994) 3725-3728.

20. Barnes M. C., Addai-Mensah J., Gerson A. R. and Smart R. St. C., "The Solubility of Sodalite and Cancrinite in Synthetic Spent Liquor and the Mechanism and Kinetics of the Sodalite to Cancrinite Phase Transformation", Light Metals, (1999) 131-140. 
21. Cizmek A. Komunjer L. and Subotic B., "Kinetics of Zeolite Dissolution: Part 1. Dissolution of Zeolite A in Hot Sodium Hydroxide", Zeolites, 11 (1991) 258-264.

22. Gasteiger H. A., Frederick W. J. and Streisel R. C., "Solubility of Aluminosilicates in Alkaline Solutions and a Thermodynamic Equilibrium Model", Ind. Eng. Chem. Res., 31 (1992) 1183-1190.

23. Grujic E., Subotic B. and Despotovic L. A., "Transformation of Zeolite A into Hydroxysodalite. III. The Influence of Temperature on the Kinetics of Transformation", Zeolites: Facts, Figures, Future, (1989) 261-270.

24. Pevzner I. Z., Eremin N. I., Rozen Y. B., Kolobov N. P. and Mironov V. E., "State of Silicon in Aluminate Solutions", Zhurnal Prikladnoi Khimii, 4712 ((1974) 2847-2849.

\subsection{References for sections 6.0-10.0}

Barnes M. C., Addai-Mensah J. and Gerson A. R., "The Kinetics of Desilication of Synthetic Spent Bayer Liquor and Sodalite Crystal Growth", Colloids and Surfaces, 147 (1999) 283-295.

Barnes M. C., Addai-Mensah J. and Gerson A. R., "The Kinetics of Desilication of Synthetic Spent Bayer Liquor Seeded with Pure Sodalite, Pure Cancrinite and Dimorphic Phase Crystals", Light Metals, (1999) 121-129.

Barnes M. C., Addai-Mensah J., Gerson A. R. and Smart R. St. C., "The Solubility of Sodalite and Cancrinite in Synthetic Spent Liquor and the Mechanism and Kinetics of the Sodalite to Cancrinite Phase Transformation”, Light Metals, (1999) 131-140.

Barnes M. C., The Kinetics and Mechanism of Sodium Aluminosilicate crystallization in Bayer Process Scale Formation, PhD Thesis, University of South Australia, (1999).

Duncan A., Groemping M., Welch B. and Muller-Steinhagen H., "The Effect of Silica, Temperature, Velocity and Particulates on Heat Transfer to Spent Bayer Liquor", Light Metals, (1995) 63.

Grujic B., Subotic B. and Despotovic L. J. A., in Jacobs P. A. and Van Santen R. A. (editors), 'Transformation of Zeolite A into Hydroxysodalite. III. The Influence of Temperature on the Kinetics of Transformation", Studies in Surface Science and Catalysis No. 24, Zeolites-Synthesis, Structure, Technology and Application, Elsevier, Amsterdam, (1989) 261.

Gualtieri A., Norby P., Artioli G. and Hanson J. "Kinetic Study of Hydroxysodalite Formation from Natural Kaolinites by Time-resolved synchrotron Powder Diffraction", Microporous Materials, 9 (1997) 189-201.

Kacirek H. and Lechert H., J. Phys. Chem. 79 (1975) 1589. 
Kacirek H. and Lechert H., J. Phys. Chem. 80 (1976) 1291.

Li, J., Prestidge, C.A., Addai-Mensah, J., Secondary Nucleation of Gibbsite Crystals From Synthetic Bayer Liquors: Effect of Alkali Metal Ions. Journal of Crystal Growth, 219 (2000) 451-464.

Marui Y., Irie R., Takiyama H., Uchida H. and Matsuoka M., "Analysis of Nucleation of Zeolite A from Clear Solutions”, Journal of Crystal Growth, 237-239 (2002) 2148-2152.

O'Neill G. A., "Prediction of Heat Exchanger-Heat Transfer Co-efficient Decay due to Fouling" Light Metals, (1986) 133.

Schoeman B. J., Sterte J. and Otterstedt J. -E., "Analysis of the Crystal Growth Mechanism of TPA-silicalite-1", Zeolites 14 (1994) 568-575.

Zhdanov S. P. and Samulevich N. N., in Rees L. V. C. (Editor), Proceedings of the Fifth International Conference on Zeolites, Heyden, (1980) 75.

Zhdanov S. P., in Gould R. F. (Editor), Molecular Sieve Zeolites I, advences in Chemistry Series, vol. 101, American Chemical Society, Washington, DC, (1971) 20. 